ChipCflow - uma ferramenta para execução de algoritmos utilizando o modelo a fluxo de dados dinâmico em hardware reconfigurável 


\title{
ChipCflow - uma ferramenta para execução de algoritmos utilizando o modelo a fluxo de dados dinâmico em hardware reconfigurável
}

\author{
Joelmir José Lopes
}

Orientador: Prof. Dr. Jorge Luiz e Silva

Tese apresentada ao Instituto de Ciências Matemáticas e de Computação - ICMC-USP, como parte dos requisitos para obtenção do título de Doutor em Ciências - Ciências de Computação e Matemática Computacional. EXEMPLAR DE DEFESA.

USP - São Carlos

Maio de 2012 
Ficha catalográfica elaborada pela Biblioteca Prof. Achille Bassi e Seção Técnica de Informática, ICMC/USP, com os dados fornecidos pelo(a) autor(a)

Lopes, Joelmir José
Chipcflow - uma ferramenta para execução de
algoritmos utilizando o modelo a fluxo de dados
dinâmico em hardware reconfigurável / Joelmir José
Lopes; orientador Jorge Luiz e Silva. -- São Carlos,
2012.
233 p.
Tese (Doutorado - Programa de Pós-Graduação em
Ciências de Computação e Matemática Computacional) --
Instituto de Ciências Matemáticas e de Computação,
Universidade de São Paulo, 2012.
1. Arquiteturas a fluxo de dados. 2. Arquiteturas
paralelas. 3. Sistemas de alto desempenho. 4.
Hardware reconfigurável. 5. Protocolos assíncronos.
I. Silva, Jorge Luiz e, orient. II. Título.


Dedico este trabalho aos meus queridos pais, Jarbas Lopes

$\mathrm{e}$

Maria Inês Garcia Lopes 



\section{Agradecimentos}

Aos meus pais, Jarbas Lopes e Maria Inês Garcia Lopes, pelo carinho, dedicação e confiança. Ao meu irmão Juliano Henrique Lopes pelo apoio em todos os momentos. Ao meu orientador, professor Jorge Luiz e Silva e sua esposa Elizabeth Luisa Moretti e Silva pelo apoio, confiança, orientações acadêmicas e pessoais, e pela amizade.

Aos amigos, pelas alegrias e dificuldades compartilhadas: Micahell David Calabrez, Jamile Zulim, Sheila Alkin Padilha, Juliana Calabrese, Isabell Pinto. A todos os colegas do ICMC que contribuíram direta ou indiretamente para realização deste trabalho.

À equipe do Projeto ChipCflow, em especial aos colegas Bruno de Abreu Silva e Antônio Carlos Fernandes Silva pelas discussões extremamente produtivas e momentos de descontração.

Ao Conselho Nacional de Desenvolvimento Científico e Tecnológico (CNPq) pelo apoio financeiro.

Às funcionárias da secretaria de pós-graduação do ICMCUSP por todas as informações e serviços prestados.

Para todos aqueles que direta ou indiretamente contribuíram para a realização deste trabalho, em especial a Angela Cristina Pregnolato Giampedro do Centro Cultural da USP - São Carlos. 

Não se mede o valor de um homem pelas suas roupas ou pelos bens que possui, o verdadeiro valor do homem é o seu caráter, suas ideias e a nobreza dos seus ideais.

(Charles Chaplin) 



\section{Sumário}

Lista de Figuras . . . . . . . . . . . . . . . v

Lista de Tabelas . . . . . . . . . . . . . . . . xi

Lista de Abreviaturas . . . . . . . . . . . . . . . . xiii

Lista de Algoritmos . . . . . . . . . . . . . . . . xix

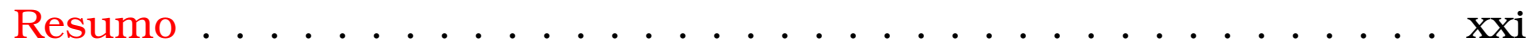

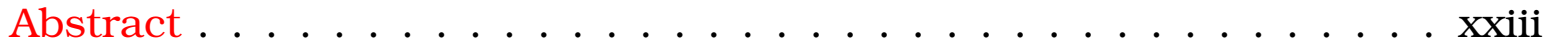

1 Introdução 1

1.1 Contextualização e Motivação ． . . . . . . . . . . . . . . . 1

1.1.1 Field Programmable Gate Arrays - FPGAs . . . . . . . . 2

1.1 .2 Computação Reconfigurável . . . . . . . . . . . 5

1.1 .3 O modelo von-Neumann . . . . . . . . . . . . . 10

1.1.4 Circuitos assíncronos . . . . . . . . . . . . . 13

1.1.5 Arquiteturas a fluxo de dados . . . . . . . . . 15

1.1 .6 Projeto ChipCflow . . . . . . . . . . . . 18

1.2 Motivação . . . . . . . . . . . . . . . . . . 18

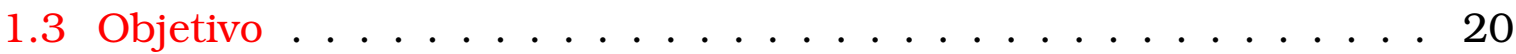

1.4 Organização do trabalho $\ldots \ldots \ldots \ldots \ldots \ldots$

2 Dispositivos Lógicos Programáveis PLDs 23

2.1 Circuitos Digitais . . . . . . . . . . . . . . . 23

2.2 A tecnologia dos FPGAs . . . . . . . . . . . . . 27

2.2 .1 Arquitetura dos FPGAs . . . . . . . . . . . . 27

2.2 .2 Tecnologias de programação . . . . . . . . . . . . . 31

2.2 .3 Classificação dos FPGAs . . . . . . . . . . . . . . 32

2.2.4 FPGAs com Reconfiguração Parcial Dinâmica . . . . . . . . 33

3 Plataforma de desenvolvimento $\quad 43$

3.1 Família VIRTEX-II Pro da Xilinx . . . . . . . . . . . . . . . . 43

3.1.1 Plataforma de desenvolvimento XUP V2P . . . . . . . . 47 
3.2 Ferramentas EDA da Xilinx . . . . . . . . . . . . . . . 49

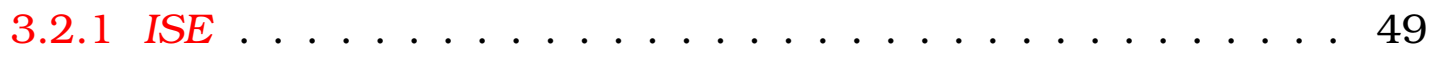

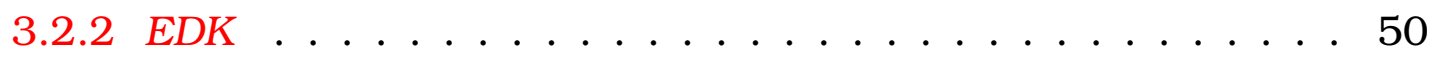

4 Ferramentas de Programação C para Plataformas FPGA 53

4.1 Introdução às ferramentas de programação $C$ para plataformas

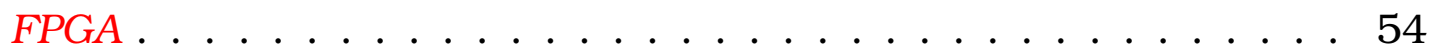

4.1 .1 Pico Express . . . . . . . . . . . . . . . . . . . . . . 55

4.1 .2 Galadriel e Nenya . . . . . . . . . . . . . . . . 57

4.1 .3 Spark . . . . . . . . . . . . . . 58

4.1 .4 DK-Design Suit . . . . . . . . . . . . . . . 60

4.1 .5 Impulse $-C \ldots \ldots \ldots \ldots$

5 Máquinas a Fluxo de Dados $\quad 69$

5.1 O modelo Fluxo de Dados . . . . . . . . . . . . . . 70

6 Trabalhos Relacionados $\quad 79$

$6.1 M F D M \ldots \ldots \ldots \ldots \ldots \ldots \ldots \ldots$

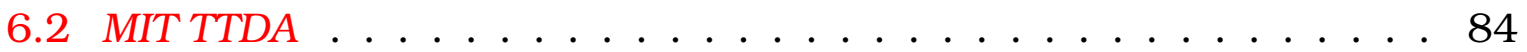

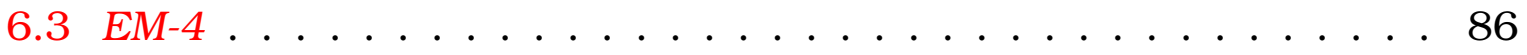

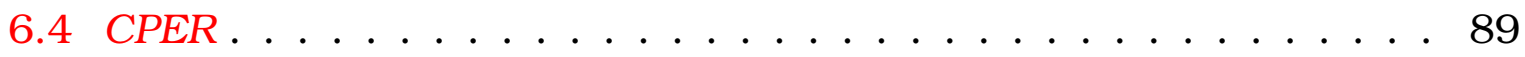

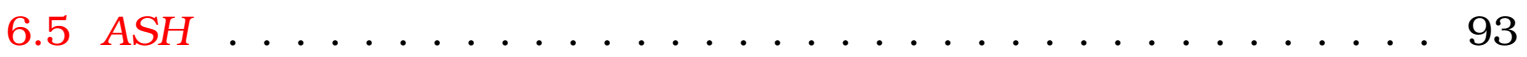

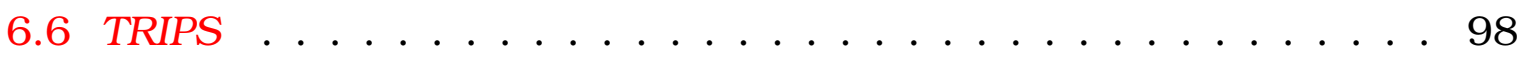

6.7 WaveScalar . . . . . . . . . . . . . . . . . . 99

7 Projeto ChipCFlow 107

7.1 Operadores propostos para o ChipCflow . . . . . . . . . . . 109

8 Operadores Assíncronos e suas Instâncias 125

8.1 O modelo de instâncias . . . . . . . . . . . . . . . . . . . 126

8.2 Implementação dos operadores e suas instâncias . . . . . . . . . 128

8.2.1 Operador Deterministic Merge . . . . . . . . . . . 128

8.2 .2 Operador Branch . . . . . . . . . . . . . . . . . . . 168

8.2 .3 Operador Operator . . . . . . . . . . . . . . . . . . 170

8.2 .4 Operador Decisor . . . . . . . . . . . . . . . . . . . 172

8.2.5 Operador Non-Deterministic Merge . . . . . . . . . . . 173

8.2.6 Operador Copy . . . . . . . . . . . . . . . . . 176

8.3 Resultados de síntese nos FPGAs da empresa Xilinx . . . . . . 177

8.3.1 Síntese dos operadores . . . . . . . . . . . . 177

8.3.2 Variação no número de instâncias no operador Deterministic Merge . . . . . . . . . . . . . . . . . . . . 179 
9 Conclusões e Trabalhos Futuros

Referências

193 


\section{Lista de Figuras}

1.1 Uma década de evolução dos FPGAs . . . . . . . . . . . . 4

1.2 Flexibilidade versos desempenho dos sistemas programáveis . . . 6

1.3 Benefícios da Computação Reconfigurável . . . . . . . . . . 7

1.4 Comparação de desempenho entre GPP e FPGA . . . . . . . . . 8

1.5 Análise de desempenho nas arquiteturas $65 \mathrm{~nm} \ldots \ldots \ldots . . \ldots 9$

1.6 Análise de desempenho nas arquiteturas $45 \mathrm{~nm} \ldots \ldots \ldots$

1.7 Arquitetura von-Neumann . . . . . . . . . . . . . 11

1.8 Comunicação entre blocos em sistemas assíncronos . . . . . . . 14

1.9 Máquina a Fluxo de Dados . . . . . . . . . . . . . . . 16

1.10 Taxonomia de Arquiteturas Paralelas . . . . . . . . . . 17

2.1 Evolução dos FPGAs em número de transistores - $32 \mathrm{~nm}$ corresponde a 5 bilhões de transistores . . . . . . . . . . . 24

2.2 Taxonomia para Projetos de Sistemas Digitais . . . . . . . . . . . 25

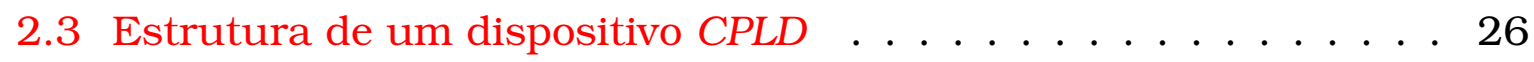

2.4 Estrutura básica de um FPGA . . . . . . . . . . . . . 28

2.5 Bloco básico dos FPGAs Xilinx . . . . . . . . . . . . . 28

2.6 Exemplo de uma LUT . . . . . . . . . . . . . . . . . . . . . . 29

2.7 CLB do Virtex II, Virtex-II Pro e Virtex-4 . . . . . . . . . . . . 30

2.8 Conexões entre blocos lógicos . . . . . . . . . . . . 30

2.9 Arquitetura de um sistema em um ambiente reconfigurável em tempo de execução . . . . . . . . . . . . . . . . 35

2.10 Reconfiguração parcial dinâmica . . . . . . . . . . . . 35

2.11 Arquitetura de configuração do Virtex-II . . . . . . . . . . . 36

2.12 Arquitetura de configuração Virtex-4 . . . . . . . . . . . 37

2.13 Geração do bitstream para a reconfiguração parcial . . . . . . . 38

2.14 Roteamento em dois caminhos diferentes . . . . . . . . . . 39

2.15Esboço de um projeto básico com dois ou mais módulos reconfi-

guráveis . . . . . . . . . . . . . . 40 
2.16 Esquema de uma aplicação reconfigurável que possui um barramento que não pode ser interrompido . . . . . . . . . . . . 41

3.1 Arquitetura da Virtex-II Pro . . . . . . . . . . . . . . . 45

3.2 Bloco de CLB da Virtex-II Pro . . . . . . . . . . . . . . . . 45

3.3 Slice da Virtex-II Pro . . . . . . . . . . . . . . . . . . . 45

3.4 Blocos de SelectRAM e Multiplicadores . . . . . . . . . . . . 46

3.5 Placa de desenvolvimento XUP V2P da Digilent . . . . . . . . . . 48

3.6 Diagrama da placa de desenvolvimento XUP V2P . . . . . . . . 49

3.7 Fluxo de desenvolvimento de um projeto em FPGA . . . . . . . . 51

3.8 Fluxo de desenvolvimento de projetos em FPGA com ISE e EDK . 52

4.1 Vendas de ferramentas para síntese de alto nível . . . . . . . 55

4.2 Possíveis implementações geradas pela ferramenta Pico Express . 56

4.3 Visão geral da ferramenta Pico Express . . . . . . . . . . . . . . 57

4.4 Arquitetura do hardware gerado pelos compiladores Galadriel e

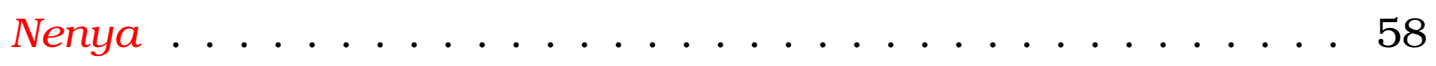

4.5 Fluxo de compilação feitos por Galadriel e Nenya . . . . . . . . . . 59

4.6 Visão geral de HLS . . . . . . . . . . . . . . . . . . . . . . 60

4.7 Visão geral do Spark HLS . . . . . . . . . . . . . . . . . 61

4.8 Visão geral do DK - Design Suit . . . . . . . . . . . . . . . 62

4.9 Streams, sinais e memória compartilhada . . . . . . . . . . . 64

4.10 Ambiente completo do CoDeveloper . . . . . . . . . . . . 66

4.11 Ambiente de implementação do CoDeveloper (CoDeveloper Application Manager . . . . . . . . . . . . . . . . . . . . . . . 67

4.12 Exemplo do Application Monitor . . . . . . . . . . . . . . . 68

5.1 Exemplo de um programa seqüencial tradicional versus máquina a fluxo de dados . . . . . . . . . . . . . . 71

5.2 Processo de execução de um programa a fluxo de dados . . . . . . 72

5.3 Problemas em grafos cíclicos . . . . . . . . . . . . . . 73

5.4 Gabarito da operação soma . . . . . . . . . . . . 75

5.5 Diagrama funcional de uma máquina a fluxo de dados típica . . . 76

5.6 Diagrama funcional de uma máquina a fluxo de dados típica utilizando tagged-token . . . . . . . . . . . . . 76

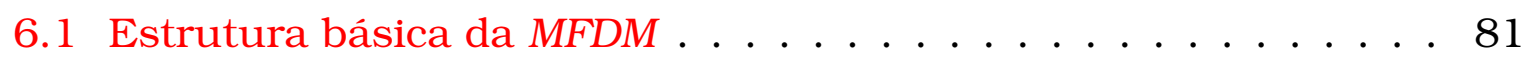

6.2 Estrutura da Máquina do TTDA . . . . . . . . . . . . 85

6.3 Organização do protótipo EM-4. . . . . . . . . . . . . . 87

6.4 Diagrama de blocos do EMC-R (EP da Máquina EM-4)) . . . . . . . 88

6.5 Arquitetura do CPER . . . . . . . . . . . . . 90

6.6 Formato da tag na MFDD . . . . . . . . . . . . . . 93 
6.7 (A) Fluxo da ferramenta ASH (B) Tradução do programa em hardware . . . . . . . . . . . . . . . . . . . 94

6.8 Programa Fibonacci e sua implementação em ASH . . . . . . . . . 96

6.9 Ferramenta de fluxo ASH - tool-flow ASH . . . . . . . . . . . 97

6.10Visão geral da arquitetura TRIPS: O Chip TRIPS . . . . . . . . . . . 99

6.11 Representação abstrata de um core e um EP de TRIPS . . . . . . . 100

6.12 O WaveCache e cluster: Um WaveCache 3x3 com nove clusters . 101

6.13 Loops no WaveScalar: (a) um loop simples; (b) uma implementa-

ção a fluxo de dados; e (c) implementação WaveScalar . . . . . . . 103

6.14 Problema relacionado a falta de dependência em uma máquina a fluxo de dados . . . . . . . . . . . . . . . . . . 103

6.15O loop da Figura 6.13c mapeado sobre dois domains WaveCache 104

6.16 Diagrama de Blocos do EP . . . . . . . . . . . . . . . . . . . 104

7.1 Diagrama de Fluxo da Ferramenta ChipCflow. . . . . . . . . . . 109

7.2 Tipos de enlace das máquinas a fluxo de dados . . . . . . . . . . 109

7.3 Operadores usados na máquina a fluxo de dados do ChipCflow, tokens chegando nos arcos de entrada dos operadores (circulo preenchido, circulo sem preenchimento, quadrado, letras $F$ e $T$ indicam diferentes tokens . . . . . . . . . . . . 110

7.4 Tokens processados nos arcos de saída dos operadores (circulo preenchido, circulo sem preenchimento, circulo preenchido dentro do quadrado, letras $F$ e $T$ indicam diferentes tokens gerados pelo processamento dos operadores . . . . . . . . . . 111

7.5 Protocolo handshake entre operadores . . . . . . . . . . . . . . 112

7.6 Exemplo de uma máquina a fluxo de dados usando os operadores do ChipCflow . . . . . . . . . . . . . . . . . . . 112

7.7 Exemplo de uma máquina a fluxo de dados para uma expressão condicional usando os operadores do ChipCflow . . . . . . . . 113

7.8 Formato do token no ChipCflow . . . . . . . . . . . . . . . . 113

7.9 Exemplo de uma máquina a fluxo de dados para uma itaração usando os operadores NTM, NIG, NTD, do ChipCflow . . . . . . . 114

7.10 Criação de tags iniciais utilizando o operador ITG . . . . . . . . 115

7.11 Loop utilizando o operador NIG . . . . . . . . . . . . . 116

7.12 Possível entrada de dados fora de ordem em um bloco . . . . . . . 117

7.13 Grafo onde um token deve recuperar sua tag antiga . . . . . . . 118

7.14 Estrutura da memória OTT . . . . . . . . . . . . . . . . . 120

7.15 Modelo para gerenciamento de memória, operadores load e store 121

7.16 Formato dos operadores load e store . . . . . . . . . . . . 121 
7.17 Soma de vetores, elemento por elemento, que utiliza todos os operadores de gerenciamento de tags propostos para a arquitetura ChipCflow . . . . . . . . . . . . . . . . . . . . . . . . 122

8.1 Instâncias diferentes para o operador $" * "$. . . . . . . . . . 126

8.2 Transporte de tokens entre operadores na máquina a fluxo de dados . . . . . . . . . . . . . . . . . . . 128

8.3 Fluxo de sinais para entradas de dados no operador $D M \quad \ldots . .129$

8.4 Fluxo de sinais para saídas de dados no operador $D M$. . . . . . 129

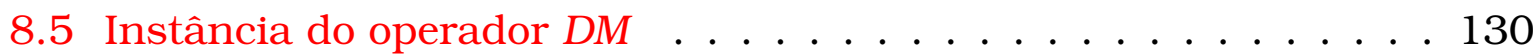

8.6 Fluxo de sinais para acesso à uma instância do operador $D M \quad$. . 130

8.7 Operador DM implementado para funcionar utilizando-se o modelo de instâncias . . . . . . . . . . . . . . . . . . . . . . . . 132

8.8 Fluxo de sinais para gerenciamento do operador $D M$ e suas instâncias . . . . . . . . . . . . . . . . . . . . . . 133

8.9 Módulo Confirma do operador DM . . . . . . . . . . . . . . . . . 133

8.10 Fluxo de sinais do módulo Confirma no operador DM . . . . . . 134

8.11 Diagrama de Sinais do módulo Confirma - com instâncias desocupadas . . . . . . . . . . . . . . . . . 135

8.12 Diagrama de Sinais do módulo Confirma - com envio de token para instâncias ocupadas . . . . . . . . . . . . . . . 136

8.13 Diagrama de Sinais do módulo Confirma - com recebimento de reconhecimento pelas instâncias . . . . . . . . . . . . 137

8.14 Diagrama de Sinais do módulo Confirma - com recebimento de não reconhecimento pelas instâncias . . . . . . . . . . . . 138

8.15 Simulação do operador DM, exemplo do funcionamento do módulo Confirma . . . . . . . . . . . . . . . . . . . . . . . . . . 139

8.16 Módulo Match do operador DM . . . . . . . . . . . . . 141

8.17 Simulação do módulo Match do operador DM . . . . . . . . . . . 142

8.18 Módulo Aloca do operador DM . . . . . . . . . . . . . . . . . 144

8.19 Fluxo de sinais do módulo Aloca no operador DM . . . . . . . . 145

8.20 Diagrama de sinais do módulo Aloca - com apenas um token de entrada . . . . . . . . . . . . . . . . 146

8.21 Diagrama de sinais do módulo Aloca - com envio de token às instâncias . . . . . . . . . . . . . . . . . . . . . . . 147

8.22 Diagrama de sinais do módulo Aloca - com recebimento de reconhecimento pelas instâncias . . . . . . . . . . . . . . . . 148

8.23 Diagrama de sinais do módulo Aloca - com recebimento de não reconhecimento pelas instâncias . . . . . . . . . . . . . . 149

8.24 Diagrama de sinais do módulo Aloca - com envio simultâneo de dois tokens às instâncias . . . . . . . . . . . . . . . . . 150 
8.25 Diagrama de sinais do módulo Aloca - com alocação de dois tokens simultâneos nas instâncias . . . . . . . . . . . . 151

8.26 Diagrama de sinais do módulo Aloca - com recebimento de reconhecimento de dois tokens simultâneos pelas instâncias . . . . 152

8.27 Simulação da função de localização de instâncias desocupadas 154

8.28 Simulação do módulo Aloca do operador DM . . . . . . . . . . . 155

8.29 Módulo Disparo do operador DM . . . . . . . . . . . . . . . 157

8.30 Fluxo de sinais do módulo Disparo no operador DM . . . . . . 158

8.31 Situação em que o módulo Disparo do operador DM recebe três tokens disparados simultaneamente . . . . . . . . . . . . . . 159

8.32 Diagrama de sinais do módulo Disparo - quando não ocorre disparo anterior . . . . . . . . . . . . . . 160

8.33 Diagrama de sinais do módulo Disparo - com um primeiro disparo 160

8.34 Diagrama de sinais do módulo Disparo - com recebimento de reconhecimento para um disparo . . . . . . . . . . 161

8.35Diagrama de sinais do módulo Disparo - com dois disparos simultâneos .................... . 161

8.36 Diagrama de sinais do módulo Disparo - com envio de dado do operador DM e armazenamento de dado da instância "um" . . . . 162

8.37 Diagrama de sinais do módulo Disparo - com recebimento de reconhecimento para dois disparos simultâneos . . . . . . . . . . . . 162

8.38 Simulação do módulo Disparo do operador DM . . . . . . . . . . . 163

8.39 Operador branch projetado para funcionar utilizando-se o modelo de instâncias . . . . . . . . . . . . . . . . . . . . 169

8.40 Operador operator projetado para funcionar utilizando-se o modelo de instâncias . . . . . . . . . . . . . . . 171

8.41 Operador decisor projetado para funcionar utilizando-se o modelo de instâncias . . . . . . . . . . . . . . . . . 173

8.42 Operador NDM . . . . . . . . . . . . . . 174

8.430perador Copy . . . . . . . . . . . . . . 176

8.44 Gráfico com o resultado de síntese dos módulos Match dos operadores DM, Decider, Operator e Branch . . . . . . . . . . . . . 178

8.45Gráfico com diferentes resultados no número de Slices gastos no FPGA para a implementação do operador DM com diferentes números de instâncias . . . . . . . . . . . . . . . . . . . . 180

8.46 Gráfico com diferentes resultados no número de Slice Flip Flops gastos no FPGA para a implementação do operador DM com diferentes números de instâncias . . . . . . . . . . . . . . . 180 
8.47 Gráfico com diferentes resultados no número de LUTs de 4 entradas gastos no FPGA para a implementação do operador DM com diferentes números de instâncias . . . . . . . . . . . . . . . 181

8.48Gráfico com diferentes resultados no número da Freqüência Máxima de operação nos FPGAs FPGA Virtex-II Pro e Virtex-7 xc7v2000t2-ffg1925, para a implementação do operador DM com diferentes números de instâncias . . . . . . . . . . . . . . . . . . . . 182

9.1 Abstração das instâncias no projeto ChipCflow . . . . . . . . . . . 189 


\section{Lista de Tabelas}

1.1 Comparação de desempenho entre Microprocessadores e FPGAs . 8

2.1 Capacidade lógica dos blocos lógicos . . . . . . . . . . . 33

2.2 Principais característica dos FPGAs Stratix-IV, Virtex-6 e Virtex-7 . 34

3.1 Características dos FPGAs da família Virtex-II Pro da Xilinx . . . . 44

3.2 Características do dispositivo XC2VP3O . . . . . . . . . . . . 44

8.1 Diferentes situações, nas quais podem chegar tokens simultaneamente nas entradas A, B e C do operador . . . . . . . . . . . . 153

8.2 diferentes situações para a expressão $\mathrm{F} 2 \ldots$. . . . . . . . . . 167

8.3 Guantidade de recursos lógicos disponiveis no FPGA Virtex-II Pro

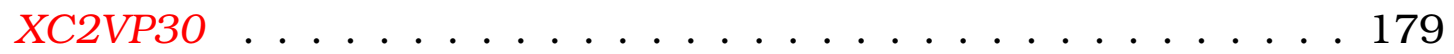




\section{Lista de Abreviaturas}

ALU Arithmetic Logic Unit

API Applica-tion Programming Interface

ASH Application-Specific Hardware

ASICs Application Specific Integrated Circuit

CAD Computer-aided Design

CAM Content Addressable memory

CASH Compiler for Application Specific Hardware-

CCT Centro de Ciências e Técnologia

CDFG Control Dataflow Graph

CDG Control-Dependence Graph

CFG Control Flow Graph

CIs Circuitos Integrados

CLB Configurable Logic Block

CMP Chip MultiProcessors

CPER Computador Paralelo Estruturado Recursivamente

CPLD Complex Programmable Logic Device

CPUs Central Processing Units

CSP Communicating Sequential Processes

CUDA Compute Unified Device Architecture 
DC Departamento de Computação

DCM Digital Clock Manager

DCR Device Control Register Bus

DDG Data-Dependence Graph

DDR Double Data Rating

DFC DataFlow C

DFG Data Flow Graph

DLP Data Level Parallelsim

DM Deterministic Merge

DMA Direct memory Access

DPR Dynamic Partial Reconfiguration

DSP Digital Signal Processing

DVD Digital Video Disc

EAPR Early Access Design Flow

EDA Electronic Design Automation

EDGE Explicit Data Graph Execution

EDIF Electronic Design Interchange Format

EDK Embedded Development Kit

EEPROM Electrically Erasable Programmable Read-Only Memory

EP Elemento de Processamento

EPLDs Classic Erasable programmable logic devices

EPROM Erasable Programmable Read-Only Memory

EXU Execution Unit

FDsim Fluxo de Dados Simulador

FIFO First In, First Out

FMU Fetch and Matching Unit

FPGA Field Programmable Gate Array 
FPSoC Field Programmable System on Chip

FPU Floating point unit

GOPS Giga-Operations Per Second

GPA Grid Processors Architecture

GPP General Purpose Processor

GPU Graphics Processing Unit

GUI Graphical User Interface

HDLs Hardware Description Language

HDTV High-Definition Television

HLS High-level synthesis

HPC High-performance Computing

HPDG Hierarchical Program Dependence Graph

HTG Hierarchical Task Graphs

IBU Input Buffer Unit

ICMC Instituto de Ciências Matemáticas e de Computação

IDE Integrated Development Environment

ILP Instruction-Level Parallelism

IOB Input/Output Block

IP Intellectual Property

IR Intermediate Representation

ISA Instruction Set Architecture

ISE Integrated Software Environment

ITG Initial Tag Generator

LCR Laboratório de Computação Reconfigurável

LMB Local Memory Bus

LSI Large Scale Integration

LUT Lookup Tables 
LUTs Look-Up Tables

MAC Multiply-Add-Accumulate

MCU Memory Control Unit

MDG Merge-Dependence Graph

MFDD Máquina a Fluxo de Dados Dinâmica

MFDM Máquina de Fluxo de Dados de Manchester

MFLOPS Million FLoating-point Operations Per Second

Mgates Milhões de portas lógicas

MIMD Multiple Instruction Stream/Multiple Data Stream

MIPS Millions of Instructions Per Second

MISD Multiple Instruction Stream - Single Data Stream

MIT Massachu-setts Institute of Technology

MPEG Moving Pictures Experts Group

MPGAs Mask-programmable Gate Array) / Standard Cells

NDM Non-Deterministic Merge

NIG New Iteration Generator

NTD New Tag Destructor

NTM New Tag Manager

OCM On-Chip Memory

OPB On-Chip Peripheral Bus

OpenMP Open Multi-Processing

OTT Old Tag Table

PAL Programmable Array Logic

PHLS Parallelizing highlevel synthesis

PLA Programmable Logic Array

PLB Processor Local Bus

PLD Programable Logic Devices 
PPAs Pipeline of Processor Arrays

PSP Platform Support Package

Pthreads POSIX threads

RAMs Random Access Memory

RBMs Restricted Boltzmann Machines

RISC Reduced Instruction Set Computing

RPU Reconfigurable Processing Unit

RTL Register Transfer Level

SCB Strongly Connected Block

SCC Synphony C Compiler

SDK Software Development Kit

SDRAM Synchronous Dynamic RAM

SIMD Single Instruction Stream/Multiple Data Stream

SMP Symmetric Multiprocessor

SoC System-on-chip

SOPC System-On-a-Programable-Chip

SPICE Simulation Program with Integrated Circuit Emphasis

SPLD Simple Programmable Logic Device

SPMD Single Process, Multiple Data or Single Program, Multiple Data

SRAM Static RAM

SU Switching Unit

SUIF Stanford Universal Intermediate Format

TLP Thread-Level Parallelism

TR Tag Remover

TRIPS Tera-op Reliable Intelligently adaptive Processing System

TTDA Tagged-Token Dataflow Architecture

UART Universal Asynchronous Receiver Transmitter 
UFSCar Universidade Federal de São Carlos

ULA Unidade Lógica e Aritmética

USB Universal Serial Bus

VHDL VHSIC Hardware Description Language

VHSIC Very High Speed Integrated Circuit

VLIW Very Long Instruction Word

VLSI Very Large Scale Integration

XCL Xilinx CacheLink

XPS Xilinx Platform Studio 


\section{Lista de Algoritmos}

1 Soma de vetores, elemento por elemento . . . . . . . . . . . 120

2 Um exemplo de um algoritmo que caracteriza o uso do "taggedtoken" através da instrução para . . . . . . . . . . . . . . 126 


\section{Resumo}

Devido à complexidade das aplicações, a demanda crescente por sistemas que usam milhões de transistores e hardware complexo; tem sido desenvolvidas ferramentas que convertem $C$ em Linguagem de Descrição de Hardware, tais como VHDL e Verilog. Neste contexto, esta tese apresenta o projeto ChipCflow, o qual usa arquitetura a fluxo de dados, para implementar lógica de alto desempenho em Field Programmable Gate Array (FPGA).

Maquinas a fluxo de dados são computadores programáveis, cujo hardware é otimizado para computação paralela de granularidade fina dirigida por dados. Em outras palavras, a execução de programas é determinado pela disponibilidade dos dados, assim, o paralelismo é intrínseco neste sistema. Por outro lado, com o avanço da tecnologia da microeletrônica, o FPGA tem sido utilizado principalmente devido a sua flexibilidade, facilidade para implementar sistemas complexos e paralelismo intrínseco.

Um dos desafios é criar ferramentas para programadores que usam linguagem de alto nível (HLL), como a linguagem $C$, e produzir hardware diretamente. Essas ferramentas devem usar a máxima experiência dos programadores, o paralelismo das arquiteturas a fluxo de dados dinâmica, a flexibilidade e o paralelismo do FPGA, para produzir um hardware eficiente, otimizado para alto desempenho e baixo consumo de energia.

O projeto ChipCflow é uma ferramenta que converte os programas de aplicação escritos em linguagem $C$ para a linguagem $V H D L$, baseado na arquitetura a fluxo de dados dinâmica. O principal objetivo dessa tese é definir e implementar os operadores do ChipCflow, usando a arquitetura a fluxo de dados dinâmica em FPGA. Esses operadores usam tagged tokens para identificar dados, com base em instâncias de operadores. A implementação dos operadores e das instâncias usam um modelo de implementação assíncrono em FPGA para obter maior velocidade e menor consumo. 
Xxii 


\section{Abstract}

Due to the complexity of applications, the growing demand for both systems using millions of transistors and consecutive complex hardware, tools that convert C into a Hardware Description Language (HDL), as VHDL and Verilog, have been developed. In this context this thesis presents the ChipCflow project, which uses dataflow architecture to implement high-performance logics in Field Programmable Gate Array (FPGA). Dataflow machines are programmable computers whose hardware is optimized for fine-grain data-flow parallel computation. In other words the execution of programs is determined by data availability, thus parallelism is intrinsic in these systems. On the other hand, with the advance of technology of microelectronics, the FPGA has been used mainly because of its flexibility, facilities to implement complex systems and intrinsic parallelism. One of the challenges is to create tools for programmers who use HLL (High Level Language), such as C language, producing hardware directly. These tools should use the utmost experience of the programmers, the parallelism of dynamic dataflow architecture and the flexibility and parallelism of FPGA to produce efficient hardware optimized for high performance and lower power consumption. The ChipCflow project is a tool that converts application programs written in C language into VHDL, based on the dynamic dataflow architecture. The main goal in this thesis is to define and implement the operators of ChipCflow using dynamic dataflow architecture in FPGA. These operators use tagged tokens to identify data based on instances of operators and their implementation and instances use an asynchronous implementation model in FPGA to achieve faster speed and lower consumption. 


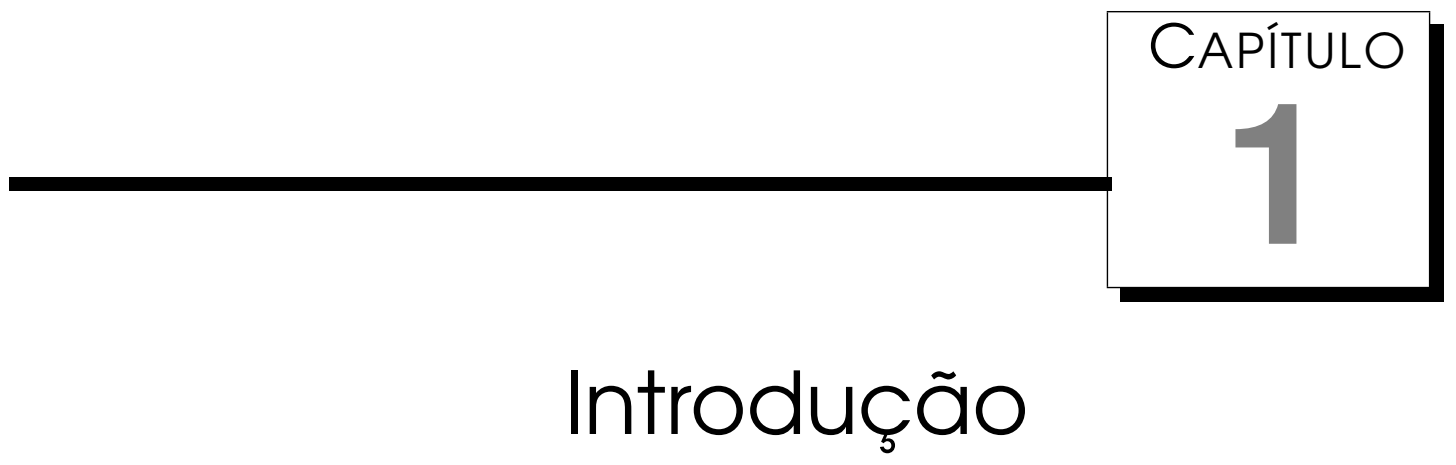

Neste capítulo é apresentado a contextualização que envolve o conjunto de circunstâncias para a elaboração dessa tese e a motivação de realizá-la. Em seguida, são mostrados os objetivos, bem como as contribuições geradas por ela. Finalmente é apresentada a organização da tese.

\subsection{Contextualização e Motivação}

Nos últimos 50 anos, o desempenho computacional aumentou 10 vezes mais suas ordens de grandeza (Najjar and Villarreal (2009)).

O aumento constante no desempenho dos processadores, segundo Santos (2007) e Najjar and Villarreal (2009), foi devido, principalmente, ao avanço na tecnologia Very Large Scale Integration (VLSI), que tem possibilitado encapsular bilhões de transistores dentro de um único chip. Esse avanço foi impulsionado por dois fatores:

1. Lei de Moore que afirma que o número de transistores dos chips tem um aumento de cem por cento, pelo mesmo custo, a cada período de 18 meses;

2. A diminuição do tamanho dos transistores, que resultou em um aumento da freqüência do clock.

Este aumento de desempenho foi acompanhado por um decréscimo no consumo de energia, custo e tamanho, nos chips. Atualmente, a tecnologia VLSI tem como maior barreira a diminuição do tamanho dos transistores. 
A discussão em torno dos limites tecnológicos para a construção de dispositivos de processamento cada vez menores e com maior capacidade de processamento não é algo recente. A busca e a pesquisa por alternativas a esses limites já dura algumas décadas.

Os efeitos secundários da revolução da tecnologia VLSI fomentaram pesquisas em modelos de computação paralela, tais como: algoritimos, linguagens de programação, compiladores paralelizáveis e arquiteturas paralelas nas décadas de 70,80 e 90.

Durante esse período, grandes empresas e grupos de pesquisa iniciaram suas pesquisas tendo como base o modelo de classificação de Flynn (1972) para arquiteturas paralelas tais como Single Instruction Stream/Multiple Data Stream (SIMD), Single Process, Multiple Data or Single Program, Multiple Data (SPMD), Multiple Instruction Stream/Multiple Data Stream (MIMD), Multiple Instruction Stream - Single Data Stream (MISD), Symmetric Multiprocessor (SMP), (MARQUES (1993)), (Silva (1992)), (FERLIN (2008)). Essas pesquisas dobraram nos últimos anos, devido a impossibilidade de competir com a lei de Moore (Najjar and Villarreal (2009)).

Em 2004, a empresa de processadores Intel Inc. anunciou uma mudança em sua estratégia de pesquisa na evolução de seus microprocessadores devido ao limite de aquecimento nos chips (MARKOFF (2004)). Com essa mudança, o número de transistores continua aumentando na forma de multicores. Segundo Najjar and Villarreal (2009), esse fenômeno inaugurou a nova era do paralelismo.

\subsection{Field Programmable Gate Arrays - FPGAs}

No início da década de 80 a maioria dos sistemas em hardware eram implementados usando Circuitos Integrados (CIs) como padrões de integração em larga escala, conhecidos como Large Scale Integration (LSI), foi o caso dos microprocessadores, memórias e controladores de entrada/saída. Cada sistema tinha necessidade de alguma lógica para conectar esses grandes CIs. Essas lógicas eram conhecidas como "glue logic". ${ }^{1}$

Os CIs customizados eram muitas vezes projetados para substituir glue logic, mas tinham alto custo de fabricação e consumiam muito tempo de desenvolvimento. Assim, o uso de CIs customizados só era viável para produtos com grande volume de fabricação.

A empresa Xilinx introduziu em 1984 a tecnologia Field Programmable Gate Array (FPGA) como uma alternativa ao uso de CIs customizados para implementar os glue logics.

\footnotetext{
${ }^{1}$ glue logic ou lógica de cola: circuito lógico simples utilizado para conectar dois circuitos, mesmo que sua interface não seja completamente compativel.
} 
Com o advento dos FPGAs e suas respectivas plataformas de desenvolvimento, que permitiram flexibilidade para correções e atualizações de forma rápida e segura em projetos até então considerados glue logic, ocorreu uma redução do número de componentes em um sistema e uma diminuição nos erros de desenvolvimento dos mesmos.

Os primeiros FPGAs eram relativamente simples e continham apenas alguns milhares de portas lógicas. Atualmente, eles oferecem milhões de portas lógicas alguns integrados a componentes embarcados, tais como Digital Signal Processing (DSP), blocos de memórias internas, Central Processing Units (CPUs) e outros blocos dedicados, formando-se assim um sistema completo numa única pastilha (Pellerin and Thibault (2005)) e são utilizados no projeto e controle de inúmeros sistemas com aplicações específicas, significativamente mais complexas e dedicadas do que no início de seu advento (Piacentino et al. (1999)) e (Najjar and Villarreal (2009)).

Com a evolução da microeletrônica e conseqüentemente aumento na densidade e velocidade dos FPGAs, esses dispositivos começaram a ocupar um lugar intermediário entre os processadores de propósito geral, os General Purpose Processor (GPP) e os Application Specific Integrated Circuit (ASICs) (Hauck (1998)), (Compton and Hauck (2002)), (Scott et al. (2006)), (Villasenor and Smith (1997)) e (Bobda (2007)).

Na Figura 1.1, é possivel observar nos atuais FPGAs Stratix 5 da Altera e Virtex-7 da Xilinx, o dobro de capacidade lógica e memória embarcada, se comparados aos FPGAs Stratix e Virtex-II, respectivamente da Altera e Xilinx, há uma década (Koch and Torresen (2010)).

Segundo Koch and Torresen (2010), ao passar pela fronteira de um milhão de Look-Up Tables (LUTs), a alta densidade dos FPGAs seria suficiente para receber 250 CPUs soft-cores ${ }^{2}$, juntamente com os periféricos necessários a eles.

Os FPGAs tem tido sua capacidade aumentada em número de transistores no mesmo circuito integrado de forma mais acentuado do que os próprios microprocessadores (Cardoso (2000)). Este crescimento, apenas comparável ao das memórias RAMs, deve-se à regularidade da estrutura dos FPGAs e ao fato destes dispositivos não terem custos de teste tão elevados como os microprocessadores. A taxa de crescimento da capacidade dos FPGAs acentua cada vez mais a discrepância entre as capacidades atuais do projeto de hardware e de área disponível (Reiner et al. (1996)).

Nos sistemas paralelos tradicionais um caminho para se obter maior desempenho é a exploração do paralelismo da aplicação por meio de múltiplos

\footnotetext{
${ }^{2}$ Soft cores são descritos com o emprego de linguagens de descrição de hardware, como VHSIC Hardware Description Language (VHDL) ou Verilog, oferecendo flexibilidade na modificação dos seus parâmetros, além de ser independência de tecnologia.
} 


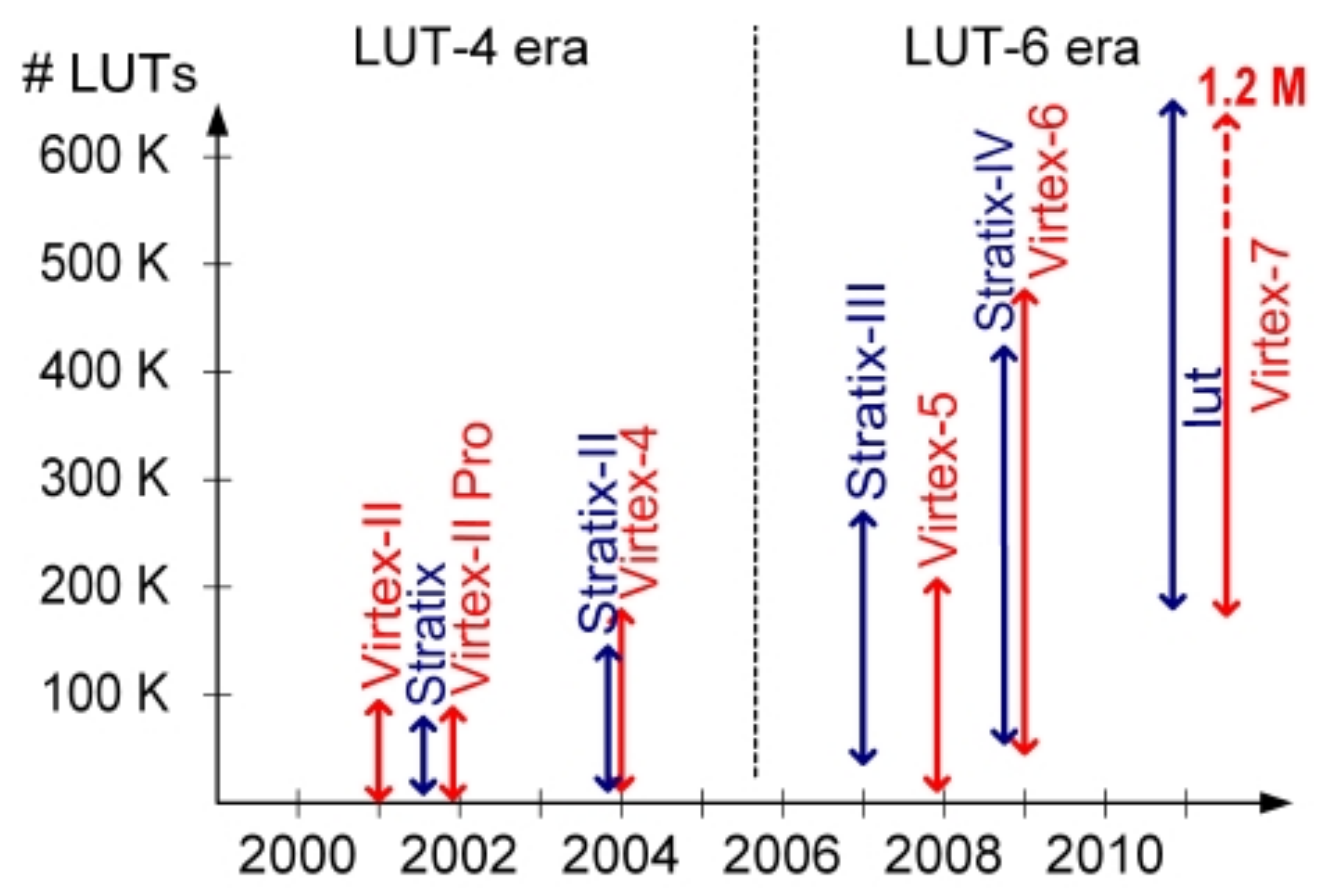

Figura 1.1: A Figura representa o aumento da densidade lógica sobre o tempo e sobre os processos tecnológicos correspondentes (Koch and Torresen (2010)).

microprocessadores. Nos sistemas computacionais reconfiguráveis, um dos caminhos é a implementação em hardware das partes do programa de aplicação computacionalmente mais intensas. No segundo caso, a exploração do paralelismo existente em uma aplicação tem a característica de ser um modelo intrinsecamente concorrente no hardware em vez dos modelos baseados na estrutura seqüencial de von-Neumann, utilizados pela maioria dos sistemas de suporte ao processamento paralelo. Além disso, as máquinas personalizadas ao nível de portas lógicas não possuem a limitação de largura de banda no carregamento de instruções, fato que limita o desempenho das arquiteturas paralelas baseadas em vários microprocessadores. Contudo, apesar de novas arquiteturas terem sido propostas e novos conceitos apresentados, tendo como base os sistemas reconfiguráveis (Radunovic' and Milutinovic' (1998)) e (Scott et al. (2006)), a utilização desses sistemas requer etapas morosas e complexas e conhecimentos específicos de projeto de hardware (Cardoso and Neto (2003)) e (Najjar and Villarreal (2009)).

Essa dificuldade, tanto na implementação como na verificação funcional dos sistemas reconfiguráveis, deve-se ao aumento na quantidade de portas lógicas em um FPGA, sendo portanto necessária a utilização de Hardware Description Language (HDLs), como Verilog e VHDL para o desenvolvimento de sistemas, que é um processo que demanda mais tempo de desenvolvimento, se comparado ao tempo para se programar sistemas em alto nível, como por exemplo, o $\mathrm{C} / \mathrm{C}^{++}$. 
Essas implementações, em geral, requerem decisões e conhecimentos tanto da micro-arquitetura do FPGA quanto das linguagens HDLs, além dos conhecimentos necessários das ferramentas dos seus fabricantes. Ainda, dependendo da implementação, torna-se necessário explorar alternativas de arquiteturas e divisão entre hardware e software do projeto. Uma solução para tal problema seria elevar o nível de abstração na implementação do sistema (Pellerin and Thibault (2005)).

\subsubsection{Computação Reconfigurável}

Não há uma definição formal sobre computação reconfigurável. Porém, a definição geralmente aceita é que sua implementação é feita sobre uma estrutura de hardware, cuja funcionalidade é definida pelo usuário (Najjar and Villarreal (2009)). Segundo Bobda (2007), a computação reconfigurável pode ser definida como o estudo da computação envolvendo dispositivos reconfiguráveis, incluindo arquiteturas, algoritmos e aplicações.

O dispositivo mais utilizado atualmente para computação reconfigurável é o FPGA, cuja configuração é realizada pelo projetista. A prototipação rápida permite que um projeto seja testado em um hardware real antes da produção final em um circuito ASIC, assim, os erros podem ser corrigidos antes das peças serem produzidas. Isso permite uma redução significativa do time-tomarket ${ }^{3}$ (Redaelli et al. (2008)).

Na literatura são muito comuns os termos hardware reconfigurável, dispositivo reconfigurável ou unidade de processamento reconfigurável, em inglês Reconfigurable Processing Unit (RPU), para se descrever um dispositivo reconfigurável (Bobda (2007)).

As aplicações da computação reconfigurável, segundo Najjar and Villarreal (2009), podem ser divididas em duas amplas categorias:

- Sistemas embarcados: Estão incluídas nessa categoria os sistemas embarcados de alto desempenho, tais como sistemas de telecomunicações, aplicações de codificação e manipulação de áudio e vídeo para o padrão High-Definition Television (HDTV).

- Computação de alto desempenho: Nesses sistemas tenta-se utilizar o potencial dos FPGAs para, junto com os processadores, acelerar aplicações.

A distinção nem sempre é clara nesses dois domínios de aplicações, pois há diferentes requisitos sobre eles. Na primeira, o custo e consuno de energia são considerações primárias. Na segunda, a aceleração deve ser suficientemente grande para justificar os custos de um grande número de dispositivos FPGAs.

\footnotetext{
${ }^{3}$ o tempo requerido para desenvolver um sistema até um ponto em que ele possa ser disponibilizado para o usuário
} 
Apesar dos FPGAs não terem inicialmente sido projetados para computação reconfigurável, atualmente está sendo amplamente utilizado como elemento fundamental nesse novo paradigma, a computação reconfigurável (Aragão (1998)) e (Bobda (2007)).

A computação reconfigurável combina o desempenho do hardware dedicado com graus de flexibilidade alcançados nos softwares. Entretanto, enquanto que os componentes de software estão limitados às arquiteturas dos microprocessadores, a computação reconfigurável permite ter arquiteturas adaptadas às aplicações. Essa característica pode ser verificada na Figura 1.2 .

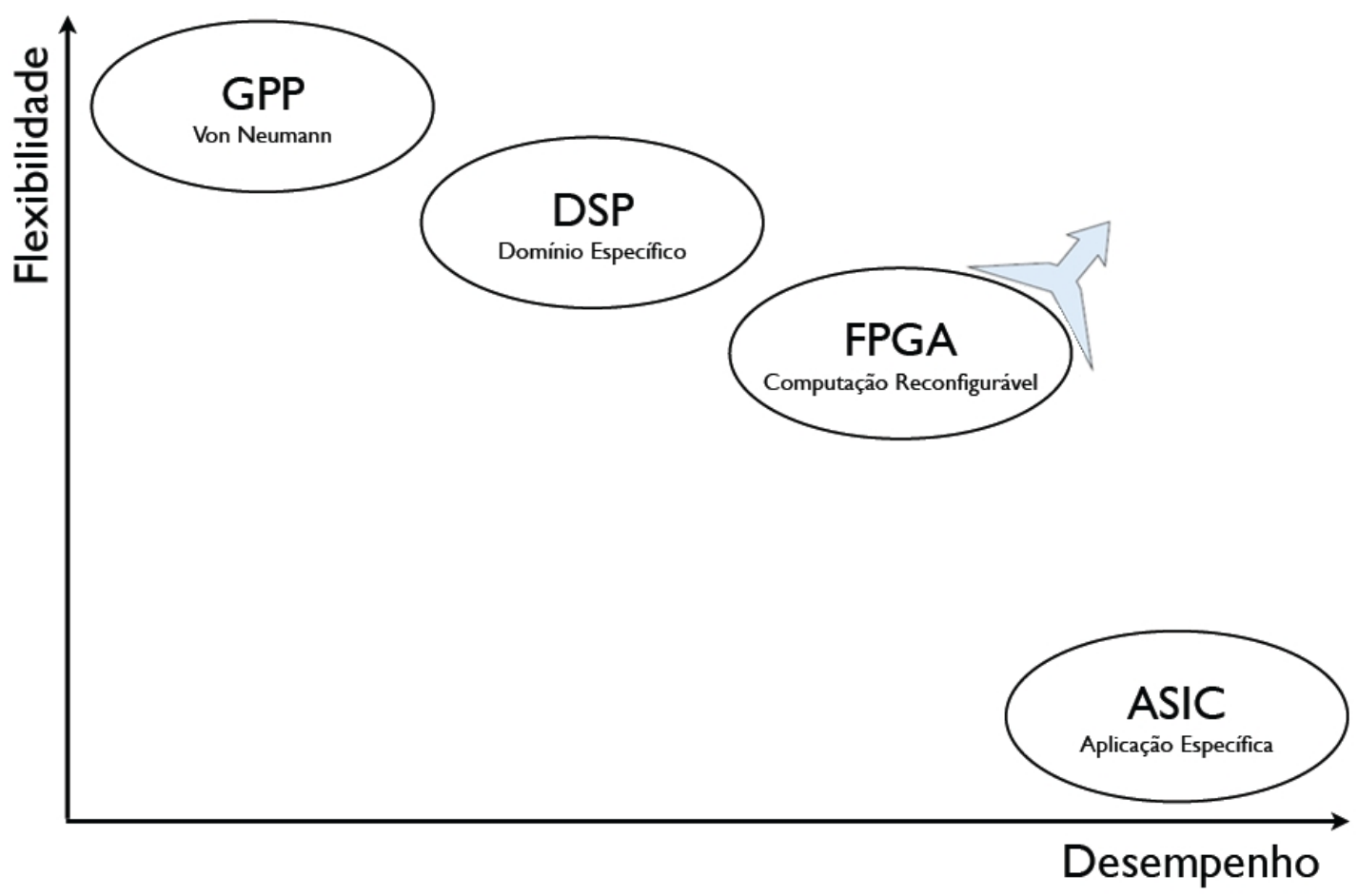

Figura 1.2: Flexibilidade versos desempenho dos sistemas programáveis.

Na Figura1.2 pode-se observar que a computação reconfigurável, que faz uso de dispositivos reconfiguráveis como o FPGA, está posicionado entre as arquiteturas von-Neumann e os circuitos ASICs.

Segundo Ribeiro (2002), Compton and Hauck (2002) e Scott et al. (2006), os sistemas de computação reconfigurável são plataformas, nas quais a arquitetura pode ser modificada em tempo real, para melhor adequar-se à aplicação. Assim, um processador reconfigurável, gerado a partir de um FPGA, passa a trabalhar com uma arquitetura desenvolvida exclusivamente para um determinado tipo de aplicação, permitindo uma eficiência muito maior do que a normalmente encontrada em processadores de uso geral. Essa característica pode ser visto na Figura 1.3.

Na Figura 1.3, são descritos três sistemas: o primeiro sistema, Figura 1.3a, representa um ASIC; o segundo sistema, Figura 1.3b representa um GPP e o 


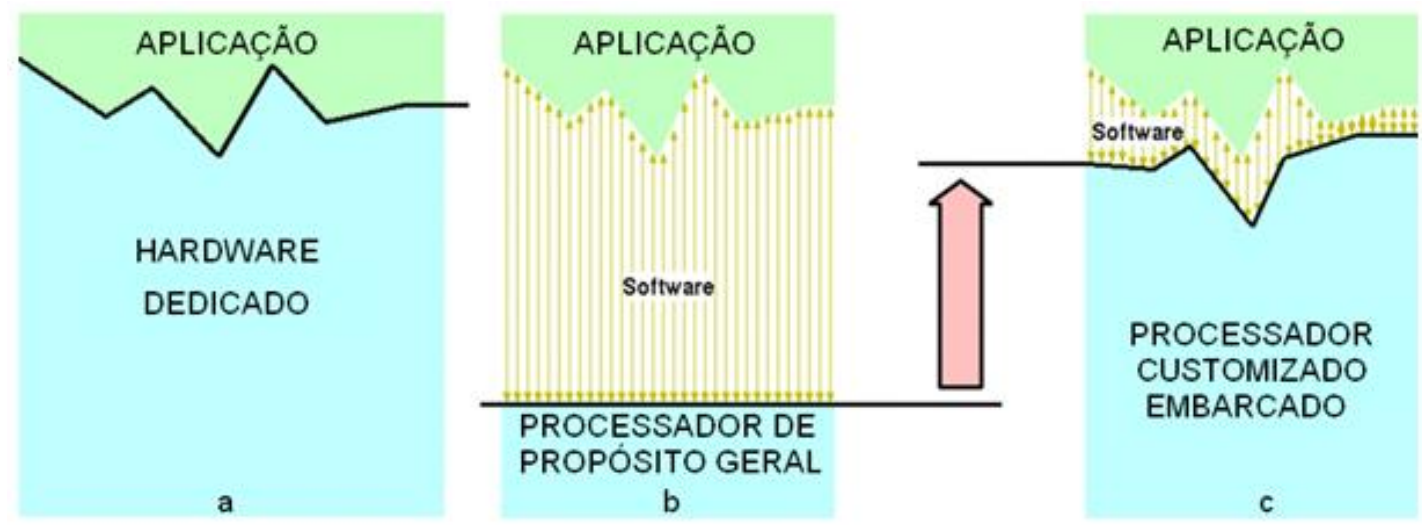

Figura 1.3: Benefícios da Computação Reconfigurável.

terceiro sistema, Figura $1.3 \mathrm{c}$ representa um processador customizado em um FPGA. O primeiro sistema é o que tem o maior desempenho, menor flexibilidade, menor gasto de energia, porém, longo time-to-market, além do fato de que o projeto final não pode ser alterado, tanto para atender outras aplicações quanto para futuras melhorias. O segundo sistema é o que possui o menor desempenho dos três descritos na Figura 1.3, entretanto, é o que possui maior flexibilidade, porém, é o que possui menor time-to-market. O terceiro sistema, em geral, possui desempenho e time-to-marquet intermediário entre os dois primeiros sistemas, mas perde no consumo, apesar de já estar sendo superados pelos atuais modelos 28nm FPGA (Xilinx (2011a)).

Ainda, na Figura 1.3, observa-se que no primeiro sistema o hardware é modelado perfeitamente na aplicação. Isso significa que o hardware pode ser customizado, possuindo apenas instruções utilizadas naquela aplicação, comprovando assim o melhor desempenho, menor consumo, mas pouca flexibilidade nesse sistema. No segundo sistema, por ser definido a partir de um GPP, a camada de software necessária para que esse hardware seja adequado à aplicação pode ser grande, comprovando assim a maior flexibilidade, porém, dependente de um processador de uso geral com as tradicionais taxas de consumo, custo e desempenho para este sistema. Finalmente, no terceiro sistema, por se tratar de um processador customizado para aquela aplicação, mas dependente das tecnologias dos FPGAs, fica comprovado sua flexibilidade, adequação à aplicação nos limites de custo, consumo e desempenho previstos para estes dispositivos.

Como um FPGA pode ser configurado para operar como uma variedade de arquiteturas computacionais específicas, (Bolsens (2006)) traz uma comparação de desempenho entre o microprocessador Itanium 2 da Intel e os FPGAs Virtex-II Pro e Virtex-4 da Xilinx, cujos resultados são descritos na Figura 1.4. Na Figura 1.4a é descrito a comparação entre os três sistemas, com relação ao Giga-Operations Per Second (GOPS). Nas Figuras 1.4b e 1.4c são descritos 
a largura de banda de memória e a largura de banda de $E / S$, respectivamente para os três sistemas.

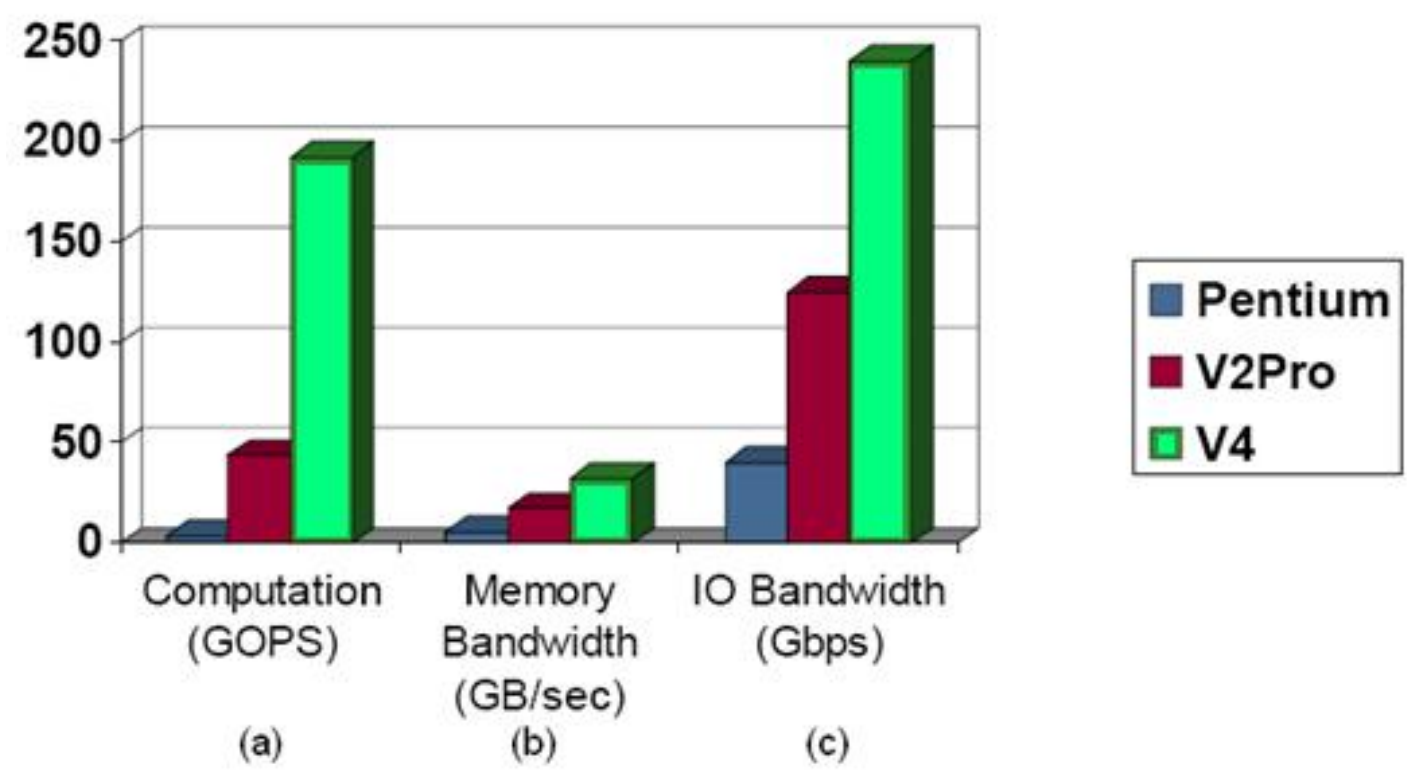

Figura 1.4: Comparação de desempenho entre GPP e FPGA (Bolsens (2006) )

Tabela 1.1: Comparação de desempenho entre Microprocessadores e FPGAs (Bolsens (2006))

\begin{tabular}{lll}
\hline & Microprocessador Itanium 2 & FPGA Virtex 2VP100 \\
\hline $\begin{array}{l}\text { Velocidade de clock } \\
\text { (memória interna) }\end{array}$ & $1.6 \mathrm{GHz}$ & $180 \mathrm{MHz}$ \\
\hline $\begin{array}{l}\text { Unidades de } \\
\text { processamento }\end{array}$ & $5 \mathrm{FPU}$ & $7.5 \mathrm{TBytes} / \mathrm{seg}$ \\
\hline Consumo de energia & $130 \mathrm{Watts}$ & $212 \mathrm{FPU}$ \\
\hline $\begin{array}{l}\text { Pico de } \\
\text { desempenho }\end{array}$ & $8 \mathrm{GFLOPs}$ & $15 \mathrm{Watts}$ \\
\hline $\begin{array}{l}\text { Desempenho } \\
\text { normal }\end{array}$ & $2 \mathrm{GFLOPs}$ & $38 \mathrm{GFLOPs}$ \\
\hline $\begin{array}{l}\text { E/S / largura de } \\
\text { banda (memória } \\
\text { externa) }\end{array}$ & $6.4 \mathrm{GBytes} / \mathrm{seg}$ & $19 \mathrm{GFLOPs}$ \\
\hline
\end{tabular}

Como descrito nas Figura 1.4 e complementado na Tabela 1.1, nas análises realizadas por Bolsens em 2006, os FPGAs Virtex-II Pro e Virtex-4 superam o processador Itanium 2 no que se refere a GOPS, largura de banda de memória e largura de banda de E/S.

Esse crescimento em desempenho nos FPGAs continua, como descrito nos próximos parágrafos. Sang et al. (2009) mostra um desempenho 25 vezes maior para a Restricted Boltzmann Machines (RBMs) implementada em um 
FPGA Stratix III EP3SL34O da empresa Altera sobre um processador Core 2 da empresa Intel.

Nas Figuras 1.5 e 1.6 são descritas algumas comparações entre Graphics Processing Unit (GPU), processadores IBM Cell, Intel Xeon, Intel Core i7, FPGAs Virtex-5 e Virtex-6, tendo como base o Simulation Program with Integrated Circuit Emphasis (SPICE) para a simulação de diferentes tipos de modelos de circuitos que fazem uso de aritmética de precisão simples em tecnologia 65 $\mathrm{nm}$ e $45 \mathrm{~nm}$. Os diferentes tipos de modelos usados foram o bjt, diode, jfet, mos 1, vbic, mos3, hbt, mext., bsim3, bsim4 e psp. Todos esses modelos foram descritos por meio do compilador Verilog AMS, (Nachiket and André (2009)), que incorpora diferentes estratégias de paralelismo para arquiteturas específicas, em particular, o Open Multi-Processing (OpenMP), para os processadores multicores; o POSIX threads (Pthreads) para os processadores Cell; Compute Unified Device Architecture (CUDA) para GPUs e arquiteturas Very Long Instruction Word (VLIW) para os FPGAs.

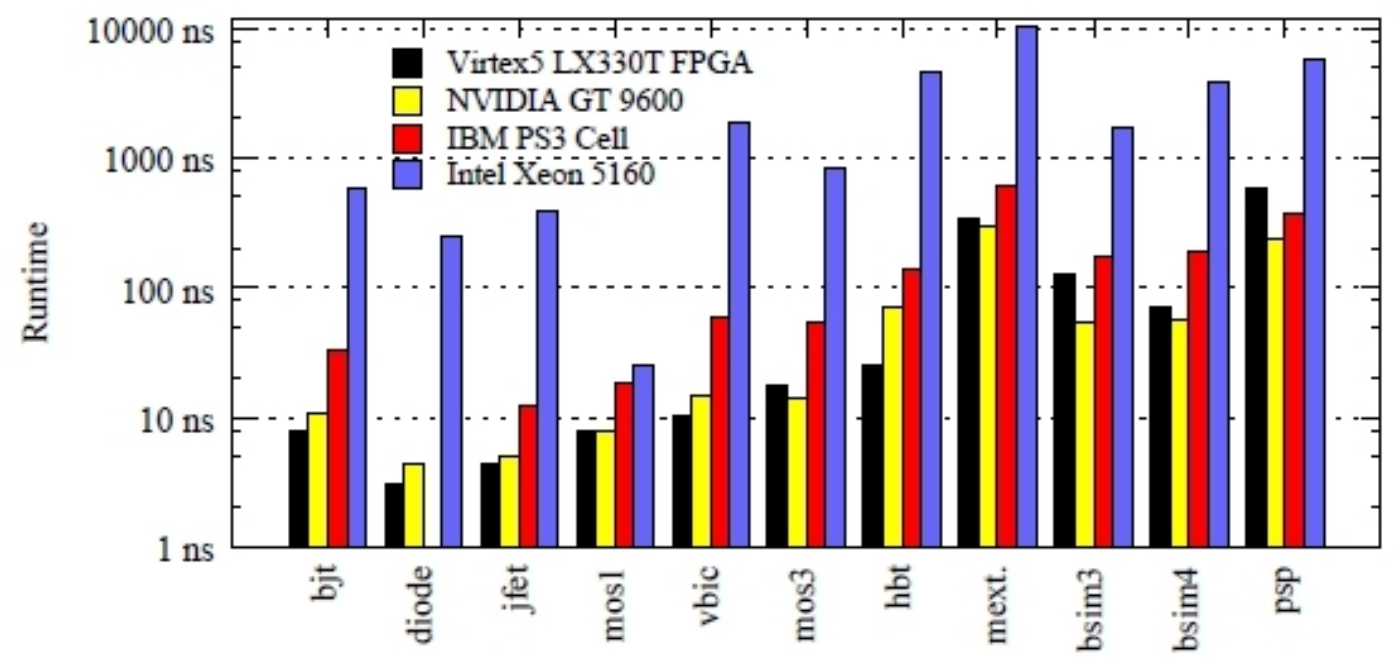

Figura 1.5: Análise de desempenho nas arquiteturas 65nm (Nachiket and André (2009))

Na Figura 1.5, pode-se observar que o processador multicore Xeon de 3 GHz da Intel é superado pelos dispositivos: FPGA Virtex-5 LX330T da Xilinx, GPU 9600 GT da empresa NVIDIA, PS3 Cell (primeira geração) da empresa IBM. Na Figura 1.6, é mostrado a comparação de desempenho entre o FPGA Virtex-6 LX 760 da empresa Xilinx e o processador Core i7 965 da empresa Intel, ambas arquiteturas de $45 \mathrm{~nm}$, destacando-se o melhor desempenho do FPGA.

Alguns FPGAs são completamente reconfiguráveis, ou seja, a configuração anterior é completamente apagada antes de se inserir uma nova configuração.

Em FPGAs parcialmente reconfiguráveis é possivel selecionar uma área do FPGA e colocar um novo módulo nessa área ou apenas substituir módulos 


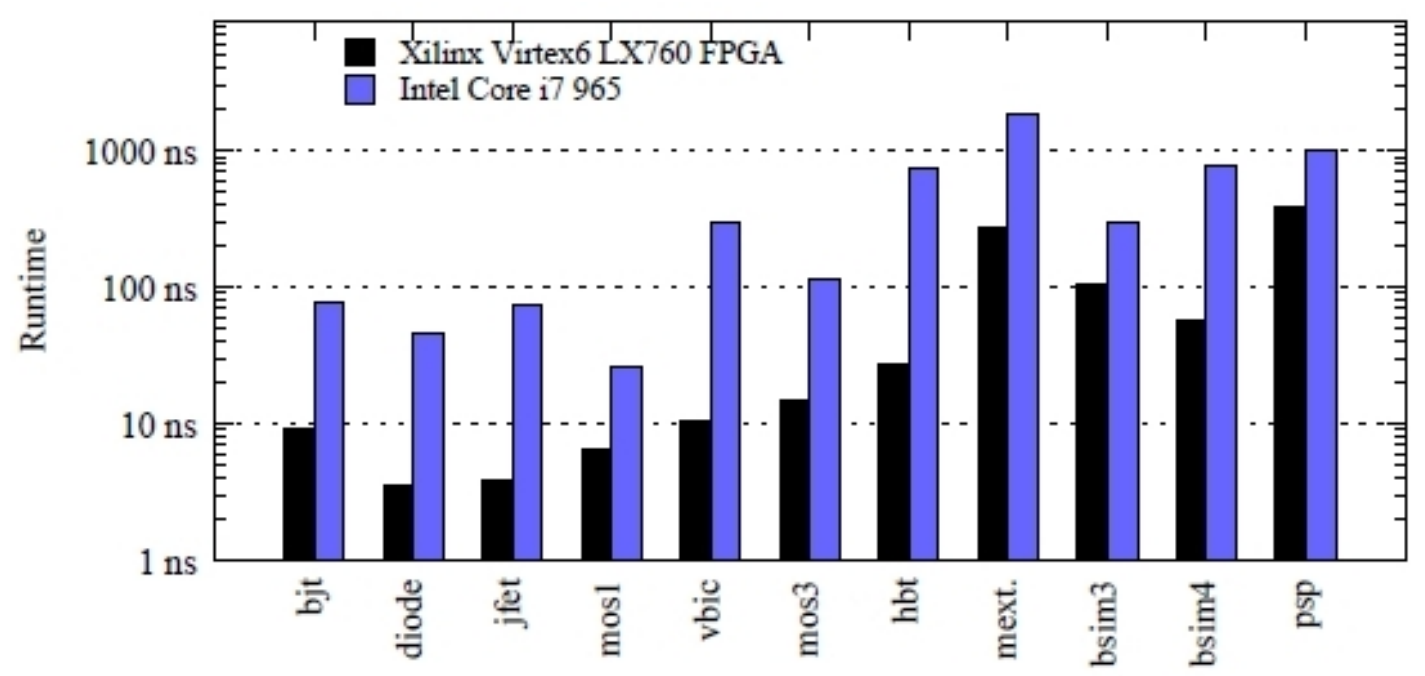

Figura 1.6: Análise de desempenho nas arquiteturas 45nm (Nachiket and André (2009))

ociosos, porém, a execução do FPGA deve ser interrompida para que essa configuração parcial aconteça. Por fim, existem os FPGAs que permitem configuração parcial e dinâmica. Os FPGAs com essas características possuem áreas no chip para essa finalidade, podendo ser reconfigurados de forma seletiva enquanto estiverem ativos. Os termos "on-the-fly reconfiguration" e "run-time reconfiguration" são encontrados na literatura, para descrever reconfiguração parcial e dinâmica (Ribeiro (2002)).

Os FPGAs da família Virtex da Xilinx permitem a reconfiguração parcial e dinâmica (Bobda (2007)). A capacidade de reconfiguração parcial possibilita que muitas funções sejam temporariamente implementadas no dispositivo viabilizando por exemplo a implementação de sistemas adaptativos.

\subsubsection{O modelo von-Neumann}

A grande maioria dos computadores seguem o modelo de arquitetura von Neumann, definida por John Louis von Neumann. Esse modelo consiste na associação de um processador e uma memória, os quais são fisicamente separados e, nesta memória, ficam armazenados tanto o programa, quanto os dados a serem processados (Tanenbaum (2005)).

Segundo Bobda (2007), uma das razões para a aceitação mundial do modelo de arquitetura von-Neumann é a sua simplicidade de programação que segue o caminho seqüencial do pensamento humano, o que torna a programação intuitiva. A estrutura geral da máquina de von-Neumann, mostrado na Figura 1.7 consiste de:

- uma memória, utilizada simultaneamente para armazenar programas e dados; 
- uma unidade de controle, em inglês control path, com um contador de programa que contém o endereço da próxima instrução a ser executada;

- uma unidade lógica aritmética, em inglês data path, na qual as instruções são executadas.

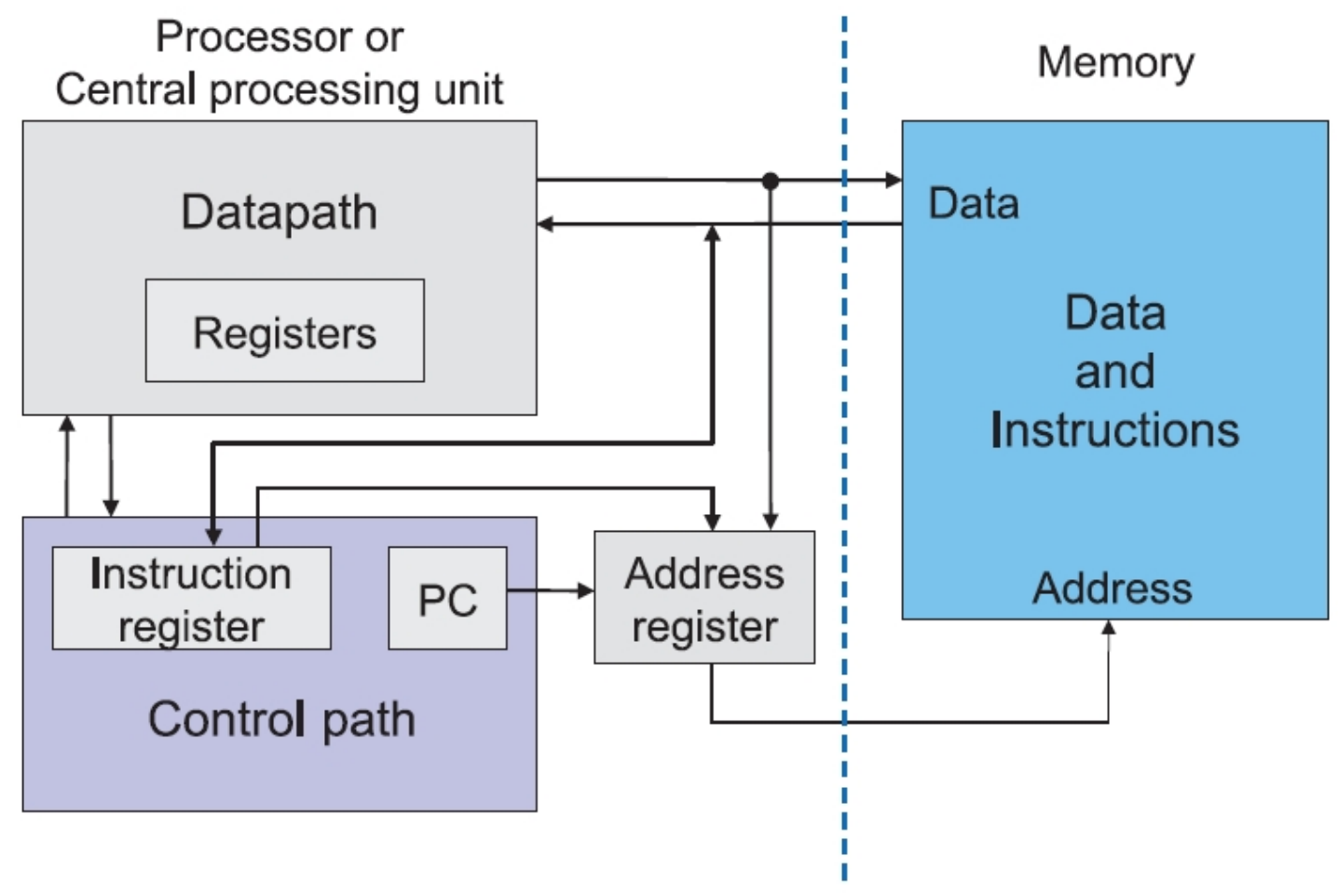

Figura 1.7: Arquitetura von-Neumann (Bobda (2007))

Para que seja possivel a construção de programas, existe a necessidade de uma interface entre o hardware e o programador. Esta interface designa-se por Instruction Set Architecture (ISA) e define as palavras que a máquina entende, sendo o seu vocabulário designado por um conjunto de instruções, em inglês definido como Instruction Set, do processador. Um programa é codificado como um conjunto de instruções a serem executadas em seqüencia, uma instrução após outra.

Os programas armazenados na memória necessitam de algo físico que os execute. Esta é a função da $C P U$ ou processador. Tal como foi visto a $C P U$ é dividido essencialmente em dois componentes: uma unidade lógica aritmética e uma unidade de controle. A CPU utiliza alguns passos para a execução dos programas. Essa seqüencia de passos é referida como ciclo de "buscadecodifica-executa", em inglês, instruction fetch, instruction decode e execute. Este ciclo é o centro de operação da grande maioria dos computadores. Esse ciclo, pode ser resumido como (Ordonez et al. (2003)):

1. Busca a proxima instrução da memória e a envia ao registrador de instrução. 
2. Atualiza o contador de programa, para que ele referencie a instrução seguinte na memória.

3. Determina o tipo da instrução.

4. Se a instrução usa dados da memória, determina em que posições eles estão.

5. Busca os dados, se houver algum, e envia aos registradores internos da CPU.

6. Executa a instrução.

7. Armazena resultado(s) em determinadas posições de memória ou registradores da CPU.

8. Volta ao passo 1, para iniciar a execução da próxima instrução.

O que pode-se observar nesta estrutura é um controle baseado em uma seqüencia de eventos bem definidos que vai da busca da instrução na memória até a completa execução daquela instrução, inclusive com o armazenamento de dados, e só então uma nova busca deverá ocorrer, característica essa fundamental nas máquinas convencionais.

O modelo von-Neumann pode ser caracterizado como um modelo linearmente centralizado, ao que se refere ao processo de execução (Silva and Lopes (2010)). Entretanto é possivel introduzir alguma forma de paralelismo. Linguagens de programação concorrentes permitem obter paralelismo em uma máquina baseada no modelo von Neumann, porém o paralelismo aqui é obtido de forma temporal e não espacial (Silva (1992)). Para se obter um paralelismo espacial seria necessário incluir à organização da máquina, modificações que vão desde estruturas tipo pipeline até estruturas com vários processadores executando computações simultaneamente. Apesar das diferentes características nestas estruturas, a execução dos programas a nível convencional, continua sendo executado de forma seqüencial, é o caso de multiprocessadores, onde programas são executados simultaneamente, mas em cada processador individual de forma seqüencial (Silva (1992)).

Em FERLIN (2008), verifica-se que em muitas aplicações com paralelismo ao nivel de threads Thread-Level Parallelism (TLP), consegue-se apenas algum ganho no desempenho por processador adicionado à arquitetura. Ferlin destaca como um dos problemas dominantes no paralelismo ao nivel de threads, o tempo de busca das instruções no modelo von Neumann, problema este inexistente, por exemplo, em arquitetura a fluxo de dados, em inglês dataflow (Schneider Beck Fl. and Carro (2010)), que será discutido em detalhes mais a frente. 


\subsubsection{Circuitos assíncronos}

A área de computação de alto desempenho, em inglês High-performance Computing (HPC), tem exigido cada vez mais sistemas digitais complexos. Isso acarreta circuitos mais densos, com altas freqüências de operação e construídos em áreas cada vez menores. Por outro lado, necessidades como baixo consumo de potência, principalmente em aplicações portáteis alimentadas por bateria, são requisitos básicos atualmente.

Uma das características presentes na grande maioria dos circuitos é a utilização da metodologia síncrona, tendo como base um sinal de clock que permite o sincronismo entre todos os blocos lógicos de um circuito. Segundo MÔCHO (2006), o período desse sinal clock é previamente definido levandose em consideração o maior atraso para que uma informação possa avançar para outros blocos, também conhecido como throughput. Além disso, sempre que há transições no sinal de clock, o mesmo é propagado para todo o circuito. Como conseqüência, mesmo os blocos que poderiam permanecer inativos, acabam chaveando os seus transistores, gerando consumo desnecessário de energia (SARTORI (2005)). O tempo entre as transições do sinal do clock garante a estabilização dos valores nas entradas e saídas de elementos de armazenamento, bem como a ocorrência e descarte de valores transitórios no interior do circuito (Pontes (2008)).

A adoção do modelo síncrono pelos projetistas, deve-se à simplificação do projeto de sistemas digitais, se comparado ao modelo assíncrono. Entretanto, com o aumento de transistores nos chips, o modelo síncrono torna os circuitos menos confiáveis, devido aos limites de potência e o custo para manter sua robustez (Pontes (2008)).

Com o objetivo de superar as limitações do projeto síncrono, diversos grupos de pesquisa vêm trabalhando no desenvolvimento de circuitos assíncronos (Pontes (2008)), (MÔCHO (2006)), (SARTORI (2005)), (Pham-Quoc and DinhDuc (2010)), (Teifel and Manohar (2004b)), (Mahram et al. (2007)).

Em geral, estes grupos de pesquisa propõem um modelo de circuito assíncrono realizado por meio de um protocolo handshake para comunicação entre blocos do circuito. Sinais informam aos blocos envolvidos no protocolo que um dado é válido e está disponível. Uma outra característica é que esses sinais não são enviado para todos os blocos do circuito, limitando-se àqueles blocos que estiverem realizando a comunicação em um dado instante (Pham-Quoc and Dinh-Duc (2010)), (Spars and Furber (2010)). Esse protocolo é composto por um par de sinais, como ilustrado na Figura 1.8. Na Figura 1.8, um bloco emissor precisa enviar dados a um bloco receptor, o bloco emissor envia um sinal de requisição (req), juntamente com o dado. O bloco receptor, então, envia um sinal de reconhecimento (ack), informando ao bloco emissor que o dado 
chegou. Afim de manter essa seqüencia de eventos, os blocos comunicantes devem obedecer as seguintes regras (Pham-Quoc and Dinh-Duc (2010)):

- O bloco emissor não deve produzir uma nova requisição até que o pedido anterior tenha sido reconhecido.

- O bloco receptor não deve produzir um sinal de reconhecimento a menos que tenha recebido uma requisição,

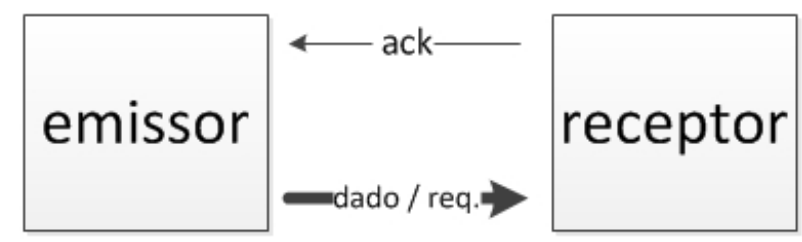

Figura 1.8: Comunicação entre blocos em sistemas assíncronos

Circuitos assíncronos, portanto, apresenta a vantagem de possuir blocos funcionais que trabalham somente quando requisitados, não havendo a necessidade de que todos os blocos estejam em perfeita sincronia para o correto funcionamento do circuito. Como conseqüência, há a diminuição do consumo de potência (Pham-Quoc and Dinh-Duc (2010)), (SARTORI (2005)). Além da diminuição do consumo de potência, pode-se citar como vantagens do uso de circuitos assíncronos (MÔCHO (2006)), (Spars and Furber (2010)):

- Modularidade: Nos circuitos síncronos, essa característica é uma preocupação por causa da freqüência máxima determinada pelo bloco lógico que possui o maior atraso, o que acarretam um maior pulso de clock, podendo inviabilizar todo o circuito para uma determinada aplicação. Já nos circuitos assíncronos, essa característica é natural, pois a comunicação entre os módulos é feita através do protocolo handshake, assim a inclusão de um novo bloco, seu funcionamento e o protocolo de comunicação permitirão que todo o circuito continue operando normalmente.

- Baixo ruído eletromagnético: Nos circuitos síncronos, o sinal de clock pode sofrer interferências de outros sinais que trafegam pelo circuito. Isso ocorre porque no momento de transição do sinal de clock, uma grande quantidade de corrente é drenado da fonte, ocasionando picos de consumo ao longo do tempo. Nos circuitos assíncronos, como não há sinal de clock, os picos de consumo tendem a ser distribuídos no tempo, ocasionando menor amplitude eletromagnética.

- Desempenho: O circuito assíncrono tende a ser mais rápido, porque não há um sinal de clock que limite o avanço da informação, para blocos com atrasos menores. 
Como desvantagens dos circuitos assíncronos frente aos circuitos síncronos, destaca-se a maior complexidade de projeto e aumento final de área do circuito. Segundo SARTORI (2005), esse aumento na complexidade de projeto deve-se a não existência de ferramentas de Computer-aided Design (CAD) que auxiliem no projeto dos sistemas. O acréscimo na área geralmente é causado pela necessidade em se adicionar circuitos dedicados ao protocolo de comunicação existente entre os blocos.

\subsubsection{Arquiteturas a fluxo de dados}

As organizações de computadores paralelos, tais como (SIMD, MISD, e MIMD), possibilitam um aumento da velocidade de processamento, com algum ou nenhum controle distribuído, porém mantendo alguma dependência da arquitetura von-Neumann, principalmente com relação ao contador de programas. As pesquisas em arquiteturas a Fluxo de Dados surgiram na década de 70, devido aos estudos de programação concorrente, frente as arquiteturas seqüenciais von-Neumann (Arvind (2005)), (Dennis and Misunas (1975)), (Veen (1986)), (Silva (1992)), (MARQUES (1993)).

A diferença fundamental entre as arquiteturas tradicionais von-Neumann e as arquiteturas a fluxo de dados está exatamente no controle do fluxo de informações que no caso das máquinas von-Neumann é baseado no controle seqüencial, enquanto que nas máquinas a fluxo de dados o controle é executado pela presença dos dados (Cappelli et al. (2004), (Swanson et al. (2003).

Segundo MARQUES (1993) e Silva (1992), o principal objetivo do modelo computacional a fluxo de dados é extrair o paralelismo naturalmente existente em um programa, adotando-se a filosofia de que a ordem de execução das instruções dependem exclusivamente da disponibilidade de seus dados. Assim, muitas instruções podem ser executadas em paralelo, desde que o sistema possua vários elementos de processamento, e que a dependência comportamental entre elas seja permitida.

Em Silva (1992), MARQUES (1993), Silva (2011b), pode ser encontrado um exemplo que ilustra essa situação. Considere a seguinte expressão:

$$
a:=[(b+c) *(c+d)] /[(e+f) *(c+d)]
$$

Em uma máquina tradicional, baseada no modelo von-Neumann, a expressão precisaria de sete passos seqüenciais para ser concluída. Já em uma máquina a fluxo de dados, a expressão poderia ser concluída em apenas três etapas, como descrito na Figura 1.9.

Um programa fluxo de dados é organizado na forma de grafo. No grafo, nós representam operadores e arcos representam o fluxo de dados entre os nós (Arvind and Nikhil (1990)). No instante que um nó do grafo detectar que todos os seus arcos de entrada possuem dados, esse nó é considerado habili- 


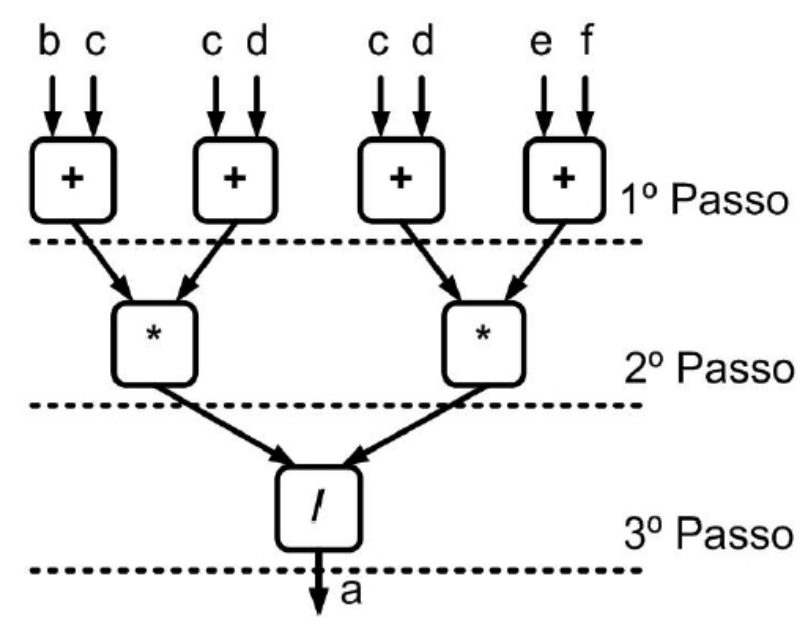

Figura 1.9: Máquina a Fluxo de Dados. (Silva (2011b)).

tado e sua operação é executada, produzindo assim um resultado no arco de saída. A saída pode habilitar outros nós do grafo. Desta forma, o paralelismo entre operadores acontece de forma natural, na medida em que os dados vão habilitando diferentes nós no grafo.

Existem dois modelos de arquiteturas a fluxo de dados: estático e dinâmico. No modelo estático apenas um dado pode estar presente em um arco. Um protocolo deve garantir o sincronismo entre os operadores para garantir que apenas um dado esteja presente em cada arco. Conseqüentemente o paralelismo fica limitado ao conjunto de operadores cujos arcos possuem apenas um dado.

No modelo dinâmico mais que um dado pode estar presente no arco. Um protocolo deve assegurar que os dados presentes nos arcos habilitem os operadores somente se todos dados presentes forem considerados parceiros. $\mathrm{O}$ "Tagged-Token" é usado no protocolo para controlar os dados parceiros em cada arco (Arvind (2005)). Neste caso, o paralelismo acontece quando há execução de vários operadores, cujos dados estejam todos disponiveis. A seqüência das operações é implícita à aplicação e sua execução depende exclusivamente do fluxo dos dados.

As arquiteturas fluxo de dados podem explorar tanto o paralelismo a nível de instruções Instruction-Level Parallelism (ILP) ${ }^{4}$ quanto o $T L P^{5}$ dependendo da complexidade das funções associadas a cada nó na máquina a fluxo de dados. No modelo fluxo de dados o paralelismo ILP aparece quando os nós do grafo representam instruções únicas, por exemplo, uma soma em uma Unidade Lógica e Aritmética (ULA). O paralelismo TLP é explorado quando os nós do grafo são associados a funções complexas, como por exemplo um

\footnotetext{
${ }^{4}$ paralelismo entre instruções individuais e independentes em uma aplicação.

${ }^{5}$ paralelismo decorrente da execução simultânea de conjuntos de instruções independentes, denominadas de tasks ou threads.
} 
microprocessador completo (FERLIN (2008)).

Segundo FERLIN (2008), o modelo fluxo de dados é altamente paralelo, dependendo da aplicação, possui alto throughput, uma vez que operadores podem ser processados simultaneamente; e não possui restrição como coerência dos dados na memória. Por outro lado, o tempo de espera dos operadores pelos dados pode ser considerado como uma desvantagem do modelo, além disso uma quantidade significativa de bits de controle são utilizados entre operadores nos nós dos grafos, necessários à sincronização.

Segundo MARQUES (1993), vários autores já classificaram as arquiteturas paralelas. Porém a mais utilizada é a classificação de Flynn (1972). Todas as categorias de Flynn baseiam-se em processamento dirigido pelas instruções, razão pela qual são denominados como modelos convencionais, ou baseados no modelo von-Neumann. No modelo computacional a fluxo de dados, a classificação de Flynn não se aplica. Na Figura 1.10 é descrito uma ampliação da classificação de Flynn que inclui o modelo a fluxo de dados, taxonomia proposta por MARQUES (1993). Essa taxonomia é mais adequada para as arquiteturas paralelas e baseia-se na estrutura de controle, na estrutura do processador e na estrutura do sistema de comunicação.

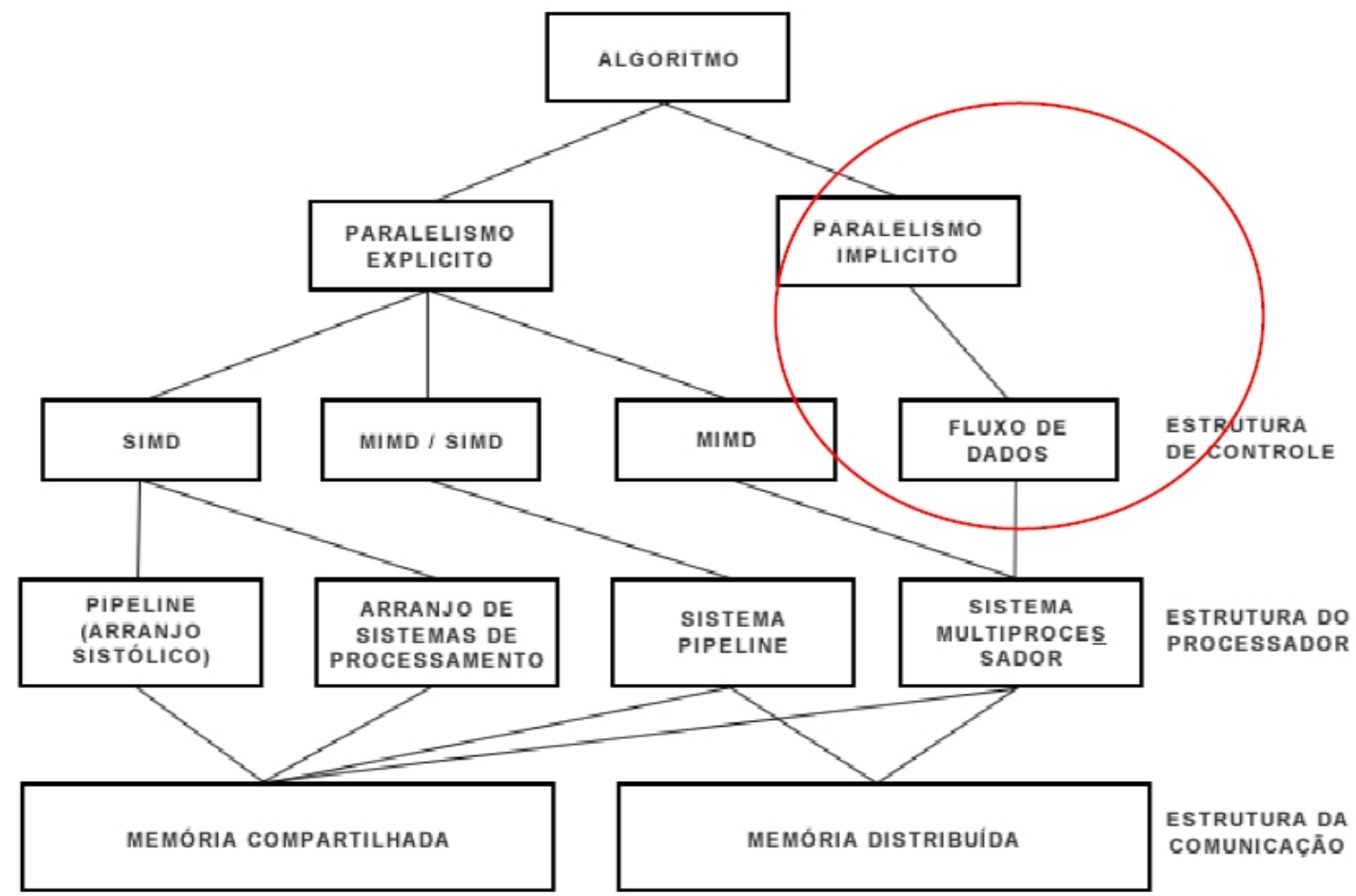

Figura 1.10: Taxonomia de Arquiteturas Paralelas (MARQUES (1993)).

Na Figura 1.10, pode ser visto dois modelos de paralelismo: explicito e implícito. A exploração do paralelismo explícito demanda dificuldades na identificação das partes que podem ser executadas em paralelo, tanto por parte do usuário, como por parte de programas especializados. O modelo fluxo de dados explora o paralelismo implícito, o que facilita a programação da máquina, 
ao mesmo tempo que deixa de exigir usuários especializados em programação concorrente, ou seja, o próprio sistema extrai o paralelismo automaticamente para a execução. A característica de distribuição, além de facilitar a tolerância a falhas no modelo, permite uma maior flexibilidade quanto ao crescimento incremental do sistema, atuando de acordo com as necessidades do usuário.

\subsubsection{Projeto ChipCflow}

As arquiteturas a fluxo de dados voltaram a ser tema de pesquisa devido aos avanços do hardware, em particular, os avanços da Computação Reconfigurável e os FPGAs, que possibilitaram combinar o desempenho do hardware com a flexibilidade do software, permitindo o desenvolvimento de sistemas extremamente complexos e compactos. Pesquisas vem sendo realizadas tendo como base o desenvolvimento de máquinas que utilizam o modelo a fluxo de dados, como as encontradas em (Swanson et al. (2007)), (Steven Swanson and Oskin (2003)), (Nagarajan et al. (2001)), (Swanson et al. (2003)), (Swanson et al. (2006)), (FERLIN (2008)), (Cappelli et al. (2004)), (Sankaralingam et al. (2003)), (Teifel and Manohar (2004a)), (Cappelli et al. (2004)), (Teifel and Manohar (2004c)), (Mercaldi et al. (2006)).

O projeto ChipCflow é uma ferramenta em desenvolvimento para execução de algoritmos utilizando o modelo a fluxo de dados dinâmico em hardware reconfigurável. Destaca-se como principal objetivo na ferramenta, utilizar o modelo de arquitetura a fluxo de dados, associado ao conceito de arquiteturas reconfiguráveis, para acelerar programas de aplicação escritos em linguagem C. Essa aceleração vai acontecer nas partes mais intensas do processamento (exemplo: loops), por meio da execução direta em hardware, aproveitando ao máximo o paralelismo considerado natural do modelo a fluxo de dados (Silva et al. (2009)), (Silva and Lopes (2010)).

O projeto ChipCflow será detalhado nos capítulos que se seguem.

\subsection{Motivação}

Há áreas de aplicação nas quais o uso da computação reconfigurável permite alcançar desempenho inalcançável por processadores de uso geral, visto que estas arquiteturas permitem explorar de forma eficiente o paralelismo. Sendo os FPGAs intrinsecamente paralelo, aliado ao paralelismo natural das arquiteturas a fluxo de dados e as vantagens da programação assíncrona, vislumbrou-se a oportunidade de desenvolver uma arquitetura paralela unindo todas essas características. Porém, como discutido nas seções anteriores, embora os FPGAs sejam uma alternativa lógica customizada, a utilização dos sistemas computacionais reconfiguráveis requer etapas morosas e complexas, 
comparado a programação por software, além de conhecimentos específicos de projeto de hardware (Cardoso and Neto (2003)).

Enquanto não existir um suporte a implementação de sistemas reconfiguráveis a partir de algoritmos em alto nível, os programadores de software não se sentirão atraídos pelo desenvolvimento de aplicações nesse modelo. Para tornar esse processo mais atrativo, seriam necessárias ferramentas que a partir da descrição de uma aplicação em uma linguagem de alto nível, gerasse o código objeto para ser executado em um microprocessador embarcado e os arquivos de descrição de hardware necessários para programação em sistemas reconfiguráveis, supondo aqui uma divisão entre parte da aplicação sendo executada em um processador e parte da aplicação sendo executada no módulo reconfigurável.

Para o projetista de hardware, essas ferramentas auxiliariam no desenvolvimento rápido desses algoritmos, evitando a conversão manual de algoritmos de software para hardware. Com o aumento da complexidade dos projetos, há uma necessidade de aumentar a abstração do mesmo. Com isso, o projetista pode concentrar-se nas especificações do projeto em detrimento aos detalhes de arquitetura do sistema. Ferramentas de compilação de software para hardware são alternativas para aumentar a abstração do projeto de sistemas.

Segundo Cardoso (2000), as ferramentas para geração automática de linguagens de descrição de hardware a partir de linguagens de alto nível têm sido desenvolvidas e ganham cada vez mais adeptos pelos seguintes fatores:

- Necessidade de aumentar os níveis de abstração, para que possam facilitar a especificação de sistemas cada vez mais complexos;

- Necessidade de proliferar o conceito de hardware reconfigurável a comunidades de software, devido à disparidade entre as semânticas dos modelos de computação;

- Reutilização de inúmeros algoritmos já implementados em linguagens com grande utilização, tal como linguagem $C$.

A motivação para este projeto foi a grande experiência, de um grupo de pesquisas do ICMC, adquirida no passado, no desenvolvimento de máquinas a fluxo de dados, a experiência também adquirida nos últimos 20 anos em computação reconfigurável, e mais recentemente o aparecimento de grupos internacionais desenvolvendo sistemas a fluxo de dados em computação reconfigurável e compiladores para arquiteturas reconfiguráveis. 


\subsection{Objetivo}

Como discutido nas seções anteriores, o projeto ChipCflow tem como principal objetivo utilizar o modelo de arquitetura a fluxo de dados dinâmico, associado ao conceito de arquiteturas reconfiguráveis, para acelerar programas de aplicação escritos em linguagem $C$. Em particular, validar a arquitetura do modelo de fluxo de dados dinâmico na plataforma Xilinx Virtex-II Pro, disponível no Laboratório de Computação Reconfigurável (LCR) do ICMC-USP.

Vários trabalhos de pesquisa já foram concluídos dentro do projeto ChipCflow, tais como: (Junior et al. (2010a)), (Astolfi (2009)), (da Costa (2009)), (Correia (2009)), (Sanches (2010)), (Junior (2011)), (SILVA et al. (2009a), (SILVA et al. (2009b))), (Astolfi and Silva (2007)), todos baseados no modelo de fluxo de dados estático. Entretanto, a idéia original do projeto ChipCflow é explorar o modelo a fluxo de dados dinâmico. Os primeiros trabalhos concluídos nesse modelo foram: (Silva (2011b)), (Silva and Lopes (2010)), além da tese original que deu inicio ao projeto ChipCflow (Silva (1992)).

O objetivo geral dessa tese foi validar o modelo de implementação assíncrona do operador e suas instâncias para que um grafo utilizando esses operadores fosse caracterizado como uma arquitetura a fluxo de dados dinâmica, explorando o máximo das vantagens do modelo assíncrono, do modelo da arquitetura a fluxo de dados dinâmica e da computação reconfigurável, no desenvolvimento de aplicações em hardware que demandam baixo consumo e alto desempenho.

Os objetivos específicos dessa tese foram: utilizar o modelo assíncrono na implementação dos operadores; nas estruturas do operador assíncrono, definir todos os requisitos necessários para que o conjunto de operadores caracterizassem o modelo de arquitetura a fluxo de dados dinâmica; definir todos os requisitos necessários para que instâncias dos operadores trabalhassem também de forma assíncrona, mas sincronizadas com seu operador de base; implementar operadores na plataforma Virtex-II Pro; implementar instâncias também na plataforma Virtex-II Pro; validar a execução dos operadores e suas instâncias e finalmente gerar dados de ocupação e desempenho para os diversos testes realizados.

\subsection{Organização do trabalho}

No capítulo 2 é apresentada a evolução dos circuitos digitais em números de transistores, abordando alguns dos principais dispositivos lógicos programáveis e a sua utilização. Neste capítulo, será dado ênfase aos tipos de $F P$ GAs existentes, suas aplicações e os principais fabricantes, destacando-se a 
Xilinx. No capítulo 3 são descritos algumas características dos FPGAs da família Virtex da Xilinx, seus processadores embarcados Microblaze e PowerPC; a plataforma de desenvolvimento $X U P-V 2 P$ e finalmente as ferramentas da $X i$ linx usadas para projetar sistemas reconfiguráveis no FPGA. No capitulo 4 são apresentados algumas ferramentas comerciais e acadêmicas para a geração de arquivos de descrição de hardware a partir de linguagens de alto nível como C e Java. No capítulo 5 são apresentadas as máquinas a fluxo de dados estáticas e dinâmicas, a arquitetura das máquinas a fluxo de dados estáticas e dinâmicas e os principais conceitos da área. No capítulo 6 são apresentas as características de algumas arquiteturas de máquinas a fluxo de dados dinâmicas disponíveis na literatura. Essas arquiteturas foram descritas tendo como base a demonstração dos principais conceitos da área, descritas nos trabalhos iniciais mais influentes e as principais máquinas a fluxo de dados contemporâneas. No capítulo 7 será apresentado a evolução do projeto ChipCflow, a estrutura do modelo a fluxo de dados, a estrutura matching de dados, a ferramenta de conversão de algoritmos escritos em linguagem $C$ em máquinas a fluxo de dados, utilizando-se os operadores e a arquitetura propostos para o projeto ChipCflow. No capítulo 8 serão apresentados os detalhes de implementação dos módulos que gerenciam os operadores e suas instâncias, bem como os resultados de desempenho, ocupação e consumo obtidos nas implementações realizadas. Finalmente, no capítulo 9 são mostrados as conclusões e os trabalhos futuros relacionados a essa tese. 


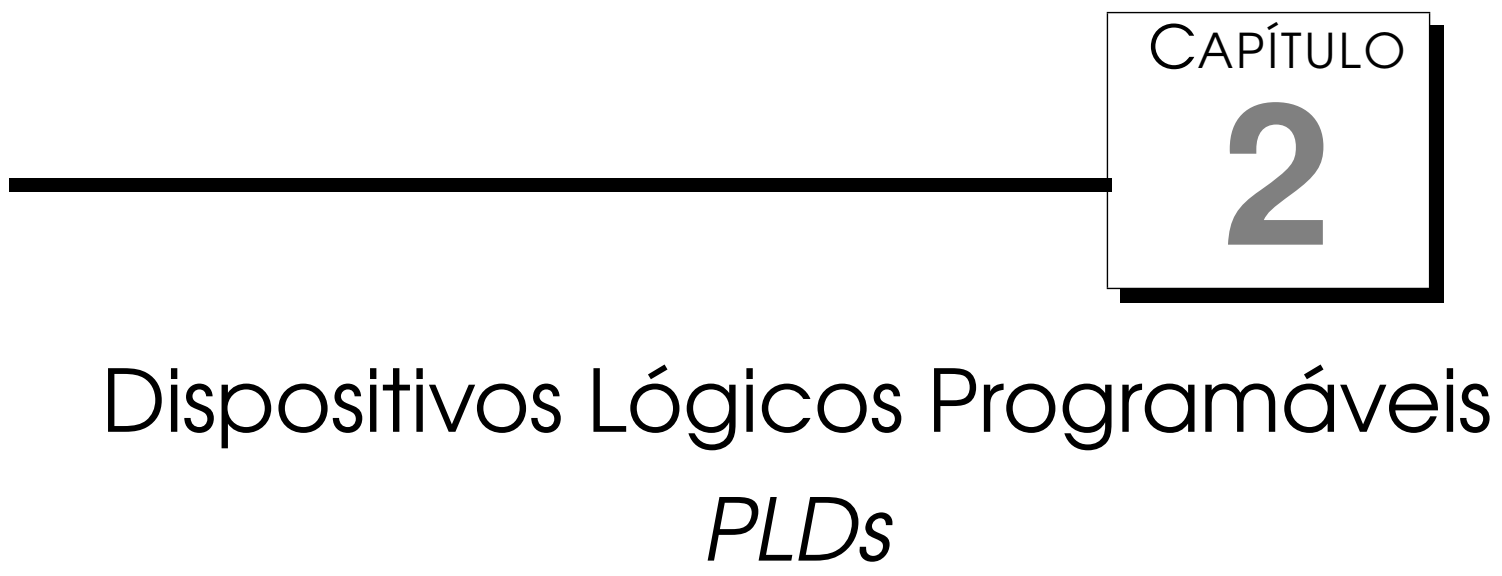

Os dispositivos lógicos programáveis, em inglês Programable Logic Devices (PLD), constituem um recurso extremamente poderoso para projetistas de sistemas digitais. Devido a evolução dos PLDs, é possível projetar sistemas digitais de grande complexidade, com o auxílio de ferramentas $C A D$ no projeto dos sistemas.

Neste capítulo, será descrito a evolução dos circuitos digitais em números de transistores, abordando alguns dos principais dispositivos lógicos programáveis e a sua utilização. O componente lógico utilizado neste projeto foi um FPGA, assim neste capítulo, será dado ênfase aos tipos de FPGAs existentes, suas aplicações e os principais fabricantes, destacando-se o Xilinx, uma vez que seus FPGAs foram utilizados nesta tese.

\subsection{Circuitos Digitais}

Os circuitos digitais têm evoluído significamente nas últimas décadas. Os componentes dos circuitos digitais passaram de transistores individuais para circuitos integrados VLSI (Aragão (1998)).

Segundo Ribeiro (2002), os FPGAs têm evoluído significativamente, alcançando elevados níveis de densidade, altos índices de desempenho e menores custos de fabricação. Devido a essa evolução, é cada vez menor à distância entre os FPGAs e os ASICs.

A Figura 2.1 mostra a evolução dos FPGAs da Xilinx em números de transistores. Segundo Bolsens (2006), os FPGAs da família Virtex-5 da Xilinx foram 
desenvolvidos utilizando-se a tecnologia de fabricação de transistores em camadas de silício na ordem de 65nm, o que significa mais de um bilhão de transistores na pastilha do FPGA. Ainda segundo Bolsens (2006), estimou-se que no ano 2010 os FPGAs da Xilinx estejam utilizando camadas de silício na ordem de $32 \mathrm{~nm}$, o que significava mais de cinco bilhões de transistores na pastilha do FPGA. Esses novos processos de tecnologia proporcionam baixos custos e a meta para o ano de 2010 era atingir o custo de 2 dólares por Milhões de portas lógicas (Mgates). Atualmente tantos os FPGAs da empresa Altera, quanto os FPGAs da empresa Xilinx possuem transistores em camadas de silício na ordem de 28nm (Ahmed et al. (2010)). Em particular, os FPGAs Virtex-7 da Xilinx possuiam 6.8 bilhões de transistores fabricados em tecnologia $28 \mathrm{~nm}$ (Xilinx (2012)).

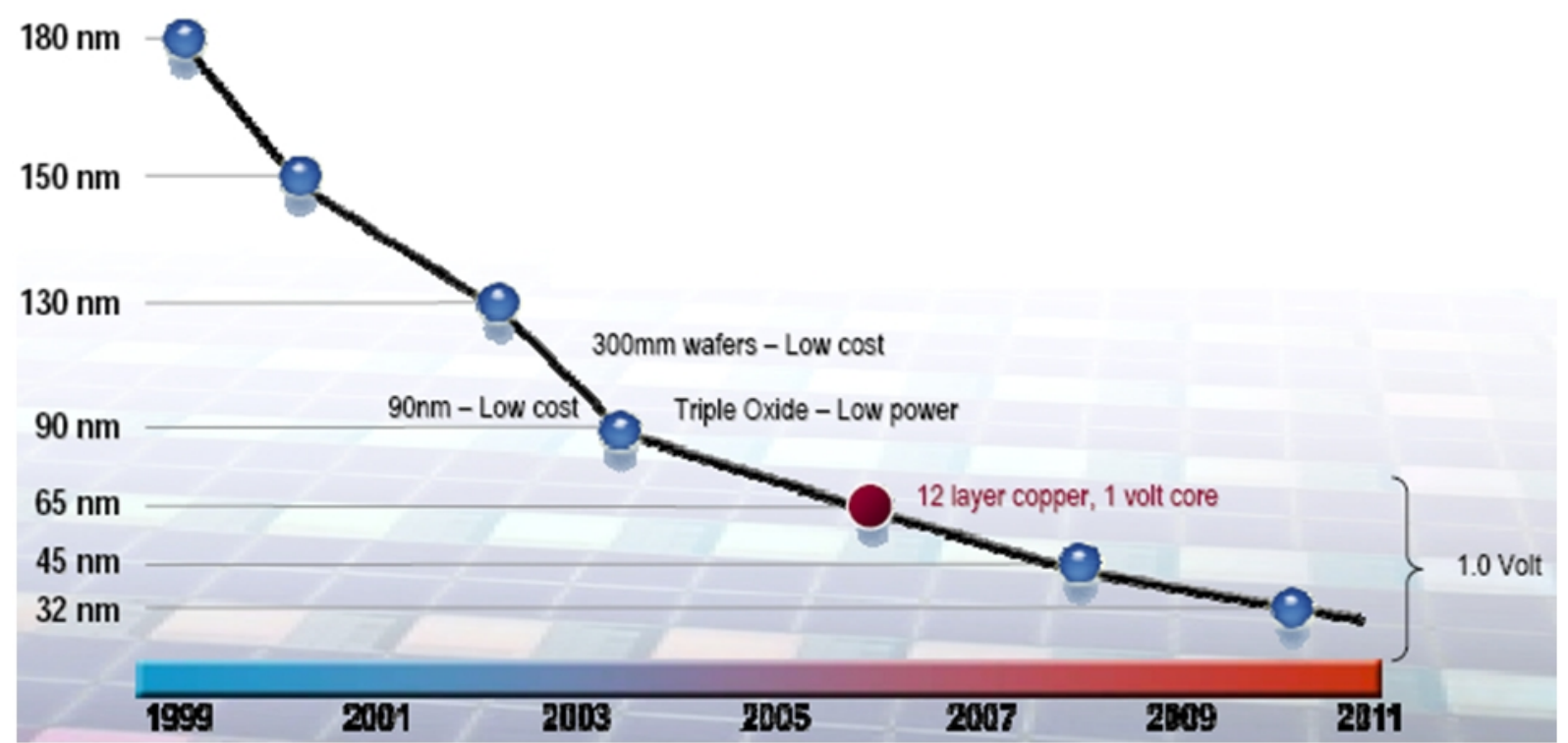

Figura 2.1: Evolução dos FPGAs em número de transistores - $32 \mathrm{~nm}$ corresponde a 5 bilhões de transistores (Bolsens (2006)).

Os CIs podem ser construídos utilizando-se diversas tecnologias e a escolha da tecnologia adequada deve ser realizada com base no tipo de projeto que se pretende executar, dependendo de fatores como tamanho, função, desempenho e custo (Ribeiro (2002)), (Aragão (1998)), (Pedrino (2008)).

Uma taxonomia de implementação de circuitos digitais pode ser vista na Figura 2.2. Conforme descrito na figura, existem grandes agrupamento de circuitos: os circuitos customizados - ASICs e circuitos semi-customizados (Pedrino (2008)), (Ribeiro (2002)).

Os circuitos customizados são indicados para aplicações em sistemas que necessitam de grande desempenho e baixo consumo de energia. As características desse tipo de implementação são o custo alto de projeto e o longo tempo de desenvolvimento. Em aplicações que requerem um grande volume 


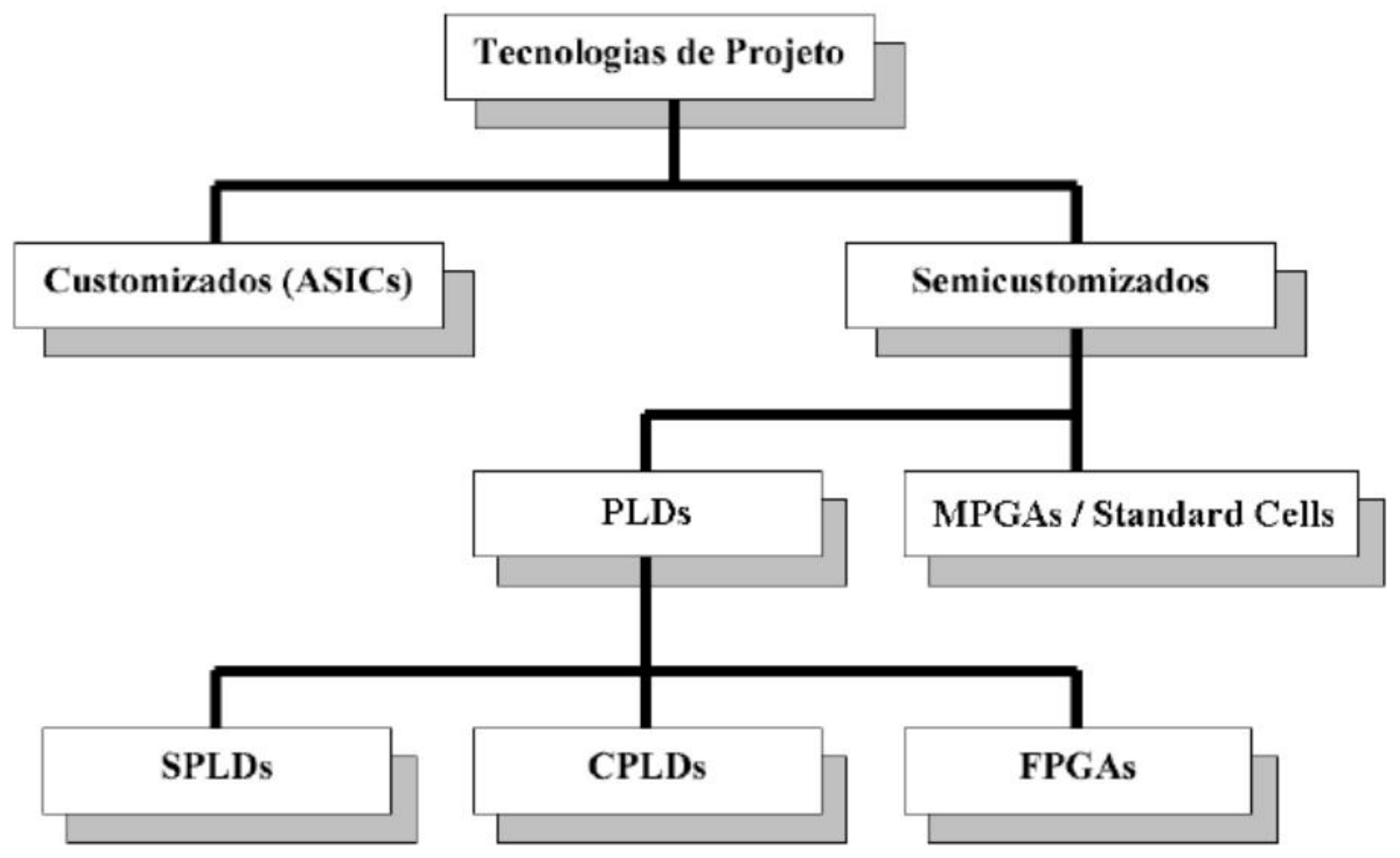

Figura 2.2: Taxonomia para Projetos de Sistemas Digitais (Pedrino (2008)).

de produção, o alto custo de desenvolvimento e dos testes são amortizados.

Nos circuitos semi-customizados, é possível encontrar duas outras categorias: PLDs e MPGAs/Standard Cells:

Os Mask-programmable Gate Array) / Standard Cells (MPGAs) e Standard Cells foram agrupadas, devido suas semelhanças, uma vez que um projeto é mapeado em um arranjo de transistores pré-fabricados numa pastilha e suas interconexões são customizadas durante o processo de fabricação. Logo, há a necessidade de máscaras específicas para as interconexões entre os blocos e portanto utilizar-se de bibliotecas de células, a partir das mascaras, facilita e agiliza o projeto. O desempenho obtido nesse método pode ser mais densos que os PLDs. Pelo fato do arranjo de transistores ser produzido em massa, os custos de fabricação são menores se comparados a CIs completamente customizados, porém, necessitam ser programados nas Foundries ${ }^{1}$ (Pedrino (2008)).

Os PLDs podem ser definidos como um arranjo de portas lógicas e possuem como principal característica a capacidade de programação (configuração) pós-fabricação pelo projetista, facilitando assim as eventuais mudanças de projetos. É possível portanto alocar muitas portas lógicas em um circuito integrado e interligá-los, tudo eletronicamente. Em comparação com outras tecnologias, os PLDs demandam um ciclo de projeto curto com baixo custo de desenvolvimento. Sua capacidade lógica cresce à mesma taxa dos micropro-

\footnotetext{
${ }^{1}$ Fábricas para a manufatura de Circuitos Integrados.
} 
cessadores, seguindo a lei de Moore (Pedrino (2008)).

Ainda com relação à taxonomia descrita na Figura 2.2, os PLDs são divididos em três categorias: Simple Programmable Logic Device (SPLD), Complex Programmable Logic Device (CPLD) e FPGAs (Ribeiro (2002)), (Aragão (1998)), (Pedrino (2008)).

Os SPLDs correspondem a categoria de todos os PLDs considerados simples, como os Programmable Logic Array (PLA) e os Programmable Array Logic (PAL). As características mais importantes dessa categoria são o baixo custo e alto desempenho. Esses dispositivos possuem apenas algumas centenas de portas lógicas e são utilizados em pequenas implementações ou em partes de um projeto maior (Bobda (2007)).

Os CPLDs foram originalmente desenvolvidos pela empresa Altera, primeiramente em sua família de chips conhecida como Classic Erasable programmable logic devices (EPLDs) e posteriormente em três séries adicionais: MAX 5000, MAX 7000 e MAX 9000 (Pedrino (2008)). Os CPLDs são constituídos de múltiplos SPLDs integrados em um único chip e apresentam interconexões programáveis para conectar os blocos SPLDs. Sua capacidade lógica é de até 50 SPLDs típicos.

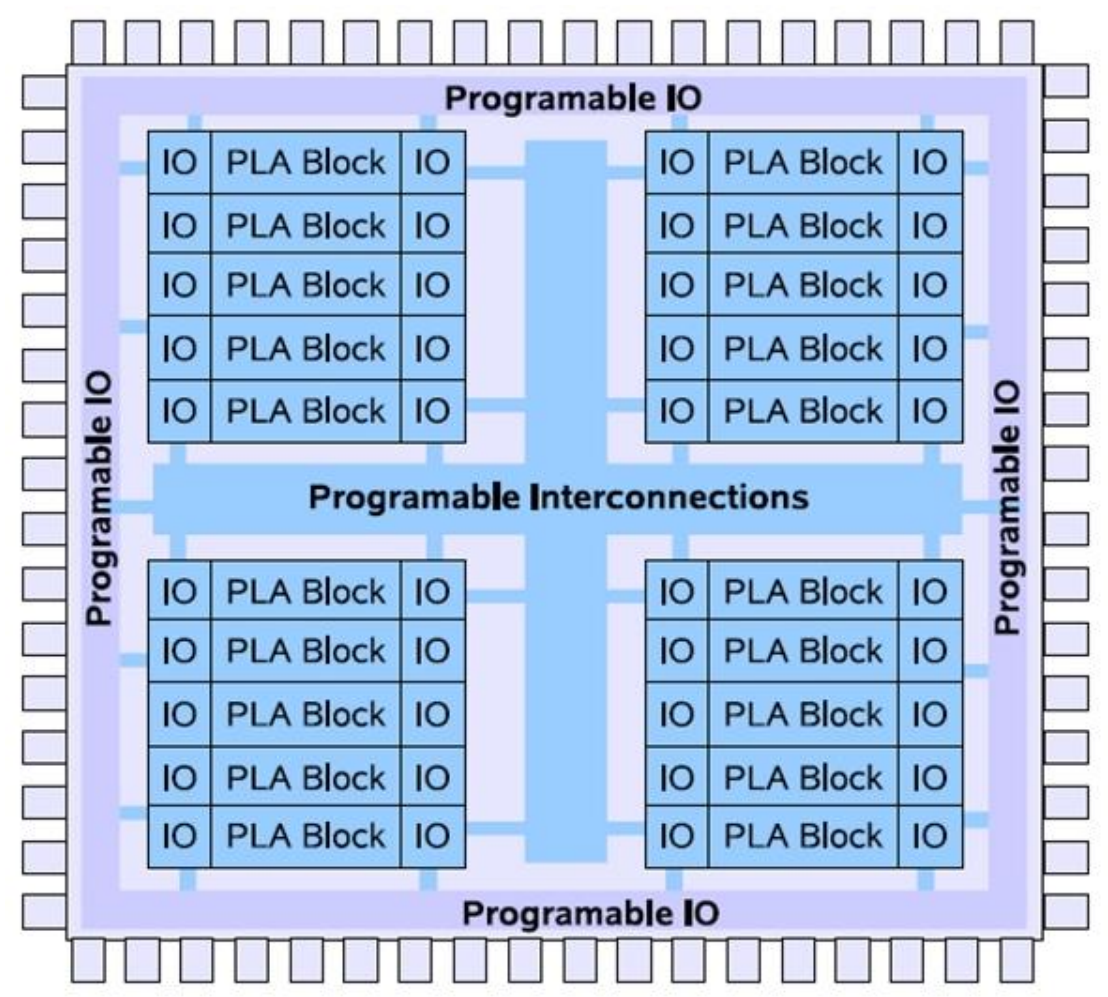

Figura 2.3: Estrutura de um dispositivo CPLD (Ribeiro (2002)).

Na Figura 2.3 é descrito a estrutura de um dispositivo $C P L D$. Como pode ser visto na Figura 2.3, um CPLD típico consiste de um grupo de macro células, tipicamente constituídas de alguns PLAs e flip-flops, blocos de entradas/saída e uma rede de interconexões. 
Apesar de possuírem uma capacidade maior, comparados aos SPLDs, os CPLDs são usualmente utilizados como "glue logic".

Os FPGAs, que foi a base do projeto aqui desenvolvido, será detalhado no item a seguir.

\subsection{A tecnologia dos FPGAs}

Introduzido em 1985 pela empresa Xilinx, um FPGA é um dispositivo reconfigurável que consiste de três partes principais: um conjunto de células lógicas programáveis, também chamados de blocos lógicos; uma rede de interconexões programáveis e um grupo de células de entrada/saída dispostos em volta do dispositivo (Bobda (2007)).

Um FPGA é um circuito integrado digital que pode ser usado para construir sistemas digitais diversos, limitado apenas pelo número de células e ligações disponíveis. É o caso, por exemplo, da prototipação de ASICs utilizando-se o FPGA como dispositivo básico (Cappelatti (2011)). Uma outra afirmação é que os equipamentos computacionais baseados em FPGAs são também denominados máquinas computacionais especializadas (Ribeiro (2002)).

Todos os dispositivos FPGAs são por definição programáveis, ou seja, configurável ao menos uma única vez. O conceito de reconfiguração está relacionado à possibilidade de reconfigurar o dispositivo muitas vezes ou constantemente se necessário.

Muitas aplicações emergentes em multimídia e processamento de imagens necessitam que suas funcionalidades sejam flexíveis mesmo depois que o sistema tenha sido manufaturado. Tal flexibilidade é fundamental, uma vez que os requisitos das aplicações e as características dos sistemas podem mudar durante a vida do produto. Essa flexibilidade propicia novas abordagens no desenvolvimento de projetos visando ganhos de desempenho, redução dos custos do sistema e redução do consumo de energia.

\subsection{Arquitetura dos FPGAs}

Segundo Ribeiro (2002), a arquitetura básica de um FPGA, ilustrada na Figura 2.4, consiste de um arranjo bidimensional de blocos lógicos, um sistema de interconexão entre os blocos (interconexão programável) e blocos de entrada e saída (blocos de $I / O$ ), que fazem a interface do FPGA com o mundo externo.

Os Blocos Lógicos podem ser tão simples como um transistor ou tão complexo quanto um microprocessador. Tipicamente funções lógicas são implementadas em seu interior. Em algumas arquiteturas os blocos lógicos possuem recursos seqüenciais tais como flip-flop ou registradores. O fabricante 


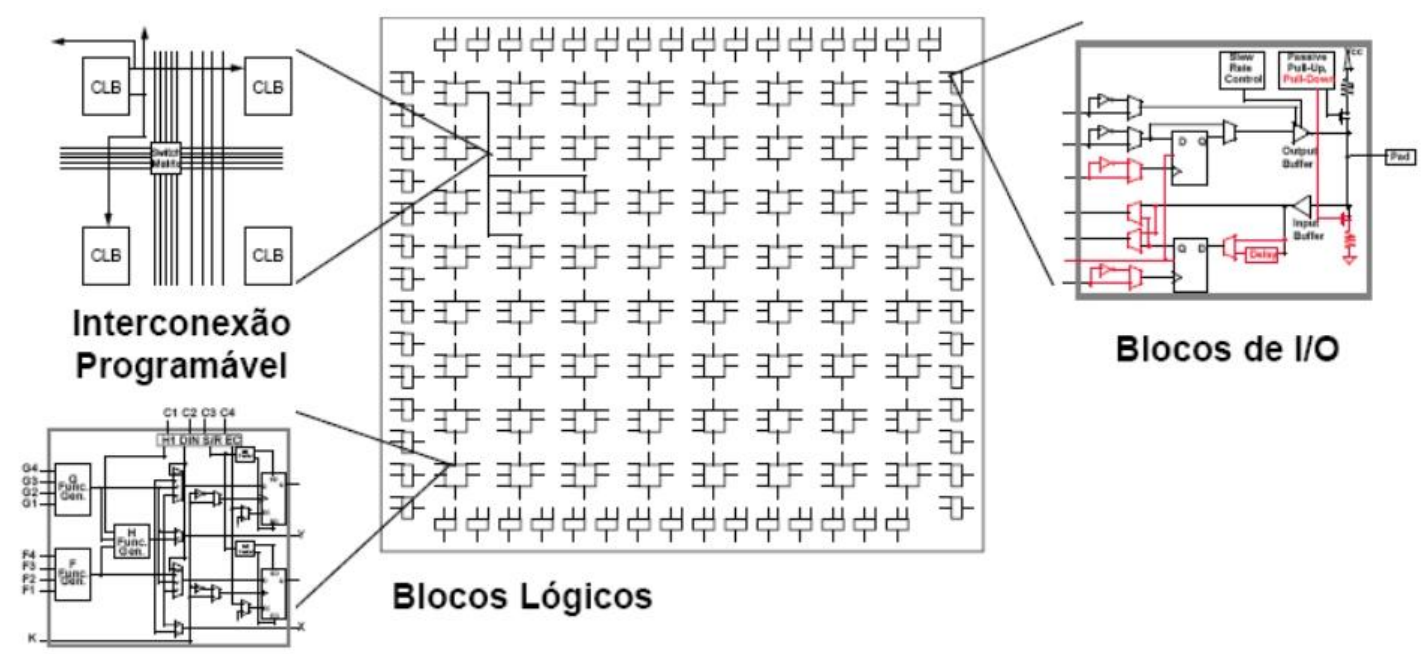

Figura 2.4: Estrutura básica de um FPGA (Ribeiro (2002)).

Xilinx chama seu bloco lógico de Configurable Logic Block (CLB).

Cada bloco lógico está conectado a uma matriz de conexões programáveis de tal forma que programando as conexões apropriadas, um conjunto de blocos podem fornecer uma variedade de funções lógicas combinacionais e/ou seqüenciais, tão complexas quanto o tamanho daquele FPGA permitir.

Como descrito na Figura 2.5, o bloco computacional básico nos FPGAs da Xilinx consiste de uma Lookup Tables (LUT) com um variado número de entradas, um grupo de multiplexadores, uma lógica aritmética e elementos de armazenamento (Bobda (2007)). A LUT é um agrupamento de células de memória do tipo Static RAM (SRAM), que contém todos os resultados possiveis de uma dada função para um dado grupo de valores de entrada. Assim, uma LUT é capaz de implementar qualquer função booleana de até "n"variáveis (Bobda (2007)).

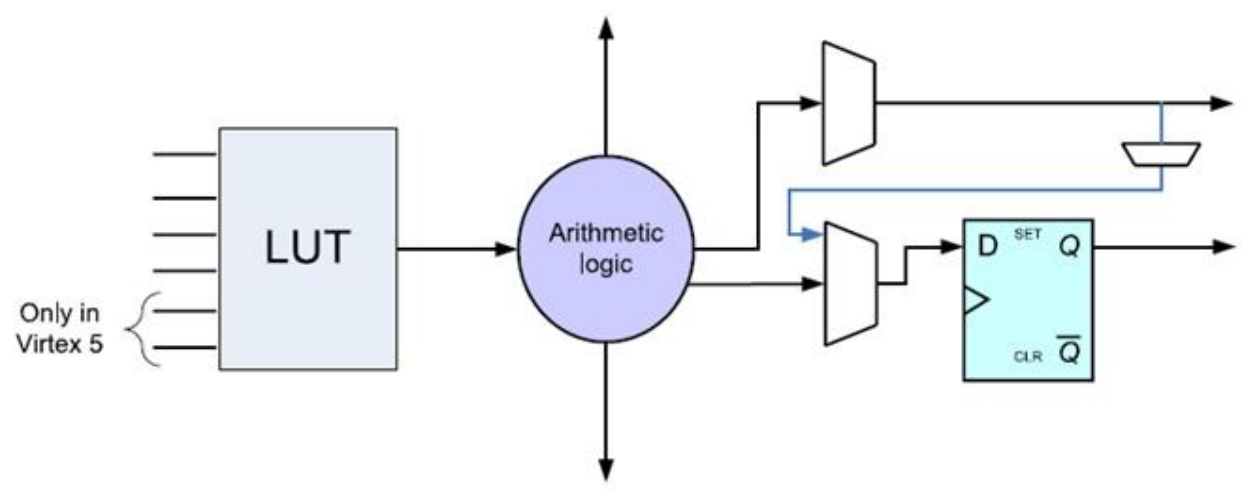

Figura 2.5: Bloco básico dos FPGAs Xilinx (Bobda (2007)).

Um exemplo de uma LUT é ilustrada na Figura 2.6. Como pode ser visto na figura, a LUT implementa uma função "AND" de 4 entradas. Quando as entradas endereçam o valor "1111", a saída é o valor "1", armazenada na posição "15" da memória. Gualquer outra combinação de entrada terá como 
saída o valor "O" (Menotti (2010)). Para implementar uma função complexa em uma FPGA baseada em LUT, a função deve ser dividida em sub-funções, cada qual sendo implementado em uma única LUT. As interconexões são usadas para conectar essas sub-funções e formar a função completa (Bobda (2007)).

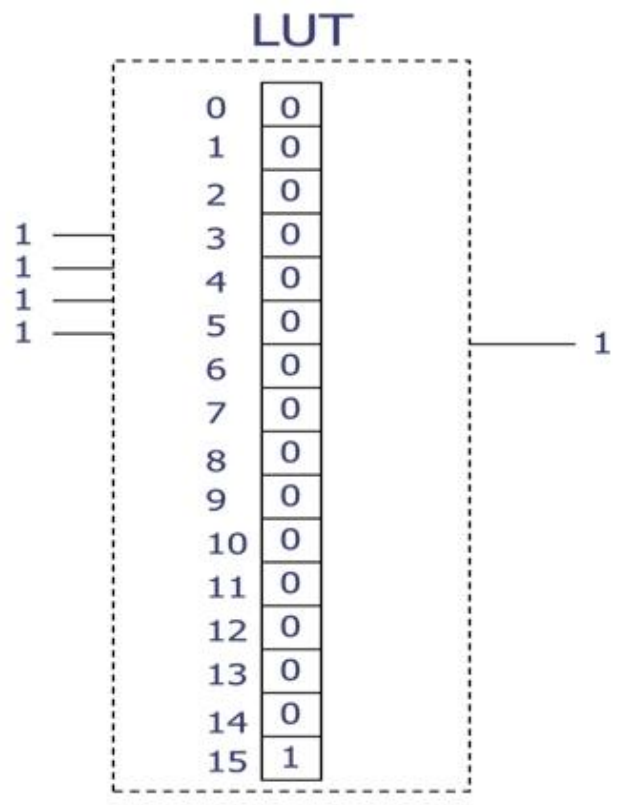

Figura 2.6: Exemplo de uma LUT

A lógica aritmética descrita na Figura 2.5 prove algumas facilidades, como lógica para construção de somadores rápidos sem a necessidade do uso de LUTs.

O número de blocos básicos em um $C L B$ varia de dispositivo para dispositivo. Nos FPGAs Virtex-II Pro e Virtex-4, os CLBs são divididos em quatro slices $^{2}$ cada qual contendo dois blocos básicos. Os CLBs do Virtex- 5 contêm apenas dois slices, cada qual contendo quatro blocos básicos (Bobda (2007)). Na Figura 2.7 é ilustrado o CLB dos dispositivos Virtex II, Virtex-II Pro e Virtex4 da Xilinx. Como pode ser visto na figura, na parte esquerda dos slices de um CLB, também chamado de $S_{L I C E M^{3}}$ podem ser configurados como lógica combinacional, memória SRAM de 16 bits ou ainda um registrador de deslocamento, enquanto que no lado direito o SLICEL ${ }^{4}$ pode apenas ser configurado como lógica combinacional (Bobda (2007)).

Com relação as interconexões programáveis, matrizes de conexões são usadas para estabelecer ligações entre entradas e saídas dos blocos lógicos, enquanto matrizes de chaveamento são empregadas para rotear os sinais entre as várias matrizes de conexões, conforme descrito na Figura 2.8 (Bobda

\footnotetext{
${ }^{2} \mathrm{Na}$ família Virtex da Xilinx, a menor unidade lógica configurável ou unidade lógica básica é denominada slice.

${ }^{3}$ Par de slices da coluna à esquerda.

${ }^{4}$ Par de slices da coluna à direita.
} 


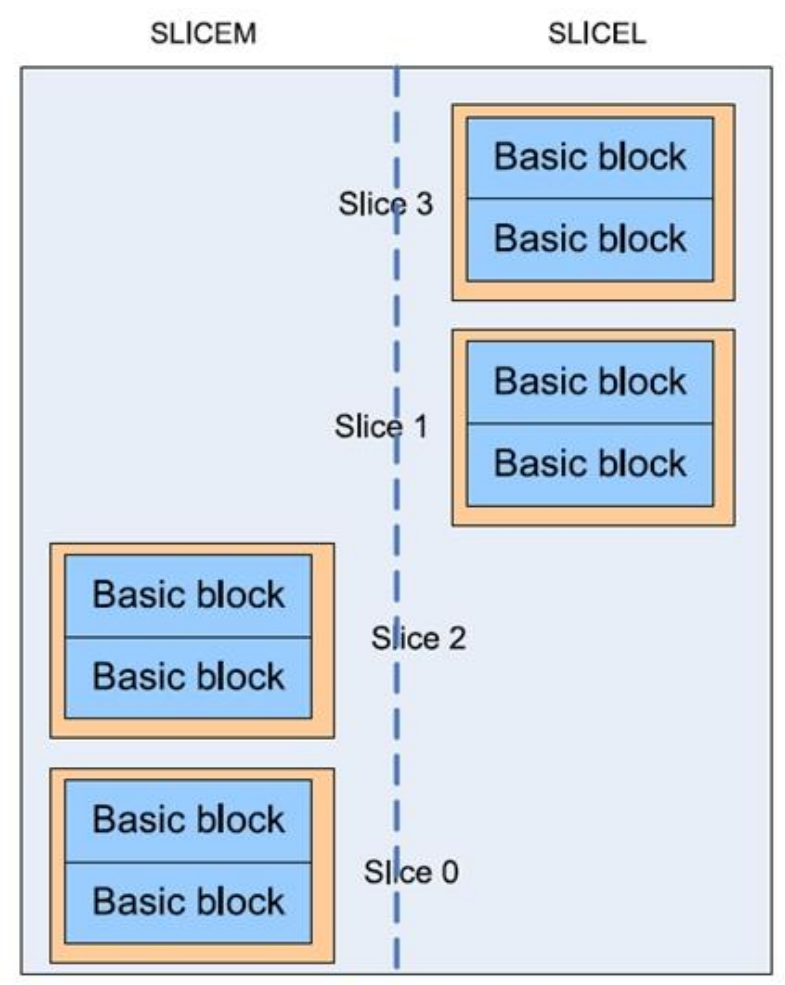

Figura 2.7: CLB do Virtex II, Virtex-II Pro e Virtex-4 (Bobda (2007).

(2007)). Conforme descrito na figura, qualquer bloco lógico pode ser conectado a qualquer outro bloco lógico, programando as matrizes de conexão e matrizes de chaveamento.

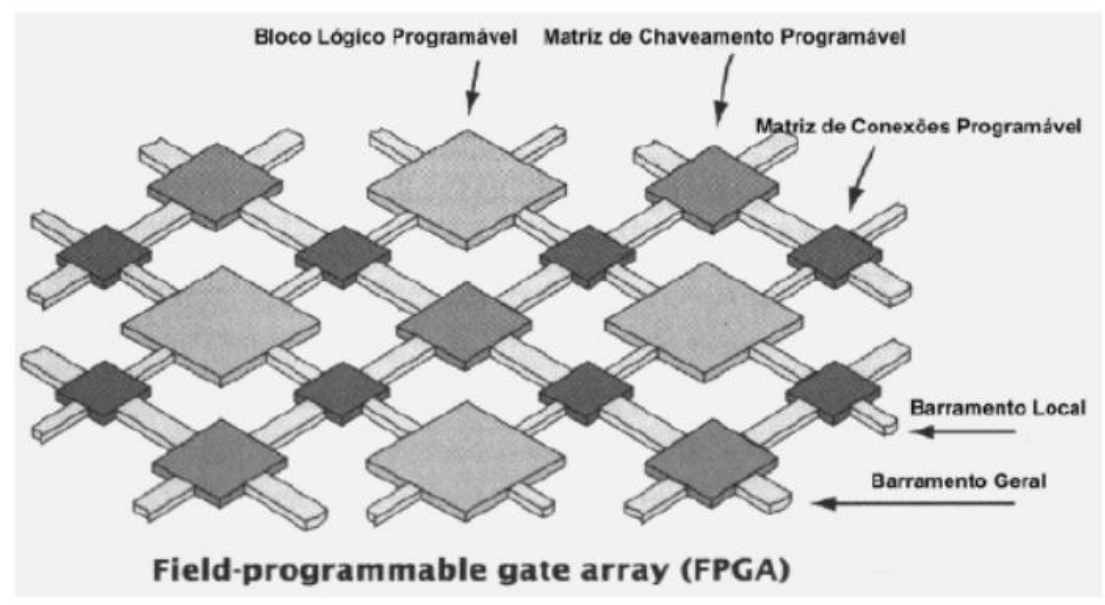

Figura 2.8: Conexões entre blocos lógicos (Ribeiro (2002))

Finalmente, os blocos de Entrada e Saída, em inglês de Input/Output Block (IOB), são formados por estruturas bidirecionais que incluem buffer, flip-flop de entrada, buffer tri-state ${ }^{5}$ e flip-flop de saída. Assim como os CLBs, cada pino de E/S do FPGA pode ser programado pelo projetista. Um FPGA pode dispor de dezenas a centenas de pinos programáveis.

\footnotetext{
${ }^{5} \mathrm{Em}$ um barramentos de dados somente um dispositivo pode operar por vez. Os buffers tristate são utilizados para isolar os dispositivos que não estão em uso do acesso ao barramento.
} 
Estes aspectos influenciam diretamente o desempenho e a densidade das diferentes arquiteturas dos FPGAs, entretanto não se pode afirmar que há uma arquitetura, melhor ou pior e sim a mais adequada para uma determinada aplicação (Ribeiro (2002)).

\subsubsection{Tecnologias de programação}

Um FPGA é programado usando comutadores programáveis eletricamente. As propriedades desses comutadores, tais como tamanho, resistência, capacitância, tecnologia, afetam principalmente o desempenho e definem características como volatilidade e capacidade de reprogramação, que devem ser avaliadas na fase inicial do projeto para a escolha do dispositivo (Aragão (1998)), (Ribeiro (2002)), (Pedrino (2008)), (Bobda (2007)). Em todos os tipos de FPGAs os comutadores programáveis ocupam uma grande área. Existem basicamente dois tipos de tecnologias de programação: Antifuse e SRAM (Bobda (2007)).

Na tecnologia Antifuse, um dispositivo com dois terminais é considerado não programado quando existe uma alta impedância entre eles. Quando aplicado uma tensão entre os terminais, na faixa de 11 a 20 Volts o antifuse "queima", criando uma conexão de baixa impedância entre eles, não permitindo reprogramações posteriores (Bobda (2007)).

Entre as vantagens do antifuse está o seu tamanho reduzido e maior velocidade. A desvantagem está no espaço extra gasto para conseguir isolar os transistores no circuito de programação, já que eles trabalham com tensão de até $20 \mathrm{~V}$.

Na tecnologia SRAM, células de memória SRAM são utilizadas para controlar transistores de passagem ou multiplexadores. A SRAM apresenta três grandes vantagens: é rapidamente reprogramado, comparada com a tecnologia Erasable Programmable Read-Only Memory (EPROM) ou Electrically Erasable Programmable Read-Only Memory (EEPROM); requer apenas a tecnologia padrão de circuitos integrados para a sua fabricação (Ribeiro (2002)) e os FPGAs com essa tecnologia podem ser reprogramados indefinidamente, pois é necessário apenas modificar os valores nas células SRAM para realizar uma nova conexão ou uma nova função (Bobda (2007)). Como desvantagem da tecnologia SRAM, ao contrário da tecnologia antifuse, é uma memória volátil, portanto perde sua configuração na ausência de eletricidade, necessitando de uma memória externa, como uma EPROM ou EEPROM ou um dispositivo não volátil de armazenamento, tal como o CPLD para guardar suas configurações na ausência de eletricidade. Outra desvantagem é que essa tecnologia ocupa muito espaço no chip, pois para cada comutador estão associados pelo menos seis transistores.

A grande maioria dos FPGAs e dispositivos reconfiguráveis utilizam a tec- 
nologia de programação SRAM. Porém, Segundo Compton and Hauck (2002), o termo "SRAM" é tecnicamente incorreto para muitas arquiteturas de FPGAs, isto porque, a memória de configuração nem sempre suporta acessos randômicos (Bobda (2007)).

\subsubsection{Classificação dos FPGAs}

Os FPGAs possuem uma grande variedade de tamanhos e com muitas combinações diferentes de características internas e externas. O que eles têm em comum é o fato de serem compostos por blocos lógicos configuráveis. Em um FPGA, a estrutura interna dos blocos lógicos, como por exemplo, LUTs, registradores, multiplexadores, podem ser replicadas milhares de vezes para construir um grande dispositivo reconfigurável (Compton and Hauck (2002)), (Pellerin and Thibault (2005)). Em FPGAs mais complexos, esses blocos lógicos são combinados com lógicas digitais maiores, como lógicas aritméticas, estruturas de controles, tais como multiplicadores e contadores.

Com a finalidade de classificar os FPGAs quanto à capacidade lógica dos blocos lógicos, pode-se dividi-los em três categorias: de granularidade fina, media e grossa (Ribeiro (2002)), (Compton and Hauck (2002)), (Hauck and DeHon (2008)). Cada bloco lógico pode ser simples como uma LUT de três entradas ou complexo como uma ULA de 4 bits. As diferenças entre os blocos podem ser referenciadas como granularidade do bloco lógico. Uma LUT de 3 entradas é um exemplo de um bloco lógico de granularidade fina e uma ULA de 4 bits é um exemplo de bloco lógico de granularidade grossa (Compton and Hauck (2000)).

Os blocos lógicos de granularidade fina são úteis para manipulações de informação a nível de bits, em geral manipulam apenas 2 ou 3 dados de 1 bit (Compton and Hauck (2000)). Como exemplo para um bloco de granularidade fina seria um bloco contendo alguns transistores inter-conectados ou portas lógicas básicas. Para se implementar um somador, deve-se utilizar várias dessas células (Cardoso (2000)), (Hauck and DeHon (2008)). Como vantagem, esse tipo de bloco é quase que totalmente utilizado, fornecendo um alto grau de funcionalidade com um número relativamente pequeno de transistores. A desvantagem principal é que por serem blocos muito pequenos, tem baixa capacidade lógica, podendo ser requeridos muitos blocos lógicos para uma determinada aplicação, elevando a quantidade de trilhas de conexões e comutadores programáveis podendo inviabilizar a aplicação. Um exemplo de um FPGA fabricado com essa granularidade é o FPGA XC6200 da Xilinx (Ribeiro (2002)). Os blocos lógicos de granularidade media operam com 2 ou mais dados de 4 bits. Isso aumenta o número total de linhas de entrada do circuito e prove estruturas computacionais mais eficientes para problemas 
computacionais mais complexos. Esses blocos podem implementar operações lógico-aritméticas (Cardoso (2000)) e máquinas de estado finito (Compton and Hauck (2000)), (Hauck and DeHon (2008)). Os FPGAs da família Virtex da Xilinx são exemplos de dispositivos de granularidade média (Ribeiro (2002)). Os blocos lógicos de granularidade grossa são úteis para aplicações que manipulam dados com grandes quantidades de bits. Somadores, multiplicadores de 16 bits, por exemplo, são considerados de granularidade grossa (Compton and Hauck (2000)), (Hauck and DeHon (2008)).

Na Tabela 2.1 são descritos algumas famílias de FPGAs de alguns fabricantes, quanto a sua granularidade (Ribeiro (2002)).

Tabela 2.1: Capacidade lógica dos blocos lógicos (Ribeiro (2002))

\begin{tabular}{lll}
\hline Família & Fabricante & Granularidade \\
\hline XC6200 & Xilinx & Fina \\
Virtex & Xilinx & Média \\
Virtex II & Xilinx & Média \\
Virtex-II Pro & Xilinx & Média / Grossa \\
APEX 20K & Altera & Média \\
Stratix & Altera & Média / Grossa \\
\hline
\end{tabular}

Atualmente, ainda são poucas as empresas que fabricam FPGAs. O mercado encontra-se fragmentado por alguns fabricantes, como: Xilinx, Altera, Lattice Semiconductor, Actel, Achronix, Atmel, QuickLogic, Cypress, Achronix e SiliconBlue. Os dois principais fabricantes dividem suas famílias nas de baixo custo (Cyclone para Altera e Spartan para Xilinx) e nas de alto desempenho (Stratix da Altera e Virtex da Xilinx, respectivamente).

Recentemente, os fabricantes Xilinx e Altera lançaram o que consideram ser a nova geração de FPGAs cujo processo de fabricação passou para 28nm. Os dispositivos são Stratix-V da Altera e Virtex-7 da Xilinx. A competição acirrada entre as duas empresas faz com que as famílias equivalentes tenham características semelhantes.

Para exemplificar os tipos e a quantidade dos recursos presentes nos FPGAs atuais, na Tabela 2.2 são descritas algumas propriedades das famílias Stratix-IV da Altera e Virtex-6 e Virtex-7 da Xilinx.

\subsubsection{FPGAs com Reconfiguração Parcial Dinâmica}

Como citado anteriormente, alguns FPGAs suportam a reconfiguração parcial, onde é possível selecionar uma área do FPGA e colocar novo módulo nessa área ou apenas substituir módulos ociosos, porém a execução do FPGA deve ser interrompida para que a reconfiguração parcial aconteça. 
Tabela 2.2: Principais característica dos FPGAs Stratix-IV, Virtex-6 e Virtex-7 (Xilinx (2011a)), (Xilinx (2011b)) (Júnior (2010))

\begin{tabular}{llll}
\hline Capacidade Máxima & Stratix-IV & Virtex-6 & Virtex-7 \\
\hline Tecnologia & $40 \mathrm{~nm}$ & $40 \mathrm{~nm}$ & $28 \mathrm{~nm}$ \\
\hline Células Lógicas & $803 \mathrm{~K}$ & $588 \mathrm{~K}$ & $1,955 \mathrm{~K}$ \\
\hline Block RAMs & $33 \mathrm{Mb}$ & $33 \mathrm{Mb}$ & $68 \mathrm{Mb}$ \\
\hline$D S P$ & 1024 & 864 & 3,600 \\
\hline Transceiver & Até 48 & Até $48+24$ & 96 \\
\hline E/S & 920 & 720 & 1,200 \\
\hline Freqüência & $600 \mathrm{MHz}$ & $600 \mathrm{MHz}$ & $740 \mathrm{MHz}$ \\
\hline
\end{tabular}

Na reconfiguração parcial dinâmica, em inglês Dynamic Partial Reconfiguration (DPR), diferente da reconfiguração parcial simples, certas áreas do dispositivo podem ser reconfiguradas enquanto outras áreas continuam em operação e não são afetadas pela reconfiguração (Tadigotla et al. (2006)). Os FPGAs que suportam a configuração parcial dinâmica são os FPGAs da família Virtex da Xilinx e recentemente a fabricante Altera anunciou o completo suporte a configuração parcial e dinâmica de FPGAs para sua família Stratix-V (Koch and Torresen (2010)).

A Xilinx chama o suporte de reconfiguração parcial dinâmica por "on the fly" às vezes por "run-time reconfiguration" (Xilinx (2006)), (Xilinx (2004)), (Hauck and DeHon (2008)), (Bobda (2007)).

Segundo Bobda (2007), na implementação de um sistema no modo runtime reconfiguration, nem a computação nem a seqüência de configuração do projeto são conhecidas em tempo de compilação, assim, os requisitos para implementar uma dada tarefa são conhecidas em tempo de execução. Runtime reconfiguration implicam desfragmentação do dispositivo e comunicação entre os módulos recentemente aplicados. A reconfiguração parcial dinâmica de FPGAs exige dois tipos de particionamento:

1. Particionamento espacial: forma espacial com que os módulos de hardware serão distribuídos na lógica reconfigurável;

2. Particionamento temporal: definição dos intervalos de tempo em que cada módulo de hardware deverá estar presente no FPGA, já que algum módulo reconfigurável pode ocupar recursos no dispositivo, já ocupado por outro (Bobda (2003)), (Bobda (2007)).

Conforme descrito na Figura 2.9, o gerenciamento do dispositivo reconfigurável é usualmente feito por um escalonador e um placer $^{6}$ que podem ser implementados como parte de um sistema operacional executando em um processador (Bobda (2007)), (Hauck and DeHon (2008)).

\footnotetext{
${ }^{6}$ Placer determina a posição que cada módulo reconfigurável deve ocupar no FPGA.
} 
Conforme descrito na Figura 2.9, o escalonador determina qual tarefa deverá ser executada no FPGA e então, a envia para o placer que irá tentar alocála no dispositivo. Se o placer não for capaz de encontrar uma localização para a execução da nova tarefa no dispositivo, ele irá devolvê-la ao escalonador que poderá decidir reenviá-la mais tarde e assim irá enviar uma nova tarefa para o placer. Nesse caso, diz-se que a tarefa foi rejeitada (Bobda (2007)).

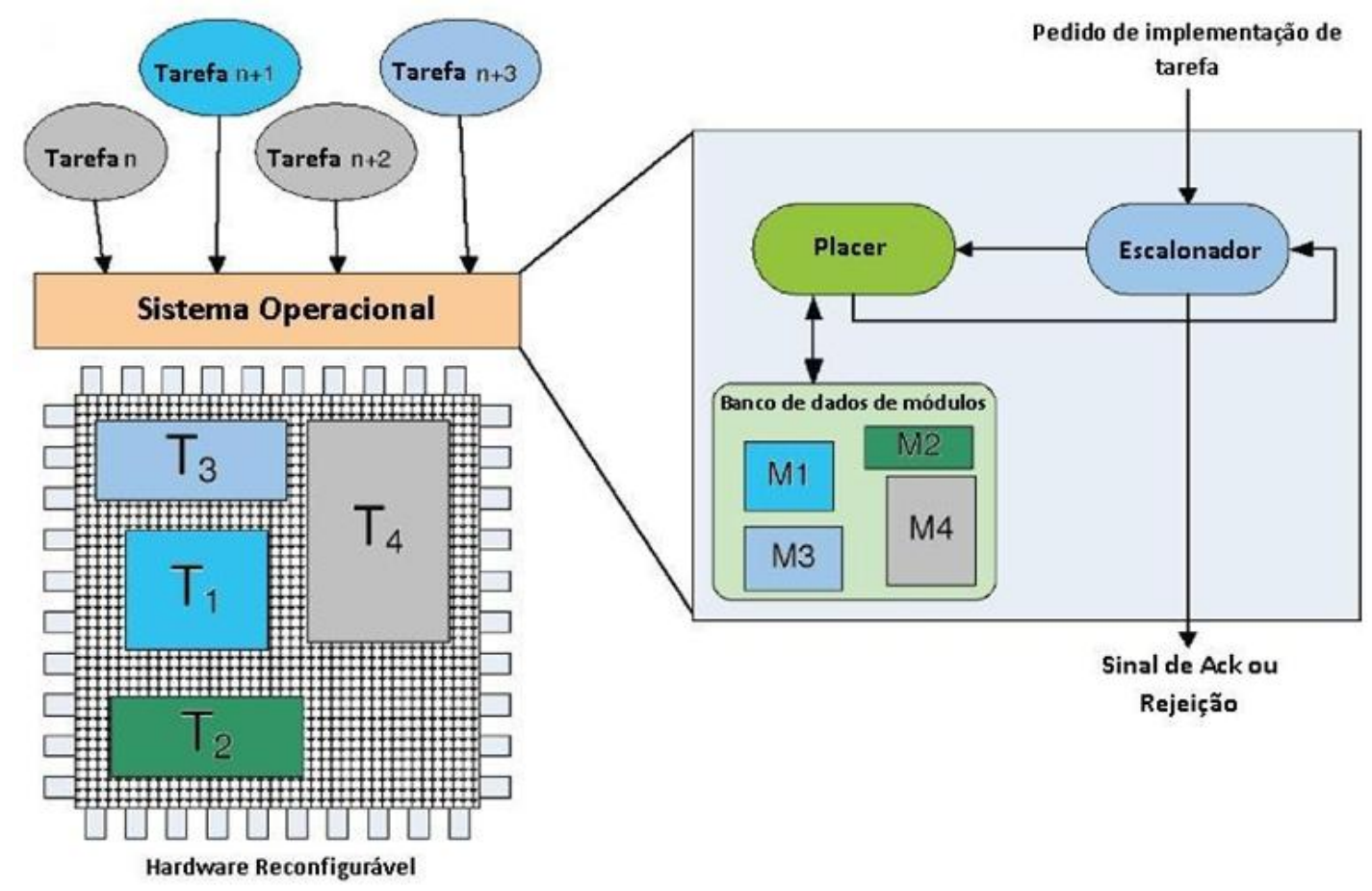

Figura 2.9: Arquitetura de um sistema em um ambiente reconfigurável em tempo de execução (Bobda (2007))

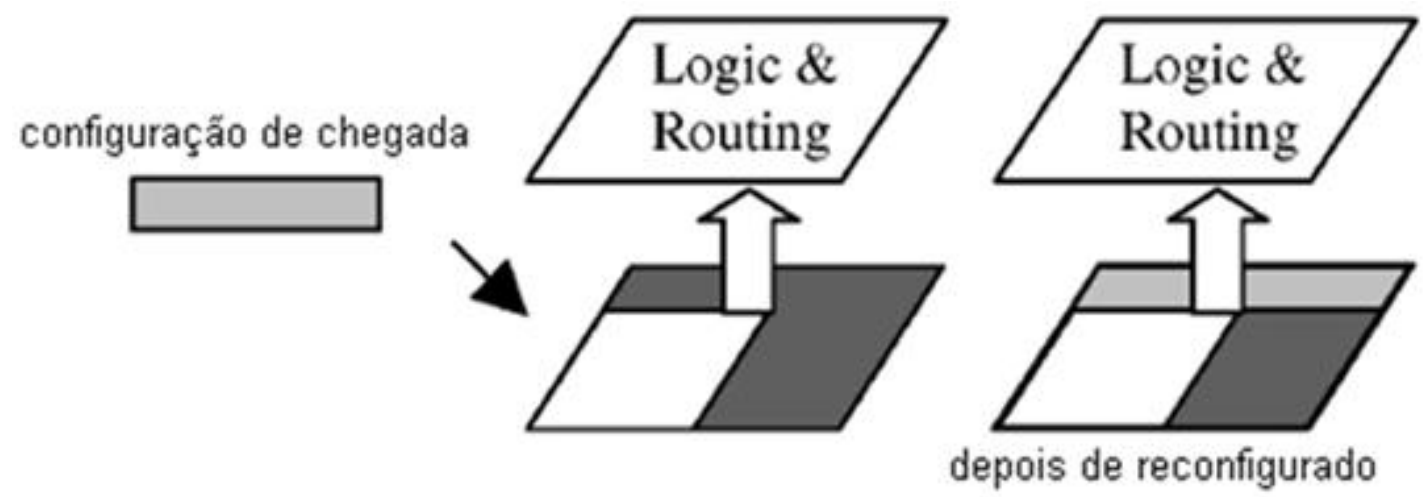

Figura 2.10: Reconfiguração parcial dinâmica (Bobda (2007))

Na Figura 2.10 é descrito um exemplo de reconfiguração parcial onde um FPGA possui uma configuração já definida, mas com a chegada de uma nova configuração, e após a reconfiguração parcial, a nova configuração passa a fazer parte do FPGA juntamente com a parte que não foi alterada.

Como descrito na Figura 2.10, a reconfiguração parcial dinâmica é útil 
quando um projeto não precisa ocupar todo o FPGA em um dado tempo, ou quando apenas uma parte do projeto necessita ser modificada.

Esses FPGAs são configurados com dados de configuração chamados de bitstream, os quais podem ser descarregados no dispositivo por uma porta de configuração e a idéia por trás da reconfiguração parcial dinâmica é realizar a reconfiguração apenas mudando algumas partes dos bits de configuração sendo executadas no FPGA. Fragmentos do bitstream chamados de pacotes (packets) são enviados para o dispositivo para reconfigurar as partes necessárias. Uma cópia da configuração existente no FPGA é mantida em uma parte dedicada da memória do processador, chamada de memória de configuração (configuration memory).

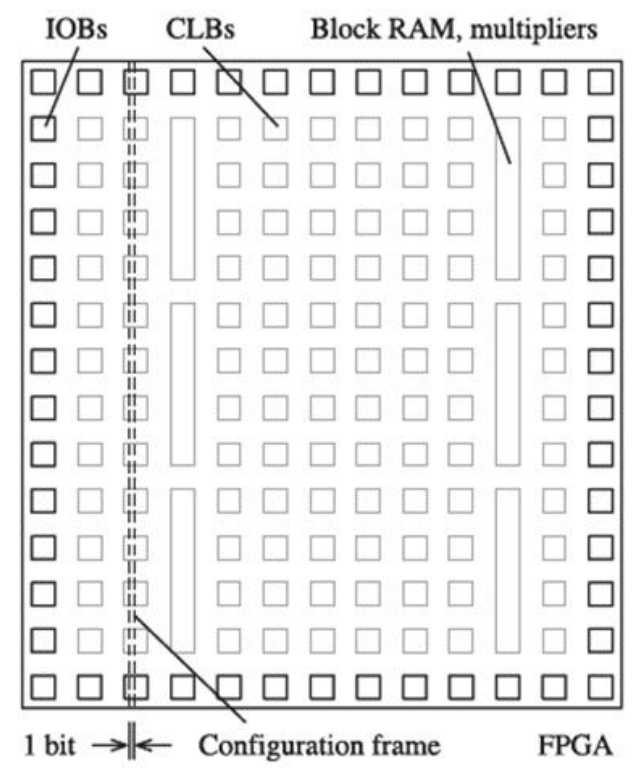

Figura 2.11: Arquitetura de configuração do Virtex-II(Bobda (2007))

A arquitetura dos FPGAs Virtex da Xilinx é organizada em frames ou colunas de slices. O frame é a menor unidade de reconfiguração para FPGA Virtex-II Pro da Xilinx. A Figura 2.11 mostra a arquitetura de configuração utilizada nos dispositivos Virtex-II e Virtex-II Pro (Hauck and DeHon (2008)).

No Virtex-II Pro, um frame corresponde uma coluna completa no FPGA, isso faz com que a reconfiguração de um módulo afete todos os módulos que compartilham aquela coluna, dificultando muito o processo de reconfiguração parcial dinâmica, uma vez que para qualquer alteração em algum frame, a parte do frame que não muda, deverá ser reprogramada juntamente com a parte que realmente muda (Bobda (2007)), (Hauck and DeHon (2008)).

As últimas gerações de FPGAs Virtex, tais como os da família Virtex-4, marcaram uma significativa mudança na arquitetura, com relação às famílias anteriores. Como mostra a Figura 2.12, a arquitetura de configuração é baseada em frames, como nas famílias anteriores, porém, nessas famílias de FPGAs, 


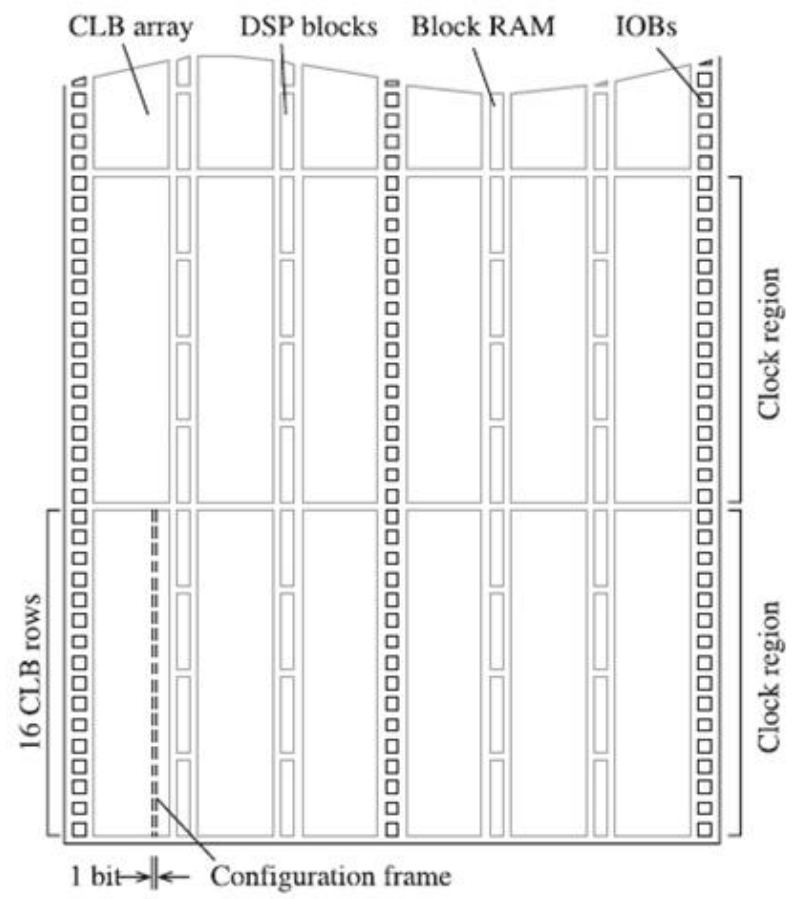

Figura 2.12: Arquitetura de configuração Virtex-4 (Bobda (2007)).

as colunas são constituídas de múltiplos frames independentes, ou seja, um frame transpõe apenas 16 linhas de blocos lógicos, ao invés de uma coluna inteira (Craven (2008)). Isso significa que a reconfiguração de um módulo presente em um bloco afeta apenas aquele módulo (Bobda (2007)).

O maior problema da reconfiguração parcial dinâmica é justamente produzir o bitstream de reconfiguração. Há pelo menos duas formas para fazer a extração do bitstream, representando um dado módulo (Bobda (2003):

- A primeira abordagem é chamada construtiva, representada na Figura 2.13-a, que permite fazer a implementação de um dado módulo separadamente usando ferramentas comuns de desenvolvimento, tal como o Integrated Software Environment (ISE) da Xilinx e então, juntar esse módulo no bitstream completo ou construí-lo como somas de módulos parciais.

- A segunda possibilidade, representada na Figura 2.13-b consiste primeiramente em gerar o bitstream completo separadamente. As partes fixas bem como as partes reconfiguráveis são implementadas como componentes e juntadas em outro bitstream. As diferenças entre os dois bitstream estão nas partes reconfiguráveis e, então, os dois bistreams são computados para se obter o bitstream parcial dinâmico.

Existem quatro abordagens de projetos utilizadas para a reconfiguração parcial dinâmica nos FPGAs da família Virtex da Xilinx: a abordagem JBits, a abordagem Difference-based flow, a abordagem Modular Design Flow e a 
a)

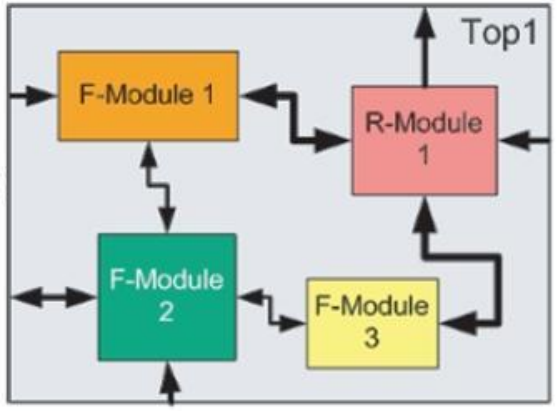

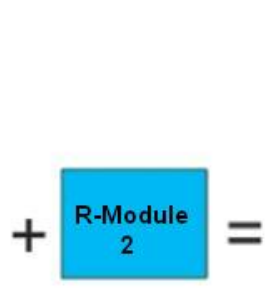
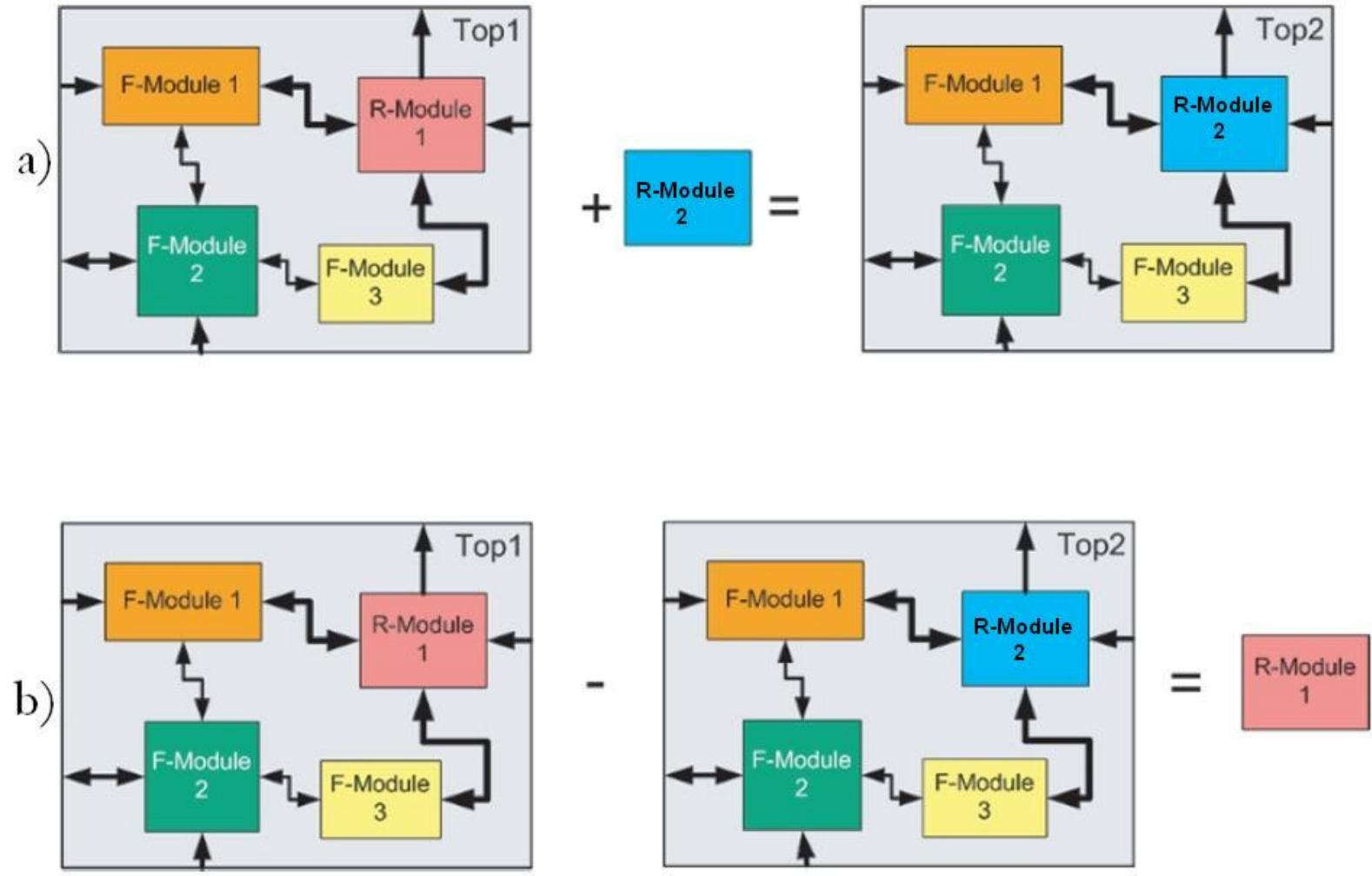

Figura 2.13: Geração do bitstream para a reconfiguração parcial(Bobda (2007)).

abordagem Early Access Design Flow (EAPR) (Tadigotla et al. (2006)) (Xilinx (2004)).

Segundo Zheng et al. (2005), Hauck and DeHon (2008) Jbits é uma Application Programming Interface (API) desenvolvida pela Xilinx e é formado por um grupo de classes Java, métodos e ferramentas que podem ser utilizadas para modificar o conteúdo de uma LUT bem como interconexões dentro do FPGA, sem a necessidade de outra ferramenta de configuração. Segundo Bobda (2003), isso é tudo o que é exigido para implementar funções em um FPGA. JBits possui centenas de "cores" ${ }^{\prime 7}$ pré-definidos, tais como somadores, subtratores, multiplicadores. Eles também podem ser combinados para gerar "cores" mais complexos.

Embora qualquer função possa ser implementada inteiramente com o JBits, não é a melhor abordagem utilizada para reconfiguração parcial dinâmica por que torna muito complexo a construção de componentes a nível de portas lógicas e interconexões. Ainda segundo Zheng et al. (2005) o JBits possui um baixo nível de abstração, comparando-se à utilizada na síntese lógica encontrada nas ferramentas de descrição de hardware. Além disso, o suporte para dispositivos Virtex, está limitado a família Virtex-II, até o presente momento. As abordagens mais utilizadas para os FPGAs Virtex atualmente são EAPR De-

\footnotetext{
${ }^{7}$ Núcleos de propriedade intelectual, núcleos Intellectual Property (IP), ou simplesmente "cores"
} 
sign Flow e a Modular Design Flow (Bobda (2007)), (Hauck and DeHon (2008)).

Na abordagem Difference-based flow, a reconfiguração parcial dinâmica é realizada a partir da diferença do bitstream do projeto inicial e o gerado após as mudanças no projeto original (Montminy et al. (2007)), (Eto (2007)). Segundo Upegui and Sanchez (2005), nesse método o projetista deve fazer manualmente as mudanças no projeto, ao nível das interconexões internas do FPGA, utilizando, por exemplo, o FPGA Editor, uma ferramenta de edição nesse nível. Essa ferramenta faz parte do conjunto de recursos do ISE da Xilinx. Nessa ferramenta, o projetista pode mudar as configurações dos componentes tais como: equações nas LUTs, conteúdos na RAM interna, multiplexadores, inicialização de flip-flops e roteamentos. Depois de editado as mudanças, um bitstream parcial é gerado, contendo apenas as diferenças entre o projeto original e as modificações. Para projetos complexos, esse método seria impraticável devido a edição no nível de interconexões no arquivo bistream.

A abordagem Modular Design Flow tenta solucionar algumas das desvantagens dos dois métodos propostos anteriormente, o Jbits e o Difference-based flow, que segundo Bobda (2007), não garantem um roteamento livre entre módulos reconfigurados.

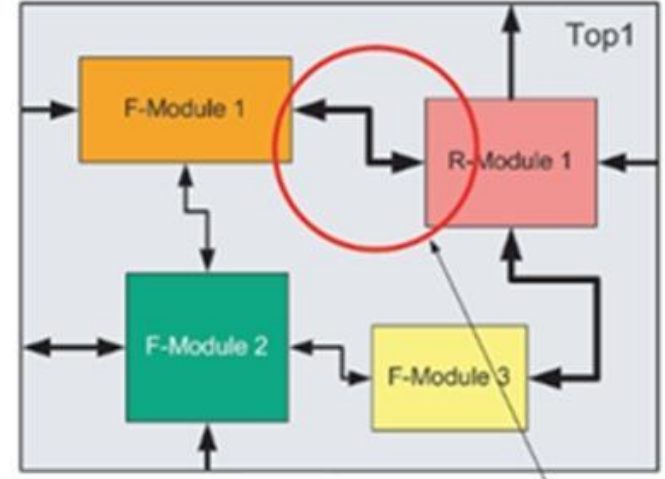

(a)

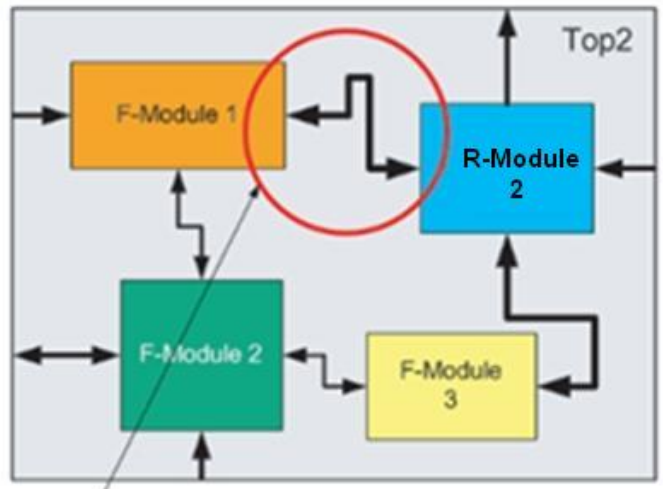

(b)

Diferentes possibilidades de roteamento

Figura 2.14: Roteamento em dois caminhos diferentes (Bobda (2007))

Na Figura 2.14 é ilustrado um exemplo do problema citado por Bobda. Conforme descrito na Figura 2.14, existem dois projetos: Top1 e Top2. Após a reconfiguração parcial dinâmica, o módulo R-Module 1 em Top1 é substituído pelo módulo R-Module 2, gerando assim o projeto Top2. Tanto os módulos fixos quanto os reconfiguráveis foram colocados nas mesmas posições originais, como em Top1. A conexão F-Module 1 <-> R-Module 1 está roteada em um caminho diferente em relação a conexão F-Module 1 <-> R-Module 2, considerado um problema no processo de reconfiguração. Uma das principais contribuições da abordagem Modular Design Flow é o uso da primitiva Bus 
Macro que garante canais de comunicação fixos entre componentes que serão reconfigurados em tempo de execução e os componentes fixos do projeto (Bobda (2007)).

Ainda segundo Bobda (2007), Bobda (2003), a abordagem Modular Design Flow não foi desenvolvida inicialmente para dar suporte à reconfiguração parcial dinâmica, ela foi desenvolvida para permitir a cooperação entre engenheiros que trabalham no mesmo projeto, permitindo que o projeto completo fosse dividido em módulos.

Ainda na abordagem Modular Design Flow, módulos fixos e reconfiguráveis serão alocados em regiões no FPGA. Quando um módulo reconfigurável necessitar comunicar-se com um módulo fixo ou reconfigurável, isto deve ser feito por meio do Bus Macro. O Bus Macro mantém de forma correta as conexões entre os dois módulos durante a reconfiguração parcial dinâmica. Um projeto com dois ou mais módulos reconfiguráveis é mostrado na Figura 2.15 (Tadigotla et al. (2006)).

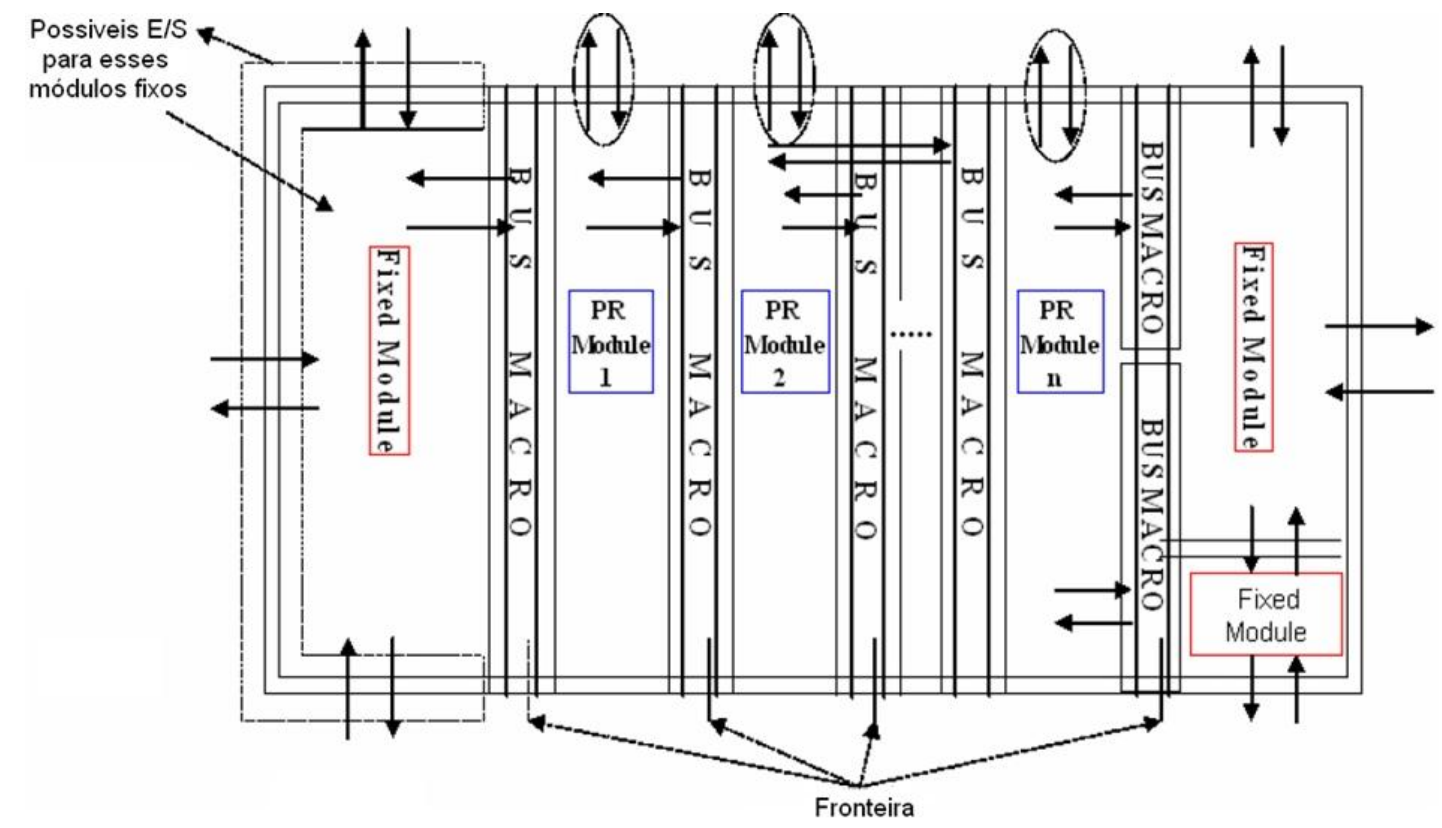

Figura 2.15: Esboço de um projeto básico com dois ou mais módulos reconfiguráveis (Tadigotla et al. (2006))

Na Figura 2.15 é mostrado um exemplo de um projeto com módulos fixos e reconfiguráveis. Como mostrado na figura, o Bus Macro fornece a comunicação necessária entre os módulos (Tadigotla et al. (2006)).

Uma restrição dessa abordagem, segundo Nezami et al. (2008), é que ela não permite a comunicação direta de módulos fixos e outros blocos se os sinais tiverem que atravessar a região parcialmente reconfigurável.

Finalmente na abordagem EAPR Design Flow, introduzido pela empresa Xilinx em março de 2006 para reconfiguração parcial dinâmica, trata-se de um projeto modular cujas principais mudanças estão relacionadas às restrições 
da abordagem anterior, o que reduz significativamente a complexidade de reconfiguração parcial dinâmica (Quadri et al. (2007)), (Tadigotla et al. (2006)), (Nezami et al. (2008)), (Bobda (2007)). Um dos principais benefícios dessa abordagem é que ela permite ao projetista realizar a reconfiguração parcial dinâmica em regiões de qualquer tamanho, eliminando assim um dos requisitos de reconfiguração parcial das abordagens anteriores (Tadigotla et al. (2006)), (Xilinx (2006)), (Hauck and DeHon (2008)), disponivel apenas para dispositivos Virtex-4 e superiores ((Bobda (2007)). Quando uma pequena região é configurada, a coluna inteira é escrita, mas o controlador de configuração no FPGA verifica se a reconfiguração deveria modificar o conteúdo dos CLBs. Assim a execução da reconfiguração é feita apenas onde as mudanças são necessárias, conseqüentemente, a reconfiguração não irá afetar os blocos que deveriam manter-se inalterados ((Bobda (2007)).

Na Figura 2.16 é descrito uma aplicação que faz uso de alguns filtros configurados nos diferentes módulos descritos na figura, por onde passarão imagens utilizando um barramento que atravessa toda a largura do chip. Em uma eventual reconfiguração em um dos módulos, o barramento não será alterado e nem seu funcionamento será afetado (Bobda (2007)).

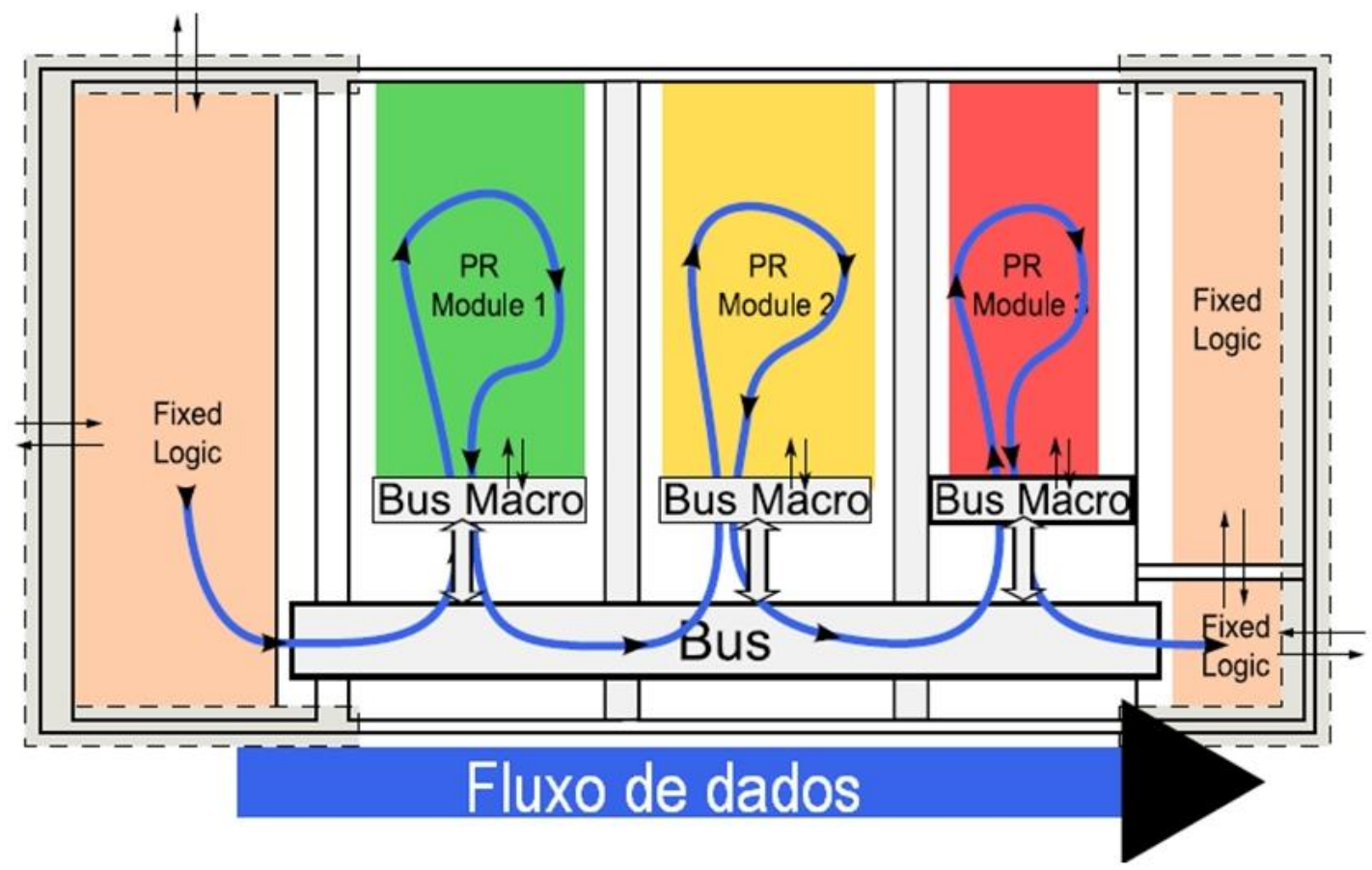

Figura 2.16: Esquema de uma aplicação reconfigurável que possui um barramento que não pode ser interrompido (Bobda (2007))

A mais importante característica do EAPR Desing é que ela permite a comunicação entre diferentes regiões do FPGA. Na abordagem modular, quando um sinal de um módulo estático atravessar um módulo reconfigurável, era necessário fazê-lo por meio de bus macros (Quadri et al. (2007)). Na abordagem $E A P R$, os sinais que apenas atravessam módulos reconfiguráveis, sem intera- 
gir com eles, não terão que utilizar o bus macro. O algoritmo de roteamento é capaz agora de determinar esses sinais e usar longos sinais de comunicação que não serão afetados pela reconfiguração parcial dinâmica (Bobda (2007)). Essa característica possibilita o aumento de desempenho no sistema e simplifica o processo de construção de um projeto com reconfiguração parcial dinâmica (Xilinx (2006)), (Nezami et al. (2008)). 


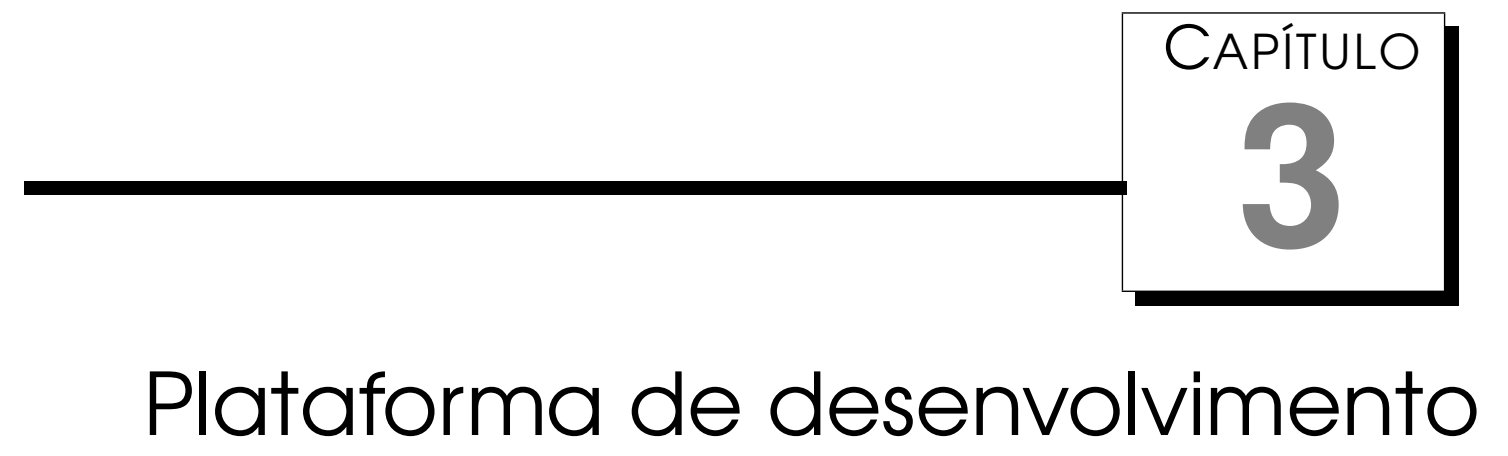

Nesse capítulo serão descritos algumas características dos FPGAs da família Virtex da Xilinx, seu processador embarcado PowerPC, a plataforma de desenvolvimento XUP V2P e finalmente as ferramentas da Xilinx usadas para projetar sistemas reconfiguráveis no FPGA. O principal objetivo nesse capítulo é descrever a tecnologia usada neste trabalho para implementação das arquiteturas de hardware propostas.

\section{1 Família VIRTEX-II Pro da Xilinx}

A família de dispositivos FPGAs da empresa Xilinx (Xilinx (2007c)), para alto desempenho e alta densidade, é a Virtex e o seu lançamento ocorreu no ano de 1998. Das famílias de FPGA Virtex existentes, como Virtex, Virtex-E, Virtex-E Extended Memory, Virtex-II, Virtex-II Pro, Virtex-4, Virtex-5, Virtex-6 e Virtex-7, apenas a Virtex-II Pro será abordada nesse trabalho, uma vez que foi o FPGA utilizado na implementação do projeto proposto, mais especificadamente o FPGA XC2VP3O.

A família Virtex-II Pro faz parte da quarta geração de dispositivos do grupo Virtex (Bonato (2004)) e é fabricada com a tecnologia SRAM. Essa família de FPGA possui arquitetura híbrida de granularidade média com alguns elementos de granularidade grossa (Ribeiro (2002)), (Bobda (2007)), (Xilinx (2008)).

Conforme a Tabela 3.1, essa família pode variar de 11.088 a 125.136 células lógicas, de 1 a 4 processadores RISC PowerPC da IBM (hard core ${ }^{1}$ ) embarcados e 44 a 556 multiplicadores de 18x18 bits.

\footnotetext{
${ }^{1}$ Módulos de hardware já sintetizados, são otimizados para uma tecnologia específica e não podem ser modificados pelo projetista
} 
Tabela 3.1: Características dos FPGAs da família Virtex-II Pro da Xilinx (Xilinx (2008)))

\begin{tabular}{llllll} 
Família & FPGA & $\begin{array}{l}\text { Células } \\
\text { Lógicas }\end{array}$ & $\begin{array}{l}\text { BRAM } \\
\text { (Kbits) }\end{array}$ & $\begin{array}{l}\text { Processadores } \\
\text { PowerPC }\end{array}$ & $\begin{array}{l}\text { Multiplicadores } \\
18 \times 18 \text { Bits }\end{array}$ \\
\hline \multirow{4}{*}{ Virtex-II Pro } & XC2VP7 & 11.088 & 792 & 1 & 44 \\
& XC2VP20 & 20.880 & 1.584 & 2 & 88 \\
& XC2VP30 & 30.816 & 2.448 & 2 & 136 \\
& XC2VP40 & 43.632 & 3.456 & 2 & 192 \\
& XC2VP50 & 53.136 & 4.176 & 2 & 232 \\
& XC2VP100 & 74.448 & 5.904 & 2 & 328 \\
XC2VP125 & 125.136 & 7.992 & 2 & 444 \\
\hline
\end{tabular}

Especificamente, o FPGA Virtex-II Pro XC2VP3O tem as características, conforme descrito na Tabela 3.2 (Xilinx (2008)).

Tabela 3.2: Características do dispositivo XC2VP3O (Xilinx (2008)))

\begin{tabular}{ll} 
Características & XC2VP30 \\
\hline Slices & 13969 \\
Tamanho de arranjo (array) & $80 \times 46$ \\
RAM Distribuídas & $428 \mathrm{~Kb}$ \\
Blocos RAMs & $2448 \mathrm{~Kb}$ \\
DCMs & 8 \\
\hline
\end{tabular}

Como ilustra na Figura 3.1, o Virtex-II Pro possui dois processadores embarcados PowerPC, CLBs, Select $I / O^{2}$, Rocket I/O, Digital Clock Manager (DCM), multiplicadores e SelectRAM. O CLB, descrito na Figura 3.1, contém quatro slices e dois buffers tri-state e pode ser visto na Figura 3.2. Cada slice contém: 2 geradores de funções $\mathrm{F}$ e $\mathrm{G}$, dois elementos de armazenamento, portas lógicas aritméticas, multiplexadores e lógicas diversas. Os geradores de funções F e G podem ser configurados como LUTs de 4 entradas, registradores de 16 bits ou SelectRAM de 16 bits. Um exemplo básico da estrutura do slice é dado na Figura 3.3.

Os blocos SelectRAM mostrados, na Figura 3.1, são blocos de memória $R A M$ que permitem armazenamento de $18 \mathrm{kbits,} \mathrm{distribuídos} \mathrm{em} \mathrm{colunas} \mathrm{por}$ todo o FPGA.

Blocos multiplicadores, mostrados na Figura 3.1, permitem a multiplicação de dados com $18 \times 18$ bits e também estão distribuídos em colunas por todo FPGA.

Blocos SlectRAM e multiplicadores são conectados utilizando-se quatro matrizes de interconexão para terem acesso ao roteamento global, como é mos-

\footnotetext{
${ }^{2}$ Seletores de $E / S$
} 


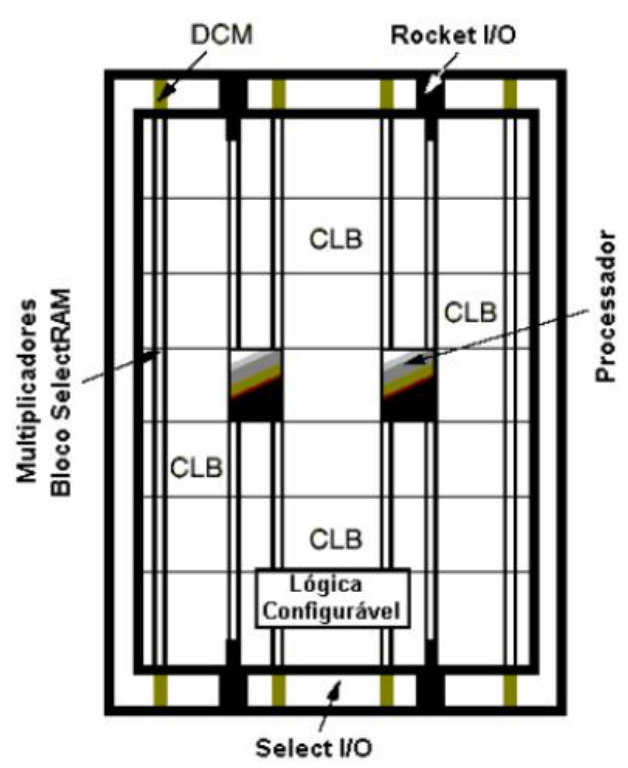

Figura 3.1: Arquitetura da Virtex-II Pro (Xilinx (2005))

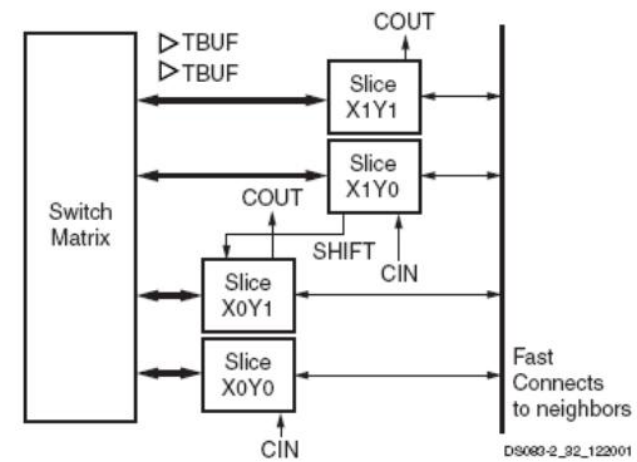

Figura 3.2: Bloco de CLB da Virtex-II Pro (Xilinx (2005))

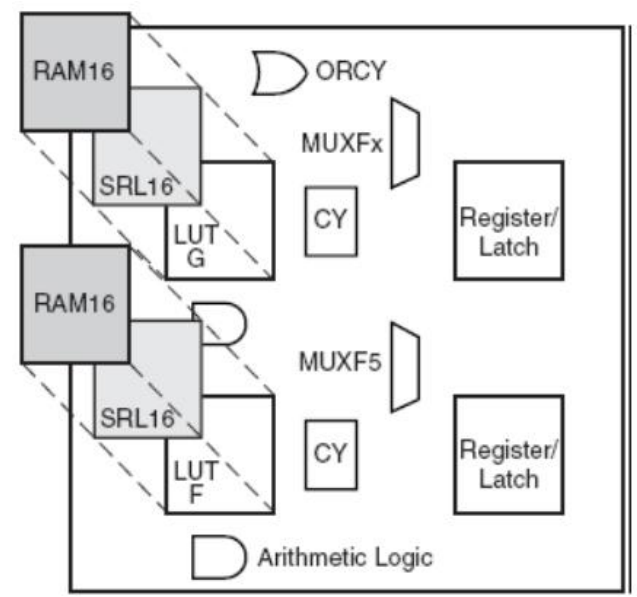

Figura 3.3: Slice da Virtex-II Pro(Xilinx (2005)) 
trado na Figura 3.4 .

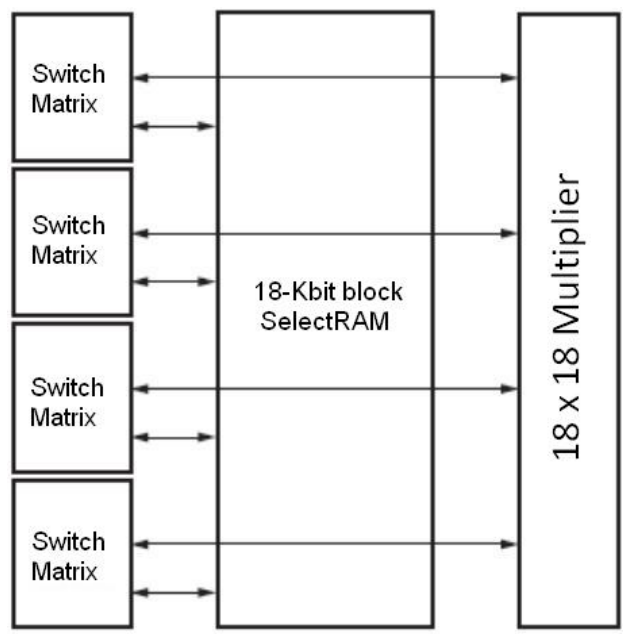

Figura 3.4: Blocos de SelectRAM e Multiplicadores (Xilinx (2005))

Os blocos de multiplicação podem ser associados aos blocos SelectRAM ou podem ser utilizados independentemente. Interconexões permitem que os blocos de memória SelectRAM e blocos de multiplicadores sejam utilizados ao mesmo tempo. O uso da SelectRAM, dos multiplicadores, juntamente com um acumulador permitem a implementação de um Multiply-Add-Accumulate (MAC) (Xilinx (2005)).

Os blocos DCMs, mostrados na Figura 3.1, dividem o clock global, para blocos que necessitam de valores menores de clock.

Os blocos de Rocket $I / O$, também mostrado na Figura 3.1, implementam um conversor paralelo-serial e vice-versa, que junto aos blocos IOBs proporcionam comunicação do FPGA com dispositivos externos.

O processador PowerPC, também mostrado na Figura 3.1 é organizado em uma arquitetura harvard ${ }^{3}$, possuindo barramentos separados para instruções e dados; é um processador de 32 bits, com cinco estágios de pipeline, possui unidade de multiplicação e divisão e trabalha no máximo a $300 \mathrm{MHz}$ com cachê de instruções e dados. Como esse processador é embarcado no FPGA, ele não usa recursos reconfiguráveis do mesmo. Embora esse processador esteja presente fisicamente no FPGA, há necessidade de lógica programável para implementar os periféricos, tais como o controlador da memória Synchronous Dynamic RAM (SDRAM), ethernet, Universal Asynchronous Receiver Transmitter (UART) (Szewinski (2005)). Até quatro processadores PowerPC podem estar em um únic0 FPGA. O PowerPC trabalha com operações de 32 bits em pontofixo. Operações de 64 bits e operações de ponto flutuante podem ser emu-

\footnotetext{
${ }^{3}$ Máquinas de arquitetura Harvard utilizam o conceito de Pipeline, e possui barramentos independentes para acesso a memória de dados (RAM) e acesso a memória de programa (ROM), logo enquanto o processador grava ou movimenta valores entre os registradores, também pode buscar a próxima instrução a ser executada, tudo isso simultaneamente, pois estão em barramentos separados.
} 
ladas em software (Xilinx (2008)). Um controlador On-Chip Memory (OCM) serve como interface dedicada entre blocos RAMs configurados nos FPGAs e os sinais OCM disponíveis no core do PowerPC.

Em se tratando de processadores, algumas arquiteturas de barramento, de domínio público podem ser projetados com diferentes interfaces e protocolos de comunicação. Entre essas arquiteturas de barramentos está o CoreConnect da IBM que está vinculada a arquitetura do processador PowerPC. Segundo Palma (2002), Mesquita (2002), a arquitetura CoreConnect da IBM fornece três barramentos para interconectar cores e lógica personalizável:

1. barramento Processor Local Bus (PLB) utilizado para interconectar cores com alto desempenho e grande largura de banda, tais como o PowerPC, controladores Direct memory Access (DMA) e interfaces de memória externa.

2. Barramento Periférico On-Chip Peripheral Bus (OPB) utilizado para interconectar periféricos que trabalham com baixa taxa de dados, tais como portas seriais, portas paralelas, UARTs, e outros cores

3. Barramento Device Control Register Bus (DCR) utilizado para configurar e informar o estado entre um core processador e outros cores.

O princípio de funcionamento do CoreConnect, segundo Mesquita (2002), baseia-se em um árbitro, que decide qual core vai fazer acesso o barramento. Além do hardware core do processador PowerPC, as famílias Spartan e Virtex contam com um firm core ${ }^{4}$ do processador Microblaze, entretanto, por não ter sido utilizado não será tratado nessa tese.

\subsubsection{Plataforma de desenvolvimento XUP V2P}

O FPGA utilizado nesse trabalho é o XC2VP30 da família Virtex-II Pro da Xilinx. A plataforma de desenvolvimento é a placa XUP-V2P da Digilent e é mostrado na Figura 3.5 (Xilinx (2007d)), (Xilinx (2008)).

Conforme mostrado na Figura 3.5, a placa de desenvolvimento XUP-V2P possui: um FPGA XC2VP30 Virtex-II Pro da Xilinx; Slot para até 2GB de memória Double Data Rating (DDR) SDRAM; um Compact Flash para armazenamento de dados e armazenamento da configuração do FPGA; porta Universal Serial Bus (USB) para entrada de configuração do FPGA; uma conexão Ethernet 10/100; porta serial RS-232 com conector DB9; 2 portas PS-2; 4 LEDs; 4 switchs; 5 push buttons; codificador AC-97 de áudio, com entrada de microfone e saída de áudio; saída de Vídeo XSGA com 1200x1600 pixels e $70 \mathrm{~Hz}$ de restauração de tela; 3 portas serial SATA e um clock de $100 \mathrm{MHz}$.

\footnotetext{
${ }^{4}$ firm core é a integrado à lógica do usuário, descrita em VHDL ou Verilog
} 


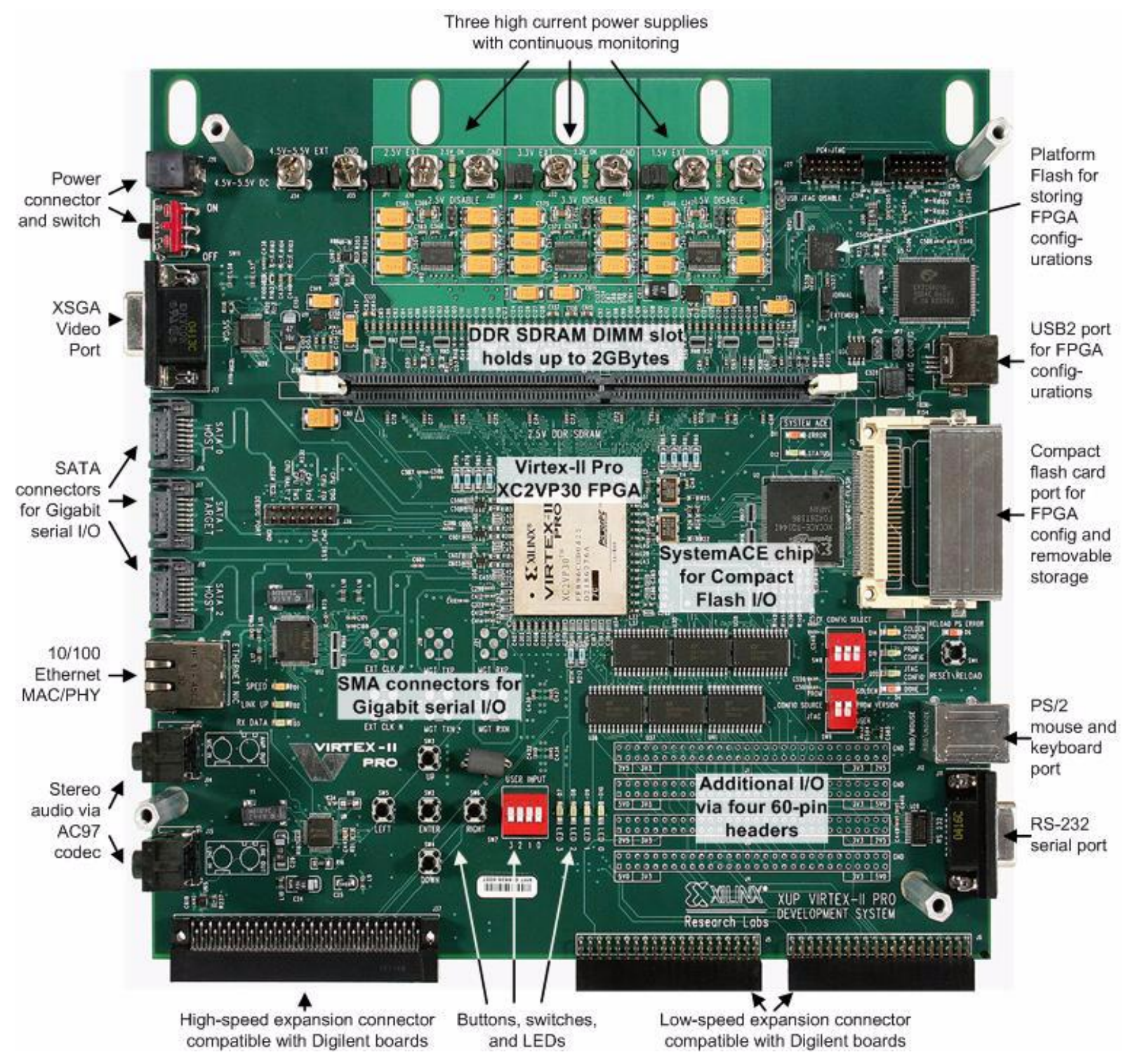

Figura 3.5: Placa de desenvolvimento XUP V2P da Digilent 
Na Figura 3.6 é mostrado um diagrama de interconexão dos dispositivos da placa com o FPGA (Xilinx (2007c)), (Xilinx (2008)).

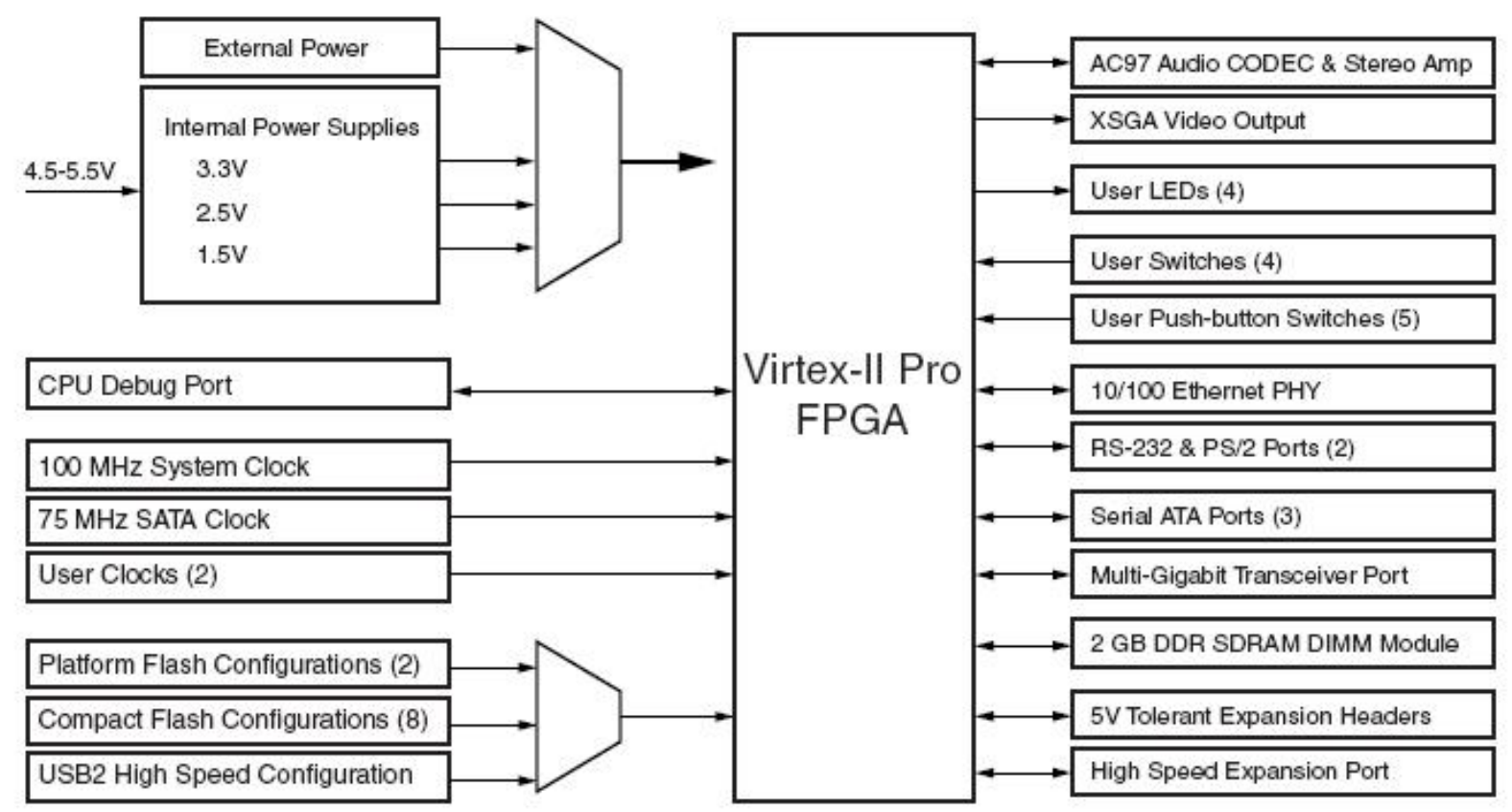

Figura 3.6: Diagrama da placa de desenvolvimento XUP V2P

\subsection{Ferramentas EDA da Xilinx}

Field Programmable System on Chip (FPSoC) tendo como plataforma uma placa de prototipação reconfigurável, oferece um ambiente de desenvolvimento que incorpora várias combinações de sistemas computacionais como ASIC, memórias, processadores customizados e lógicas diversas. Entretanto para implementar esses sistemas em um FPGA, é necessário o conhecimento de ferramentas e linguagens de descrição de hardware. A seguir são descritas algumas dessas ferramentas.

\subsubsection{ISE}

O ISE é um ambiente integrado que permite projetar sistemas reconfiguráveis nos FPGAs da Xilinx (Xilinx (2007b)).

O ambiente ISE permite a descrição de um projeto e todas as suas restrições, como por exemplo, o tempo limite para transições de sinais, seguida da síntese, implementação, simulação final do projeto, permitindo ao projetista voltar em qualquer dos passos para corrigir falhas ou otimizar o projeto final.

Na descrição de um projeto, o mesmo será modelado para atender aos requisitos de hardware necessárias a aplicação. O projeto pode ser escrito por 
meio de $H D L$, tais como VHDL ou Verilog, ou ser modelado em diagrama esquemático, além disso, o projetista pode também combinar HDL e o diagrama esquemático, caso necessário.

No processo de síntese, depois de modelar o projeto em descrição $H D L$ ou esquemático e o processo de síntese ser realizado, um arquivo netlist é gerado onde estão descritas os vários elementos lógicos do projeto e as suas interconexões.

Na implementação, o projeto lógico (arquivo netlist) é mapeado com as portas lógicas e interconexões reais pois o FPGA escolhido pelo projetista. Depois da fase de implementação, um arquivo é gerado: o bitstream. Esse arquivo pode instantaneamente ser carregado no FPGA e contém as funcionalidades implementadas pelo projetista.

Na fase de simulação, o projetista verifica se o seu projeto está funcionando corretamente, com as restrições impostas pelo mesmo, se houver, além de permitir o aperfeiçoamento do projeto e correções no projeto original.

Na Figura 3.7 são descritos os passos necessários para a geração do arquivo bitstream e download na placa, a partir da ferramenta ISE da Xilinx.

\subsubsection{EDK}

O Embedded Development Kit (EDK) é uma ferramenta que possibilita configurar os processadores PowerPC e Microblaze no FPGA, além dos periféricos e memórias na placa de prototipação (Xilinx (2007a)).

Fazem parte do EDK o Xilinx Platform Studio (XPS); Graphical User Interface (GUI); o Software Development Kit (SDK); todos oferecendo suporte para a configuração dos processadores PowerPC e Microbrase.

Como o projetista pode combinar processador embarcado e lógicas customizadas, uma vez definido a configuração do processador e demais periféricos, o XPS preparará o ISE para que o projetista configure a sua lógica customizada.

Na Figura 3.8 é mostrado um diagrama de fluxo de projeto utilizando-se as ferramentas ISE e EDK, bem como a integração entre elas, a fim de combinar uma lógica customizada com processador embarcado (Xilinx (2007a)). 


\section{Código VHDL}

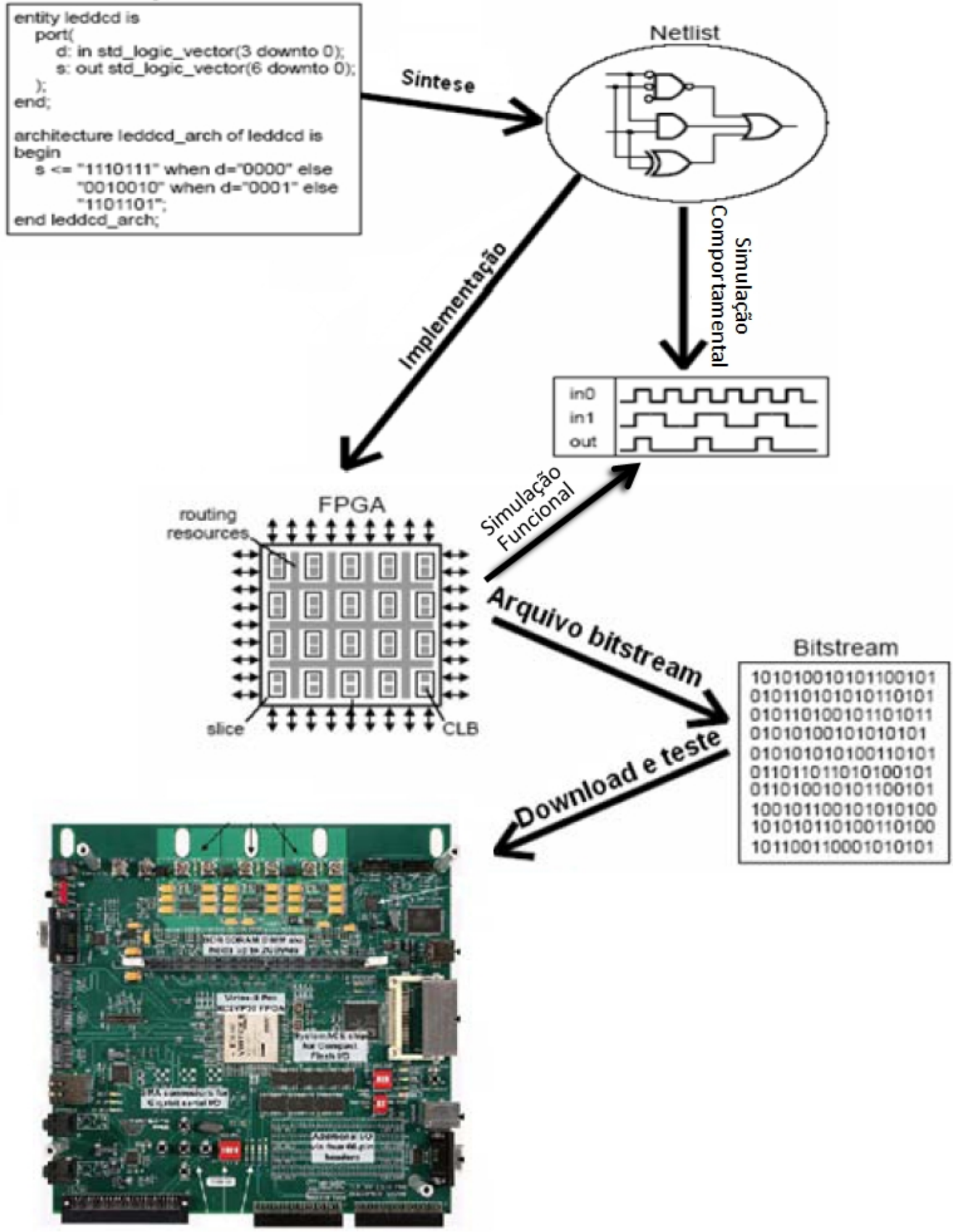

Figura 3.7: Fluxo de desenvolvimento de um projeto em FPGA 


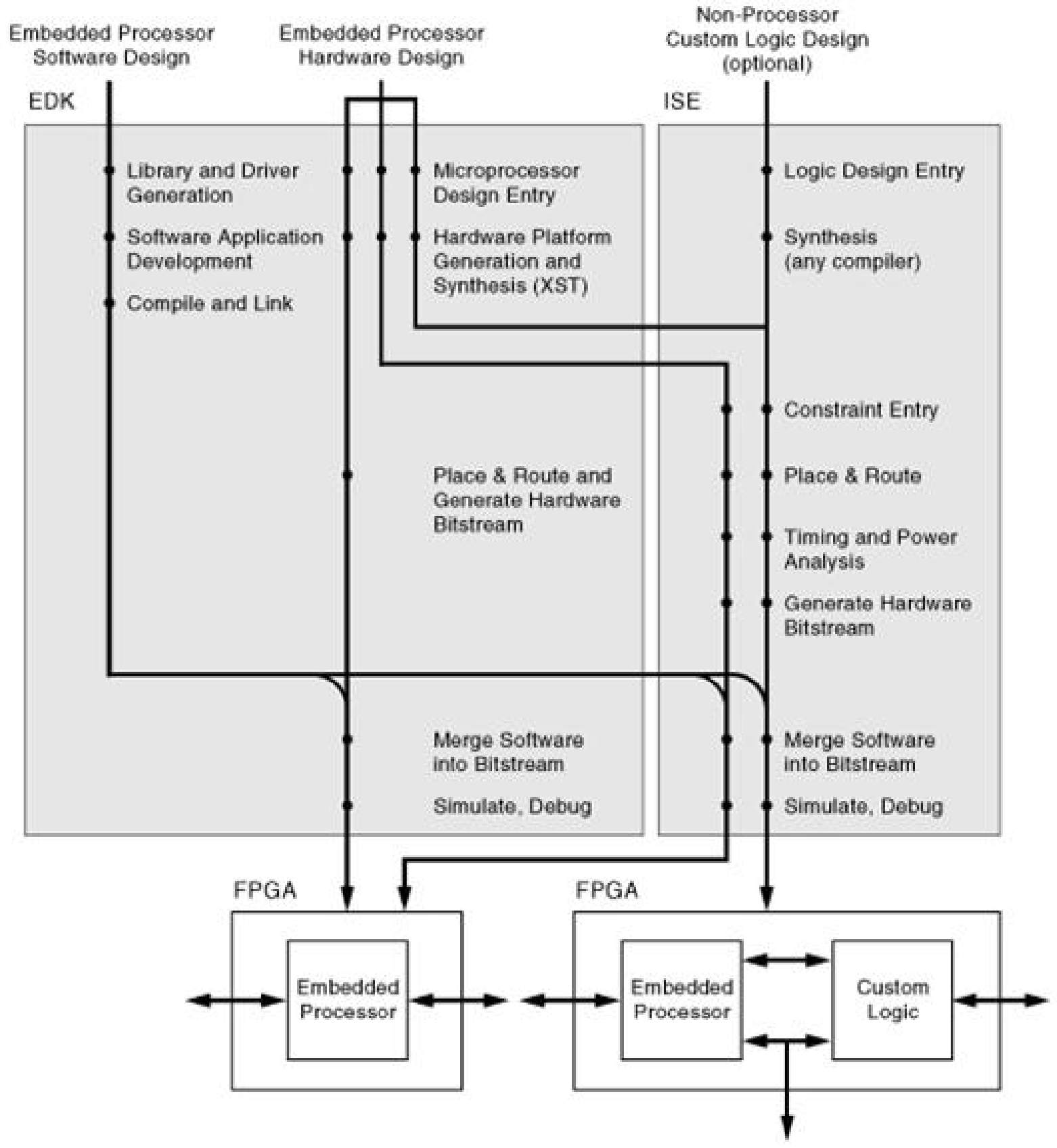

Figura 3.8: Fluxo de desenvolvimento de projetos em FPGA com ISE e EDK (Xilinx (2007a)) 


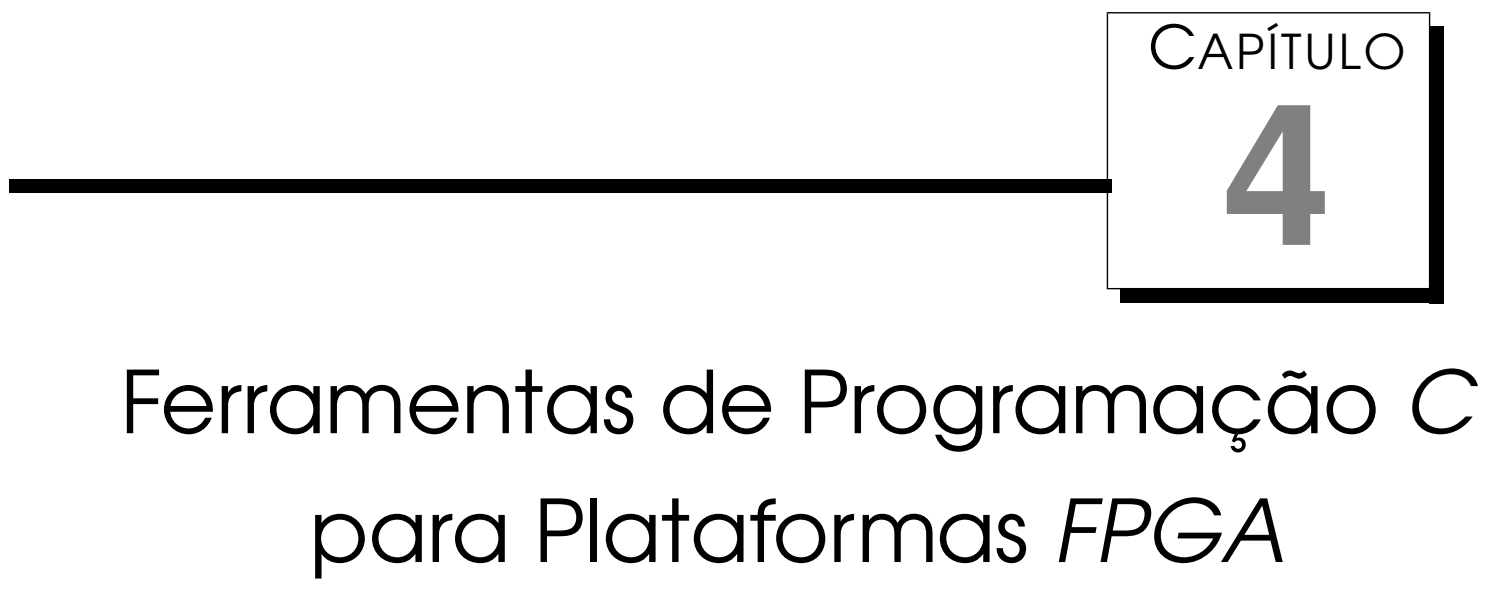

As ferramentas disponíveis, tais como ISE e EDK, vistos no capítulo anterior, permitem implementar, testar, simular e corrigir projetos eletrônicos computacionais com grande facilidade sem que se tenham gastos elevados se comparados aos gastos de desenvolvimento de circuitos ASICs.

Atualmente, é possível desenvolver rapidamente um projeto de sistema digital empregando-se novas metodologias como linguagens de descrição de hardware, as HDLs, ferramentas de síntese lógica e de simulação. Assim as linguagens de descrição de hardware estão se consolidando como forma padrão de descrição de projetos digitais.

Ferramentas de síntese lógica automáticas estão disponíveis para mapear circuitos em diversas tecnologias. Além das mudanças na tecnologia, o ciclo de vida dos produtos tornam-se cada vez mais curto, exigindo prototipações rápidas.

Apesar de novas arquiteturas terem sido propostas e novos conceitos apresentados (Radunovic' and Milutinovic' (1998)), a utilização de sistemas computacionais reconfiguráveis requer etapas morosas e complexas e conhecimentos específicos de projeto de hardware (Cardoso and Neto (2003)), (Cardoso (2000)).

Nesse capítulo foram investigadas algumas ferramentas comerciais e acadêmicas disponíveis, para conversão de algoritmos escritos em linguagens de alto nivel, tais como $C, C++$ e Java para linguagens de descrição de hardware e serão apresentadas durante o desenvolvimento do capítulo. Dar-se-a maior destaque à ferramenta CoDeveloper da empresa Impulse C, por existir mais re- 
ferências e documentações disponiveis e por ter sido utilizada em um projeto anterior (Lopes (2007).

\section{1 Introdução às ferramentas de programação C para plataformas FPGA}

Segundo Wang et al. (2006), as linguagens $C / C++$ são adotadas para descrição de hardware desde 1980. Os simuladores que adotam $C / C++$ tem desempenho de 10 a 100 vezes maior do que simuladores que adotam linguagens HDLs como VHDL ou Verilog. Porém, em (Edwards (2006)) são mostrados os desafios da utilização de linguagens de alto nível tipo $C / C++$ como linguagens de descrição de hardware, isso deve-se principalmente às lacunas existentes entre as semânticas adotadas por $\mathrm{C} / \mathrm{C}++$ e linguagens de descrição de hardware.

Muitas aplicações embarcadas, geralmente aplicações científicas, como processamento de imagens, entre outras, são escritas em linguagem $C$ e são executadas por processadores DSP. Quando detectado gargalos nessas aplicações, os trechos de código mais críticos são escritos em linguagem assembler, aumentando assim o desempenho da aplicação. Há casos em que a aplicação exige tempo crítico para execução, por exemplo, aplicações de processamento de imagens em tempo real cuja solução deve ser reescrita dessa aplicação ou parte dela em linguagem de descrição de hardware e implementá-la em um CI, por exemplo, um FPGA (Pellerin and Thibault (2005)).

O problema é que para reescrever essa aplicação em linguagem de descrição de hardware exige-se conhecimentos específicos para tal finalidade, além do conhecimento exigido em ferramentas EDA para prototipação em FPGA, como descrito anteriormente por Cardoso (2000). As ferramentas de programação $C$ para plataformas FPGA podem ajudar na diminuição do tempo de reescrita dos códigos em linguagem $C$ para HDLs, além de diminuírem os custos do projeto, já que não há necessidade de se contratar uma equipe ou empresa especializada em projetos de hardware. Os projetistas de software, com a ajuda dessas ferramentas, poderão ver os FPGAs como mais um sistema programável, por exemplo, um processador (Pellerin and Thibault (2005)).

As HDLs oferecem ao projetista de hardware o controle explícito e preciso sobre o hardware gerado. Porém, esse controle explícito sobre a geração de hardware nem sempre é necessário. Do mesmo modo que um programa é escrito em linguagem $C$ e somente depois são reescritos em assembler os trechos que causam gargalo no sistema, um sistema poderia ser escrito em linguagem $H D L$ utilizando-se ferramentas automáticas a partir de uma linguagem $C$ por exemplo, e depois ser reescritos por um projetista de hardware, 
os trechos que necessitam detalhamentos específicos ou implementar diretamente no hardware os trechos que causassem gargalo no sistema (Pellerin and Thibault (2005)).

Para a computação reconfigurável ser adotada efetivamente é necessário o desenvolvimento de ferramentas que acelerem o desenvolvimento de hardware e que eleve o nível de abstração necessário ao projeto. Em Menotti (2010) são mostrados os investimentos com ferramentas para síntese de alto nível na indústria de automação conforme descrito na Figura 4.1.

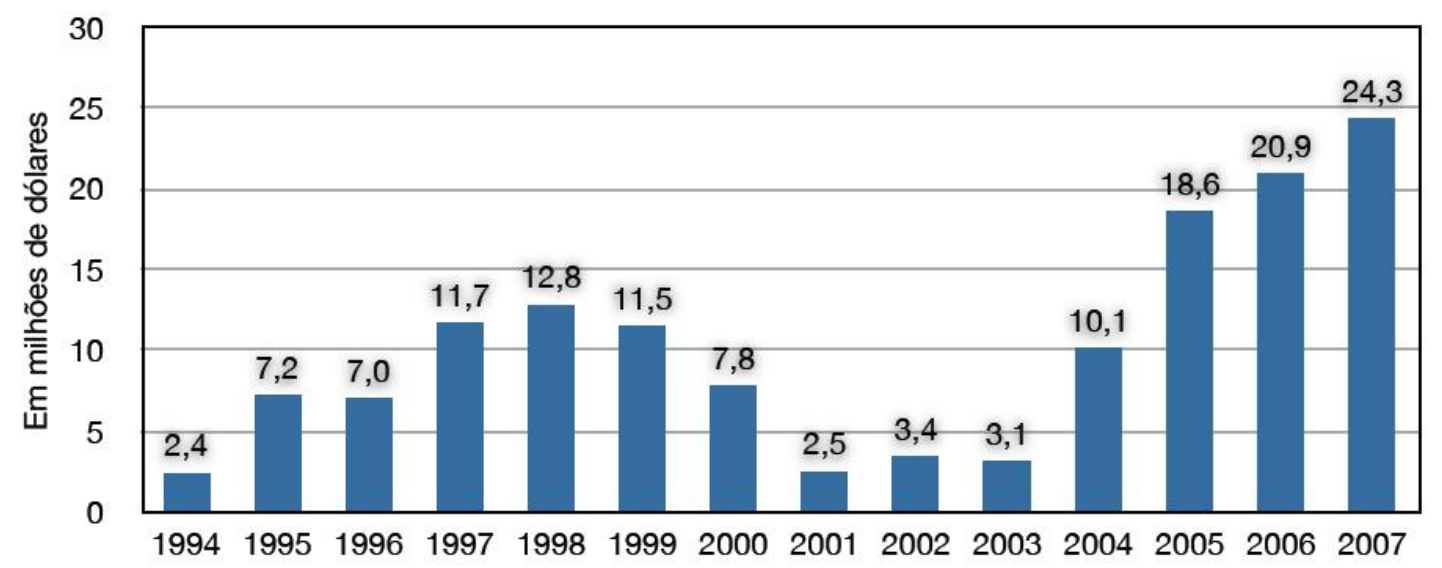

Figura 4.1: Vendas de ferramentas para sintese de alto nível(Menotti (2010)).

Há ainda uma grande controvérsia relacionada ao uso de linguagens de alto nível, como $C$ para sínteses de hardware reconfigurável. Em Edwards (2006), é questionado o uso do hardware. Os principais questionamentos estão relacionados aos objetivos pelos quais a linguagem $C$ foi desenvolvida, que diferem das necessidades encontradas em síntese de hardware, principalmente em pontos como paralelismo, clocks, administração de memórias, tipos de dados. Ainda segundo Edwards (2006), os compiladores não encontram o paralelismo necessários à síntese de hardware, em códigos seqüenciais.

Em Edwards (2006), Wang et al. (2006) são mostrados alguns compiladores que usam linguagens de alto nivel para sintese de hardware e os pontos principais a serem considerados, quando se utilizam essas linguagens para síntese de hardware. A seguir são descritos alguns desses compiladores.

\subsubsection{Pico Express}

Pico Express teve seu inicio em um projeto de pesquisa nos laboratórios da HP em 2010 (Buyukkurt et al. (2010)). Em seguida o compilador Pico Express foi comercializado pela empresa Synfora, fundada em Janeiro de 2003 (Synfora (2007b)), (Synfora (2007a)). Em junho de 2010, a empresa Synfora foi adquirida pela empresa Synopsys e a ferramenta Pico Express da Synfora deu origem a ferramenta Synphony C Compiler (SCC). SCC é uma ferramenta para 
síntese de hardware, que tem como entrada um programa escrito em linguagem $C$ e gera um hardware descrito no modelo Register Transfer Level (RTL) específico para um FPGA ou ASIC. Apesar da ferramenta Pico Express ter dado lugar a ferramenta SCC, continuar-se-á destacando Pico Express nessa tese, pois a ferramenta possui mais referência bibliográfica do que sua sucessora.

Segundo o fabricante, a ferramenta Pico Express possibilita a geração automática de arquiteturas otimizadas e sintetizáveis no modelo RTL a partir de algoritmos escritos em linguagem ANSI-C, e combina I ${ }^{1}$ configuráveis para uma implementação eficiente de algoritmos complexos. Além disso, o Pico Express permite produzir múltiplos projetos considerando diferentes características em cada projeto, como custo e desempenho. Um exemplo da geração de diferentes projetos pelo Pico Express pode ser visto na Figura 4.2 (Synfora (2007a)), (Synfora (2007c)).

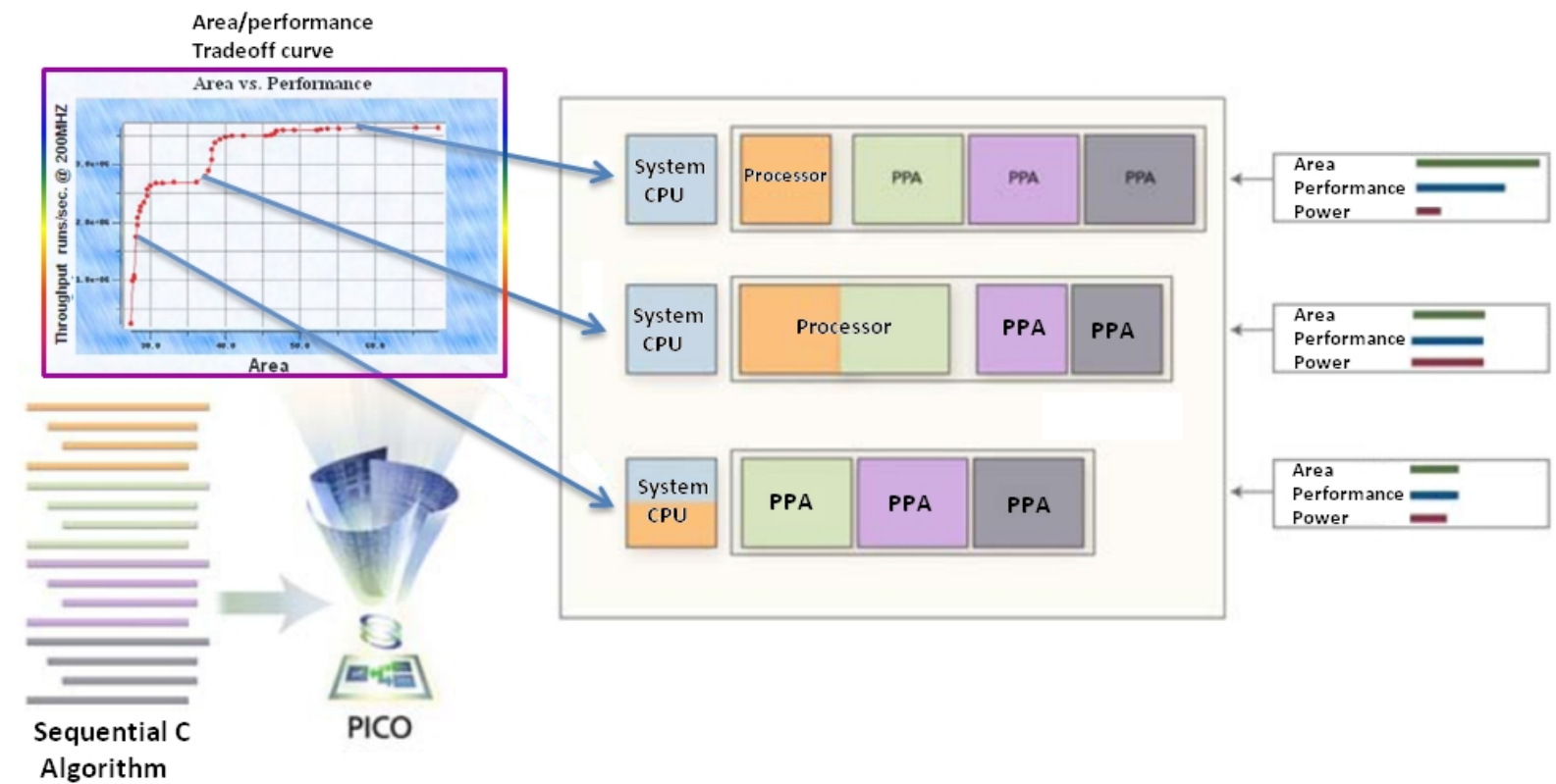

Figura 4.2: Possíveis implementações geradas pela ferramenta Pico Express (Synfora (2007c))

Na Figura 4.3 é mostrado o funcionamento geral do PICO Express. Como pode ser observado, Pico Express analisa o algoritmo escrito em linguagem $C$ e transforma as partes que necessitam de um processamento com maior desempenho, tais como multiplicação, em blocos que executam diretamente no FPGA - "accelerator 1 e 2". As partes do código que não necessitam de um processamento tão intenso, são compiladas e executadas em um processador de propósito geral embarcado no FPGA (Synfora (2007b)), (Synfora (2007a)).

\footnotetext{
${ }^{1}$ IP é um bloco lógico pré-fabricado, sintetizado e testado que pode ser utilizado na construção de projetos de sistemas em FPGA
} 


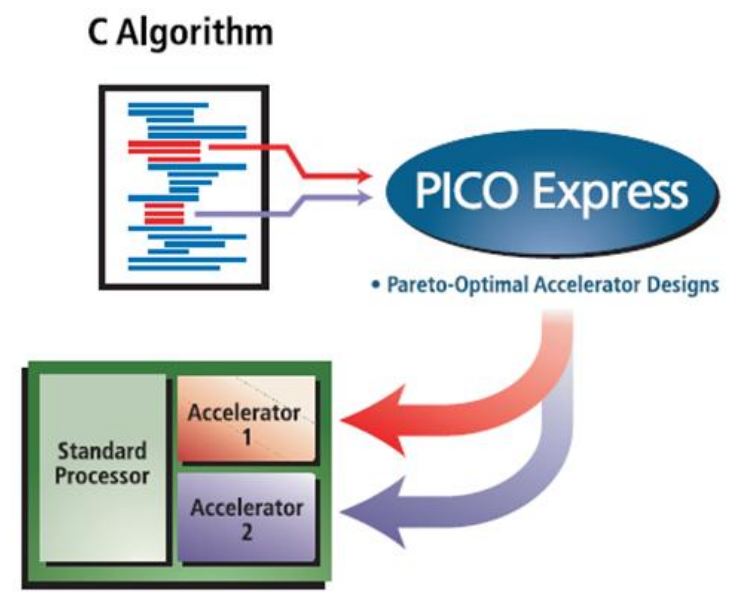

Figura 4.3: Visão geral da ferramenta Pico Express (Synfora (2007a))

\subsubsection{Galadriel e Nenya}

Galadriel e Nenya são compiladores que atuam juntos e tem como objetivo gerar um hardware reconfigurável constituído por um FPGA acoplado a uma ou mais memórias a partir de um algoritmo representado por bytecodes ${ }^{2}$ de JAVA (Cardoso (2000)), (Cardoso and Neto (2003)). O modelo de arquitetura gerado pelos compiladores Galadriel e Nenya pode ser visto na Figura 4.4. As memórias permitem que pequenas partes de um programa possam ser executadas diretamente no FPGA, sem intervenção de um processador. Desse modo, não são necessárias as transferências dos dados entre memória e processador. Na Figura 4.4, o sistema de hospedagem é um computador conectado a uma placa de prototipação.

O compilador Galadriel, a partir dos bytecodes do JAVA divide seu processo de compilação em diversas etapas gerando assim algumas representações intermediárias.

O objetivo principal do compilador Galadriel é extrair dos bytecodes do JAVA, o paralelismo existente no código da aplicação, por meio da análise de todas as representações intermediárias geradas. As representações intermediárias são: o grafo de fluxo de controle, em inglês Control Flow Graph (CFG); o grafo de dependência de controle, em inglês Control-Dependence Graph (CDG); o grafo de fluxo de dados Data Flow Graph (DFG); o grafo de dependência de dados, em inglês Data-Dependence Graph (DDG); o grafo de dependências de fusão, em inglês Merge-Dependence Graph (MDG); o grafo hierárquico de dependências de programa, em inglês Hierarchical Program Dependence

\footnotetext{
${ }^{2} \hat{\mathrm{E}}$ o resultado de um processo semelhante ao dos compiladores de código-fonte, porém, não é imediatamente executável. O bytecode irá ser interpretado numa máquina virtual, que fará a execução. Assim, o bytecode é um estágio intermédio entre o código-fonte (escrito numa linguagem de programação específica) e a aplicação final, sendo a sua vantagem principal a portabilidade.
} 


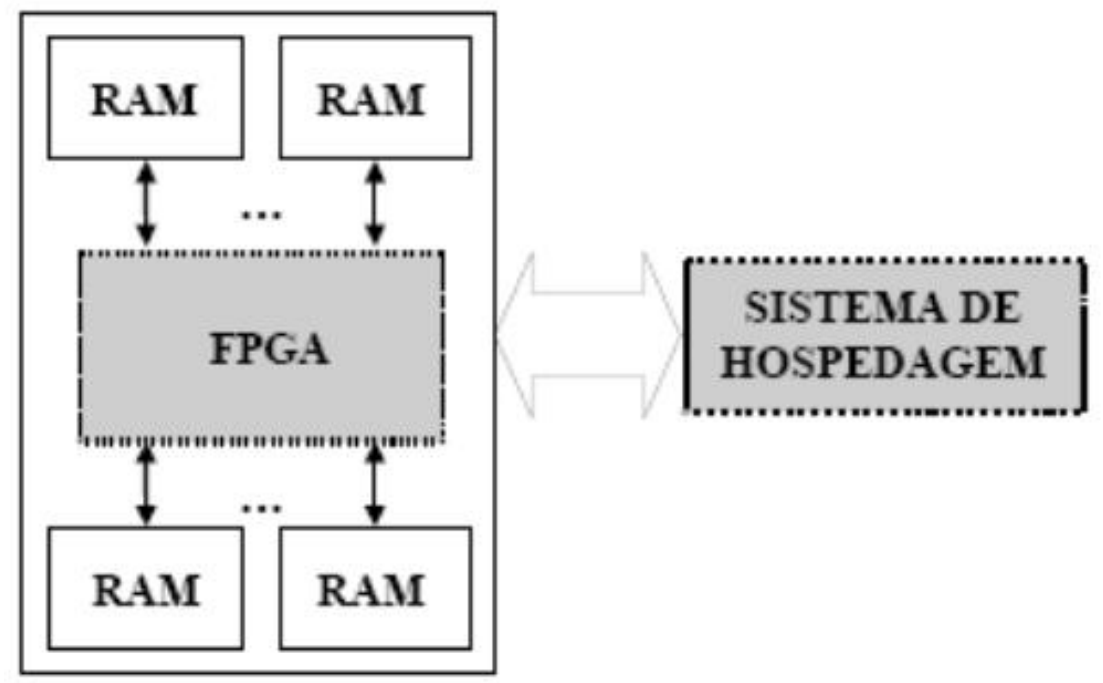

Figura 4.4: Arquitetura do hardware gerado pelos compiladores Galadriel e Nenya (Cardoso (2000), (Cardoso and Neto (2003))

Graph (HPDG), sendo que os dois últimos grafos foram propostos em (Cardoso (2000)), (Duarte (2006)).

O compilador Nenya gera um hardware reconfigurável a partir dos modelos de representação apresentados pelos arquivos gerados pelo compilador Galadriel. Nenya gera uma arquitetura constituída por um FPGA acoplado a uma ou mais memórias $R A M$ via barramentos independentes conforme descrito na Figura 4.4 (Cardoso (2000)). Nenya pode ser usado para compilar um programa completo ou segmento de código para hardware reconfigurável.

A Figura 4.5 representa o fluxo completo de compilação executados por Galadriel e Nenya. Na figura é possível ver que os bytecodes do Java são as entradas do compilador Galadriel que gera as representações intermediárias o $H P D G$ e o $D F G$, que servirão de entrada para o compilador Nenya, o qual produzirá o hardware reconfigurável.

\section{1.3 Spark}

Spark é uma ferramenta acadêmica, cujo objetivo é gerar arquivos VHDL a partir de algoritmos escritos em linguagem ANSI-C (Gupta et al. (2004)).

Síntese de alto nível, em inglês High-level synthesis (HLS) é um processo na ferramenta Spark para construir circuitos digitais a partir de descrições comportamentais do ANSI-C (Gupta et al. (2004)). Na Figura 4.6 pode ser visto um exemplo de HLS. HLS é portanto um processo para conversão de uma descrição comportamental em um circuito digital que consiste de data path, controle e elementos de memória.

A representação do programa fonte é feita através de grafos hierárquico de tarefas (HTG), pois retém informações sobre a estrutura do código, tais 


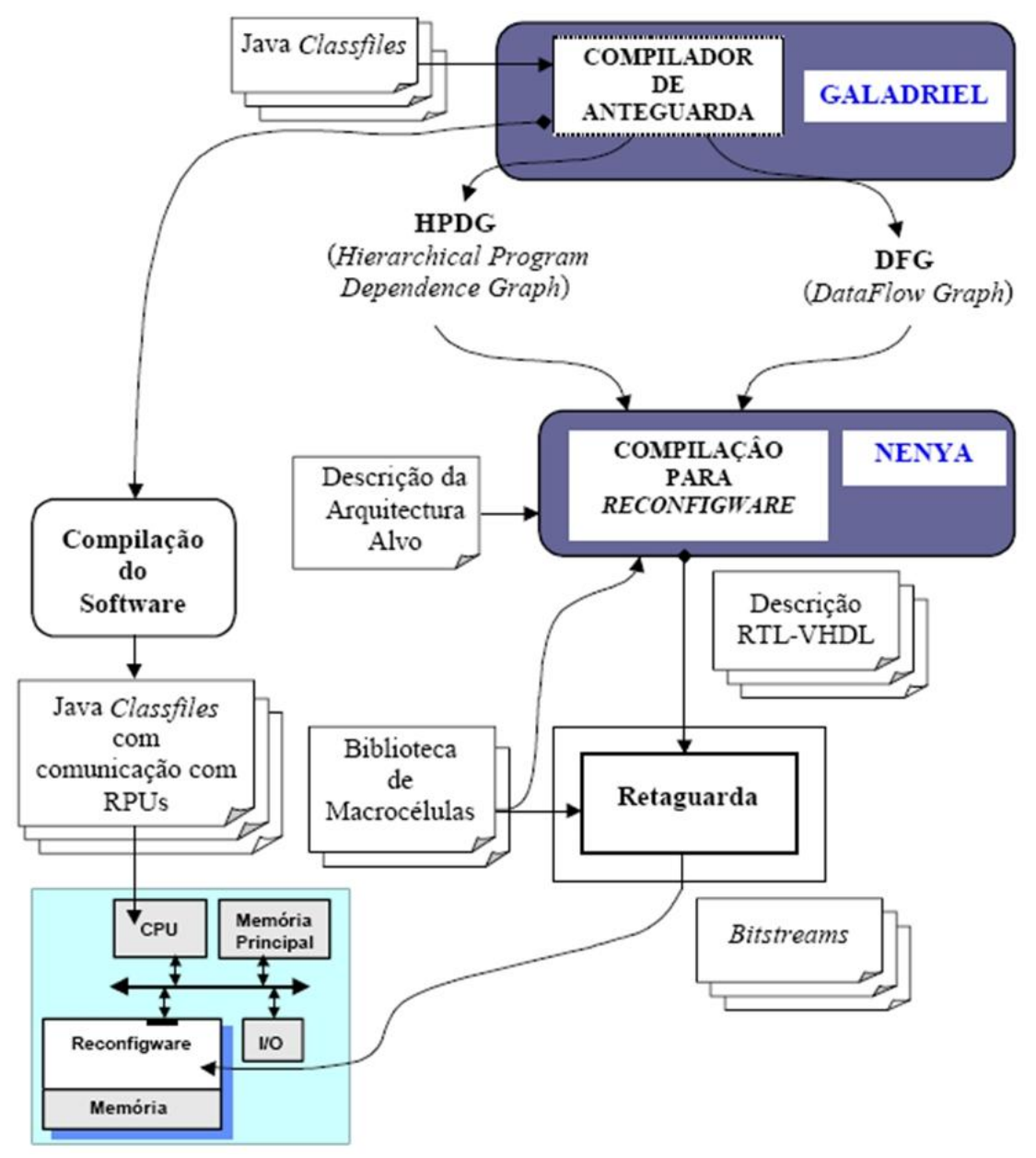

Figura 4.5: Fluxo de compilação feitos por Galadriel e Nenya (Cardoso (2000)) 
como fluxo de controle, hierarquia de controle, construções de ciclos, além de tornar possível otimizações no código que inclui, por exemplo, desenrolamento e fusão de ciclos, até eliminação de código morto (Duarte (2006)), (Gupta et al. (2004)).

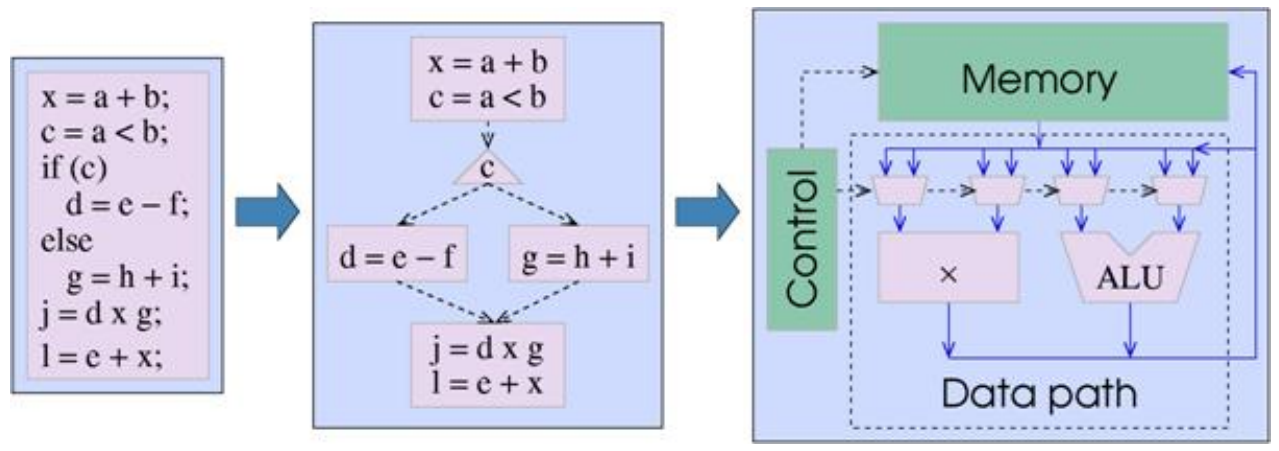

Figura 4.6: Visão geral de HLS(Gupta et al. (2004))

Como mostrado na Figura 4.7, além do código fonte $C$, o Spark também aceita como entrada informações adicionais, tais como recursos de bibliotecas de hardware, restrição de tempo, informações de tipos de dados e scripts usados pelo usuário como controle para guiar as heurísticas e transformações no código fonte. A partir das entradas, são geradas representações intermediárias do fluxo de controle e do fluxo de dados que são armazenados no módulo Intermediate Representation (IR).

Conforme descrito na Figura 4.7, as fases de paralelização e otimização foram organizadas em quatro grupos (Lopes (2007)), (Duarte (2006)), (Gupta et al. (2004)): PreSynthesis, Scheduling, Binding and Control Syntesis e Code Generation BackEnd que gera o código VHDL final.

Spark é particularmente interessante para aplicações multimídia e aplicações de processamento de imagens. Essas aplicações tipicamente consistem de operações aritméticas embutidas em loops alinhados com uma mistura complexa de construções condicionais, tais como if-then-else (Gupta et al. (2004)). Essas construções tem um grande efeito na qualidade dos resultados de síntese de hardware.

\section{1.4 DK - Design Suit}

DK Design Suit é uma ferramenta gráfica, originalmente desenvolvida pela empresa Celoxica e adquirida em seguida pela empresa Mentor Graphics (Mentor Graphics (2009)), para projetar e criar sistemas eletrônicos, tendo como base a plataforma Windows. Na Figura 4.8 é mostrado uma visão geral do DK - Design Suit. Conforme descrito na Figura 4.8, essa ferramenta utiliza a linguagem Handel- $C^{3}$ como entrada para a de descrição de projetos e gera

\footnotetext{
${ }^{3} \mathrm{~A}$ linguagem $C$ não possui sintaxe para descrição de sistemas paralelos. Handel-C, é baseada no padrão ANSI-C e é uma linguagem de alto nivel para implementação de projeto
} 


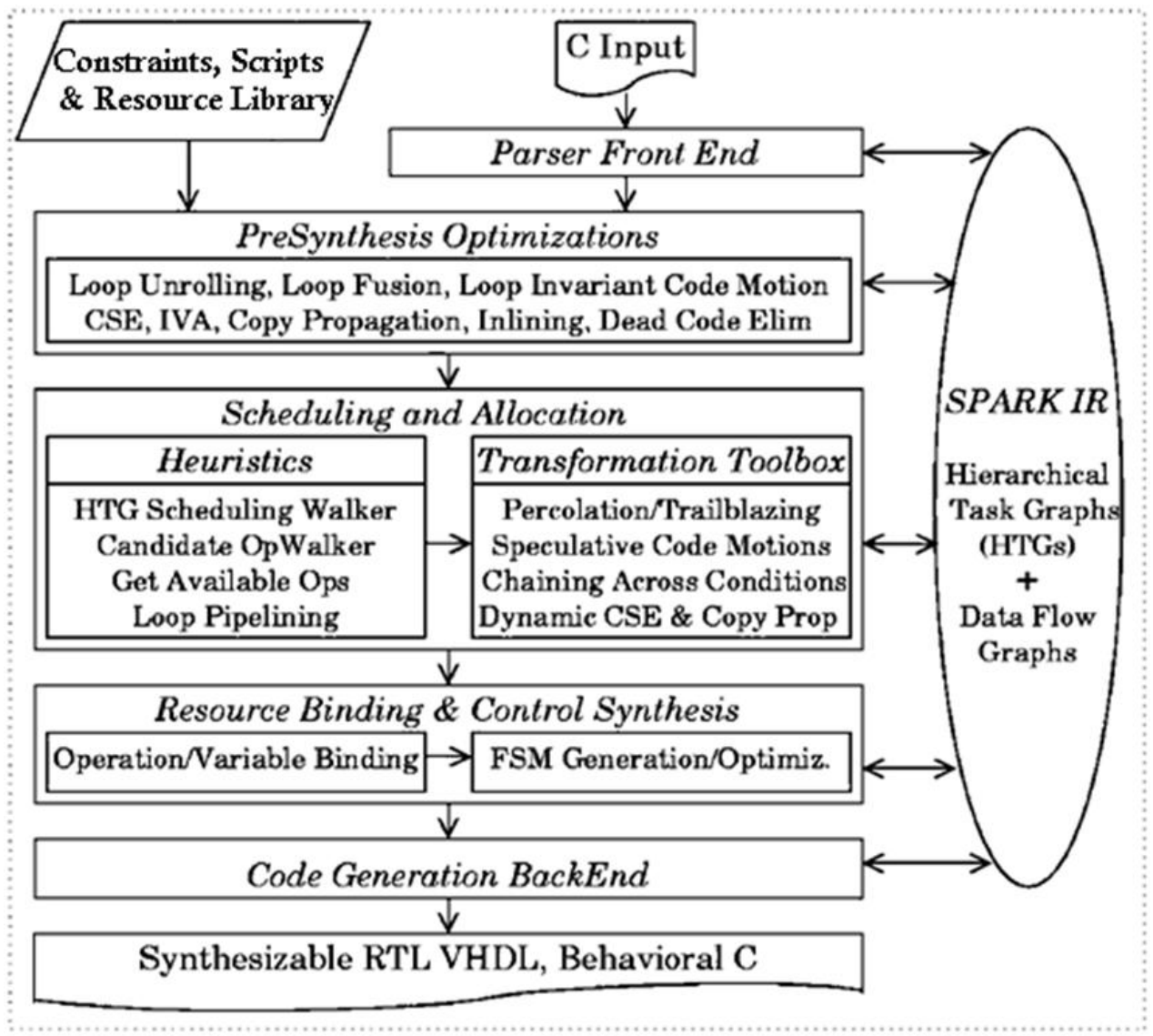

Figura 4.7: Visão geral do Spark HLS (Gupta et al. (2004))

representações finais em Electronic Design Interchange Format (EDIF) netlist, VHDL ou Verilog. DK Design Suit inclui também uma ferramenta de análise de perfil (profile) o que permite estimar gasto de área e atrasos de clock no projeto gerado (Celoxica Ltd, 2002). Ainda na ferramenta um depurador permite verificar os passos de execução no programa original, o conteúdo de qualquer variável no escopo do programa (Mentor Graphics (2010)), (Celoxica (2006)).

Depois de verificada as características e funcionalidades do sistema em linguagem de alto nível, como $C$, módulos individuais podem ser selecionados para implementação em hardware, utilizando-se o compilador Handel-C, o qual é responsável por traduzir algoritmos escritos em Handel-C para arquivos de descrição de hardware. A tradução para hardware inclui: tecnologia de mapeamento, estimação da lógica e otimização.

A tecnologia de mapeamento permite ao DK Design Suit gerar saída no formato EDIF para vários dispositivos da Xilinx e Altera, dentre eles, pode-se citar os principais dispositivos: Xilinx: Virtex-II Pro, Virtex-4, Virtex-5; Altera: Stratix, Stratix-II, Stratix-GX (Celoxica (2004)), (Celoxica (2006)), (Mentor Graphics

de hardware e para isso, traz extensões à linguagem $C$ (Celoxica (2004)). Segundo Cardoso (2000), Handel-C é um subconjunto de Occam2. Handel-C permite paralelização de operações, permitindo ao programador especificar concorrência a níveis de abstração baixos. O usuário pode escrever programas de forma seqüencial no Handel-C, para para obter-se o máximo de desempenho do hardware, deve-se usar as construções paralelas que Handel-C possui. 


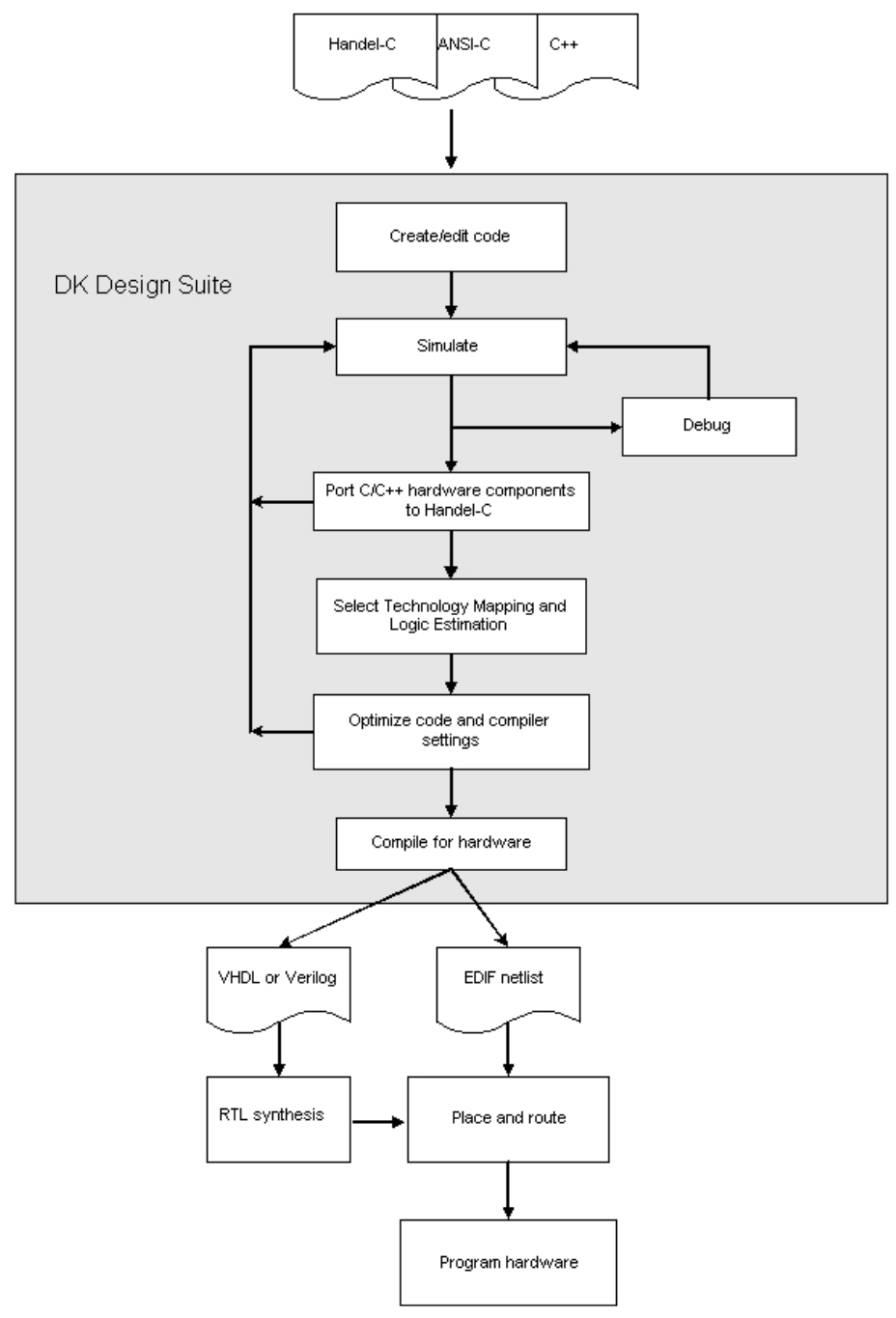

Figura 4.8: Visão geral do DK - Design Suit(Celoxica (2006)) 
(2010)).

\subsubsection{Impulse-C}

Há um problema fundamental quando se tenta programar um hardware de propósito geral (maquinas não Von Neumann), usando linguagem C. O problema é como expressar paralelismo. Processamento paralelo e programação de sistemas paralelos requerem suporte para concorrência na linguagem a ser utilizada e um entendimento pelo programador de como administrar múltiplos elementos computacionais quase independentes (Pellerin and Thibault (2005)). A linguagem $C$, como discutido nos capítulos anteriores, não contém tais características.

Linguagens de descrição de hardware, por outro lado, são projetadas para descrever sistemas altamente paralelos, embora possuam baixo nível de abstração (Pellerin and Thibault (2005)). Para fazer sentido programar em hardware baseado em FPGA, utilizando-se linguagem de alto nivel, é necessário criar um modelo de máquina abstrata e escolher um modelo de programação de software apropriada para essa máquina abstrata.

O modelo de programação usado pelo Impulse-C é baseado em processos que se comunicação de forma seqüencial, em inglês Communicating Sequential Processes (CSP). Segundo Pellerin and Thibault (2005), CSP foi proposto por (Hoare (1978)), (Hoare (1985)) e trata-se de um modelo de programação e de linguagem para descrever padrões de interações entre processos. Cada processo em um sistema pode representar um programa com software tradicional, que opera seqüencialmente, mas são limitados em termos de comunicação, uma vez que só podem comunicar-se por meio de canais de comunicação bem definidos. Ainda segundo Pellerin and Thibault (2005), cada programa em um CSP pode ser executado considerando-se uma relação processohardware, independente uns dos outros e atuar como uma máquina tradicional von-Neumann atuaria. Em lugar de ter um processo principal controlando a chamada de outros processos como sub-rotinas, a aplicação como um todo é projetada de tal forma que os movimentos dos dados por meio do sistema e por meio de vários processos na aplicação, são feitos via canais de dados com buffers. Enquanto cada processo em execução tiver recursos de acesso a memória local, para fazer o processamento e armazenar resultados intermediários, há pouca ou nenhuma comunicação entre os processos independentes, exceto via canais de dados que são chamados algumas vezes de streams ${ }^{4}$.

O modelo CSP, é conceitualmente similar ao modelo de programação a fluxo de dados, com facilidades para realizar a sincronização entre processos, por meio de buffer de dados e passagem de mensagens, simplificadando assim a

\footnotetext{
${ }^{4}$ canais para fluxos de dados
} 
geração de algoritmos paralelos em alto nível por meio de comunicação de dados, passagem de mensagens e mecanismos de sincronização entre processos.

Impulse-C faz uso do ANSI-C, particularmente das funções de bibliotecas para suporte à comunicação seqüencial de processos.

O Impulse-C teve seu inicio em pesquisa realizada no laboratório Los Alamos National Laboratories sobre a direção do Dr. Maya Gokhale. Esta pesquisa tornou pública o compilador Streams-C (Gokhale (2006)) e se tornou uma metodologia para aplicações baseadas em plataformas FPGA. Aplicações desenvolvidas usando Streams-C estão no domínio da criptografia de dados, processamento de imagens, astro-física entre outras (Pellerin and Thibault (2005)).

Funções de monitoramento incluídas nas bibliotecas do Impulse- $C$ permitem especificar processos em uma aplicação paralela para ser utilizada na depuração da aplicação. Os resultados dos processamentos são mostrados em janelas, enquanto a aplicação continua em execução.

Para a geração de hardware, o Impulse-C faz uso de um compilador de linguagem $C$ que é baseado na parte pública disponível da ferramenta Stanford Universal Intermediate Format (SUIF) (Hall et al. (1996)), e que também são combinadas com ferramentas de geração de código desenvolvida pela empresa Impulse Accelerated Technologies (Pellerin and Thibault (2005)).

Os elementos fundamentais da ferramenta Impulse- $\mathrm{C}$, como mostrado na Figura 4.9, são processos e streams.

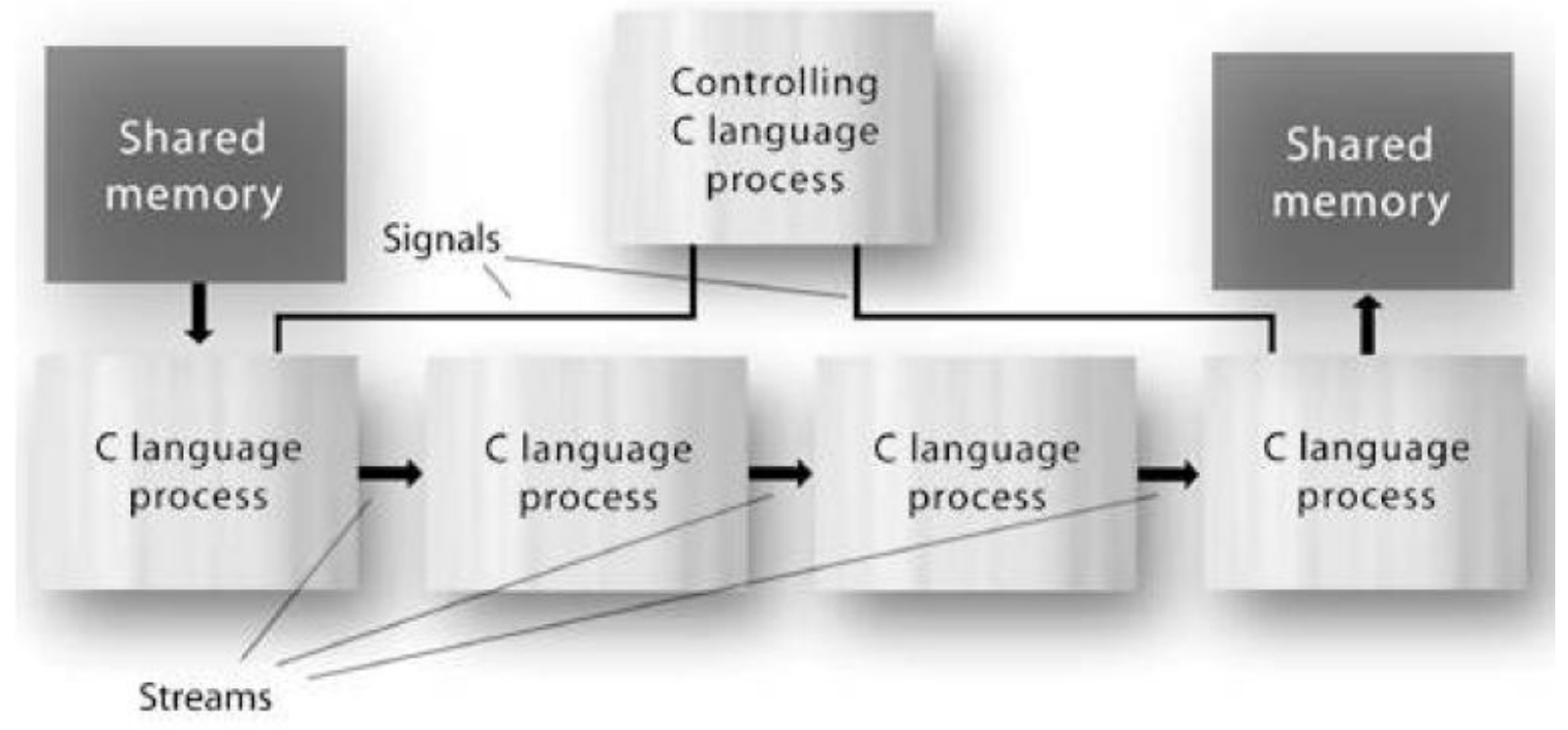

Figura 4.9: Streams, sinais e memória compartilhada(Pellerin and Thibault (2005))

Os processos são como sub-programas que aceitam vários dados, executam um processamento especifico e geram saídas, nas streams de dados, nas memórias ou outro recurso de sistema. Diferentemente dos sub-programas tra- 
dicionais, esses processos não são invocados durante a execução de um programa, mas estão sempre em execução e constantemente respondem quando dados aparecem em suas entradas (Pellerin and Thibault (2005)).

Como mostrado na Figura 4.9, o fluxo de dados entre os processos no Impulse-C são feitos por streams, mas em alguns casos por sinais e/ou memória compartilhada. Os sinais são usados quando o projetista necessita de um controle direto sobre o inicio e o termino de um processo e a sincronização dos processos para eventos externos. O uso de sinais possibilita ao projetista comunicar informações de um processo para outro, usando o esquema de passagem de mensagens, por meio das funções "co_signal_post" e "co_signal_wait". Quando um processo encontra uma função "co_signal_wait", ele fica bloqueado a espera de uma mensagem vinda de outro processo pela função "co_signal_post". Isso garante o sincronismo entre processos. A função "co_signal_wait" é bloqueante, portanto o processo que recebe este sinal ficará bloqueado até receber o sinal "co_signal_post" (Pellerin and Thibault (2005)).

O uso da memória compartilhada é uma alternativa à utilização de streams por passagem de dados. A função "co_memory_create" aloca um número específico de bytes da memória para serem lidos e/ou escritos. Vários processos podem ler e escrever na memória compartilhada. As funções "co_memory_readblock" e "co_memory_writeblock" lêem e escrevem dados na memória, respectivamente.

As bibliotecas do Impulse-C suportam plataformas de FPGA, como os da família Virtex da Xilinx, com os processadores MicroBlaze e PowerPC, bem como plataformas de FPGAs Altera, com os processadores Nios e Nios-II. Impulse$C$ também pode ser usado para gerar módulos de hardware que não fazem interface com processos de software.

Na Figura 4.10 é descrito um ambiente de desenvolvimento, o CoDeveloper, que permite que uma descrição em linguagem Impulse-C seja compilada para FPGAs, previamente especificadas na Plataform Support Package. A Plataform Support Package permite selecionar o fabricante, família e algumas características específicas tais como o processador embarcado e o barramento usado para comunicação entre os componentes internos no FPGA. Com essas informações, o CoDeveloper pode gerar o projeto completo para a plataforma FPGA escolhida, tal como código fonte para o processador embarcado, arquivo de descrição de hardware para o FPGA, arquivo de descrição de hardware contendo a interface no FPGA e drivers para que o software gerado para o processador embarcado possa se comunicar eficientemente com o projeto no FPGA. Os arquivos de descrição de hardware correspondente ao barramento utilizado também são gerados.

Na Figura 4.11 é mostrado o ambiente CoDeveloper, com uma aplicação 


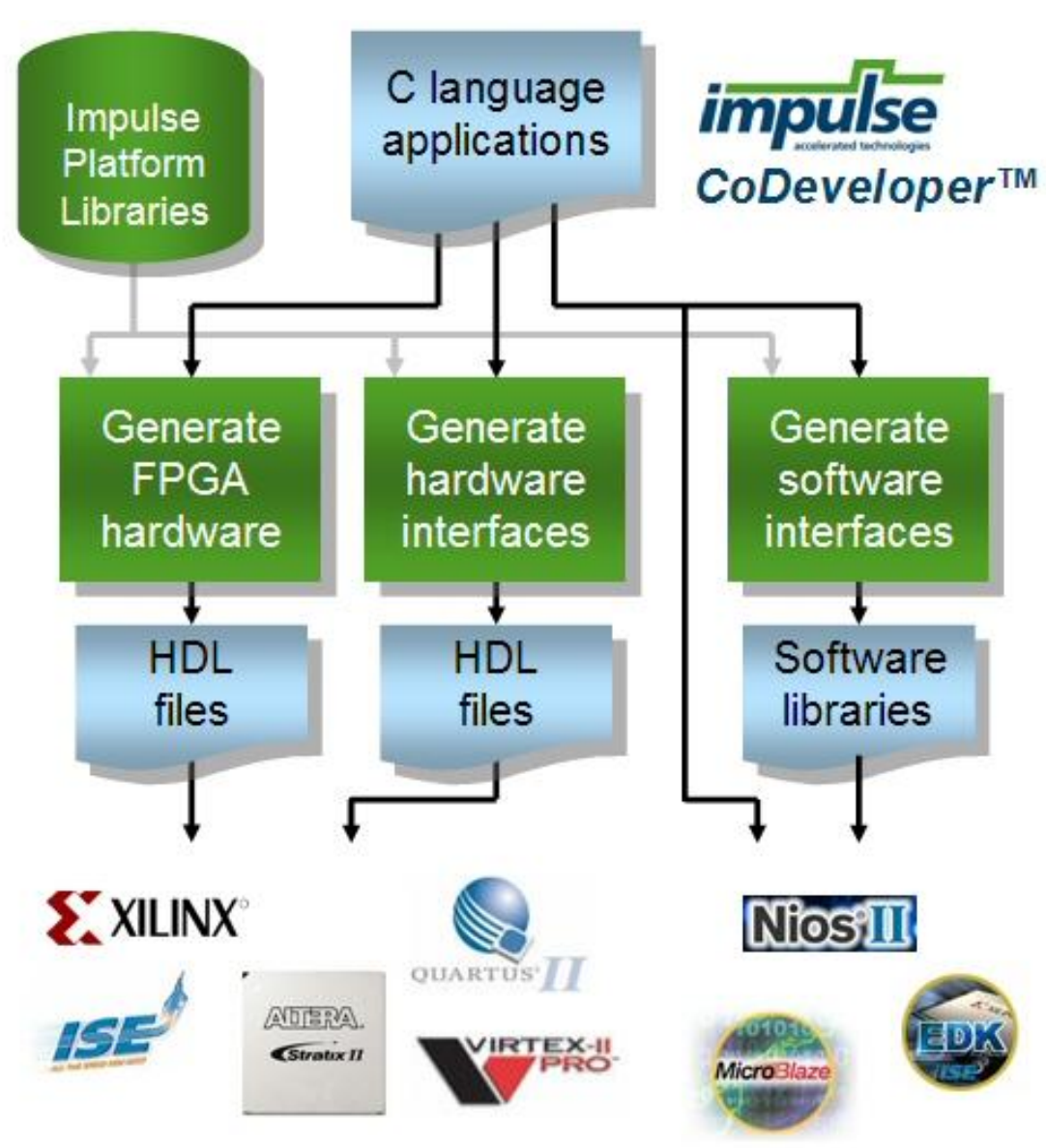

Figura 4.10: Ambiente completo do CoDeveloper (Pellerin and Thibault (2005))

chamada HelloWorld. Em source files na caixa à esquerda na figura, pode ser visto os arquivos que compõem as descrições das funcionalidades dessa aplicação: HelloWorld.c, HelloWorld_sw.c e HelloWorld_hw.c. No lado esquerdo dos nomes dos arquivos, pode ser visto um ícone sw e um ícone $h w$. O ícone $s w$ indica que o processo servirá como testbench, com o objetivo de validar o comportamento da aplicação ou pode ser usado para gerar um programa para ser executado em um processador embarcado no FPGA; $h w$ indica que o arquivo será sintetizado para o FPGA escolhido em Plataform Support Package. A simulação do comportamento da aplicação pode ser feita por ferramentas de desenvolvimento $C$, tais como Microsoft Visual Studio e gcc ou ainda pelo próprio ambiente de implementação do CoDeveloper, por meio do ícone launch simulation executable, indicado pela seta na Figura 4.11. O resultado da simulação é mostrado no prompt do MS-DOS, como qualquer programa compilado e executado em um compilador $C$.

A Figura 4.12 permite a visualização do ambiente de monitoramento do CoDeveloper, chamado Application Monitor. Por meio do Application Monitor é possivel visualizar a execução dos processos, tanto de hardware quanto de software; processos individuais ou todos ao mesmo tempo, e a interface entre os processos (entradas/saídas, através de streams, sinais ou memória 


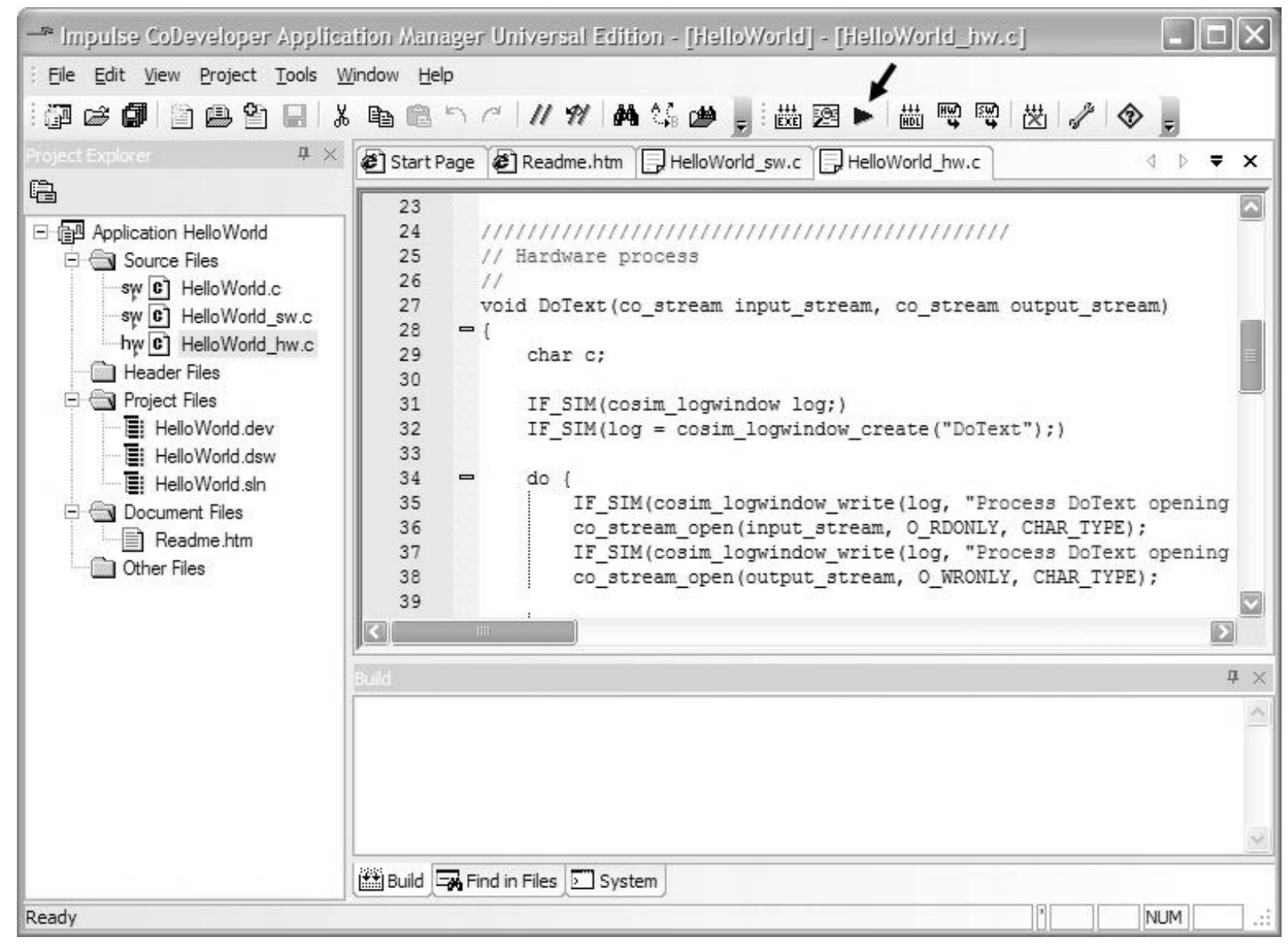

Figura 4.11: Ambiente de implementação do CoDeveloper (CoDeveloper Application Manager) (Pellerin and Thibault (2005)) 
compartilhada).

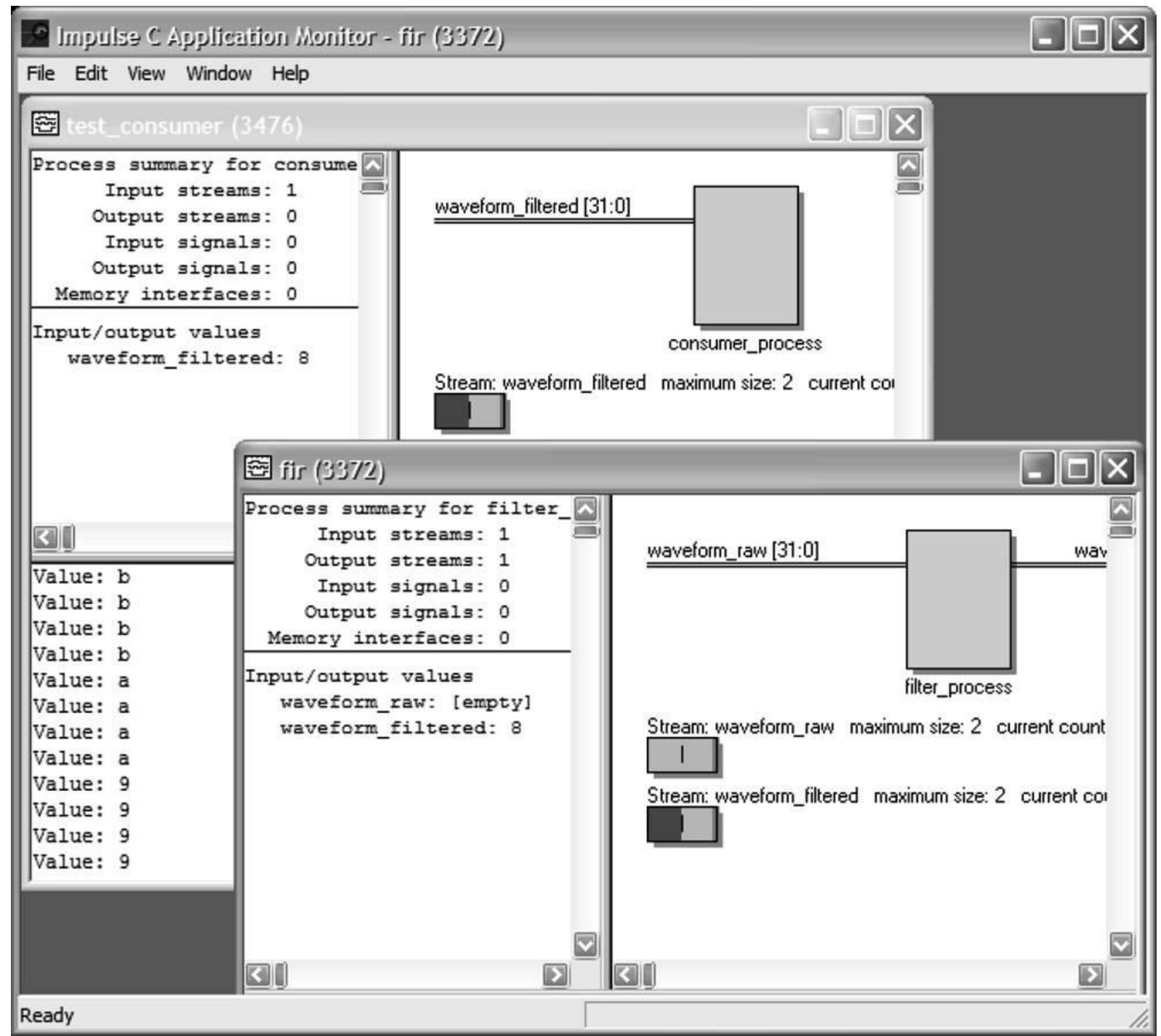

Figura 4.12: Exemplo do Application Monitor (Pellerin and Thibault (2005))

Há certas operações que são expressas em $C$ que são difíceis ou impraticáveis para serem implementadas em FPGA. Os seguintes tipos de instruções em $C$ e construções não são suportadas ou são minimamente suportadas em processos pelo Impulse-C: recursão, uma vez que um processo de hardware não pode chamar ele mesmo, direta ou indiretamente; chamada de funções, com exceção às funções pré-definidas pelo Impulse-C; e ponteiros que devem ser resolvidos em tempo de compilação (Pellerin and Thibault (2005)). 


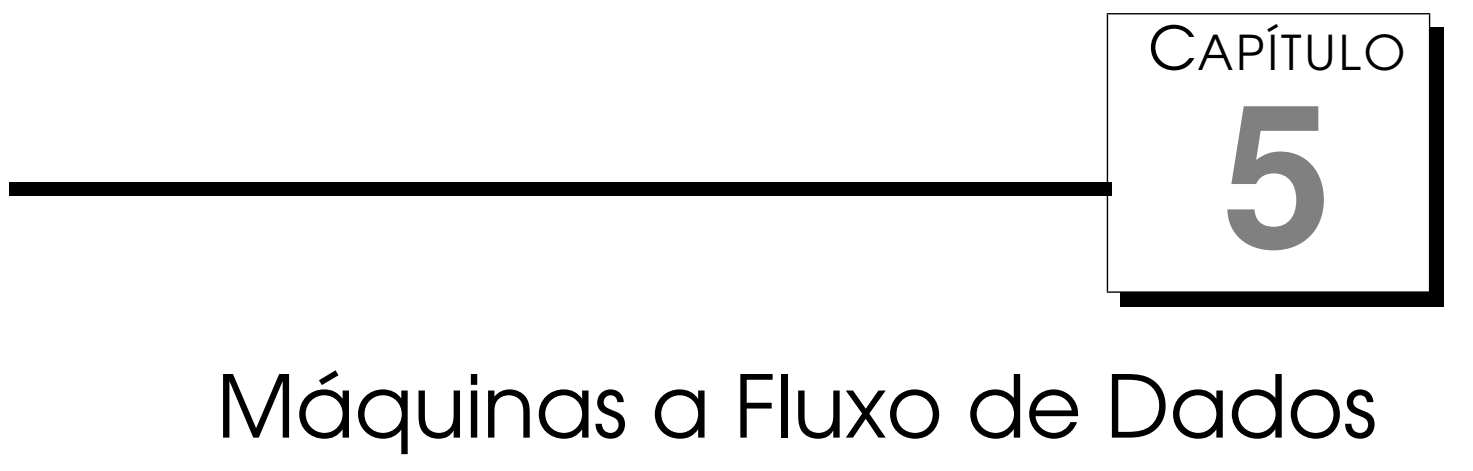

O progresso tecnológico constantemente necessita de computadores cada vez mais velozes para satisfazer as novas exigências que surgem com o avanço da ciência. Segundo MARQUES (1993), uma das formas de se atender tal demanda é a construção de máquinas com o uso de arquiteturas paralelas. Essas máquinas podem chegar a milhares de processadores e são chamadas de computadores maciçamente paralelos ou supercomputadores. Arquiteturas de alto desempenho em geral estão centradas em conceitos de processamento paralelo. Em máquinas paralelas que utilizam o modelo de von-Neumann, a seqüencia de instruções é organizada explicitamente pelo programador ou compilador, o que dificulta a identificação das partes que podem ser executadas em paralelo, tanto por parte do projetista, como por parte de programas especializados.

No sistema a fluxo de dados, a escolha das instruções a serem executadas acontece de maneira não determinística, feita em tempo de execução, limitado apenas pela ordem implícita no grafo de dependência de dados. Assim, o paralelismo é obtido se mais que um nó do grafo está ápto a ser executado, como discutido nos capítulos anteriores. Além disso o modelo a fluxo de dados facilita a programação da máquina, sem a necessidade de usuários especializados em programação concorrente ou paralela (MARQUES (1993)).

Algumas máquinas foram desenvolvidas no modelo a fluxo de dados (J.R. and Gurd (1985)), (Shimada et al. (1986)), (Dennis et al. (1980)), (Dennis (1974)), (Dennis and Misunas (1975)), (Dennis et al. (1980)), (Davis (1978)), (Sakai et al. (1989)), (Kishi et al. (1983)), (Grafe et al. (1989)), (Silva (1992)), (MARQUES (1993)), (Sankaralingam et al. (2003)), (Papadopoulos and Culler (1998)), (Culler et al. (1991)), (Swanson et al. (2003)), (Swanson et al. (2007)), 
(Swanson et al. (2006)), (Burger et al. (2004)) e serão descritos nas próximas seções.

\section{1 O modelo Fluxo de Dados}

O modelo de computação a fluxo de dados surgiu como uma nova proposta de processamento paralelo no final dos anos 60, pesquisado inicialmente nos Estados Unidos (1968), motivadas por um trabalho pioneiro, publicado por Dennis (1974), cuja idéia era a implementação de um sistema de computador altamente paralelo, que executasse simultaneamente vários fragmentos de um programa, porém este alto grau de atividades concorrentes deveria ser encontrado sem nenhum sacrifício (Dennis and Misunas (1975)), (Silva (1992)).

A criação de uma linguagem básica para o modelo a fluxo de dados contribuiu significativamente na construção de programas corretos, servindo como guia para as pesquisas em arquiteturas de computadores avançados. A linguagem utiliza grafos dirigidos (ou orientados), onde os nós representam as operações, por exemplo, adição e multiplicação e os arcos que interligam esses nós representam as dependências entre as operações.

Qualquer expressão lógica ou aritmética pode ser traduzida em uma máquina a fluxo de dados acíclico (Arvind and Culler (1986)). Na representação, a execução de uma operação é habilitada pela disponibilidade dos dados. O término de execução de uma operação libera dados para os elementos do programa cuja execução dependem deles.

As pesquisas sobre arquiteturas a Fluxo de Dados foram descontinuadas nos anos (1990) (Arvind and Gostelow (1982)), (Dennis (1998)), (Dennis et al. (1984)). Nos anos 80, acreditava-se que a arquitetura a fluxo de dados substituiria os modelos tradicionais, porém, os trabalhos entre os anos 80 e 90 mostraram a dificuldade da construção dessas máquinas. As pesquisas em arquiteturas a fluxo de dados declinaram nessa época em função principalmente das restrições de hardware (Johnston et al. (2004)).

Na Figura 5.1 é mostrado um exemplo de um programa seqüencial tradicional escrito no modelo de máquina a fluxo de dados. Na Figura 5.1 a é descrito um fragmento de código de programa seqüencial e na Figura 5.1b é descrito o mesmo código representado no modelo máquina a fluxo de dados. As setas na figura representam $\operatorname{arcos}^{1}$, os círculos representam os nós ${ }^{2}$ e o quadrado representa um valor constante. Ainda na Figura 5.1, as letras X e Y representam as entradas de dados nos nós e a letra $\mathrm{C}$ representa a saída de dado. Sempre que mais de uma seta emana de uma dada entrada, isso significa que

\footnotetext{
${ }^{1}$ os arcos são ponteiros para o envio de pacote de dados

${ }^{2}$ os nós correspondem aos operadores ou instruções a serem executadas
} 


$$
\begin{aligned}
& A:=X+Y \\
& B:=Y / 10 \\
& C:=A * B
\end{aligned}
$$

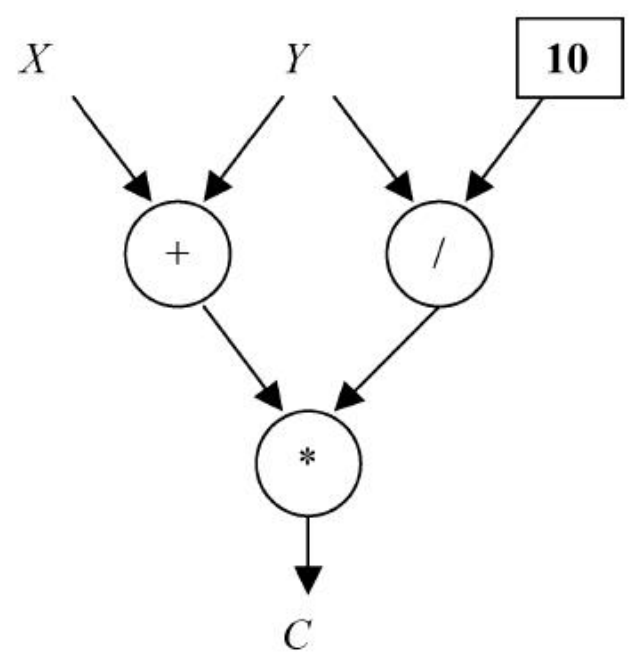

(b)

Figura 5.1: Exemplo de um programa seqüencial tradicional versus máquina a fluxo de dados (Johnston et al. (2004))

um único valor é duplicado e transmitido para cada caminho (Johnston et al. (2004)), (Dennis (1974)), (Silva (1992)).

Segundo Arvind and Culler (1986), o modelo de computação a fluxo de dados oferece um poderoso formalismo para descrever computação paralela. Existiram um número considerável de arquiteturas a fluxo de dados diferentes. Embora cada máquina a fluxo de dados possuísse uma linguagem de maquina diferente, todas foram baseadas no mesmo princípio.

A modelo de execução a fluxo de dados oferece duas propriedades atrativas para processamento paralelo (Lee and Hurson (1994)): o assincronismo e o auto-escalonamento. $\mathrm{O}$ assincronismo existente nas máquinas a fluxo de dados está presente na disponibilidade dos dados e a sincronização das atividades paralelas é implícita nesse modelo. Isto é, um programa para uma máquina de fluxo de dados não especifica a ordem real de execução das operações, mas dinamicamente realiza uma ordem particular de execução (Kamienski (1994)). No alto-escalonamento, as instruções a fluxo de dados não necessitam ser seqüenciais, portanto, a representação gráfica de um programa a fluxo de dados torna implícito todo o paralelismo existente, eliminando assim a necessidade de gerenciar explicitamente a execução paralela.

Para a computação de alto desempenho, as vantagens da abordagem a fluxo de dados sobre o método a fluxo de controle decorre do paralelismo inerente incorporados ao nível de instruções. Isto possibilita a exploração eficiente do paralelismo de granularidade fina nos programas (Broy (1987)).

Segundo Veen (1986), Whiting and Pascoe (1994), não há uma definição exata para se distinguir máquinas a fluxo de dados de todos os outros computadores. Considera-se que máquinas a fluxo de dados são todos os com- 
putadores programáveis dos quais o hardware é otimizado para computação paralela dirigida por dados. Computação dirigida por dados significa que a ativação de um processo só é determinada pela disponibilidade de seus dados de entrada. Segundo MARQUES (1993), há duas características que distinguem o modelo computacional a fluxo de dados do modelo von-Neumann, essas características são a ausência de um contador de programa e de memória global atualizável.

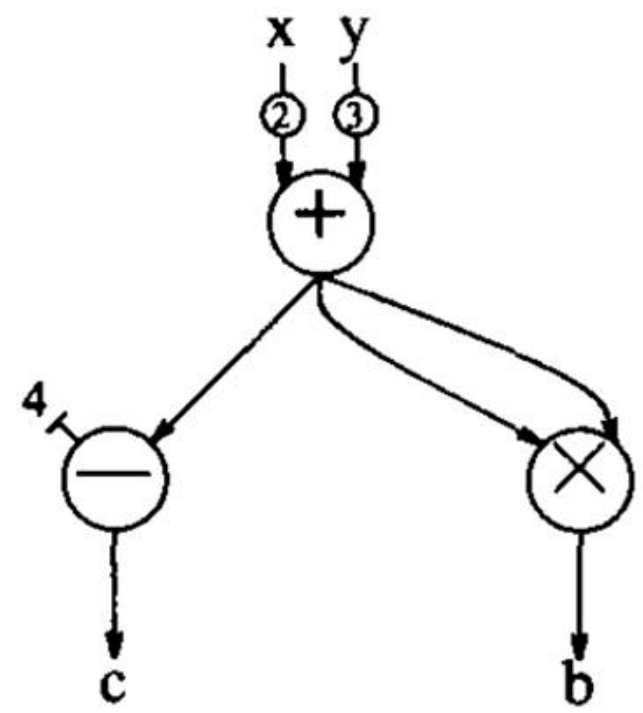

(a)

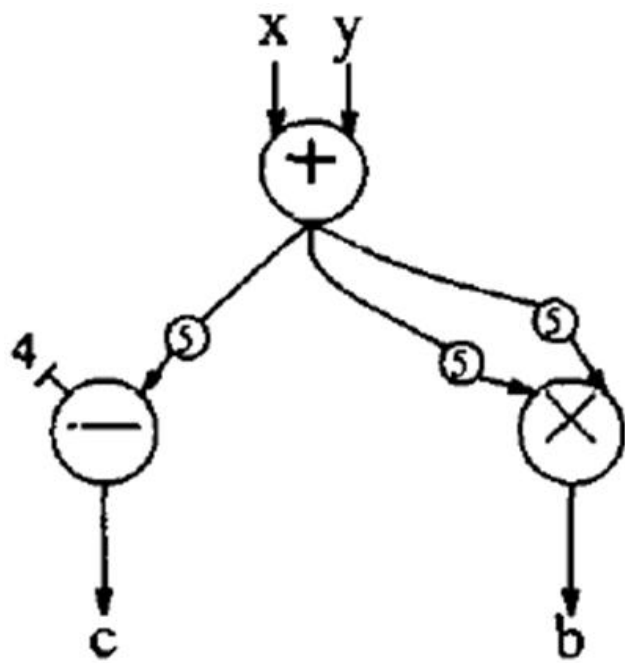

(b)

Figura 5.2: Processo de execução de um programa a fluxo de dados (Veen (1986))

Nas arquiteturas a fluxo de dados, as instruções são conhecidas como nós e os dados como tokens. Um nó produtor é conectado a um nó consumidor por um arco, e a execução de uma instrução é chamada de disparo do nó, que acontece geralmente quando todos os tokens estão presentes nas entradas de um nó (Veen (1986)). O termino de execução de uma operação libera tokens para os nós do grafo, cuja execução depende deles (Silva (1992)). Assim, podese dizer que a execução de uma instrução ou nó provoca dois efeitos: os tokens da entrada são consumidos e um novo token correspondente ao resultado daquela operação é inserido no arco de saída do referido nó, conforme descrito nas Figuras 5.2a e 5.2b, respectivamente.

Como descrito na Figura 5.2, os valores nos dados são transportados pelos tokens, os quais fluem ao longo dos arcos. Um nó pode disparar quando um token está disponível em cada arco de entrada no nó. Guando o nó é disparado, os tokens são removidos de cada arco de entrada, o resultado é computado usando esses valores e um token contendo o resultado é produzido em cada arco de saída daquele nó (Arvind and Culler (1986)).

Uma máquina a fluxo de dados pode ser visto como uma linguagem de 
máquina para uma máquina paralela, onde o ciclo básico de instruções é dado por:

1. detecta quando uma instrução é ativada (isto é equivalente a coletar os valores armazenados no token;

2. determinar a operação a ser executada (exemplo: buscar a instrução);

3. processar os resultados;

4. gerar o token resultante.

Este é um ciclo básico de instruções para qualquer máquina a fluxo de dados, porém, há uma flexibilidade grande nos detalhes de como este ciclo é executado (Arvind and Culler (1986)).

Em resumo, as principais características do modelo de fluxo de dados são (Kamienski (1994)): uma instrução está pronta para executar no momento em que todos os seus operandos estiverem disponíveis; resultados intermediários ou finais são passados diretamente entre instruções; não existe o conceito de memória de dados, de acordo com a noção tradicional de variável; a seqüência de execução das instruções é determinada somente pelas dependências de dados, abrindo um potencial muito grande para processamento paralelo.

Uma situação que pode ocorrer nas máquinas a fluxo de dados é a reentrância ${ }^{3}$, ou seja, um nó pode disparar repetidamente. Na Figura 5.3 são ilustrados os problemas que podem acontecer em grafos cíclicos (MARQUES (1993)). O grafo descrito na Figura 5.3(a) entrará em deadlock a menos que seja possível iniciar com um dado no arco de retorno. Já o grafo da Figura 5.3(b) nunca irá acabar a execução. Embora estes exemplos não sejam casos reais, estes problemas de fato podem acontecer em qualquer grafo cíclico. Para evitar estes problemas, algumas medidas devem ser tomadas e são descritas a seguir.

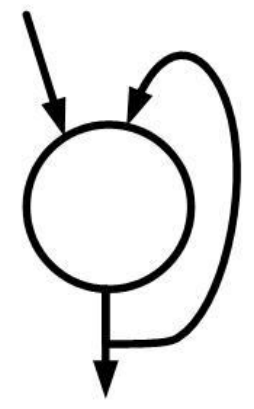

(a)

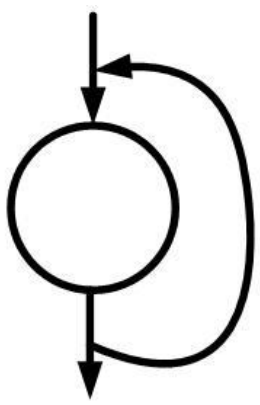

(b)

Figura 5.3: Problemas em grafos cíclicos (Silva (2011b))

\footnotetext{
${ }^{3}$ grafos que possuem ciclos
} 
O modo que a reentrância é manipulada define uma classificação para as máquinas a fluxo de dados, são elas: estáticas e dinâmicas (Veen (1986)); (Arvind and Culler (1986)).

Há quatro maneiras distintas de se tratar o problema da reentrância em um sub-grafo que determina se uma máquina a fluxo de dados é estática ou dinâmica (MARQUES (1993)), (Silva (2011b)):

Lock : atua como uma fechadura que impede a inicialização de uma nova iteração antes da anterior ter sido concluída.

Acknowledge : arcos extras de reconhecimento são inseridos entre os nós do consumidor e do produtor. Estes arcos asseguram que nenhum arco conterá mais do que um token em seus arcos. Desse modo, o grafo tornase seguro.

Code Copying : cada iteração é executada em uma instância separada do grafo reêntrante. Este método requer uma máquina com facilidades para criar instâncias e dirigir os tokens para as instâncias apropriadas.

Tagged Tokens : é uma maneira mais eficiente de implementar code copying, partilhando a comparação do nó entre as diferentes instâncias, sem confundir seus tokens. Isto é realizado adicionando-se a cada token uma tag, que identifica para qual instância o token deverá ser dirigido.

Máquinas fluxo de dados que manipulam a reentrância por lock ou acknowledge são chamadas de estáticas, aquelas que manipulam a reentrância por code copying ou tagged tokens são chamadas de dinâmicas (MARQUES (1993)), (Veen (1986)). Assim, há duas implementações de arquitetura do modelo abstrato a fluxo de dados: a arquitetura estática e a dinâmica (Arvind and Culler (1986)), (Silva (1991)).

Segundo Silva (1992), a utilização ou não de "buffers" no grafo é que caracterizam máquina a fluxo de dados dinâmica ou estática, respectivamente. Arquitetura estática permite apenas um token por arco na máquina a fluxo de dados, pelo fato de não existirem "buffers" para armazenamento temporário dos tokens, o que impede o fluxo natural dos dados pelo programa. As máquinas dinâmicas são uma evolução das máquinas estáticas, por nelas existirem os "buffers" para armazenamento temporário dos tokens, permitindo assim mais que um token no arco o que significa utilizar toda a potencialidade da programação a fluxo de dados, exigindo, no entanto um tratamento mais complexo na implementação do sistema, pois é preciso além de armazenar os dados, identificar os parceiros dos dados que disparam uma operação (Arvind and Culler (1986)), (MARQUES (1993)), (Silva (1992)). 
A arquitetura de uma máquina a fluxo de dados típica consiste de um número de elementos de processamento, os quais podem comunicar-se uns com os outros. Os nós de um programa a fluxo de dados são freqüentemente representados na forma de um gabarito contendo a descrição do nó e espaço para os tokens de entrada (Veen (1986)). A Figura 5.4 mostra um gabarito correspondendo ao operador "soma".

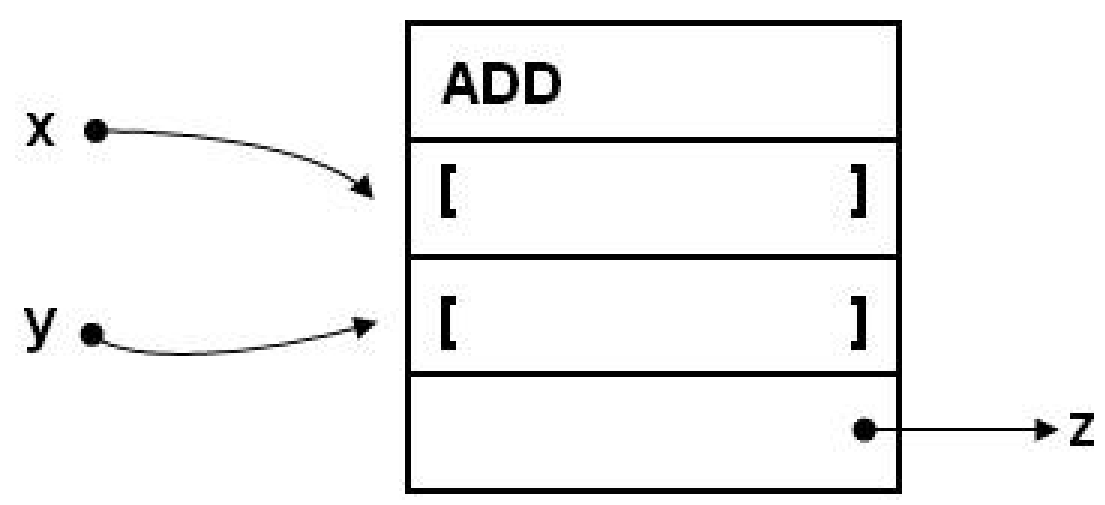

Figura 5.4: Gabarito da operação soma (Silva (1992))

Existem quatro campos no gabarito descrito na Figura 5.4: um para o código de operação especificando a operação a ser executada; dois receptores, que esperam para ser preenchidos com valores de operandos; e campo destino, que especifica o que fazer com o resultado da operação sobre os operandos (Silva (1992)).

Na Figura 5.5 é mostrado o diagrama funcional de uma máquina a fluxo de dados típica (Veen (1986)). Na figura, a unidade de habilitação enabling unit aceita um token e o armazena no endereço do nó correspondente na memory for tokens and nodes. Se o nó no qual o token foi armazenado se tornar habilitado para execução, os tokens são retirados da memória juntamente com informações sobre aquele nó, montando um pacote de informação executável que é enviado para a unidade funcional functional unit. Na unidade funcional, o pacote é analisado para ver que tipo de operação será executada e que tipo de resultado será gerado, gerando portanto, tokens de saída que são encaminhados para a enabling unit e o processo se repete até a execução completa de um grafo.

Uma vez que a unidade de habilitação e a unidade funcional trabalhem em paralelo, elas são freqüentemente referenciadas como pipeline circular. Os módulos dedicados a "buffering" ou comunicação foram deixados de fora do diagrama exposto na Figura 5.5.

Como discutido no inicio desse capítulo, as maquinas a fluxo de dados podem diferenciar nas suas arquiteturas. É o caso da máquina descrita na Figura 5.6 onde a unidade de habilitação é separada em duas unidades: a 
unidade de matching e a unidade de fetching (Veen (1986)).

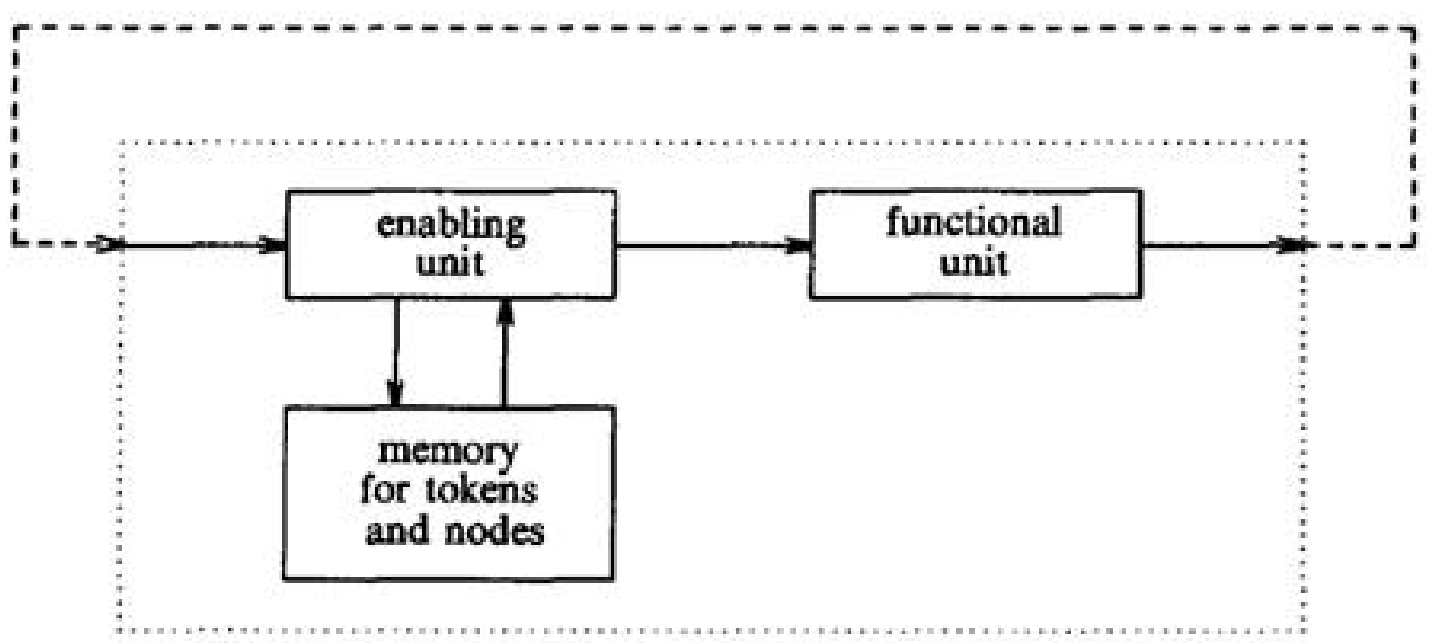

Figura 5.5: Diagrama funcional de uma máquina a fluxo de dados típica (Veen (1986))

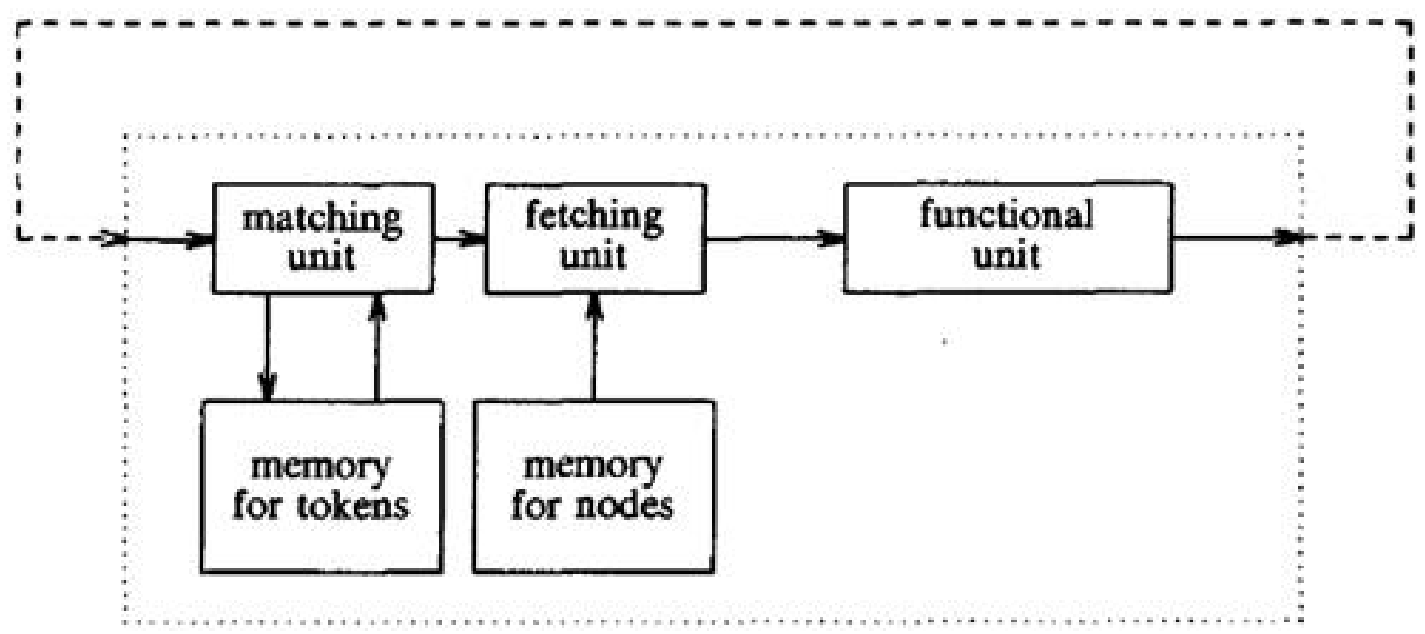

Figura 5.6: Diagrama funcional de uma máquina a fluxo de dados típica utilizando tagged-token (Veen (1986))

A matching unit tem como função identificar dados parceiros. O método utilizado para a identificação de dados parceiros é inserir uma tag no token que circula nos arcos da máquina a fluxo de dados, de tal forma que os dados parceiros possuam a mesma tag, esse método passou a ser chamado de tagged-token.

Na matching unit, dados parceiros habilitam nós para a execução. Uma vez habilitado, os tokens são transferidos para fetching unit que identificará o nó a ser executado, gerando e enviando o pacote de execução para a functional unit, que por sua vez executa a operação, conforme especificado no pacote recebido, e envia os tokens resultantes para a matching unit seguindo-se o ciclo até que todo o grafo seja executado. 
A diferença fundamental entre a máquina descrita na Figura 5.5 e na descrita na Figura 5.6 é que a primeira é considerada estática e a segunda dinâmica.

As máquinas a fluxo de dados mostram dois tipos de paralelismo na execução das instruções (Arvind and Culler (1986)):

1. Paralelismo espacial, onde qualquer dois nós podem potencialmente executar concorrentemente se não houver dependência de dados entre eles;

2. Temporal, que resulta nas ondas de dados pipelining de computação independentes sendo processados no grafo.

O ponto essencial a ser considerado nos modos de implementação do modelo a fluxo de dados está no armazenamento e identificação de tokens. 


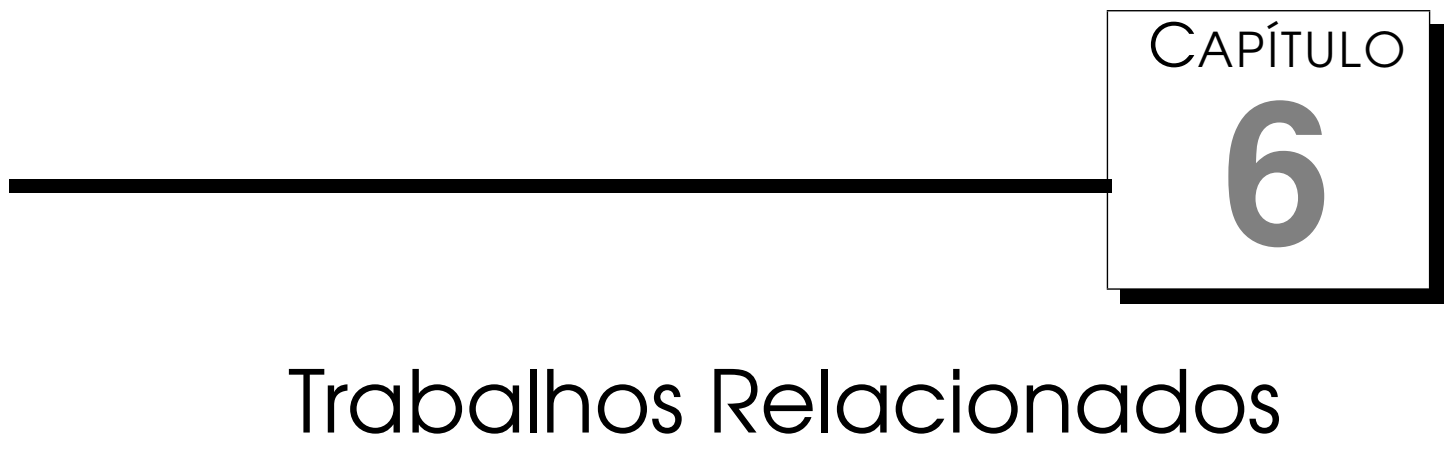

Neste capitulo são apresentas as características de algumas arquiteturas de máquinas a fluxo de dados dinâmicas disponíveis na literatura. As arquiteturas aqui descritas foram escolhidas tendo como base a demonstração dos principais conceitos da área, descritas nos trabalhos iniciais mais influentes como: a Máquina de Fluxo de Dados de Manchester (MFDM), MIT Tagged-Token Dataflow Architecture (TTDA), EM-4, Máquina a Fluxo de Dados Dinâmica (MFDD) e as principais máquinas a fluxo de dados contemporâneas: Application-Specific Hardware (ASH), Tera-op Reliable Intelligently adaptive Processing System (TRIPS) e WaveScalar.

\subsection{MFDM}

O modelo a fluxo de dados dinâmico foi proposto por Arvind no Massachusetts Institute of Technology (MIT) e por Gurd e Watson na Universidade de Manchester (Lee and Hurson (1994)). Dentre os projetos derivados do conceito de fluxo de dados, o projeto MFDM teve seu início em 1975 e foi uma das primeiras máquina fluxo de dados construída e também uma das mais divulgadas. Esse projeto foi desenvolvido, simulado e prototipado na Universidade de Manchester, Inglaterra e deu grandes contribuições à área (MARQUES (1993)), (Lorenzo (1985)), (Silva (1991)), (Cavenaghi (1992)), (Cavenaghi (1997)), (Kamienski (1994)), (Silva (1992)), (Silva (2011b)), (J.R. and Gurd (1985)), (Lee and Hurson (1994)). A máquina baseou-se no modelo de fluxo de dados dinâmico e o objetivo do projeto era construir um computador fluxo de dados tagged token com alto desempenho. O protótipo dessa arquitetura esteve operacional entre 1981 e 1989 (Kamienski (1994)). 
Na Figura 6.1 é descrito a arquitetura básica da MFDM. Como pode ser visto na Figura 6.1, diferentes unidades funcionam de forma totalmente independentes uma das outras, tendo seu funcionamento individual implementado de forma síncrona, porém, a comunicação entre elas da-se por um protocolo de comunicação de forma assíncrona. Essa independência de funcionamento entre as unidades forma um pipeline e se comunicam através de uma estrutura de fila em forma de anel(Lorenzo (1985)). Os tokens são encapsulados em pacotes de dados, que circulam no anel, de uma unidade à outra, sempre no mesmo sentido, assim, muitas vezes um dado tem que transitar pelo anel para ativar a execução da instrução imediatamente seguinte (Lorenzo (1985)).

O paralelismo do sistema é de granularidade fina, explorado ao nível de instruções executadas de forma não deterministica uma vez que a ordem de execução das instruções não é garantida, pois o modelo a fluxo de dados torna qualquer subconjunto de instruções habilitadas, candidatos a serem executadas (J.R. and Gurd (1985)).

Associando a cada token, existe uma tag, utilizado para identificar dados parceiros. A tag é formado por dois campos: nome de ativação e índice. O campo "nome de ativação" é usado para identificar o token, sendo o mesmo para cada dado circulando no grafo para uma referida instância. A funcionalidade do campo "nome de ativação" é separar os contextos das várias instâncias de um determinado dado no grafo.

Por conceito de instâncias, pode se destacar a situação onde um nó em um máquina a fluxo de dados recebe em uma de suas entradas, dados vindos de uma memória externa. Para cada dado da memória que é enviado para aquele nó, naquela entrada, no grafo, será preciso identificá-lo com uma nova tag e portanto cada dado com sua tag correspondente poderá circular por todo o máquina a fluxo de dados sem ser confundido. A entrada, portanto de um segundo dado vindo da memória naquele nó e naquela entrada descrita aqui, é considerada como uma nova instância do dado para aquele nó.

O campo "nome de ativação" da tag portanto irá identificar qual instância corresponde um determinado dado na máquina a fluxo de dados. Cabe ressaltar ainda que todos os dados que entrarem na máquina a fluxo de dados nos seus diferentes nós e diferentes entradas em um mesmo instante receberão em seus tags o mesmo valor para o campo "nome de ativação", pois todos irão corresponder a uma mesma instância de dados, o que implica em um sincronismo e será detalhado mais à frente.

O índice como parte da tag citada acima é utilizado para distinguir elementos pertencentes a uma mesma estrutura de dados, mais especificamente, quando dados circulam por um loop, eles serão considerados parceiros se estiverem no mesmo nível de ativação e mesmo índice dentro do loop (Kamienski 
(1994)).

O token nessa máquina tem o seguinte formato: (dado, rótulo, destino do token). O campo dado possui (37 bits), rótulo (36 bits) e destino (22 bits), além de um bit extra para diferenciar as mensagens especiais do sistema, totalizando (96 bits) (Silva (1991)).

Como o que circula entre as unidades da MFDM são pacotes, além dos tokens, existe um campo adicional de dados de (37 bits), totalizando (133 bits) de largura. Ainda segundo Silva (1991), um pacote executável possui um campo para a instrução (10 bits) e um segundo destino (22 bits) opcional, para a geração de uma cópia extra do resultado da operação, totalizando (166 bits) de largura.

A estrutura da arquitetura MFDM é composto, basicamente, por cinco unidades distintas, interligadas em uma rede de comunicação formando um anel, conforme já referenciado na Figura 6.1.

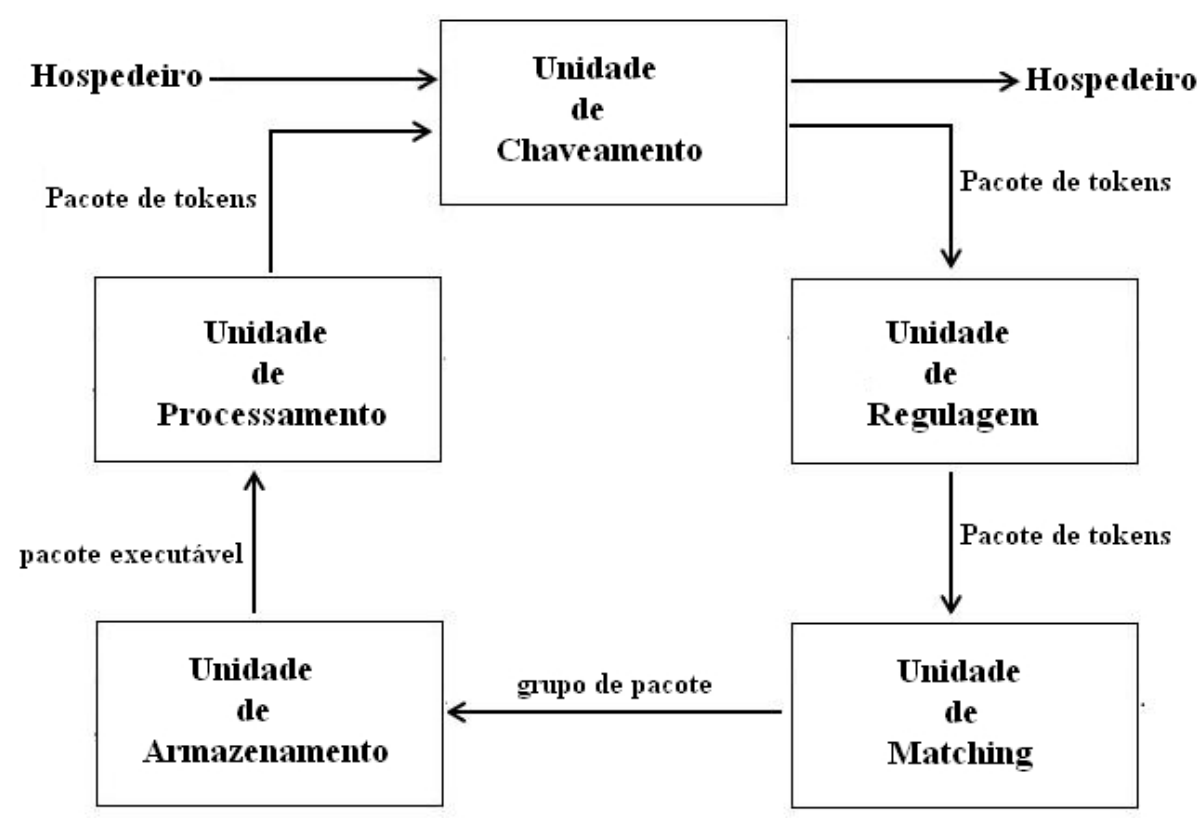

Figura 6.1: Estrutura básica da MFDM, baseado em (Lorenzo (1985), (MARQUES (1993)))

A Unidade de Chaveamento (Switch Unit) na Figura 6.1, permite à máquina comunicar-se com um computador hospedeiro. Isso permite a entrada e saída de pacotes de tokens no anel, uma vez que a máquina não possui execução autônoma (Kamienski (1994)). Segundo Silva (1991), o anel é somente um mecanismo de execução de grafos de fluxo de dados, assim foi necessária a inclusão desta unidade para possibilitar a comunicação com o meio exterior.

A Unidade de Regulagem (Token Queue) na Figura 6.1, é uma estrutura First In, First Out (FIFO) que armazena temporariamente os pacotes de tokens (até 32k tokens), recebidos da Unidade de Chaveamento com a finalidade de ajustar os diferentes tempos existentes no pipeline (MARQUES (1993)), isto é, 
tem o propósito de manter o equilíbrio entre a produção e o consumo de tokens no anel (Lorenzo (1985)), compensando assim as eventuais irregularidades no grau de paralelismo exibido pelos programas. Esta unidade serve para evitar a formação de bolhas no pipeline ${ }^{1}$, que podem resultar em queda no desempenho da máquina, mantendo uma taxa de alimentação mais equilibrada à Unidade de Matching, (J.R. and Gurd (1985)).

A Unidade de Matching (Matching Unit) na Figura 6.1, é responsável por sincronizar os pacotes de tokens destinados a uma mesma instrução, ou seja, que possuem o mesmo rótulo e o mesmo endereço (Kamienski (1994)). O primeiro pacote de token a chegar é armazenado e aguarda a chegada do seu par. Ao chegar o pacote de token esperado, o parceiro armazenado é retirado da memória e a Unidade de Matching envia o par de pacote de token em um novo pacote, chamado grupo de pacote, para a próxima unidade. Esse grupo de pacote possui o seguinte formato: (dado1, dado2, rótulo, destino) (Kamienski (1994)). A Unidade de Matching tem capacidade para 1 Mega tokens (MARQUES (1993)) e é a parte mais crítica da arquitetura MFDM, pois para a sincronização dos pacotes de tokens, a unidade deve ser associativa por natureza (MARQUES (1993)), além disso, a unidade tem que permitir o armazenamento de uma quantidade grande de pacote de tokens que esperam por seus parceiros. Na época existia falta de memória associativa de grande capacidade, então, nesta arquitetura, foram utilizadas memória pseudoassociativa, empregando técnicas de hashing implementada por hardware (Kamienski (1994)). Segundo MARQUES (1993), a máquina MFDM possui somente uma Unidade de Matching, assim, essa unidade na máquina MFDM é única e centralizada. As instruções da $M F D M$ possuem no máximo dois operandos e produzem até dois resultados, ou seja, nessa arquitetura, a Unidade de Matching sincronizará no máximo um par de pacote de tokens (MARQUES (1993)), (J.R. and Gurd (1985)), (Kamienski (1994)). Pacote de tokens endereçados a instruções que possuem no máximo um único operando, dispensam sincronização e são imediatamente enviadas à próxima unidade. A limitação em dois operandos de entrada foi necessário para simplificar a Unidade de Armazenamento e dois operandos de saída, para simplificar a largura do barramento paralelo, necessário para transportar o grupo de pacote formado, para a próxima unidade (Silva (1991)), (J.R. and Gurd (1985)).

A Unidade de Armazenamento (Node Store Unit) na Figura 6.1, armazena instruções do programa que estão prontas para serem executadas. Assim, antes do início da execução, as instruções do programa são carregadas nessa unidade (Cavenaghi (1997)), (Kamienski (1994)). Os pacotes de tokens ou os grupos de pacote que chegam são montados em um pacote executável,

\footnotetext{
${ }^{1}$ as bolhas podem provocar a ociosidade das unidades seguintes por falta de oferta de pacotes (Lorenzo (1985)).
} 
combinando estes com uma cópia da instrução endereçada (Silva (1991)), ou seja, ao receber os pacotes de tokens ou os grupos de pacote, essa unidade monta um pacote executável, o qual contém a instrução e seus operandos, rótulo e endereços de destino dos resultados. O pacote executável é composto por (dado1, dado2, código de operação, rótulo, destino1, destino2) e está pronto para a execução, que é enviado à Unidade de Processamento (Lorenzo (1985)), (J.R. and Gurd (1985)).

Finalmente, a Unidade de Processamento (Processing Unit) na Figura 6.1 é composta por um conjunto de processadores idênticos Elemento de Processamento (EP), dispostos em paralelo, que realizam operações lógicas, aritméticas e de controle sobre os pacotes de tokens (Silva (1991)). O número de processadores nessa unidade, determina quantos pacotes podem ser executados em paralelo (Lorenzo (1985)). Assim, essa unidade realiza a execução da instrução, produzindo pacotes de tokens como resultado. Após essa etapa, os pacotes de tokens são encaminhados de volta ao anel por um sistema de arbitragem (Silva (1991)). Um processador só se torna disponível para uma nova instrução quando todas os pacotes de tokens produzidos pela instrução anterior tiverem sido despachadas para o anel (Lorenzo (1985)). Todas as unidades do anel, exceto essa, trabalham de forma seqüencial (Kamienski (1994)), (MARQUES (1993)), os pacotes entram e saem também de forma seqüencial, mas várias instruções podem ser executadas em paralelo, nesta unidade (Lorenzo (1985)), (Kamienski (1994)).

Dentre os vários problemas encontrados na arquitetura MFDM, (J.R. and Gurd (1985)), (Kamienski (1994)), (MARQUES (1993)), pode-se destacar o problema de: precisão para aplicações numéricas, uma vez que como há apenas (32 bits) no campo destinado aos dados, dentro do token, a execução de aplicações que exigem maior precisão numérica seriam inviabilizadas. O aumento dos bits de dados ocasionariam aumento no barramento para transportar esses dados, além de aumento na complexidade das arquiteturas das unidades que compõem o anel.

Outro problema é o tratamento de estrutura de dados, uma vez que a realização de operações sobre uma estrutura de dados requer que todos os seus elementos sejam transformados em dados escalares e circulados no anel, pois as estruturas de dados são vistas como valores únicos, ou seja, a estrutura toda deve ser passada para cada operação referenciada, causando assim uma grande sobrecarga na transmissão dos valores pelo anel, o que causa alto custo. A manipulação de estruturas de dados, segundo MARQUES (1993), Kamienski (1994), J.R. and Gurd (1985) foi uma das principais causas que prejudicaram o desempenho da máquina MFDM. Nos sistemas baseados no paradigma von-Neumman, utiliza-se ponteiros para referenciar um dado par- 
ticular na estrutura de dados. Nas máquinas a fluxo de dados, o uso de ponteiros quebra a elegância formal do paradigma (Lorenzo (1985)).

Ainda um outro problema na estrutura MFDM está na unidade de Matching, baseado numa memória pseudoassociativa. Considera-se esse o maior problema da máquina $M F D M$, pois trata-se de uma estrutura única e centralizada tendo uma grande capacidade de armazenamento de memória para armazenar os pacotes de tokens parceiros de todo o sistema, além de um hardware relativamente eficiente para fazer o emparelhamento de todos os dados que nela chegam (J.R. and Gurd (1985)).

Finalmente o trânsito excessivo de pacote de tokens no anel também se torna um problema, pois segundo Kamienski (1994) há um grande trânsito de pacotes de tokens destinados a instruções com um único operando no anel, cerca de 60\% em média. Como o anel é seqüencial, o trafego ocasionado por esses pacotes atrapalham os pacotes maiores e causa excessiva sobrecarga.

\subsection{MIT TTDA}

O Projeto TTDA foi desenvolvido no Massachusetts Institute of Technology MIT, nos Estados Unidos (Arvind (2005)), (Arvind and Culler (1986)), (Arvind and Nikhil (1990)), (MARQUES (1993)). Essa máquina foi baseada no modelo de fluxo de dados dinâmico e o objetivo do projeto era construir um computador a fluxo de dados com alto desempenho, utilizando-se os mesmos princípios da Máquina de Manchester, os tagged-tokens (Buck (1993)). Para não utilizar linguagens seqüenciais convencionais na programação da máquina TTDA, foi desenvolvido uma linguagem chamada $I d$, com alto nível implícito de paralelismo de granularidade fina (Arvind and Nikhil (1990)), (Hicks et al. (1993)). Os programas escritos na linguagem Id eram compilados para máquinas a fluxo de dados dinâmicos e as máquinas a fluxo de dado eram executados diretamente na arquitetura de TTDA (Arvind and Nikhil (1990)), (Hicks et al. (1993)).

A estrutura da arquitetura de TTDA é composta por um conjunto de EPs idênticos e um conjunto de elementos de Estrutura-I, em inglês, I-Structure, também idênticos, conectados por uma rede de comunicação n-cúbica conforme pode ser visto na Figura 6.2 (Silva (2011b)), (MARQUES (1993)), (Cavenaghi (1997)), (Buck (1993))

Como visto anteriormente, nesse capítulo, os dados tratados nas máquinas a fluxo de dados são dados escalares. Os elementos da Estrutura-I residem em uma memória global. Um token representando uma Estrutura-I carrega apenas um descritor deste, ou seja, um ponteiro para uma Estrutura-I (Arvind and Nikhil (1990)). 


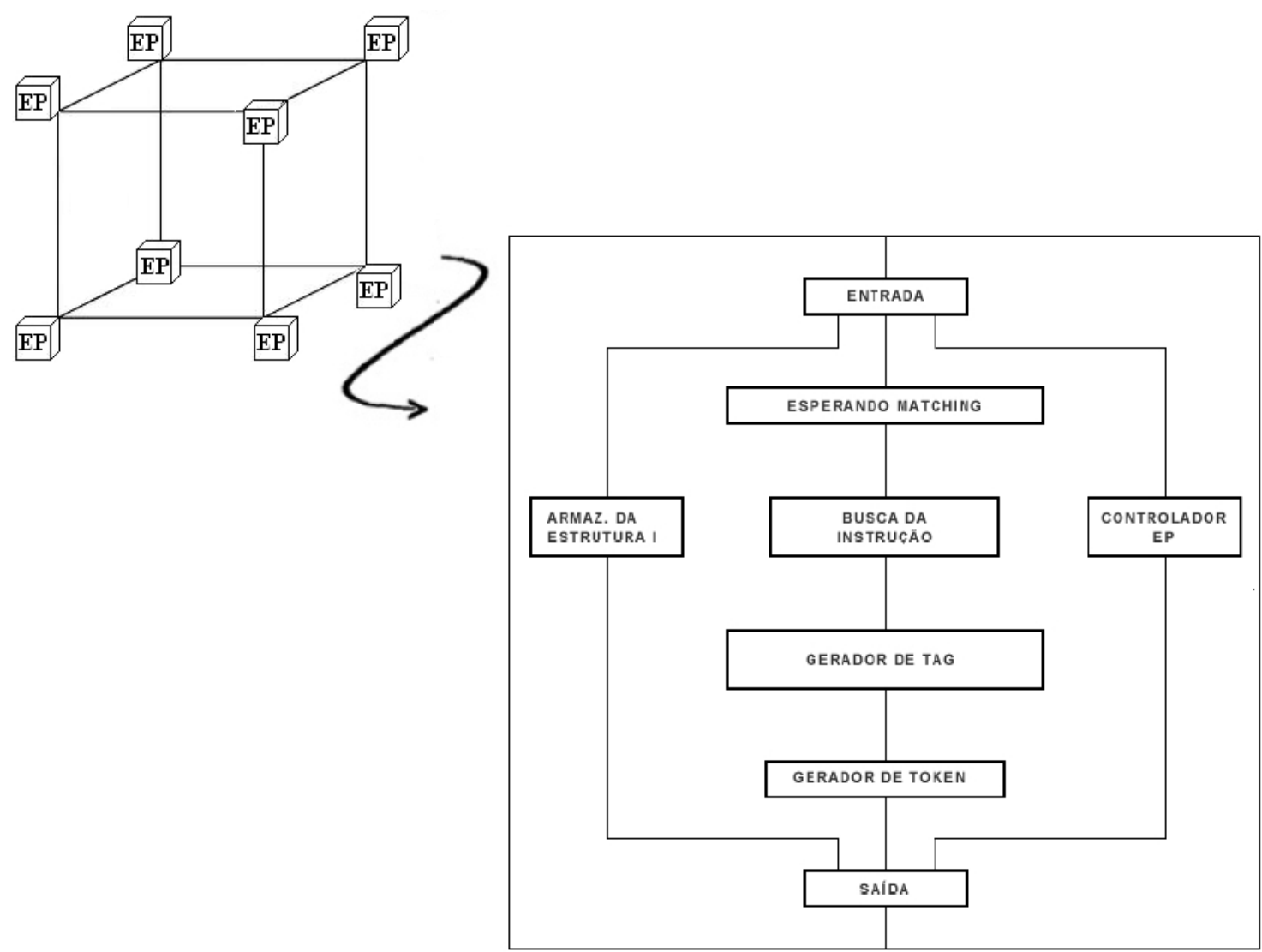

Figura 6.2: Estrutura da Máquina do TTDA (Arvind and Nikhil (1990)), (MARQUES (1993)))

Segundo Buck (1993), na máquina TTDA, o elemento de Estrutura-I é um tipo especial de armazenamento para grandes estruturas de dados. Essa estrutura permite que cada elemento da estrutura de dados possa ser escrito apena uma vez, mas pode ser lidos muitas vezes. Ainda é possível executar uma operação necessária a algum elemento da estrutura de dados, mesmo que a computação de outros elementos da estrutura ainda não estejam completos.

Conforme visto na Figura 6.2, A estrutura de um EP da Máquina do TTDA é composta pelas unidades: Unidade Controlador EP, Unidade Esperando Matching, Unidade de Busca da Instrução, Unidade Lógica Aritmética, Unidade Gerador de Tag, Unidade Gerador de Token, Unidades de Entrada e Saída. Essas unidades trabalham em pipeline e são explicadas a seguir.

A Unidade Controlador EP, PE Controller recebe tokens especiais que podem manipular qualquer parte do estado de um EP (Arvind and Nikhil (1990)). A Unidade Esperando Matching, Waiting Match é implementada com memórias associativas e formam conjuntos com dois tokens parceiros. Após formar o conjunto os tokens são enviados à Unidade de Busca da Instrução. Se um token que entra nessa unidade for destinado a uma instrução com apenas um operando em sua entrada, esse passa direto à Unidade de Busca de Instrução. 
A Unidade de Busca da Instrução, Instruction Fetch por sua vez busca numa memória local a instrução correspondente aos tokens recebidos. Nessa memória local está armazenado partes da máquina a fluxo de dados do programa em execução. Todos os dados necessários para a execução daquela instrução são recolhidos e passados à proxima unidade. Na Unidade Lógica Aritmética, Arithmetic Logic Unit (ALU) as instruções são executadas e o resultado é enviado para o EP destino por meio da interface de saída. A Unidade Gerador de Tag, Compute tag calcula os tags para a saída do operador, com base no contexto e endereços relativos das instruções de destino. A Unidade Gerador de Token, Form Token recebe um valor de dado vindo da Unidade Lógica Aritmética e os tags da Unidade Gerador de Tag e então, gera o token resultante. A Unidades de Entrada, Input recebe tokens de outros EPs e são encaminhados para a Unidade de Esperando Matching. A Unidade de Saída, Output faz a interface do EP atual com os outros EPs ligados na rede de comunicação.

Da mesma forma que na máquina $M F D M$, o número máximo de arcos de entrada em um nó, na máquina TTDA são dois. Segundo Cavenaghi (1997), MARQUES (1993), Arvind and Nikhil (1990), a arquitetura TTDA deu origem a uma nova arquitetura chamada Monsoon (Hicks et al. (1993)), (Papadopoulos (1988)), cuja maior contribuição foi o conceito de multithreading ${ }^{2}$ (Papadopoulos and Traub (1991). Ainda segundo Cavenaghi (1997), todos os resultados obtidos com esta arquitetura foram simplificados e a implementação do hardware nunca foi descrita na literatura.

\section{$6.3 \quad E M-4$}

EM-4 Hybrid Dataflow Machine é uma máquina com arquitetura a fluxo de dados de granularidade variável, que teve sua origem baseada na máquina a fluxo de dados Sigma-1 (Hiraki et al. (1986)), (Yuba et al. (1985)) (Shimada et al. (1986)), utilizando o modelo tagged-token, com o patrocínio do Projeto Nacional Japonês de Supercomputadores, desenvolvido no Electrotechnical Laboratory, no Japão (Arvind and Culler (1986)). Sigma-1 é uma máquina a fluxo de dados baseada na arquitetura TTDA e a máquina EM-4 é uma evolução da máquina Sigma-1 (MARQUES (1993)), (Sakai et al. (1991a)), (Sakai et al. (1991b). Sua sucessora, a máquina a fluxo de dados EM-5 não será abordada pois nenhum de seus conceitos se enquadram no escopo desse trabalho.

Segundo Sakai et al. (1991a), Okamoto et al. (1992a), Okamoto et al. (1992b), Yuba et al. (1985) em 1988, a máquina a fluxo de dados Sigma-1 tinha 128 EPs e executava até 170 Million FLoating-point Operations Per Second (MFLOPS).

\footnotetext{
${ }^{2}$ multithreading ou ambiente de múltiplos threads é um modelo de programação que permite a execução paralela de múltiplas linha de execução dentro de um contexto, compartilhando recursos do processo, e capazes de executar de forma independente.
} 
Porém, alguns problemas foram encontrados, como por exemplo: a adoção do sistema tagged-tokens com elevado tempo de busca e grande complexidade no hardware da unidade de Matching; o trafego de pacotes era muito intenso; e a sincronização global para detecção de término de laços/funcões consumia muito tempo.

Para resolver esses problemas, uma nova geração de computadores a fluxo de dados foram propostas (Iannucci (1988)), (Sakai et al. (1989)), (Nikhil (1989)), (Kodama et al. (1992)). O computador a fluxo de dados EM-4 era uma dessas novas gerações de computadores (Sakai et al. (1991a)), (Sakai et al. (1995)), (Sato et al. (1992)), (Kodama et al. (1991)).

O protótipo da máquina a fluxo de dados EM-4 foi construído com 80 EPs a fluxo de dados e tornou-se operacional em abril de 1990. Na Figura 6.3 é descrito a arquitetura da máquina EM-4. Conforme descrito na Figura 6.3, cada EP consiste de um único processador a fluxo de dados, implementado em um único chip denominado $E M C-R$ com organização Reduced Instruction Set Computing (RISC) e uma memória externa acoplada ao chip.

Os EPs foram agrupados em placas contendo 5 EPs cada uma e uma rede de comunicação em um total de 16 placas dispostas em um rack

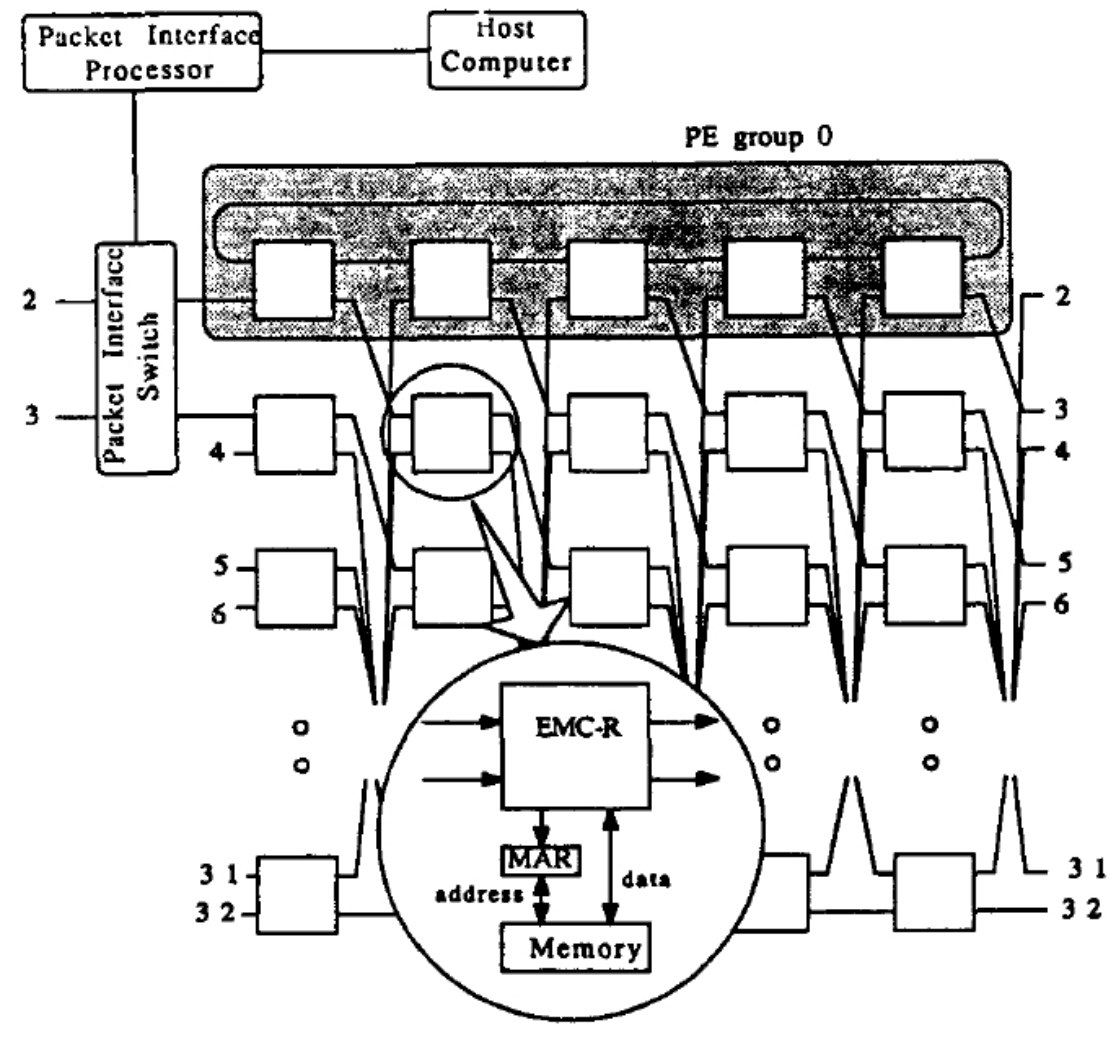

Figura 6.3: Organização do protótipo EM-4 (Sakai et al. (1991a)))

Ainda como pode ser visto na Figura 6.3, a estrutura lógica da interconexão entre os EPs é uma rede circular ômega de multi-estágios (Sakai et al. (1993)), (Sakai et al. (1991a)), (Kodama et al. (1992)), (Kodama and Yuba (1990)), (Sakai 
et al. (1995)).

A Figura 6.4 mostra um diagrama de blocos do EMC-R. Esse chip consiste de 5 unidades: a Unidade de Comutação, SU responsável pela transferência de dados de forma independentes e concorrentemente entre os EPs (Sakai et al. (1993)); a Unidade de Buffer de Entrada, Input Buffer Unit (IBU) implementada com uma estrutura FIFO para os pacotes que aguardam parceiros. Quando esse buffer está cheio, uma parte da memória externa acoplada ao chip é usada como buffer secundário (Kodama and Yuba (1990)), (Cavenaghi (1997)); a Unidade de Busca e Matching, Fetch and Matching Unit (FMU) realiza o matching dos dados parceiros, e se todos estiverem presentes, os envia juntamente com a instrução para a Unidade de Execução; a Unidade de Execução, Execution Unit (EXU) que recebe as informações enviadas pela Unidade de Busca e Matching e as executa (Cavenaghi (1997)); a Unidade de Controle da Memória, Memory Control Unit (MCU) gerencia as solicitações vindas das unidades IBU, FMU e EXU e as envia para a memória externa (Kodama and Yuba (1990)).

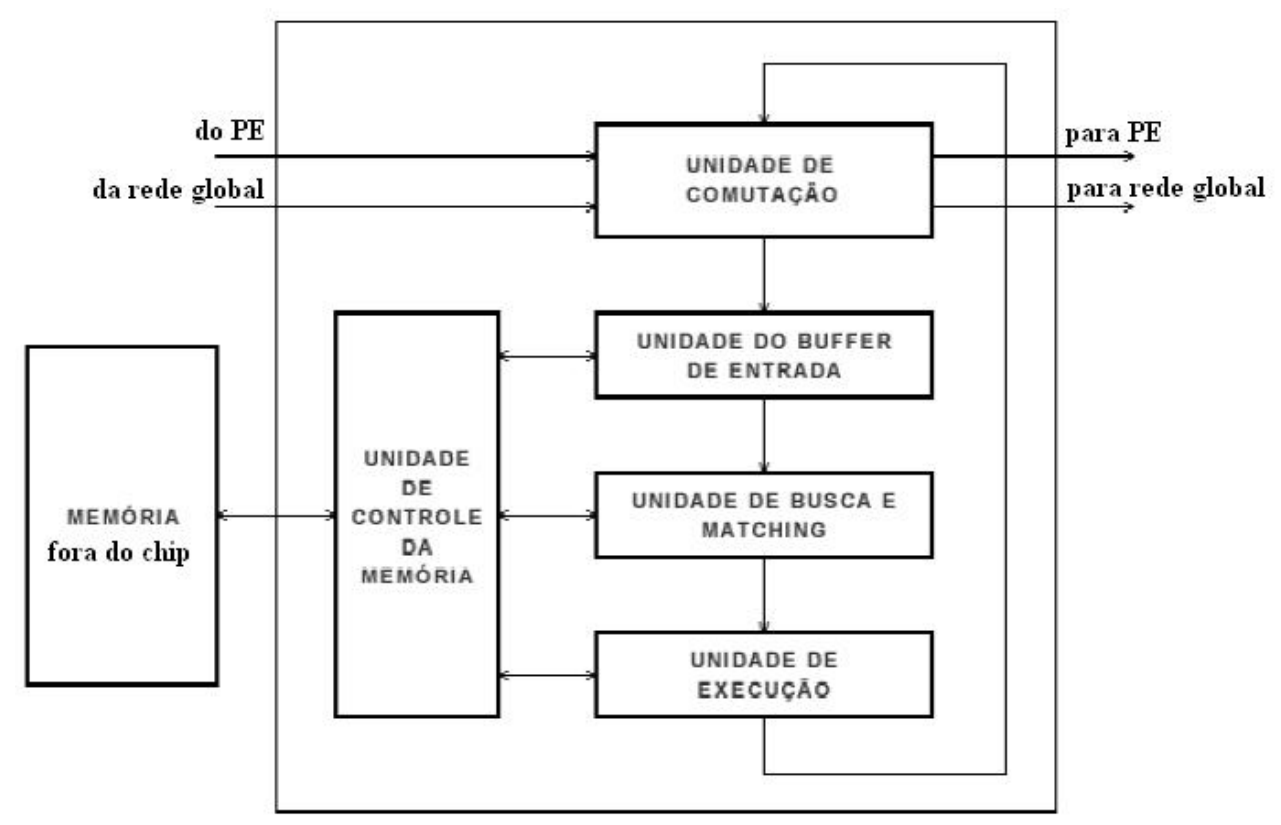

Figura 6.4: Diagrama de blocos do EMC-R (EP da Máquina EM-4) (MARGUES (1993)), (Kodama and Yuba (1990)))

A linguagem usada para a programação da máquina EM-4 é DataFlow C (DFC)-II (Sakai et al. (1991a)), (Okamoto et al. (1992a)), (Kodama et al. (1992)), (Kodama and Yuba (1990)), (Sakai et al. (1991b)), uma versão da linguagem $C$ com características de atribuição única, que não utiliza ponteiros (Cavenaghi (1997)),

O pico de desempenho do EM-4 chegou a 996 Millions of Instructions Per Second (MIPS) (Okamoto et al. (1992a)), (Kodama et al. (1992)), (Okamoto et al. (1992b)). 


\subsection{CPER}

Computador Paralelo Estruturado Recursivamente (CPER) foi desenvolvido no Departamento de Computação (DC), no Centro de Ciências e Técnologia (CCT) da Universidade Federal de São Carlos (UFSCar), no começo da década de 90 (Silva (1992)).

CPER é um computador paralelo cuja estrutura é baseada em um subsistema de comunicação estruturado hierarquicamente, composto por barramentos paralelos, redes seriais em anel e gateways. Esses elementos permitem a interligação vários EPs entre si, à uma máquina hospedeira responsável por todo o "front-end" do sistema, como mostra a Figura 6.5. Os EPs foram propostos com uma estrutura que utiliza o processador "transputer", memórias, e uma interface com o barramento, (Silva (1992)), (Kirner (1989)).

Na Figura 6.5, pode ser visto vários EPs interligados por um subsistema de comunicação formando um grupo ou cluster. Cada EP nesse grupo é considerado como processadores de nível 1. O grupo contendo processadores de nível 1 pode ser visto como um novo $E P$, mais complexo, considerado como processadores de nível 2. Vários grupos interligados com outros grupos iguais forma um novo grupo, de nível 3. A recursividade de CPER está na junção de elementos menores formando elementos maiores de processamento (Kirner (1989)). Segundo MARQUES (1993), o uso recursivo de agrupamento permite a expansão do sistema ao nível desejado.

Os EPs e o processador hospedeiro são interligados de duas maneiras nesse subsistema de comunicação: por meio de redes em barramento e por meio de redes em anel (MARQUES (1993)).

O computador hospedeiro atua como um EP especializado em entrada e saída e tem como funções: realização de operações de entrada/saída; realizar as funções iniciais do sistema, tais como: compilação, geração de grafos fluxo de dados, otimização, escalonamento, carregamento e disparo das atividades a serem executadas nos EPs e finalmente, controlar todas as atividades do sistema.

O paralelismo do CPER está na execução simultânea das operações pelos EPs e na realização das comunicações simultâneas nos seus grupos em diversos níveis. CPER apresenta uma arquitetura flexível que se ajusta a vários modelos de processamento paralelo, assim, CPER pode ser considerado como sendo uma máquina paralela genérica.

O EP no CPER contém três módulos: interface com o barramento paralelo, unidade de processamento, e interface ponto-a-ponto. A interface com o barramento paralelo é encarregada de receber e de enviar informações através do barramento paralelo. A unidade de processamento é um sistema processador- 


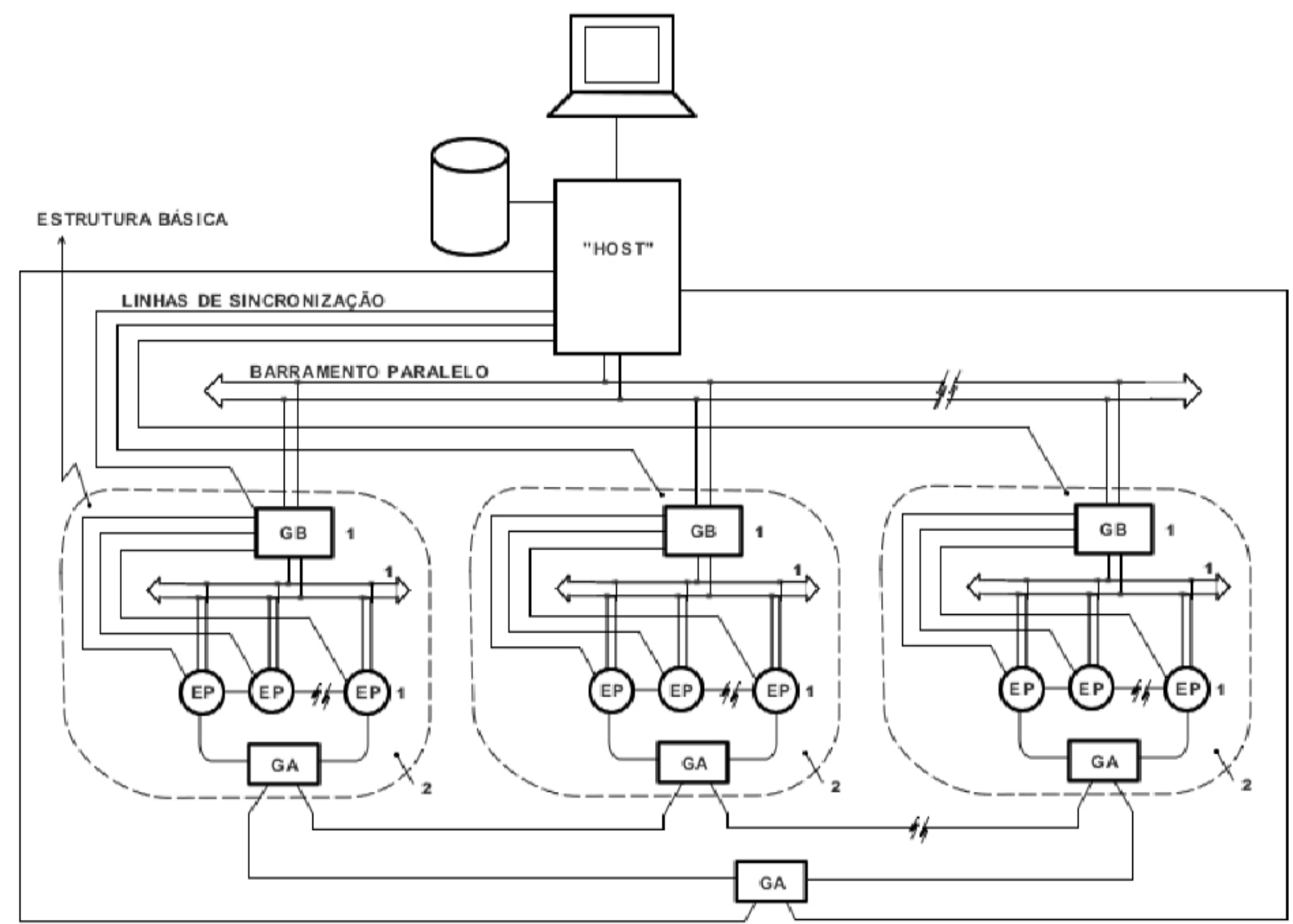

EP = ELEMENTO DE PROCESSAMENTO

$G B=$ GATEWAY DE BARRAMENTO

$G A=$ GATEWAY DO ANEL

Figura 6.5: Arquitetura do CPER (MARQUES (1993))) 
memória de alto desempenho, responsável pela movimentação e processamento dos dados. A interface ponto-a-ponto tem a função de receber e de enviar informações da rede em anel. O projeto foi estruturado utilizando-se de circuitos "MSI" e "LSl" na interface com o barramento, e com a inserção de um processador "transputer" (32 bits/20 MIPS) e 32 KBytes de "higher performance memory" na unidade de processamento e na interface ponto-a-ponto (Silva (1992)).

Uma das características do CPER é a tolerância a falhas, que ocorre através de alguns processos que garantem a nivel de hardware o seu funcionamento. Segundo Silva (1992), no barramento existem algumas linhas sobressalentes para eventual substituição de uma que falhe, em decorrência de um processo de tratamento de falha. Como toda comunicação ocorre através do barramento, os "links" do "transputer" em cada EP foram utilizados para constituírem um canal de comunicação sobressalente estruturado em forma de anel, que poderia ser utilizado em decorrência de uma falha generalizada no barramento, mas que já seria utilizado para envio de algumas mensagens curtas de controle dispensando o uso do barramento. Existe também um processo de tolerância a falhas a nivel de $E P$, detectado por um EP supervisor naquele barramento, que averigua constantemente se algum EP falhou, quando é enviado uma notificação para que a máquina hospedeira acione um processo de reconfiguração em função da falha (Silva (1992)). A este EP supervisor, cabe gerenciar toda a recepção de dados, execução das operações a fluxo de dados a ele atribuídas e transmissão dos resultados, além de proceder um controle com relação à tolerância a falhas dentro da execução do programa a fluxo de dados.

Dois trabalhos de doutorado propuseram o processamento dirigido por fluxo de dados sob o CPER (MARQUES (1993)), (Silva (1992)).

O trabalho do Prof. Eduardo Marques (MARQUES (1993)) aborda o projeto de um elemento de processamento, voltado especialmente para processamento a fluxo de dados no CPER, mais especificamente, a unidade Matching Store. Segundo MARQUES (1993), para que o CPER opere no modelo dirigido pelo fluxo de dados é necessário que seu EP possua um hardware específico para esta tarefa e uma das partes mais importantes desse hardware é a Unidade de Matching Store. Ainda para que a Matching Store permita uma execução satisfatória dos programas no EP, é preciso que ela tenha um ótimo tempo de resposta possuindo um mecanismo eficiente de pesquisa em memória. Podese dizer que a unidade Matching Store é um item de suma importância para esse hardware.

A tese (MARQUES (1993)) teve como objetivo geral o projeto do hardware da Unidade de Matching Store, a construção de seu software de gerenciamento, e 
a implementação de um simulador desta unidade em linguagem concorrente, chamada Occam ${ }^{3}$.

A maior diferença entre a Unidade de Matching Store do CPER e muitas das outras já construídas é o fato desta trabalhar com operações formada por até três operandos. Em uma unidade de Matching Store com dois operandos, um dado é armazenado na memória enquanto espera seu parceiro e tão logo ele chegue, identificado com a mesma tag, ambos são retirados do Matching Store para serem processados. Quando se trabalha com um Matching Store com três operandos, além do aumento de gasto em memória, para armazenar três dados parceiros, a detecção de dados prontos para execução (operação habilitada) será mais longa e o seu tratamento mais complexo do que na maioria das máquinas que utilizam apenas dois operandos.

O trabalho do Prof. Jorge Luiz e Silva (Silva (1992)) também aborda conceitos de programação a fluxo de dados na estrutura hierárquica do CPER. Para isso é apresentada a MFDD com características de Tolerância a Falhas na programação a fluxo de dados, baseada na arquitetura do CPER.

Um software de base configura a MFDD na estrutura do CPER como uma máquina a fluxo de dados dinâmica (Silva (1992)). No MFDD, a partir de um computador hospedeiro ligado ao CPER, um programa escrito em linguagem de alto nível é convertido na forma fluxo de dados, em seguida, um programa analisador faz a análise e carga das operações a fluxo de dados na estrutura hierárquica do CPER de forma a encontrar a melhor distribuição, dependendo da aplicação. A distribuição do programa a fluxo de dados pode ter granularidades diferentes. Um software de base é construído com um núcleo de um sistema operacional distribuído, cujas funções básicas são: comunicação e sincronização, gerenciamento de memória, tratamento de falhas, carregamento, manipulação de Entrada/Saída, reconfiguração do sistema, que é distribuído entre os EPs e o hospedeiro. Antes da execução de um programa a fluxo de dados no CPER, é necessário que as várias operações do programa sejam alocadas aos EPs, por um software carregador. Tão logo o programa a fluxo de dados seja alocado, o hospedeiro passa a enviar dados aos EPs que executarão as operações habilitadas e transferirão dados entre si, até que o resultado final do programa seja obtido (MARQUES (1993)), (Silva (1992)).

Um software básico ${ }^{4}$ instalado em cada EP tem as seguintes funções: detectar uma instrução habilitada; encaminhar essa instrução para a execução; executar propriamente dita da instrução e encaminhar os resultados.

A MFDD configurada no CPER funciona como uma máquina a fluxo de dados dinâmica usando "tagged token". A Figura 6.6 mostra o formato de uma

\footnotetext{
${ }^{3}$ a linguagem de programação concorrente Occam, a qual foi projetada especificamente para a arquitetura do transputer.

${ }^{4}$ o software básico pode ser definido a partir do nível de microprograma, se necessário
} 
tag na MFDD (Silva (1992)). Segundo Silva (1992), para cada execução de um programa, função, ou procedimento, é gerado uma "tag", representando uma ativação. No caso de existirem "loops", a entrada em cada uma dessas operações gerará uma nova "tag" que será associado aos parâmetros de entrada com os "tags" antigos. Para cada ciclo do "loop", a nova "tag" deverá ser ajustado para indicar a iteração. Como as operações iterativas podem ser aninhadas, assim, as "tag" também contém o nível de aninhamento. Ao término de cada operação iterativa, função, procedimento ou programa, a parcela de "tag" correspondente é destruída. Na fase de execução, cada operador, ao receber todos os dados de entrada necessários com a mesma "tag" associado, executará sua operação e remeterá o resultado para outro operador. Esta troca de informações ocorrerá até que o resultado final de cada ativação do programa seja produzido.

\begin{tabular}{rl|l|l|}
\cline { 2 - 3 } tag: & $\begin{array}{c}\text { Nivel de } \\
\text { aninhamento }\end{array}$ & Ativação & Iteração \\
\cline { 2 - 4 } $\begin{array}{l}\text { informação } \\
\text { transferida: }\end{array}$ & Novo tag & tag anterior & dado \\
\cline { 2 - 4 } &
\end{tabular}

Figura 6.6: Formato da tag na MFDD (Silva (1992)))

Uma vez distribuídas as operações, a MFDD inicia sua execução, recebendo os dados do programa através do hospedeiro, processando esses dados em paralelo na forma fluxo de dados, e devolvendo os resultados ao hospedeiro, garantindo ainda uma reconfiguração do sistema em decorrência de uma falha, aspecto este fundamental nesta estrutura.

Foi desenvolvido um simulador pelo Prof. Jorge Luiz e Silva (Silva (1992)), chamado Fluxo de Dados Simulador (FDsim) que permitiu validar todas as estruturas de programação a fluxo de dados tolerante a falhas na Máquina a Fluxo de Dados Dinâmica (MFDD). Esse simulador foi utilizado como um laboratório para o desenvolvimento do software de base do CPER para que este opere como a $M F D D$. Os resultados de desempenho da MFDD obtidos através do FDsim foram comparados com os obtidos pela análise teórica de filas. Além de validar as estruturas dos programas a fluxo de dados, o FDsim gera resultados de desempenho da MFDD para alguns programas que foram executados através do simulador (Silva (1992)).

\section{$6.5 \mathrm{ASH}$}

Um modelo a fluxo de dados foi apresentado por (Budiu and Goldstein (2002)), (Budiu (2003)) denominado Application-Specific Hardware (ASH). ASH 
é uma estrutura que implementa uma aplicação específica em hardware utilizando o modelo a fluxo de dados. ASH é baseado na síntese automática de linguagens de alto nível para circuitos de hardware e são gerados diretamente a partir de aplicações escritas em linguagem $C$.

O ASH utiliza o compilador Compiler for Application Specific Hardware(CASH), um compilador escalonado, que gera hardware a partir de programas escritos em linguagem $C$. O compilador explora paralelismo ao nível de instruções usando técnicas como aggressive speculation e dynamic scheduling. O compilador CASH foi construído tendo como base o projeto de pesquisa do compilador SUIF 1.3 (Budiu and Goldstein (2002)), (Wilson et al. (1994)), (Amarasinghe et al. (1993)).

Os circuitos que o ASH gera podem ser usados de forma autônoma, com a implementação da aplicação inteira no circuito ou associado a um processador de propósito geral (Budiu et al. (2005)). O principal componente do sistema ASH é o compilador CASH.

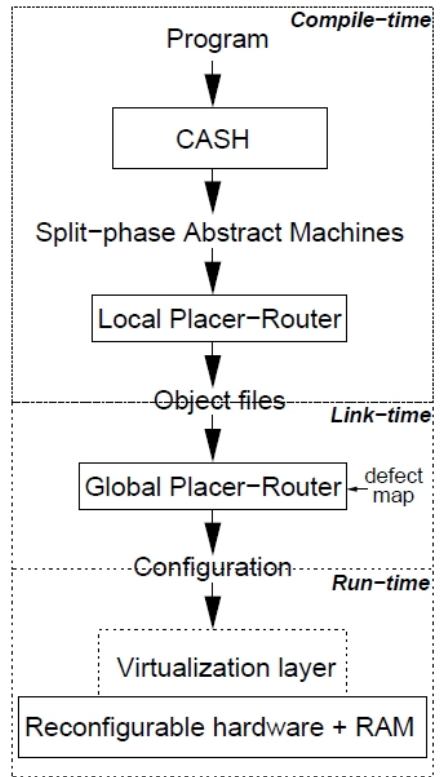

(A)

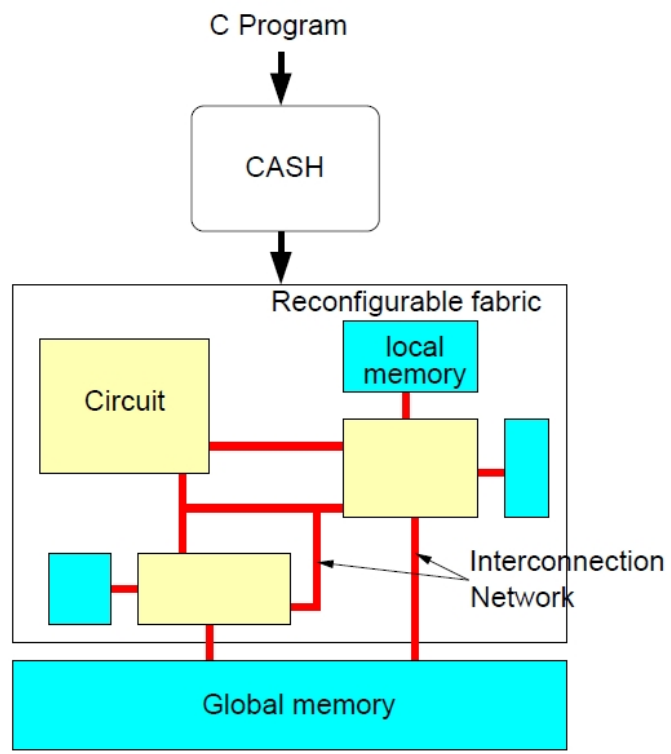

(B)

Figura 6.7: (A) Fluxo da ferramenta $A S H$ (B) Tradução do programa em hardware (Budiu and Goldstein (2002))))

A estrutura do ASH é ilustrada na Figura 6.7. Na Figura 6.7a é descrito o fluxo de execução da estrutura, onde programas escritos em linguagens de alto nível são as entradas para o compilador $C A S H$, que serão convertidos para hardware. A partir do compilador $C A S H$ na Figura 6.7a o compilador cria três diferentes tipos de objetos: estruturas de computação, interconexões e memória local. O resultado é uma arquitetura para hardware reconfigurável, como descrito na Figura 6.7b. Cada módulo é independentemente otimizado, sintetizado, alocado e roteado. Os módulos se comunicam de forma assíncrona. 
Todos os dados do programa são armazenados em uma única memória global centralizada, acessivel por meio de estruturas hierarquicas convencionais de memória, incluindo filas de load-store e cache. O hardware sintetizado é uma máquina a fluxo de dados estática específica para a aplicação compilada (Venkataramani et al. (2004)).

As aplicações são escritas em linguagem $C$ e são compiladas diretamente para circuitos de hardware em uma arquitetura a fluxo de dados estática descrita na linguagem de descrição de hardware Verilog. Os circuitos sintetizados possuem comunicação local, sem broadcast e sem controle global (Silva (2011b)) .

Estes circuitos operam independente, sem utilizar sinais de controle global (clock). Nesta arquitetura há um mapeamento das operações diretamente nas unidades funcionais, o que limita fortemente o reaproveitamento dessas unidades. Todos os sinais de um módulo tem latência previsivel, incluindo o acesso a memória local. Todavia, os módulos podem invocar operações remotas, as quais têm latência imprevisível. Sempre que um módulo necessita executar uma operação que tem latência imprevisível, é utilizada a rede de interconexões onde acesso de memória remoto e transferências de controle de fluxo são conceitualmente transformados em mensagens, as quais podem ser roteadas dinamicamente em uma rede (Budiu and Goldstein (2002)), (Budiu (2003)), (Budiu et al. (2004)), (Budiu et al. (2005)).

A maior abstração utilizada ao nível de programa é o hiper-bloco. Um hiper-bloco é parte de um grafo a fluxo de controle $C F G$, com um único ponto de entrada, mas múltiplos pontos de saídas possiveis. O compilador $C A S H$ divide a aplicação em uma coleção de hiper-blocos, transformando cada hiperbloco em linhas de código direta (sem laços), usando uma técnica em compiladores chamada speculation ${ }^{5}$, em seguida traduz cada hiper-bloco em circuitos a fluxo de dados. Uma vez que um hiper-bloco começa a executar, cada uma de suas operações são executadas exatamente uma vez.

$\mathrm{O}$ circuito produzido pelo sistema $A S H$ funciona da mesma forma que um sistema produtor/consumidor. Uma vez que o dado é consumido ele não estará mais disponível e só computa quando todos os dados estiverem presentes em suas entradas.

Segundo Budiu et al. (2004), Budiu and Goldstein (2002), os circuitos a fluxo de dados podem ser facilmente utilizados para expressar códigos diretos

\footnotetext{
${ }^{5}$ Existem dois tipos de especulação: a de dados e a de controle. Com a especulação, o compilador antecipa uma operação de forma que sua latência, ou seja, tempo gasto seja retirada do caminho crítico. A especulação é uma forma de permitir ao compilador evitar que operações lentas atrapalhem o paralelismo das instruções. A especulação de controle é a execução de uma operação antes do desvio que a precede. Por sua vez, a especulação de dados é a execução de uma carga da memória (load) antes de uma operação de armazenagem (store) que a precede e com a qual pode estar relacionada (Gupta et al. (2004)))
} 
(sem loops). Para permitir a implementação de construções a fluxo de controle com ramificações e chamadas a procedimentos, ASH aumenta o grupo de operações a fluxo de dados, com duas construções especiais: nós "merge" e "eta". Esses nós são usados entre os hiper-blocos. Os nós "merge" são denotados por um triângulo que aponta para cima, enquanto "eta" são denotados por um triângulo que aponta para baixo. O operador "eta" possui duas entradas, uma para o dado e outra para um predicado e uma saída de dados. Se o predicado é verdadeiro (true) o dado da entrada é copiado para a saída, porém, se o predicado for (falso), o dado de entrada é apenas consumido e nenhuma saída é gerada. O operador "merge" possui " $n$ " entradas e uma saída. Para que ele possa executar, não é necessário que todas as suas entradas estejam disponíveis, ele simplesmente copia uma entrada disponível para a saída. $\mathrm{O}$ operador "merge" recebe dados de múltiplos operadores, mas somente um deles pode ativá-lo. O operador merge é a única operação em que apenas uma das entradas com dado presente dispara a execução da operação.

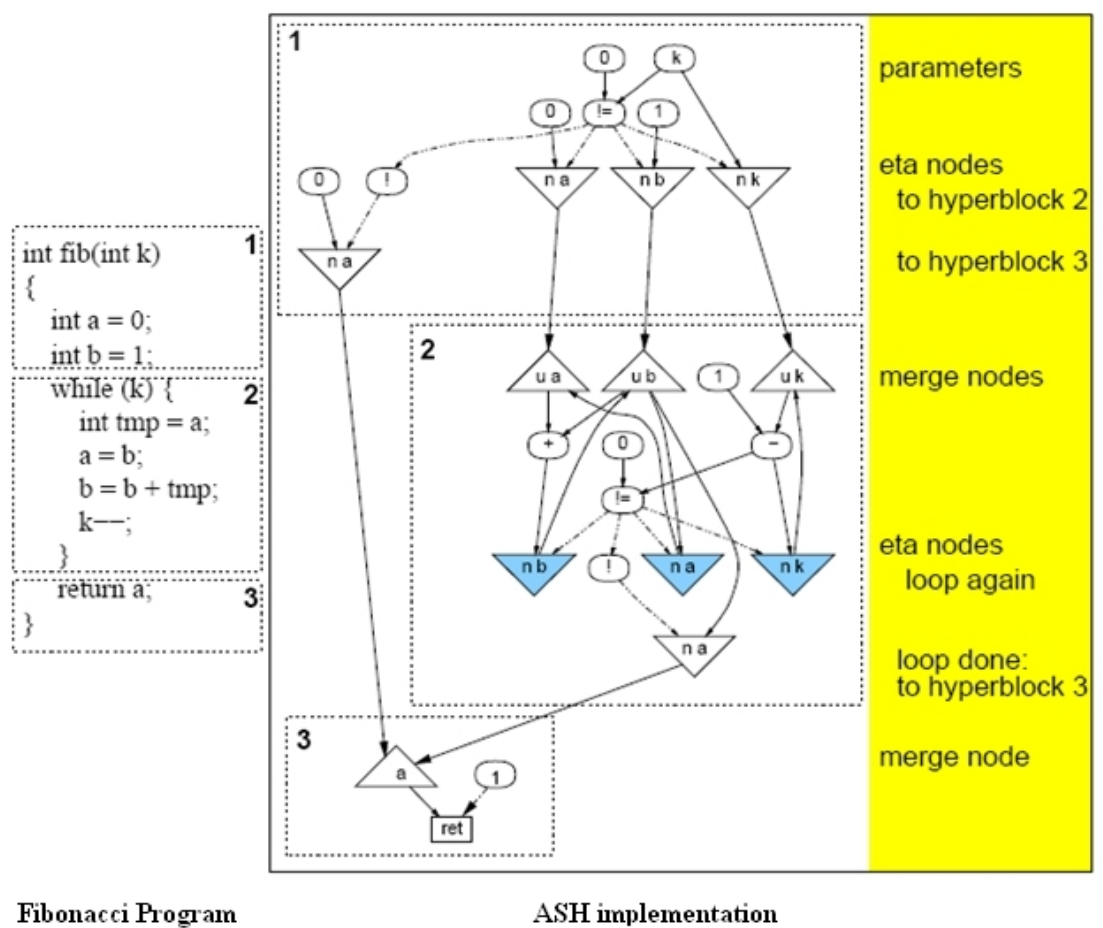

Figura 6.8: Programa Fibonacci e sua implementação em ASH (Budiu and Goldstein (2002))

Na Figura 6.8 pode ser visto que o compilador gera três hiper-blocos para a seqüência de Fibonacci, marcados do lado esquerdo da figura por linhas pontilhadas. O conjunto de hiper-blocos são convertidos e executados diretamente no hardware. Como mostra a Figura 6.8, há nós "merge" nos hiper-blocos 2 e 3. Os nós "merge" no hiper-bloco 2 aceitam dados do hiper-bloco 1 e do próprio hiper-bloco 2, controlando o laço while. Os nós "merge" no hiper-bloco 3 podem aceitar dados de controle dos hiper-bloco 1 ou do hiper-bloco 2. 
Como citado anteriormente, o hiper-bloco é a principal abstração usada ao nível de programa pelo sistema ASH. Os circuitos gerados para os hiper-blocos são interligados usando os nós "merge" e "eta". Para cada variável ativa na entrada de um hiper-bloco é criado um operador "merge" e para cada variável ativa na saída do hiper-bloco é criado um operador "eta". A saída do operador "eta" é conectado a entrada do operador "merge" correspondente no hiperbloco que o sucede (Budiu et al. (2005)). A principal desvantagem do ASH é a exigência para recursos de hardware, pois o hardware gerado pelo ASH é uma máquina a fluxo de dados real e não aquela interpretada, onde módulos são implementados por meio de elementos de processamento, executando os operadores no modelo von-Neumann e trocando informações por passagem de tokens. Porém, isso pode ser suavizado pelo particionamento da aplicação em hardware/software (Budiu et al. (2004)).

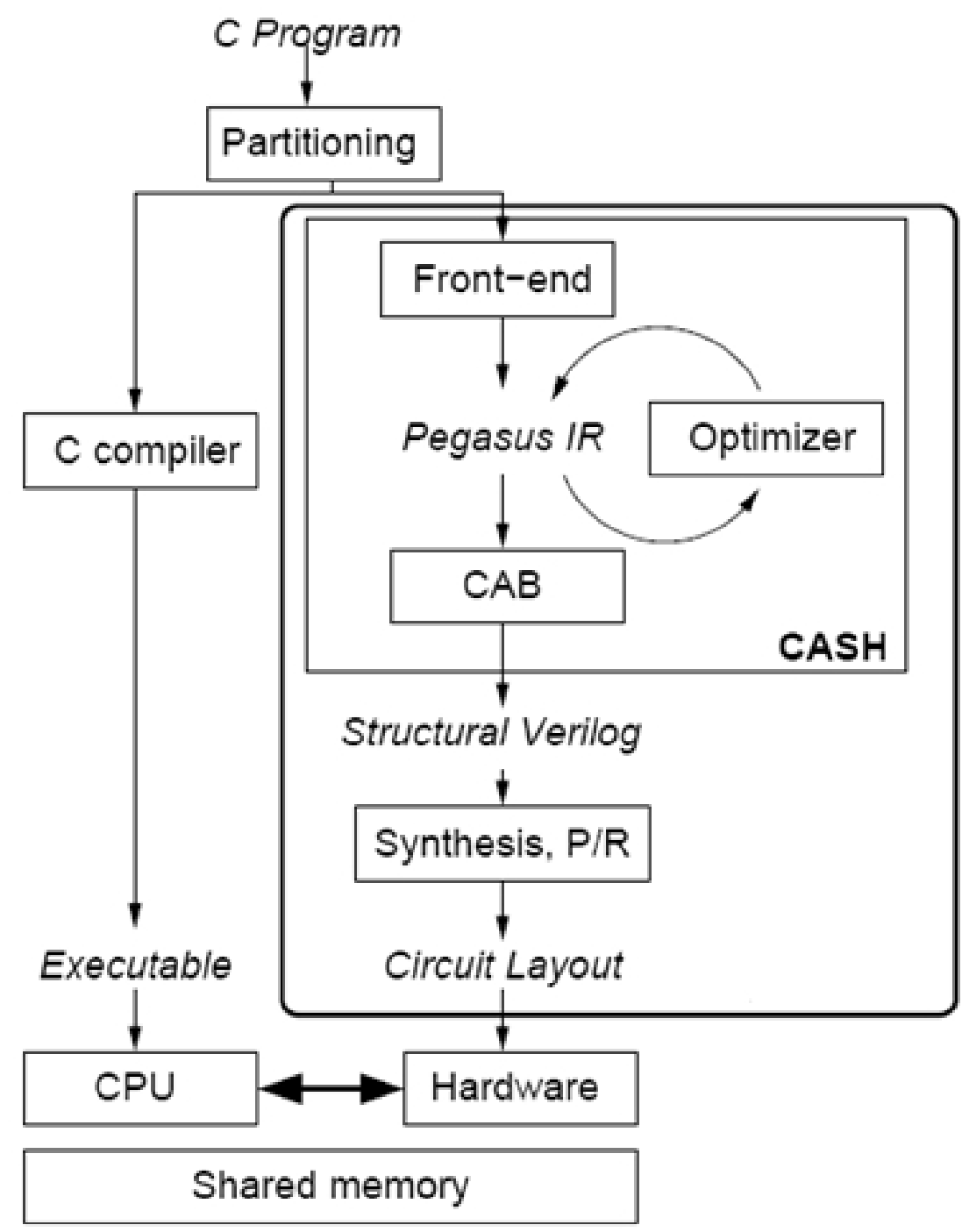

Figura 6.9: Ferramenta de fluxo ASH - tool-flow ASH (Venkataramani et al. (2004))

Na Figura 6.9 é mostrado o particionamento de um programa em linguagem $C$ em hardware/software na ferramenta $A S H$, e o modelo de execução da 
aplicação.

Os módulos são inteiramente sintetizados pelo ASH como uma unidade indivisivel. O particionador automaticamente gera um hardware específico para a comunicação de dados e controle entre as partes de hardware/software.

\subsection{TRIPS}

Tera-op Reliable Intelligently adaptive Processing System (TRIPS) é uma arquitetura de um microprocessador, que está sendo construído no Departamento de Ciências da Computação da Universidade do Texas em Austin. A Arquitetura TRIPS, anteriormente denominada Grid Processors Architecture (GPA) implementa o modelo de execução Explicit Data Graph Execution (EDGE) ${ }^{6}$ (Burger et al. (2004)).

TRIPS é uma arquitetura polimórfica, híbrida von-Neumann/fluxo de dados, a qual pode ser configurada para diferentes granularidades e tipos de paralelismo. Em (Swanson et al. (2003) o processador TRIPS é descrito como uma arquitetura híbrida VLIW-fluxo de dados.

Na Figura 6.10 é mostrado o diagrama da arquitetura TRIPS que consiste de quatro blocos polimórficos chamados CORE, com dezesseis nós de execução ou EPs, cada bloco, conectado a um arranjo de unidades de memória por meio de uma rede de roteamento.

Na Figura 6.11 é descrito de forma expandida um core do sistema TRIPS e o sistema primário de memória. Cada core é composto por: uma matriz $4 \times 4 \mathrm{de}$ EPs (bloco E na figura), Bancos de Registradores (bloco R na figura) e caches de instrução (bloco D na figura), chamado CacheI responsável por armazenar as operações que serão enviadas para os elementos da matriz e cache de dados, chamado CacheD, responsável por manter os operandos dessas operações.

TRIPS contém mecanismos que habilitam os cores de processamento e memória para serem configurados e combinados em diferentes nós para paralelismo ao nível de instruções, dados ou threads. O bloco de controle (Block Control na Figura 6.11) determina qual grupo de operações deve ser mapeado nos diferentes EPs no core e quando tal grupo termina a execução.

Ainda na Figura 6.11 é possível verificar a estrutura interna de um EP da matriz de EP de TRIPS (Schneider Beck Fl. and Carro (2010)). Cada EP da matriz possui uma ULA, uma unidade de ponto flutuante e portas de entrada para os operandos, buffers de operandos e operações, e um roteador que envia os valores de saída para portas específicas. Associada aos buffers de dados, e as operações, são configuradas estações de reservas, as quais tem unidades

\footnotetext{
${ }^{6}$ Um modelo de execução e conjunto de instruções adotado pelo processador TRIPS (Santos (2007)).
} 
de armazenamento para uma instrução e dois operandos de origem. Quando uma estação de reserva contém uma instrução válida e um par de operandos válidos, o nó pode selecionar a instrução para execução. Depois da execução, o nó pode transferir o resultado para qualquer estação de reserva local ou estações de reserva remotas. Os nós são diretamente conectados com seus vizinhos próximos, mas a rede de roteamento pode enviar os resultados a qualquer nó no arranjo.

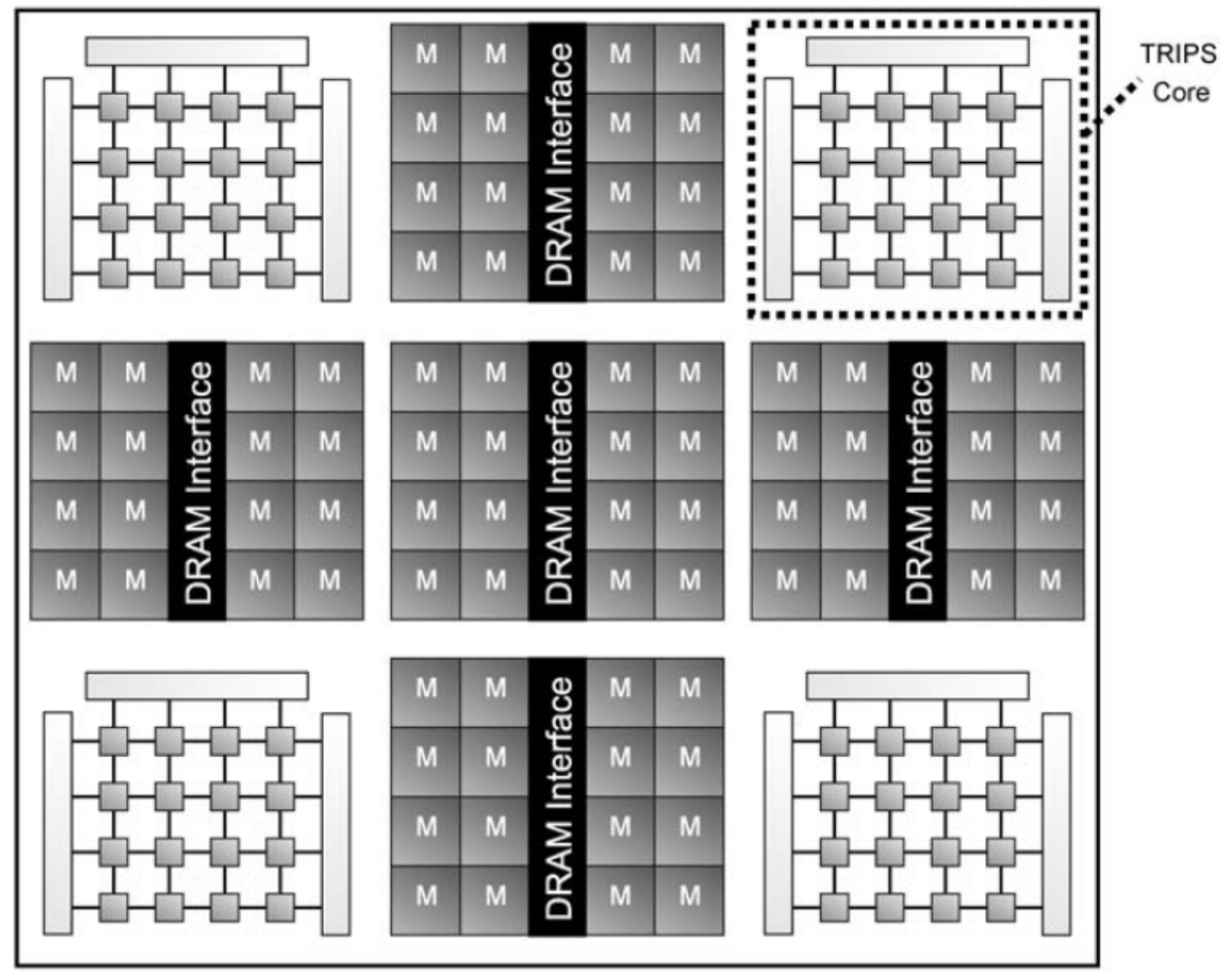

Figura 6.10: Visão geral da arquitetura TRIPS: O Chip TRIPS (Schneider Beck Fl. and Carro (2010))

Para explorar o paralelismo da aplicação e prover um grande uso dos recursos disponíveis, TRIPS usa três nós de execuções diferentes: $D$-morph, que explora o paralelismo em nível de instruções; T-morph que trabalha ao nível de thread, mapeando múltiplos threads em um único core do TRIPS e S-morph que tem como objetivo aplicações como fluxo de mídia (streaming media), com alto nível de paralelismo ao nível de dados (Rutzig et al. (2007)), (Schneider Beck Fl. and Carro (2010)).

\subsection{WaveScalar}

WaveScalar é uma máquina com uma arquitetura a fluxo de dados que possui um grupo de instruções a fluxo de dados e um modelo de execução 


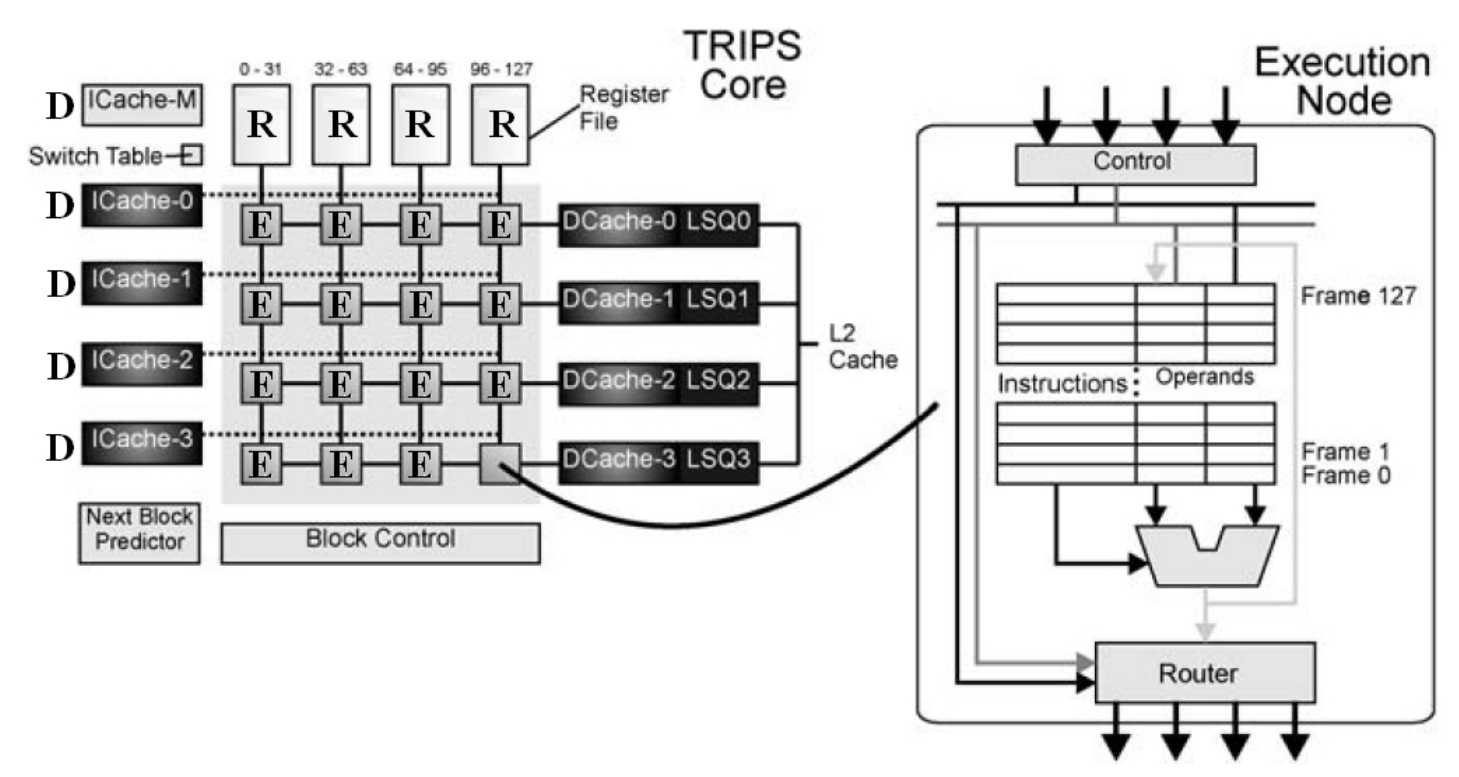

Figura 6.11: Representação abstrata de um core e um EP de TRIPS (Delavallee et al. (2011))

projetado para ser escalonado, ter baixa complexidade e alto desempenho de processamento. As propriedades que o modelo a fluxo de dados trás ao WaveScalar são a descentralização, o escalonamento e a forma natural de expressar explicitamente o paralelismo, sem depender do hardware para extraí-lo (Swanson et al. (2007)).

WaveScalar é uma arquitetura matricial de EPs denominados de WaveCache, organizados em clusters, no qual as operações são mapeadas (FERLIN (2008)). Da mesma forma que o TRIPS, o WaveScalar depende de um compilador para alocar estaticamente instruções nas estruturas de seu hardware. As instruções WaveScalar são armazenadas e executadas na WaveCache.

O WaveCache contém uma rede escalonada de EPs idênticos que são organizados hierarquicamente para reduzir os custos de comunicação. Cada nível de hierarquia usa uma estrutura de comunicação separada (Santos (2007)). Na Figura 6.12 é descrito a organização hierárquica do WaveCache.

Ao invés de projetar um core monolítico que englobe um programa inteiro, o mesmo é distribuído entre centenas ou milhares de tiled ${ }^{7}$ processador, cada qual sendo uma unidade de processamento completa, porém simples.

Como descrito na Figura 6.12, no WaveCache, cada tile é chamado de cluster. Um cluster contém quatro domínios, em inglês, domains idênticos. Os domains descrito na Figura 6.12 possuem 16 EPs cada (Mercaldi (2005)). Cada cluster é cercado por módulos de cache e por buffers de armazenamento para comunicação entre clusters. Dentro de um cluster, a comunicação se dá por

\footnotetext{
${ }^{7} \mathrm{Na}$ indústria de processadores, muitos projetistas estão abandonando o conceito de processadores monolíticos, complexos e de alto desempenho em favor de EPs, mais simples, replicados dentro do chip, a fim de reduzir a complexidade do barramento, o consumo de energia, fornecendo assim desempenho por explorar melhor o paralelismo.
} 
barramentos compartilhados.

A arquitetura WaveScalar considera um programa como um conjunto de grafos de fluxo de dados que devem ser executados obedecendo as relações de dependência entre as operações. Diferente de arquiteturas orientadas a um contador de programa, uma operação WaveScalar envia seus resultados para operações consumidoras e essas executam assim que todos os seus operandos estejam disponíveis nas entradas de um EP. As operações WaveScalar são agrupadas em blocos chamados Waves que, por sua vez, são mapeados para os EPs do WaveCache. Assim que todas as operações de uma Wave terminam sua execução, uma nova Wave é carregada sobre os EPs (Santos (2007)).

Cada EP contém lógica para controlar o posicionamento e execução de instruções, filas de entrada e saída para os operandos, lógica de comunicação e uma unidade funcional. Como pode ser observado na Figura 6.12, o EP básico é muito semelhante ao encontrado na máquina TRIPS (Schneider Beck Fl. and Carro (2010)).

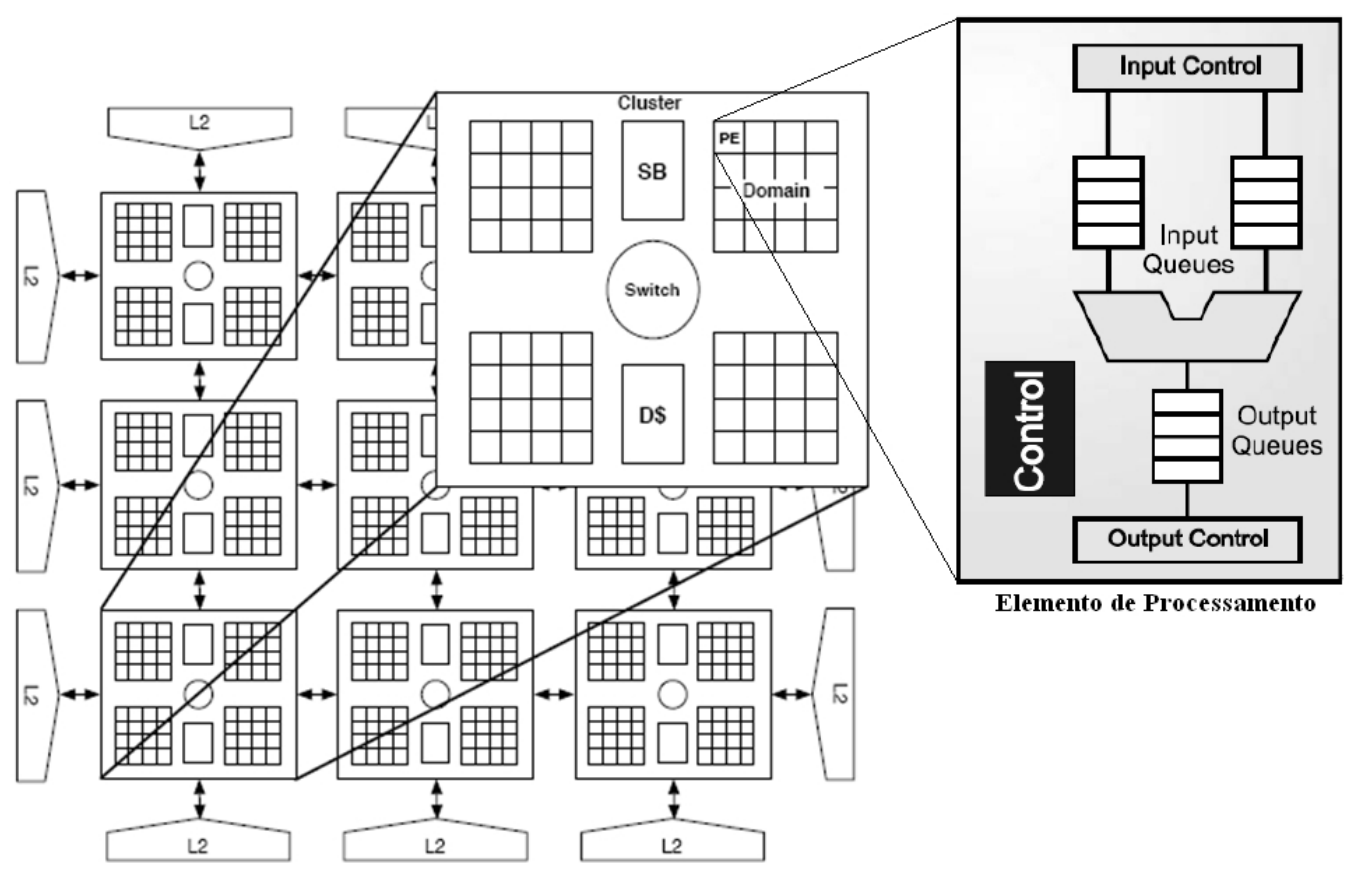

Figura 6.12: O WaveCache e cluster: Um WaveCache 3x3 com nove clusters baseado em (Mercaldi (2005)) e complementado com (Schneider Beck Fl. and Carro (2010))

Diferente das máquinas a fluxo de dados existentes, WaveScalar pode fornecer de forma eficiente as semânticas de memória seqüencial (estilo vonNeumann) que as linguagens imperativas exigem. Para permitir aos programadores expressar facilmente o paralelismo, WaveScalar suporta estilos de programação pthread ${ }^{8}$, multithread e fluxo de dados (Swanson et al. (2007)).

\footnotetext{
${ }^{8}$ Interface de manipulação de threads padronizada em 1995 pelo IEEE (IEEE POSIX 1003.1c) (Giering and Baker (1992))
} 
No WaveScalar, como em toda arquitetura a fluxo de dados, o programa é representado para o processador como máquinas a fluxo de dados. Cada nó no grafo é uma instrução e os arcos entre os nós codificam estaticamente a dependência de dados entre instruções. Além disso, WaveScalar permite combinar os estilos de programação em uma aplicação ou até em uma simples função (Swanson et al. (2007)).

Segundo Swanson et al. (2007) o modelo antigo para arquiteturas a fluxo de dados não permitiam executar de forma eficiente a semântica seqüencial de memória que as linguagens imperativas, tais como $C, C++$ e Java exigem. A execução nessa ordem é necessária para preservar as dependências entre as instruções de leitura e escrita na memória, por exemplo. WaveScalar explora as propriedades do modelo a fluxo de dados e supera essas limitações por meio de um esquema de ordenação de memória, chamado de wave-ordered memory, necessário para linguagens imperativas. Os programadores podem combinar esses diferentes modelos de threads no mesmo programa ou na mesma função.

Ainda segundo Swanson et al. (2007), aplicar diversos estilos de threads em um único programa pode expor de forma significante o paralelismo no código. Expor o paralelismo é apenas o primeiro passo. O processador deve então traduzir esse paralelismo em desempenho. A utilização de técnicas de threads em programas WaveScalar, necessita de um compilador próprio para a arquitetura.

O WaveScalar opera com uma arquitetura a fluxo de dados dinâmica. Nela, os tags são chamados de waves numbers. Os tokens são simbolizados com waves numbers " $w$ " e valor " $v$ " como " $w . v^{\prime \prime}$ (Swanson et al. (2007)). Ao invés de atribuir diferentes wave numbers para diferentes instâncias de uma instrução específica, como faz a maioria das maquinas a fluxo de dados dinâmicas, o WaveScalar atribui waves numbers em porção delimitada da máquina a fluxo de dados, chamada waves.

Na Figura 6.13 é descrito um exemplo simples para um comando de repetição for (Figura 6.13a), implementada inicialmente no modelo a fluxo de dados (Figura 6.13b) e o mesmo implementado na arquitetura WaveScalar (Figura 6.13c).

Como pode ser visto na Figura 6.13c, no topo de cada wave existe um grupo de instruções chamadas wave advance, WA, cuja função é incrementar o valor wave number de cada token que passa por ela. Assumindo que o valor de entrada, antes do loop tenha valor 0 , como parte do wave number, após a execução das duas instruções const, o wave number gerado será 0.0 (wave number 0 , valor 0 ). A instrução wave advance irá receber esses tokens como entrada e produzir tokens com wave number (1.0) e assim sucessivamente. 


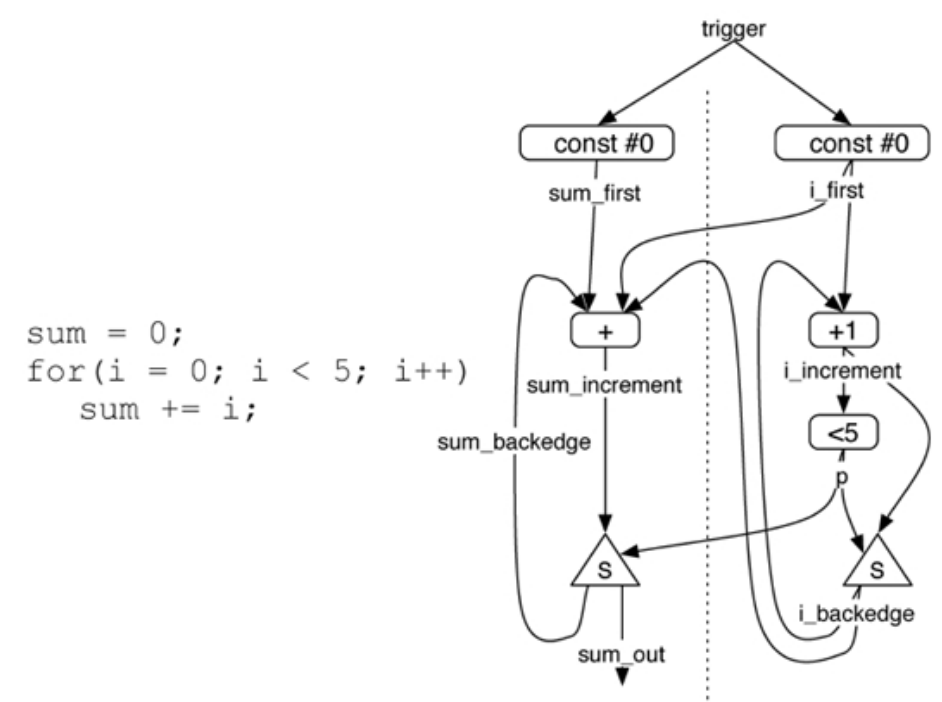

(a)

(b)

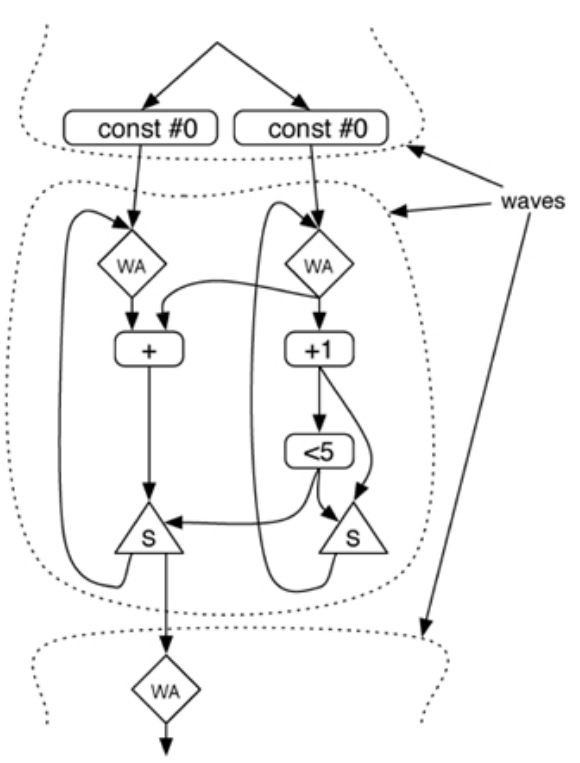

(c)

Figura 6.13: Loops no WaveScalar: (a) um loop simples; (b) uma implementação a fluxo de dados; e (c) implementação WaveScalar (Swanson et al. (2007))

As arquiteturas baseadas em fluxo de dados não possuem mecanismos que assegurem que as instruções armazenadas na memória sejam executadas na ordem presente nos programas.

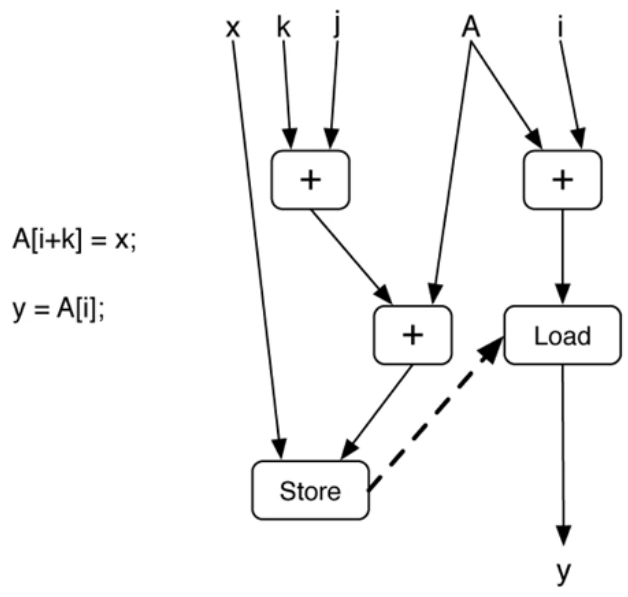

Figura 6.14: Problema relacionado a falta de dependência em uma máquina a fluxo de dados (Swanson et al. (2007))

Na Figura 6.14 é mostrado a diferença entre o que pode acontecer na execução de um programa em uma linguagem imperativa e um programa em execução no modelo a fluxo de dados. No grafo descrito na Figura 6.14, a instrução "load" deve executar depois da instrução "store". A máquina a fluxo de dados não expressa esta dependência implícita entre as duas instruções. Como já mostrado anteriormente, o WaveScalar fornece um mecanismo para codificar esta dependência implícita para suportar linguagens imperativas. Waveordered memory resolve o problema de ordenação de memória em máquinas 
a fluxo de dados usando waves, ou seja, embora a execução seja guiada pelo fluxo de dados, os acessos à memória seguem a ordem do programa para preservar sua semântica, o que é garantido pelo compilador assegurando que instruções e dados estejam semanticamente corretos quando da geração dos waves (Marzulo (2011)).

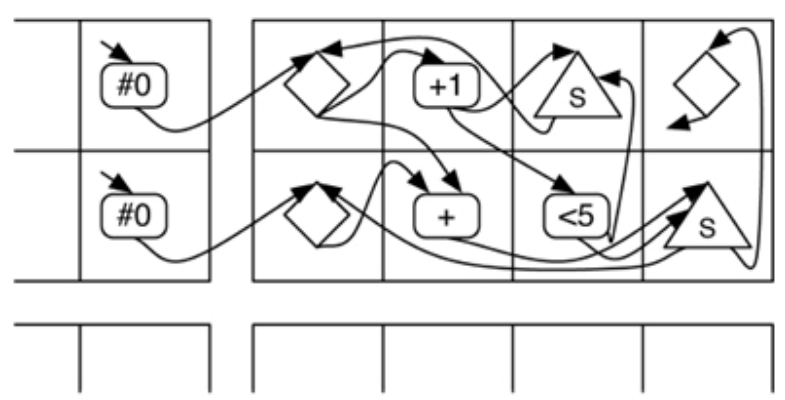

Figura 6.15: O loop da Figura 6.13c mapeado sobre dois domains WaveCache (Swanson et al. (2007))

Na Figura 6.15 é representado a execução do loop da Figura 6.13c mapeada sobre dois domains. Cada quadrado representa um EP.

Um EP possui cinco estágios que permitem a execução de instruções dependentes no mesmo EP. Na Figura 6.16 é mostrado a estrutura do EP (Swanson et al. (2006)):

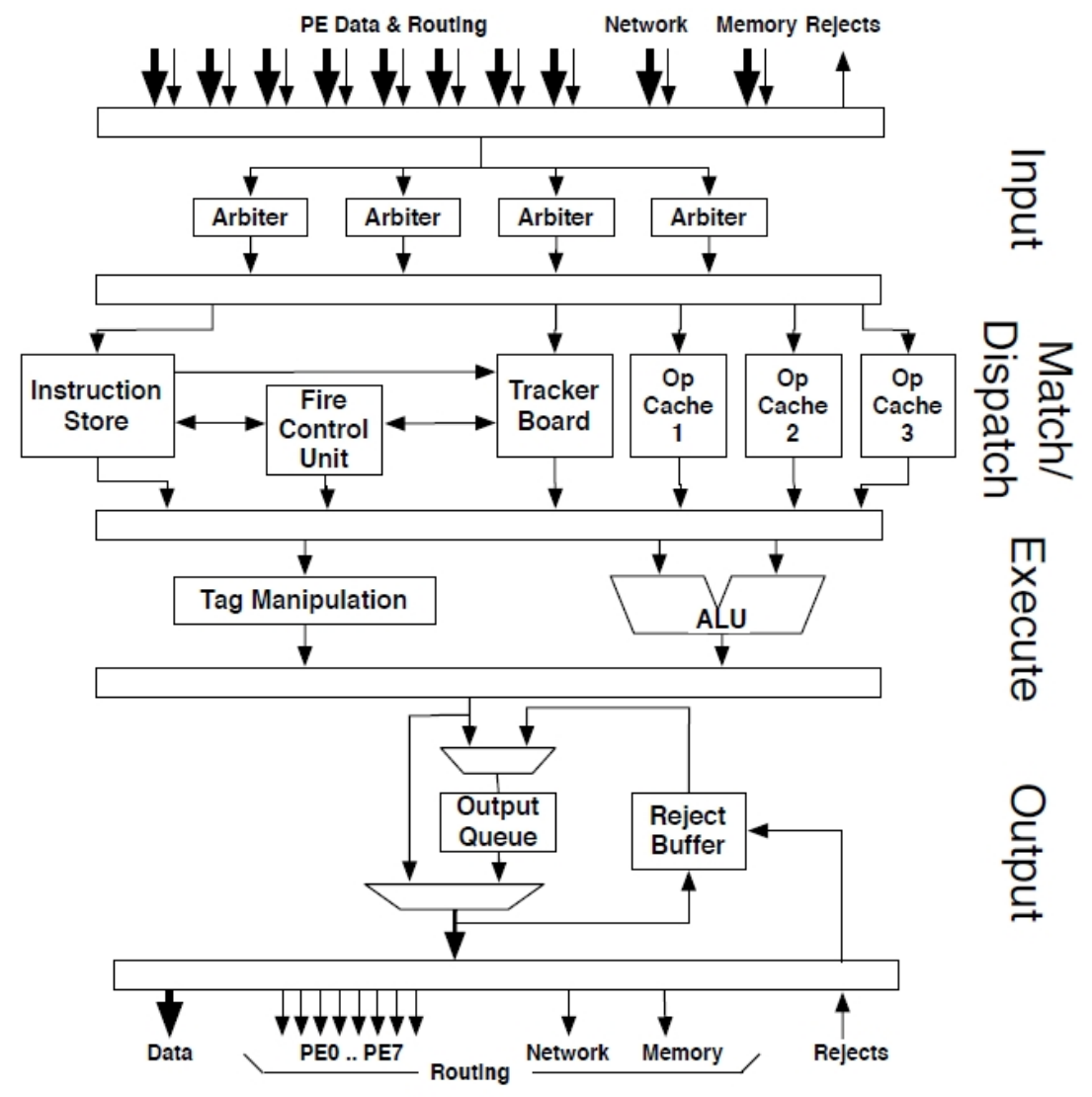

Figura 6.16: Diagrama de Blocos do EP (Swanson et al. (2006)) 
O primeiro estágio corresponde a Entrada (input), onde tokens chegam ao $E P$ vindos de outro EP ou do próprio. O segundo estágio corresponde a Correspondência (match), onde os tokens entram na tabela de matching, chamada matching table, que determina quais instruções estão prontas para disparar. Quando uma instrução já possui todos os seus operandos disponíveis ela é movida para uma fila de instruções prontas para execução, chamada scheduling queue. O Match pode ocorrer também de forma especulativa, quando o EP supõe que alguma instrução que está executando localmente produzirá operandos para uma outra, também local (Marzulo (2011)). O terceiro estágio corresponde ao Envio (dispatch), o EP define uma instrução da fila de execução, lê seus operandos pela tabela de matching, e os envia para o estágio "execução". O quarto estágio, Execução (execute) é onde a instrução é executada e seus resultados enviados para a fila de saída e/ou para a rede de comunicação local. No quinto estágio Saída (output), um token resultante da execução de uma instrução é enviado para instruções em outros EPs ou no próprio. 


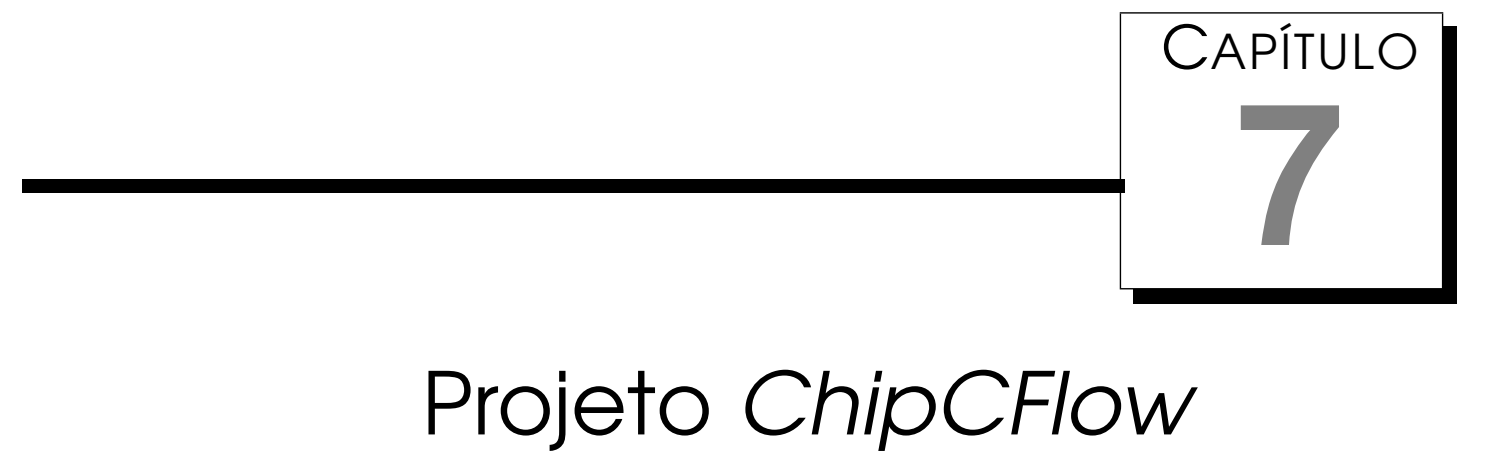

O projeto ChipCflow é o projeto de uma ferramenta para execução de algoritmos utilizando o modelo a fluxo de dados dinâmico em hardware reconfigurável, sendo desenvolvido no $L C R$, vinculado ao Departamento de Sistemas de Computação do Instituto de Ciências Matemáticas e de Computação da Universidade de São Paulo. Tem como principal objetivo utilizar o modelo de arquiteturas a fluxo de dados, associado ao conceito de computação reconfigurável, para acelerar programas de aplicação escritos em linguagem C. Assim, a ferramenta ChipCflow aproveita a potencialidade tanto do processamento paralelo quanto da computação reconfigurável e conseqüentemente, proporciona uma rápida adequação da máquina paralela ao problema a ser resolvido, garantindo um alto desempenho e flexibilidade em adaptar o sistema paralelo à aplicação desejada. Essa aceleração vai acontecer nas partes mais intensas do processamento (por exemplo: loops), por meio da execução direta em hardware, aproveitando ao máximo o paralelismo considerado natural no modelo a fluxo de dados (SILVA et al. (2009a)), (Silva and Lopes (2010)).

A origem do projeto ChipCflow deu-se motivado por pesquisas realizadas em 2005 e 2006, pelo prof. Dr. Jorge Luiz e Silva, coordenador do projeto, envolvendo máquinas a fluxo de dados sendo implementadas utilizando-se computação reconfigurável e aproveitando a tese de doutorado do próprio professor (Silva (1992)), cujo tema na época foi a proposta de uma Máquina a Fluxo de Dados Dinâmica, a MFDD tolerante a falhas em um Computador Paralelo Estruturado Recursivamente CPER, já referenciado anteriormente nesta tese. O projeto ChipCflow teve seu inicio no primeiro semestre de 2006 (Silva and Marques (2006)), (Silva (2006)).

Na tese original do Prof. Jorge foram propostos: um formato para as tags 
dos tokens; um conjunto de operadores para a manipulação destas tags; um carregador que servia para escalonar o grafo DFG nos EPs do CPER e um conjunto de operadores básicos para representar programas a fluxo de dados dinâmicos. Também, como já visto nos capítulos anteriores, os operadores foram simulados no simulador FDsim. Embora a idéia tenha surgido na tese do prof. Jorge, tanto a arquitetura da máquina CPER, quanto os operadores desenvolvidos são totalmente diferentes dos operadores e arquiteturas propostos no projeto ChipCflow.

Na Figura 7.1 é descrito o Diagrama de Fluxo proposto para a ferramenta ChipCflow. Conforme descrito na Figura 7.1, uma aplicação originalmente escrita em linguagem $C$ passa por um compilador (front-end, back-end) que fará uso de módulos de operadores pré-definidos para compor o programa da aplicação, agora na linguagem $V H D L$, e em seguida ser utilizado em ferramentas $E D A$, até a geração final do arquivo de programação para um FPGA.

Uma vez definido o projeto e suas diferentes partes, vários alunos de iniciação científica, mestrado e doutorado, sob orientação do prof. Jorge, iniciaram suas pesquisas tendo como base a proposta do projeto ChipCflow. Pode-se destacar a definição e implementação dos operadores básicos (mestrado defendido (Astolfi (2009)) e publicado (Astolfi and Silva (2007))); a implementação de grafos completos utilizando os operadores implementados (mestrado defendido (Correia (2009)) e publicado (Silva and Correia (2009)); co-orientação informal das implementações de um front-end para um compilador no ChipCflow (doutorado defendido (da Costa (2009)) e publicado (Silva et al. (2009)), (SILVA et al. (2009b)), (SILVA et al. (2009a))); estudos diversos sobre a reconfiguração parcial dinâmica para o projeto ChipCflow (dois mestrados defendidos (Junior (2011)) e (Sanches (2010))) e publicados ((Junior et al. (2010a)), (Junior et al. (2010b))); definição dos operadores iterativos para gerenciamento de loops (mestrado defendido (Silva (2011b))) e alguns resultados gerados pelo prof. Jorge como o protocolo de comunicação (ack e strobe) para sincronizar os dados em um operador (Silva and Marques (2006)) uma proposta para unidade de Matching de dados localizados dentro de cada operador (Silva (2006)) e implementação de benchmarks considerando o ChipCflow estático, submetido ao WSEAS Transaction on Computer.

Duas teses estão em andamento no projeto ChipCflow, a que motivou este texto, que trata do operador assíncrono e a que propõe um conversor de código $C$ para VHDL, usando como front-end um open-source e gerando todo o back-end com as características do modelo a fluxo de dados para o projeto ChipCflow. 


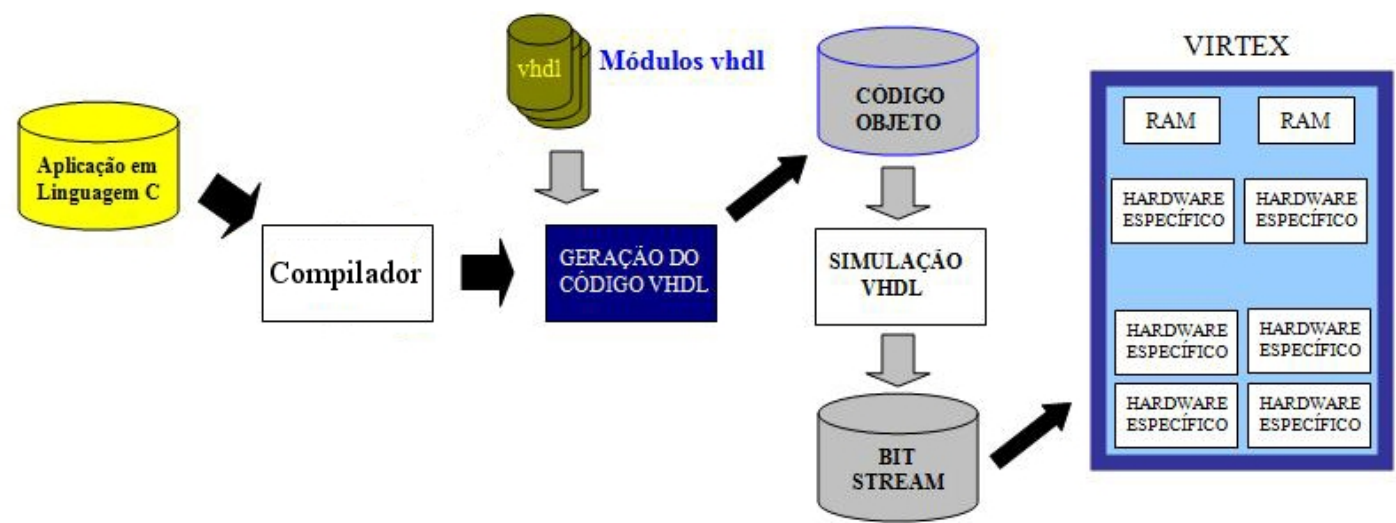

Figura 7.1: Diagrama de Fluxo da Ferramenta ChipCflow (Silva (2011a))

\subsection{Operadores propostos para o ChipCflow}

Um programa para uma máquina a fluxo de dados é organizado como uma máquina a fluxo de dados. Na máquina a fluxo de dados os nós representam as instruções e os arcos representam a dependência entre as instruções e por onde fluem os dados entre os nós. No projeto ChipCflow, as representações definidas em (Silva (1992)) serão utilizadas. Como mostra a Figura 7.2, há dois tipos de arcos sobre uma máquina a fluxo de dados, um representado por linhas contínuas, que transporta dados, chamado (data link), e outro que transporta valores booleanos, que transportam sinais de controle, chamado (logical link), representado por linhas tracejadas.

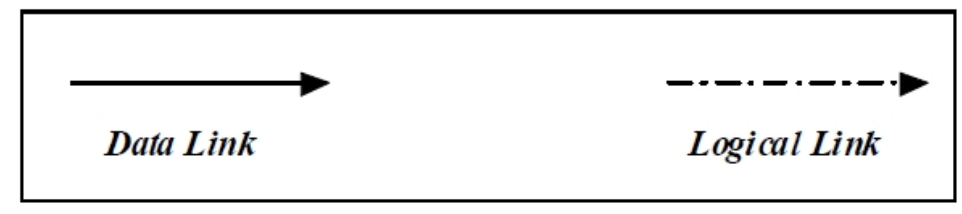

Figura 7.2: Tipos de enlace das máquinas a fluxo de dados (Silva (1992))

O ChipCflow utiliza um conjunto de operadores, conforme descrito na Figura 7.3. Ainda na Figura 7.3 é possivel verificar os tokens chegando nos arcos de entrada dos operadores e a Figura 7.4 mostra os tokens resultantes, na saída dos operadores, gerado após o processamento.

O operador decider, possui duas entradas de dados e uma saída de controle. O operador gera um pacote (ou token) de controle, verdadeiro ou falso, dependendo de seus valores de entrada e da função de teste $T$, armazenada nesse operador.

O operador Non-Deterministic Merge (NDM), possui duas entradas de dados e uma saída de dado. Não há uma regra de habilitação estrita, isto é, o nó é habilitado tão logo uma de suas portas de entrada contenha um token. Quando ele dispara, uma cópia de seu token de entrada é enviada para a saída. Assim 

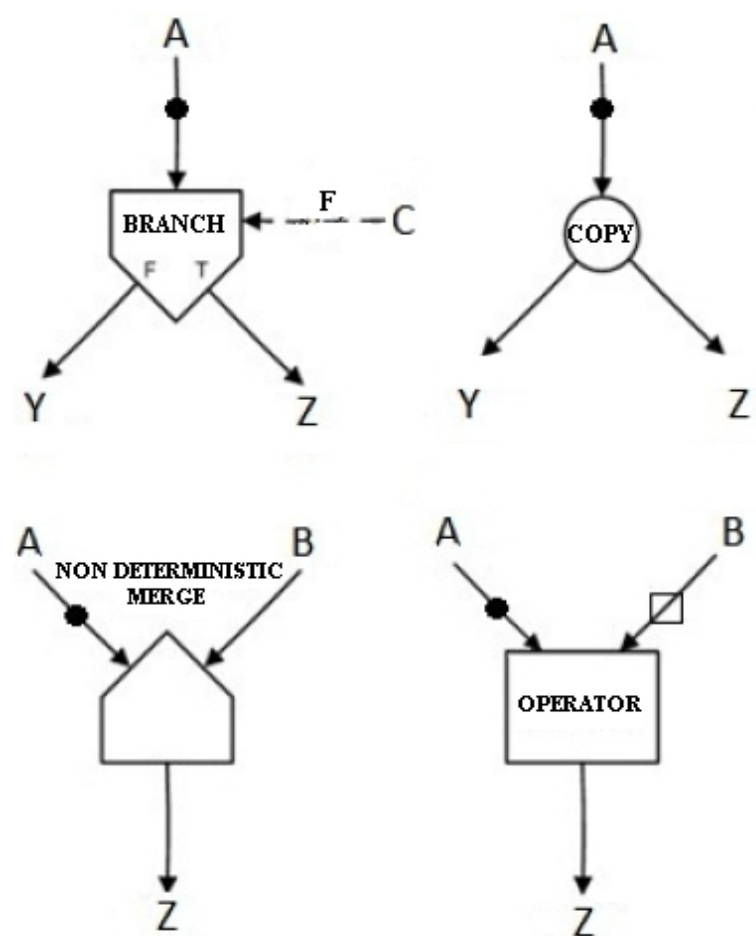
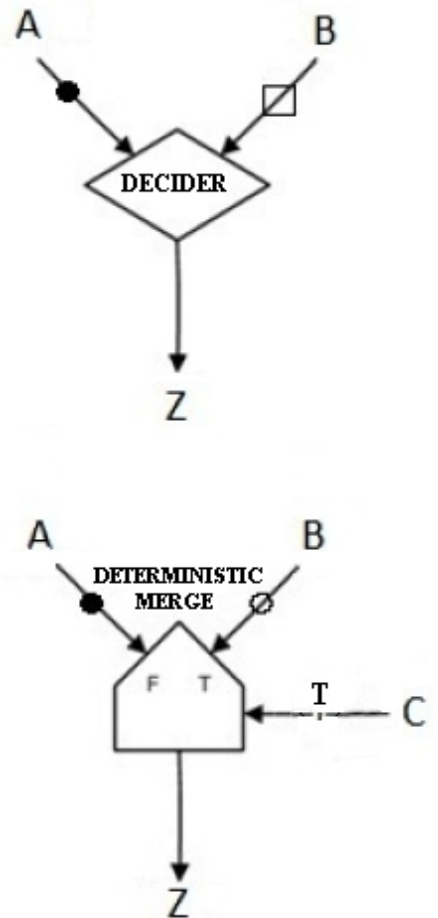

Figura 7.3: Operadores usados na máquina a fluxo de dados do ChipCflow, tokens chegando nos arcos de entrada dos operadores (circulo preenchido, circulo sem preenchimento, quadrado, letras $F$ e $T$ indicam diferentes tokens (Silva and Lopes (2010))

como o operador deterministic merge, esse operador é responsável por unir um de dois sub-grafos de entrada.

O operador Deterministic Merge (DM), possui três entradas e uma saída, sendo duas entradas de dados, uma entrada de controle e uma saída de dado. $\mathrm{Na}$ entrada de controle, será recebido um token com um valor booleano que irá determinar qual dos dois tokens de dados, recebidos pelas entradas será enviado para a saída. Esse operador é responsável por unir um de dois subgrafos de entrada.

O operador branch, possui duas entradas e duas saídas, sendo uma entrada de dado, uma entrada de controle e duas saídas de dados. Na entrada de controle, será recebido um token com um valor booleano que irá determinar qual das duas saídas, será enviado o token recebido pela entrada de dados. Esse operador é responsável por ramificar a entrada em um de dois sub-grafos de saída.

O operador copy, possui uma entrada de dado e duas saídas de dados. Não há uma regra de habilitação estrita para esse operador. Assim, esse operador é responsável por gerar duas cópias do token de entrada, uma para cada saída.

Finalmente o operador operator, possui duas entradas de dados e uma saída de dado. Não há uma regra de habilitação estrita para esse operador. Esse operador é responsável por gerar um token com o resultado de alguma 
operação lógica ou aritmética, dependendo da função $F$, armazenada nesse operador.
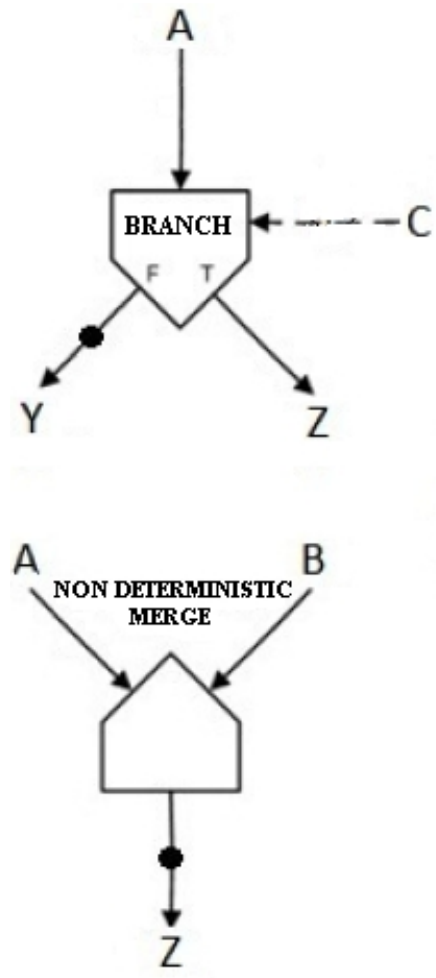
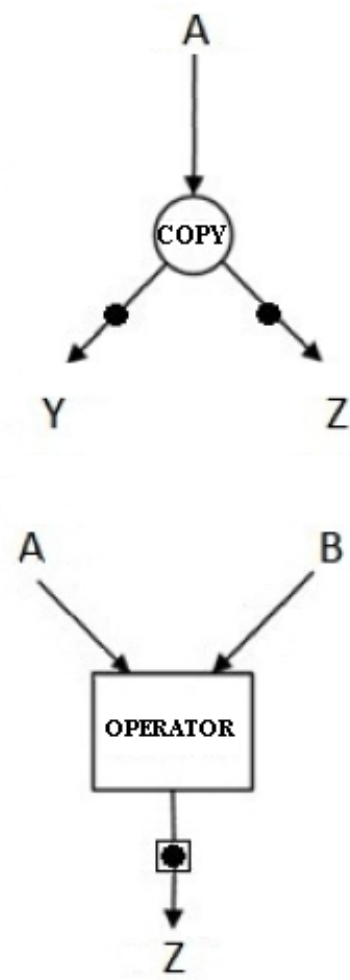
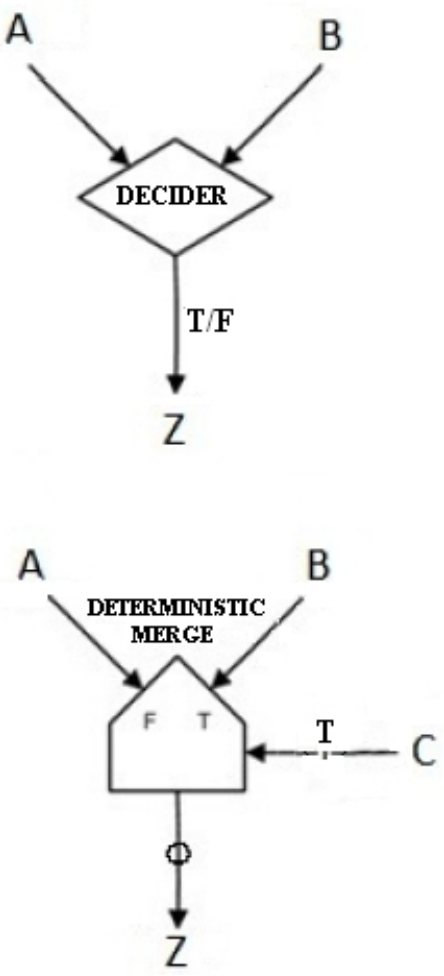

Figura 7.4: Tokens processados nos arcos de saída dos operadores (circulo preenchido, circulo sem preenchimento, circulo preenchido dentro do quadrado, letras $F$ e $T$ indicam diferentes tokens gerados pelo processamento dos operadores (Silva and Lopes (2010))

Os operadores branch, DM, NDM e decider são usados para representar computações iterativas e condicionais na máquina a fluxo de dados (Silva and Lopes (2010)).

Os operadores recebem ou enviam tokens por meio do protocolo handshake descrito em (Silva and Marques (2006)). Assim, para cada entrada ou saída de um operador, existe um par de sinais (ack e strobe) responsáveis pela implementação do protocolo. Esse protocolo sincroniza os tokens nas entradas e saídas dos operadores e está descrito na Figura 7.5. Conforme descrito na Figura 7.5, para cada arco de entrada ou saída, o protocolo de comunicação define que deve haver um par de sinais associados. Quando um token chega em um operador consumidor, um sinal de strobe vindo do operador produtor vem junto e serve para sinalizar que existe um novo token naquela entrada. O sinal de ack então é enviado do operador consumidor para o operador produtor indicando que o token foi consumido. Assim, o operador produtor não pode enviar tokens ao operador consumidor, até que este envie um sinal de ack indicando que a operação anterior foi realizada com êxito.

Na Figura 7.6 é mostrado um exemplo de uma máquina a fluxo de dados usando os operadores do ChipCflow, para a expressão $F<=(a \star b) *(b+c)$, sem 


\section{Produtor Consumidor}

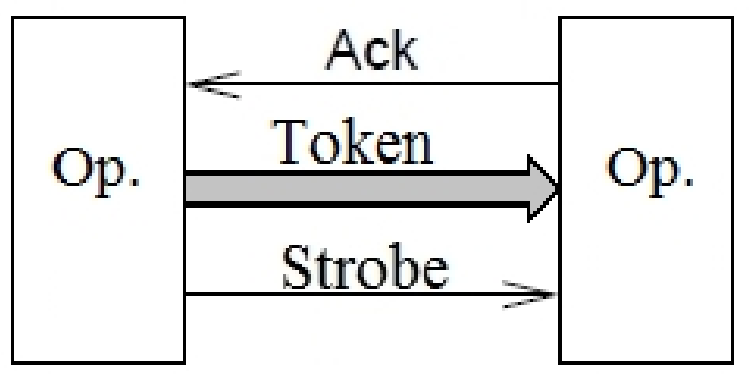

Figura 7.5: Protocolo handshake entre operadores

comandos iterativos ou condicionais.

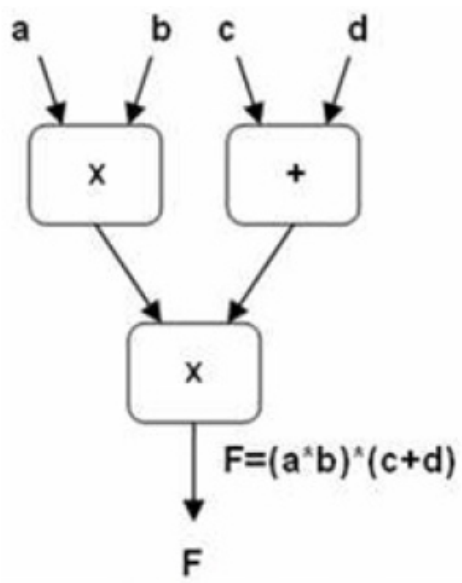

Figura 7.6: Exemplo de uma máquina a fluxo de dados usando os operadores do ChipCflow (Silva and Lopes (2010))

Na Figura 7.7 é mostrado o exemplo de uma máquina a fluxo de dados para um bloco de código condicional da linguagem $C$.

A Figura 7.8 é mostrado o formato do token utilizado pelo ChipCflow. Os campos "Ativação", "Aninhamento" e "Iteração" compõem a tag, que como já mostrado nos capítulos anteriores, definem o contexto computacional. A tag junto com o dado é chamado de token. Os três campos da tag indicam, respectivamente, qual é a ativação de grafo que o dado pertence; qual é a ativação de sub-grafo, que também será referenciado como aninhamento da construção iterativa na qual o dado está circulando em determinado instante e; qual é a iteração atual do dado, caso esteja em uma construção iterativa (Silva (2011b)). O campo "dado" na figura representa o valor do dado que o token carrega.

Como discutido na máquina WaveScalar, no capítulo anterior, o campo "ativação" da tag descrita na Figura 7.9, é gerada toda vez que um novo token entre em uma máquina a fluxo de dados, valendo para todos os nós de entrada naquele grafo. Isso significa que um conjunto de dados de entrada em uma máquina a fluxo de dados irá circular pelo grafo, tendo o mesmo valor para 


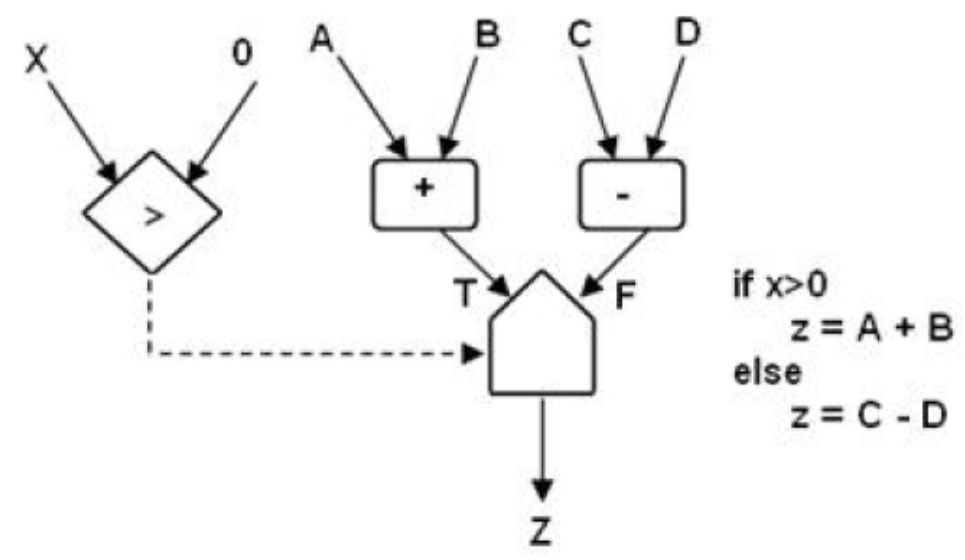

Figura 7.7: Exemplo de uma máquina a fluxo de dados para uma expressão condicional usando os operadores do ChipCflow (Correia (2009))

\begin{tabular}{|c|c|c|c|}
\hline \multicolumn{1}{|c}{4 bits } & \multicolumn{1}{c}{4 bits } & \multicolumn{1}{c}{8 bits } & 16 bits \\
\hline Ativação & Aninhamento & Iteração & Dado \\
\hline
\end{tabular}

Figura 7.8: Formato do token no ChipCflow (Silva and Lopes (2010))

o campo "ativação" na tag para todos os tokens que entram no grafo em um determinado instante. Novos conjuntos de dados podem ser recebidos nas entradas da máquina a fluxo de dados, conseqüentemente, novos valores serão gerados para o campo "ativação" para cada conjunto de dados que entram no grafo. Assim, tokens poderão circular por uma máquina a fluxo de dados com diferentes tags, especificado em seu campo "ativação".

Os campos "aninhamento" e "iteração" no formato da tag, descrito na Figura 7.9, descreve apenas a qual nível de aninhamento (por exemplo, loop dentro de loop) o dado se encontra e em que passo da iteração o dado está sendo referenciado, respectivamente. Assim, para qualquer dado, sua tag especifica a qual conjunto da ativação o dado pertence, em que nível de aninhamento o dado está e em qual iteração, naquele nível de aninhamento, o dado está sendo utilizado.

Em (Silva (2011b)) foram propostos alguns operadores, específicos para a correta manipulação dos campos da tag e serão discutidos a seguir.

A idéia principal do modelo tagged-token é que a cada dado esteja associado uma tag e somente dados com a mesma tag são processados juntos em um determinado operador. Dados com a mesma tag são chamados de dados parceiros. Desta forma, a regra de disparo de um operador é tal que: um operador dispara somente quando todos os dados que possuem a mesma tag estão disponíveis nas suas entradas. O conceito de tagged-token implica em operadores específicos para realizar o gerenciamento das tags, mais especificamente, criar, manter e destruir tags durante a execução de um programa (Silva (2011b)). 
Os operadores propostos para manipulação das tags no projeto ChipCflow, são: New Tag Manager (NTM), New Iteration Generator (NIG), Initial Tag Generator (ITG), Tag Remover (TR), New Tag Destructor (NTD), além de uma estrutura de memória chamada Old Tag Table (OTT). Na Figura 7.9 há um exemplo de um grafo com os operadores iterativos NTM, NIG e NTD, propostos em (Silva (2011b)).

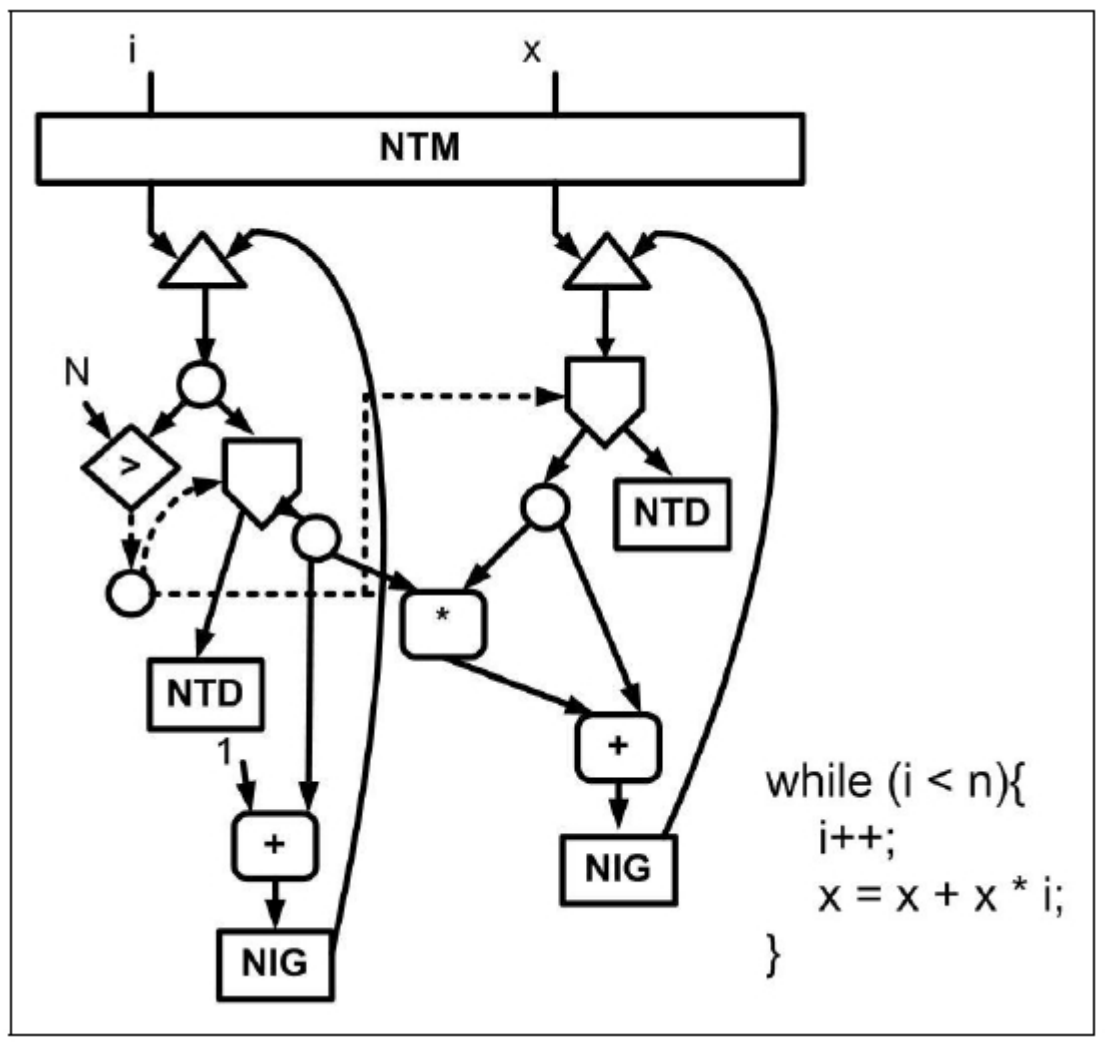

Figura 7.9: Exemplo de uma máquina a fluxo de dados para uma itaração usando os operadores NTM, NIG, NTD, do ChipCflow (Silva (2011b))

Como pode ser visto na Figura 7.9, o bloco responsável por gerar uma nova tag a um conjunto de dados e devolver essa tag ao conjunto de tags disponíveis é o NTM. O bloco responsável por ajustar a tag a cada iteração de um loop é o NIG. O bloco NTD recupera a tag antiga dos dados de saída recebida pelo NTM (Silva (2011b)).

No começo da execução do programa, os dados estão armazenados em memória e esses dados não possuem tags (Silva and Lopes (2010)). Assim, essas tags devem ser geradas em tempo de execução quando os dados entram no grafo. O operador responsável por criar uma tag inicial para cada dado que chega a um grafo é o ITG. Cada variável que entra no grafo deverá passar por um operador ITG. O ITG deve manter um registrador interno, que começa com zero armazenado e cada vez que um dado passa por ele, o dado recebe em sua ativação de grafo o valor do registrador e este valor é incrementado em seguida. Para os campos "Aninhamento"e "Iteração"inicialmente é atribuído 
zero. Formalmente para o token inicial tem-se (Silva (2011b)):

$$
\begin{gathered}
\text { ITGentrada }=<\text { dado > } \\
\text { ITGsaída = <"Ativação":0:0; dado > }
\end{gathered}
$$

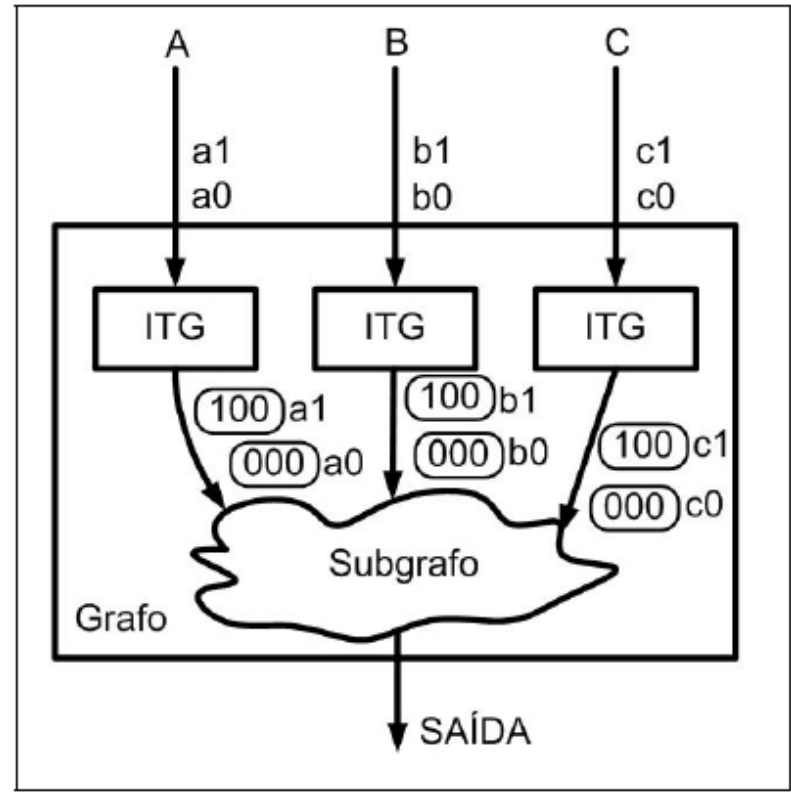

Figura 7.10: Criação de tags iniciais utilizando o operador ITG (Silva (2011b))

Na Figura 7.10 é descrito um exemplo da utilização do operador ITG. Conforme descrito na Figura 7.10, um grafo possui três entradas $A, B$ e $C$ e que recebe dois conjuntos de entradas $e O=\langle f a O ; b 0 ; c 0 g\rangle$ e $e 1=\langle a 1 ; b 1 ; c 1\rangle$. No grafo gerado pelo compilador, existirá um operador ITG ligado a cada entrada do grafo. Cada dado chega sem tag no grafo e após passar pelo ITG ele passa a circular no grafo juntamente com sua tag, representada na figura pelo retângulo de bordas arredondadas. No caso, a0 deve chegar antes de a1, b0 antes de bl e assim por diante. A garantia desta ordem é feita pelo compilador ao gerar o grafo e as operações de acesso a memória (Silva (2011b)).

A saída de um grafo pode estar ligada em diferentes estruturas, como por exemplo, dispositivos de entrada e saída. Um dado que sai do grafo e vai para uma destas estruturas não necessita mais de sua tag, portanto ela deve ser removida. O operador responsável por remover a tag de um token é o TR. Dados que passam pelo TR não voltam mais para o grafo. Formalmente, seu funcionamento em termos de entrada e saída pode ser descrito como (Silva (2011b)):

$$
\begin{gathered}
\text { TRentrada }=\text { < "Ativação", "Aninhamento", "Iteração"; dado > } \\
\text { TRsaída }=<\text { dado > }
\end{gathered}
$$

Como mostrado anteriormente, vários dados de diferentes iterações de uma construção iterativa podem estar circulando ao mesmo tempo em um grafo. 
Por isso, a tag dos dados deve ter um campo utilizado para armazenar qual é a iteração atual do dado. Conseqüentemente, ao final de cada iteração deve haver um operador que ajustará o campo da iteração atual da tag do dado que passar por ele. Tal operador é o NIG. Na Figura 7.11 é mostrado um exemplo do operador NIG, para diferenciar as diversas iterações de um loop. Em termos de entrada e saída, o funcionamento do NIG pode ser descrito como (Silva (201 1b)):

NIGentrada = < "Ativação", "Aninhamento", "Iteração"; dado > NIGsaída = < "Ativação", "Aninhamento", "Iteração + 1"; dado >

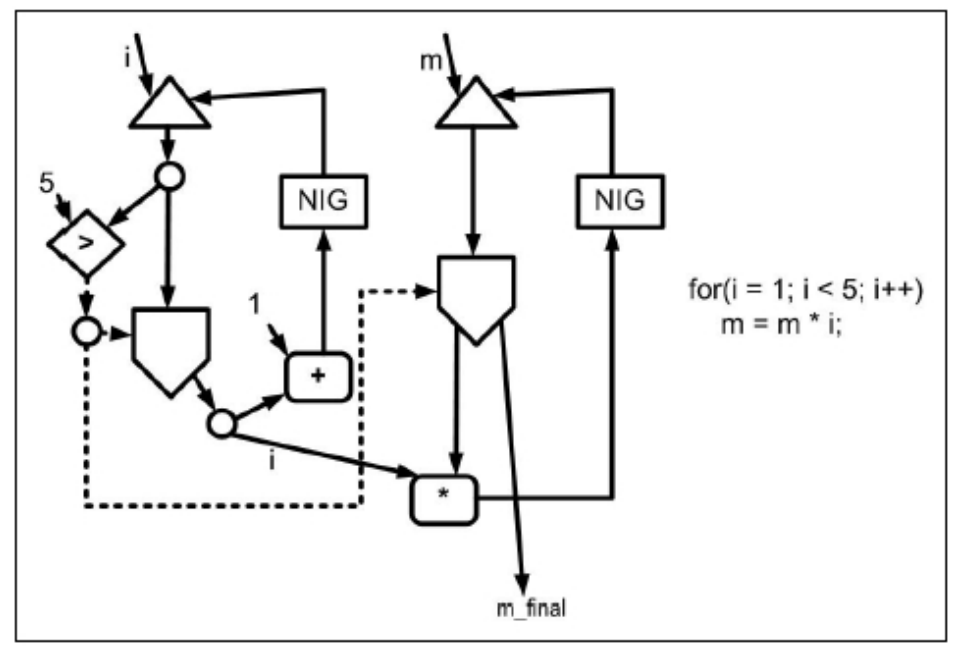

Figura 7.11: Loop utilizando o operador NIG (Silva (2011b))

Segundo Silva (2011b), diferentemente do que acontece na entrada de um grafo, os dados que entram em uma construção iterativa podem não respeitar a ordem dos conjuntos de entradas. A Figura 7.12 ilustra este problema.

Inicialmente o grafo recebe um conjunto de entradas e $0=(1,10)$ e logo em seguida recebe outro conjunto de entradas $e 1=(3,-10)$. Ao passar pelos operadores ITG, cada dado recebe sua tag, tornando-se e0 $=(<0.0 .0$; $1>,<0.0 .0 ; 10>)$ e e1 $=(<1.0 .0 ; 3>,<1.0 .0 ;-10>)$. O lado esquerdo do grafo, que é referente a entrada a, irá incrementar cada um dos valores e gerará em ordem os seguintes tokens na entrada do bloco for: $(<0.0 .0$; $2>e<1.0 .0 ; 4>$ ). O lado problemático do grafo é o lado direito, que é referente ao processamento da entrada b. Quando o token $(<0.0 .0 ; 10\rangle)$ passar pelo grafo, o operador de decisão irá redirecioná-lo para o operador de multiplicação. Já o token $(<1.0 .0 ;-10\rangle)$ será redirecionado para o operador de soma. Considerando que uma multiplicação leva muito mais tempo para executar do que uma soma, o token $(<1.0 .0 ;-10>)$ que após a soma se torna $(<1.0 .0 ; 0>)$ chegará na entrada do bloco for antes do token $(<0.0 .0$; $10>$ ), que virá do resultado da multiplicação. 


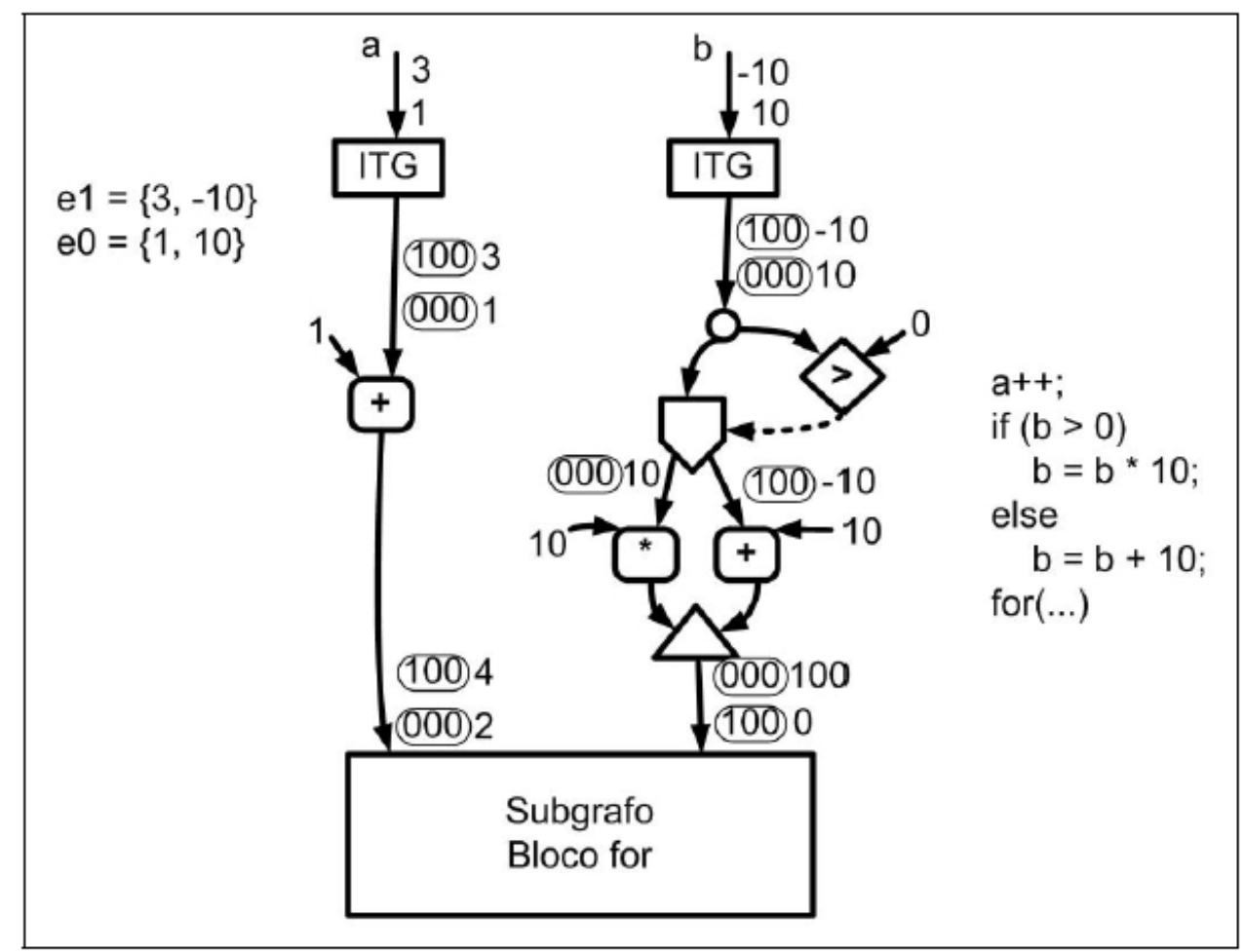

Figura 7.12: Possivel entrada de dados fora de ordem em um bloco (Silva (2011b))

Suponha que exista um operador de gerenciamento de tags na entrada do bloco for, conforme descrito na Figura 7.12, e que ele recebesse os dados fora de ordem e gerasse uma nova ativação de sub-grafo para os mesmos. Neste caso, dados que faziam parte de diferentes conjuntos de entradas poderiam passar a fazer parte de um mesmo conjunto de entradas. Conseqüentemente, o processamento realizado pelo grafo provavelmente não seria o desejado. Para evitar este problema, o operador de gerenciamento de tags posicionado na entrada de uma construção iterativa deve esperar que todos os dados com a mesma tag cheguem. Somente após isto, o operador deve atribuir uma nova ativação de sub-grafo para estes dados e enviá-los para o processamento dentro da construção iterativa (Silva (2011b)).

O operador responsável por atribuir uma nova ativação de sub-grafo ou aninhamento para um token é o $N T M$, o qual possui um registrador interno que começa com zero armazenado e, para cada conjunto de entradas recebido, o NTM atribui o valor do registrador ao campo ativação de sub-grafo dos tokens e incrementa o valor do registrador. O NTM segue a regra de disparo que por definição qualquer operador de uma máquina a fluxo de dados dinâmica tagged-token deve seguir, uma vez que ele deve esperar que todas as entradas tenham recebido os dados com a mesma tag para realizar seu processamento. Além disso, o NTM deve atribuir zero para o campo iteração atual da tag, pois uma nova ativação de sub-grafo de uma construção iterativa se inicia na 
iteração zero (zero neste caso representa a iteração inicial e não o valor da variável que controla a construção iterativa). Seu funcionamento em termos de entradas e saídas é descrito abaixo (Silva (2011b)):

$$
\begin{gathered}
\text { NTMentrada }=<\text { "Ativação", "Aninhamento", "Iteração"; dado > } \\
\text { NTMsaída }=<\text { "Ativação", "Aninhamento + 1", "0"; dado > }
\end{gathered}
$$

Como os dados que entram em um grafo sempre chegam em ordem, pode haver um ITG diferente relacionado com cada entrada. Porém no caso do NTM, deve haver um único operador para todas as entradas de uma construção iterativa para que seja possivel atribuir o mesmo valor de ativação de subgrafo para todos os dados que possuem a mesma tag.

Além dessas funcionalidades descritas, o NTM deve realizar mais uma tarefa que será detalhada a seguir e descrito na Figura 7.13 (Silva (2011b)).

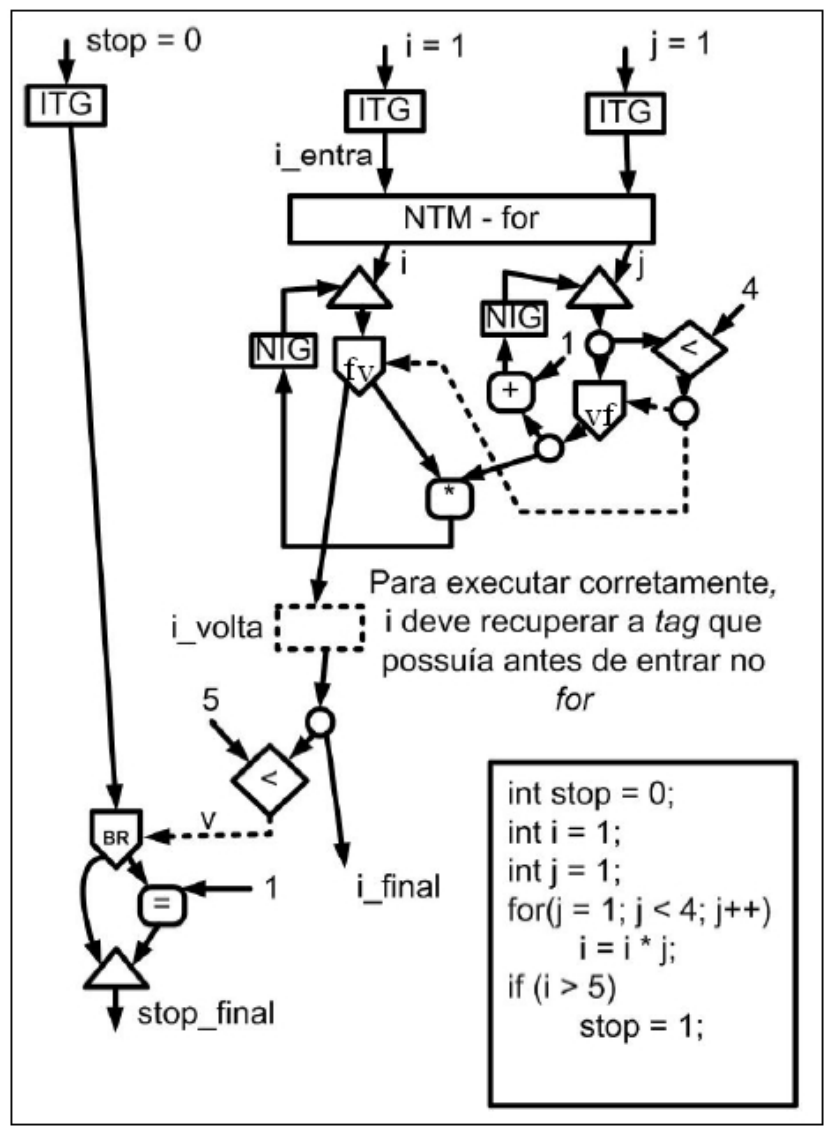

Figura 7.13: Grafo onde um token deve recuperar sua tag antiga (Silva (2011b))

O grafo da Figura 7.13 possui três variáveis de entrada: stop, i e j. Como declarado no código, os valores recebidos na entrada do grafo são 0 para stop, 1 para i e 1 para $j$.

Todos os três dados entram em seus respectivos ITG e se tornam stop $=(<0.0 .0 ; 0>), i=(<0.0 .0 ; 1>)$ e $j=(<0.0 .0 ; 1>)$. O token da variável stop ficará esperando que seu dado parceiro chegue no operador branch (BR) 
através do arco v. O for presente no grafo e descrito na Figura 7.13, irá executar três iterações. Os tokens $i$ e j produzidos no final da primeira, segunda e terceira iteração são, respectivamente:

$$
\begin{aligned}
& i=(<0.0 .1 ; 1>) \text { e } j=(<0.0 .1 ; 2>) \\
& i=(<0.0 .2 ; 2>) \text { e } j=(<0.0 .2 ; 3>) \\
& i=(<0.0 .3 ; 6>) \text { e } j=(<0.0 .3 ; 4>)
\end{aligned}
$$

A comparação $j<4$ no grafo retorna falso e o token $i$ vai para o arco i_volta, onde a comparação é feita e um token $v=(<0.0 .3$; Verdadeiro $>)$ é gerado, ao chegar no branch $\mathrm{BR}$, terá esperando o token stop $=(<0.0 .0$; $0>)$. Entretanto, as tags de stop e v não são iguais. Para resolver este problema, deve haver um operador posicionado na saída da construção iterativa, na Figura 7.13 é o retângulo com bordas em linhas pontilhadas, capaz de recuperar a tag que o token possuía antes de entrar na construção iterativa (Silva (2011b)). O operador responsável por recuperar a tag antiga de um token que está saindo da construção iterativa para voltar para um nível de aninhamento anterior é o NTD. Mais especificamente, as informações que devem ser recuperadas são aninhamento e iteração. Formalmente, em termos de entrada e saída, o funcionamento do NTD é (Silva (2011b)):

$$
\begin{gathered}
\text { NTDentrada = < "Ativação", "Aninhamento", "Iteração"; dado > } \\
\text { NTDsaída = < "Ativação", "Aninhamento - 1", "Iteração - 1"; dado > }
\end{gathered}
$$

Para ser possivel recuperar a tag antiga de um token, é necessário armazenála em alguma memória no momento em que o dado chega na construção iterativa. O operador NTD então consulta esta memória quando o token passar por ele e recupera a tag antiga. Esta memória é uma estrutura chamada OTT e é descrito na Figura 7.14. A OTT armazena duas informações por conjunto de entradas: a old tag (representada pelos campos aninhamento e iteração) dos tokens e a new tag (representada pelos campos ativação e aninhamento). Não é necessário armazenar na OTT qual é a nova iteração atual dos tokens, já que a iteração atual de todos os tokens é sempre ajustada para zero pelo NTM na entrada da construção iterativa (Silva (2011b)).

O operador responsável por enviar as informações que serão salvas na OTT é o $N T M$, além de realizar as outras funções já explicadas anteriormente. O NTD recupera os valores das old tag na OTT por meio dos valores das new tag observando os campos ativação e aninhamento. A OTT e o NTD existem apenas nos casos onde pelo menos um token que entra em uma construção iterativa necessita voltar para o nível de aninhamento anterior. Nos casos onde nenhuma variável volta a ser processada no nível anterior, não há necessidade de recuperar suas tags antigas (Silva (2011b)). 


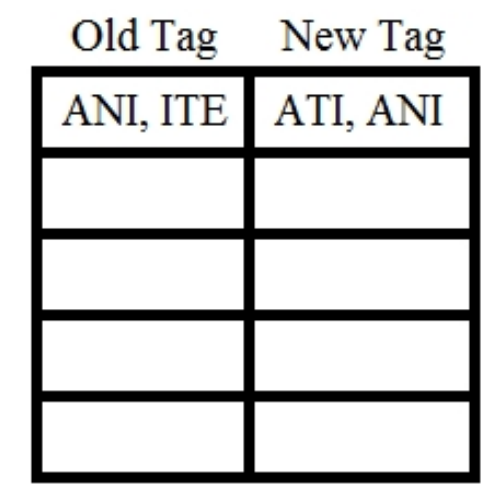

Figura 7.14: Estrutura da memória OTT

Os operadores propostos para manipulação de memória no projeto ChipCflow, ainda em desenvolvimento são: Load, Store e Gerenciador de Memória. Considerando o Algoritmo 1, uma proposta de organização de memória para este algoritmo pode ser vista na Figura 7.15.

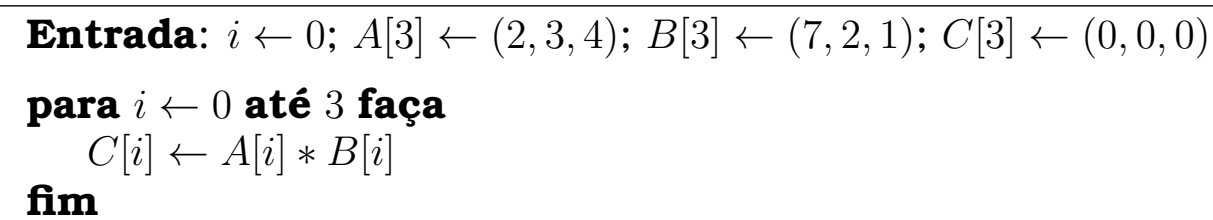

Algoritmo 1: Soma de vetores, elemento por elemento (Silva (2011b))

Como descrito na Figura 7.15, nesta proposta de organização de memória, cada variável possui um banco de memória localizado acima do gerenciador de memória. O gerenciador de memória é o intermediário entre as solicitações de load e store e os bancos de memória. As instruções de load e store se comunicam com a máquina a fluxo de dados solicitando e recebendo dados.

A instrução load recebe como entrada o endereço base da variável, representado por $(\& i, \& A, \& B)$; o deslocamento representado na figura como $(0$, i ), que pode ou não ser definido em tempo de execução pela máquina a fluxo de dados; um canal para solicitar o dado ao gerenciador de memória, na figura representado por (Solicita i[0], Solicita A[i], Solicita B[i]); um canal para receber este dado do gerenciador, na figura representado por (Recebe i[0], Recebe A[i], Recebe B[i]) e um canal para devolver o dado lido para o grafo, representado na figura por (i, $A[i], B[i])$.

Já o operador store recebe o dado que deverá ser armazenado em memória, na Figura 7.15 representado por $\mathrm{A}[i] \star \mathrm{B}[i]$; o endereço base para armazenamento, na Figura 7.15 representado por \&C; o deslocamento, na Figura 7.15 representado por i e; um canal para solicitar o armazenamento ao gerenciador, na Figura 7.15 representado por Envia C [i].

Os operadores load e store também seguem o protocolo de comunicação definido para os outros operadores. Quando matrizes de mais de uma dimen- 


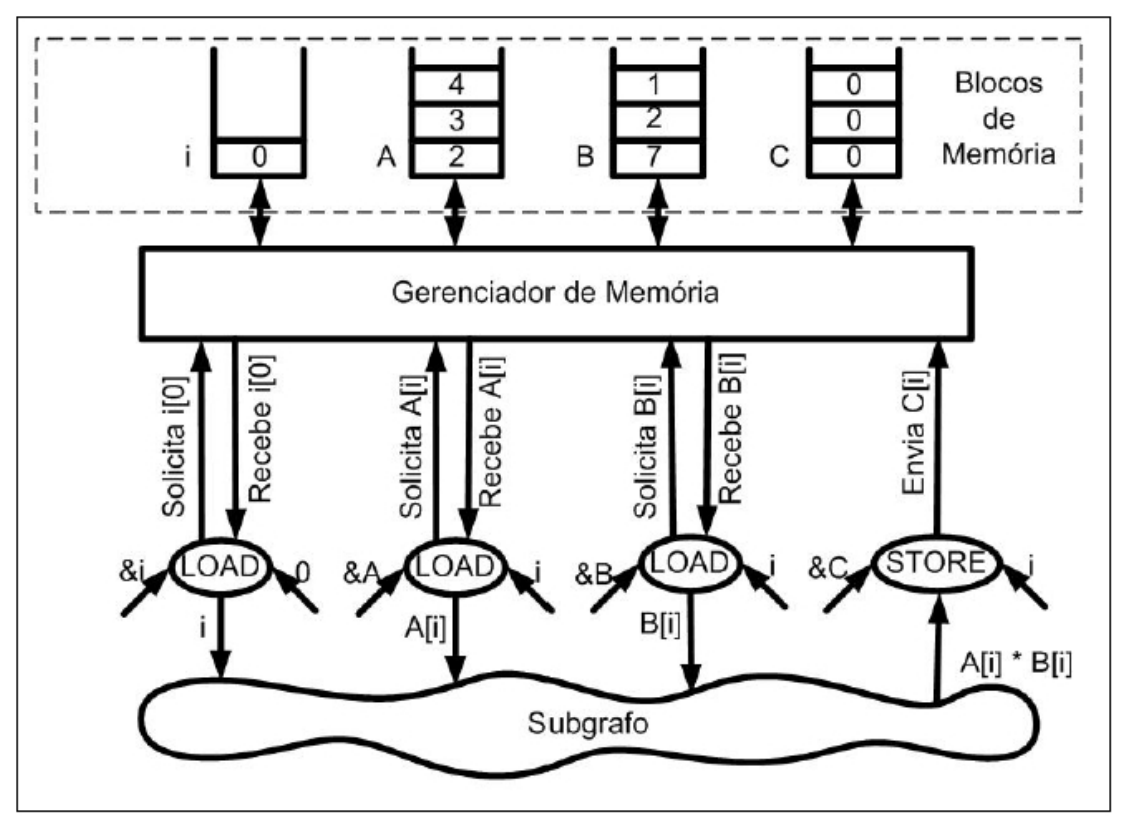

Figura 7.15: Modelo para gerenciamento de memória, operadores load e store (Silva (2011b))

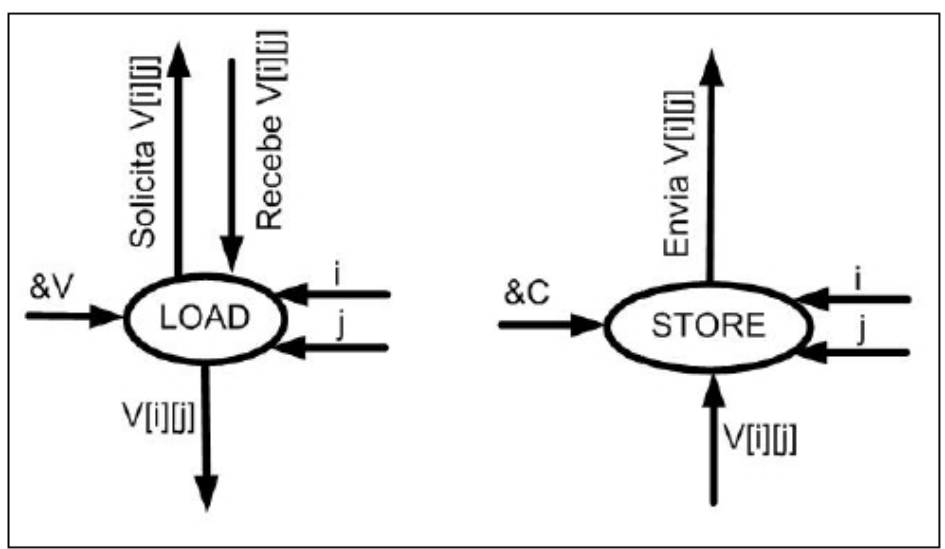

Figura 7.16: Formato dos operadores load e store (Silva (2011b)) 
são necessitam utilizar operações de load e store, o cálculo do deslocamento deve ser resolvido na própria máquina a fluxo de dados. Assim, para fins práticos, foi definido que os programas tratados pelo ChipCflow manipularão dados de até duas dimensões, apenas como prova-de-conceito. Sendo assim, uma versão mais específica para as instruções de load e store foi proposta e é descrito na Figura 7.16. Esta versão já calcula o deslocamento dentro do próprio operador (Silva (2011b)).

O valor do endereço base das variáveis, vetores ou matrizes é uma constante gerada pelo compilador ao criar a máquina a fluxo de dados (Silva (2011b)) Na Figura 7.17 é mostrado um exemplo de uma máquina a fluxo de dados, com os operadores NTM, NIG, ITG, TR, NTD, OTT, Load, Store. Na figura não foi mostrado o operador Gerenciador de Memória.

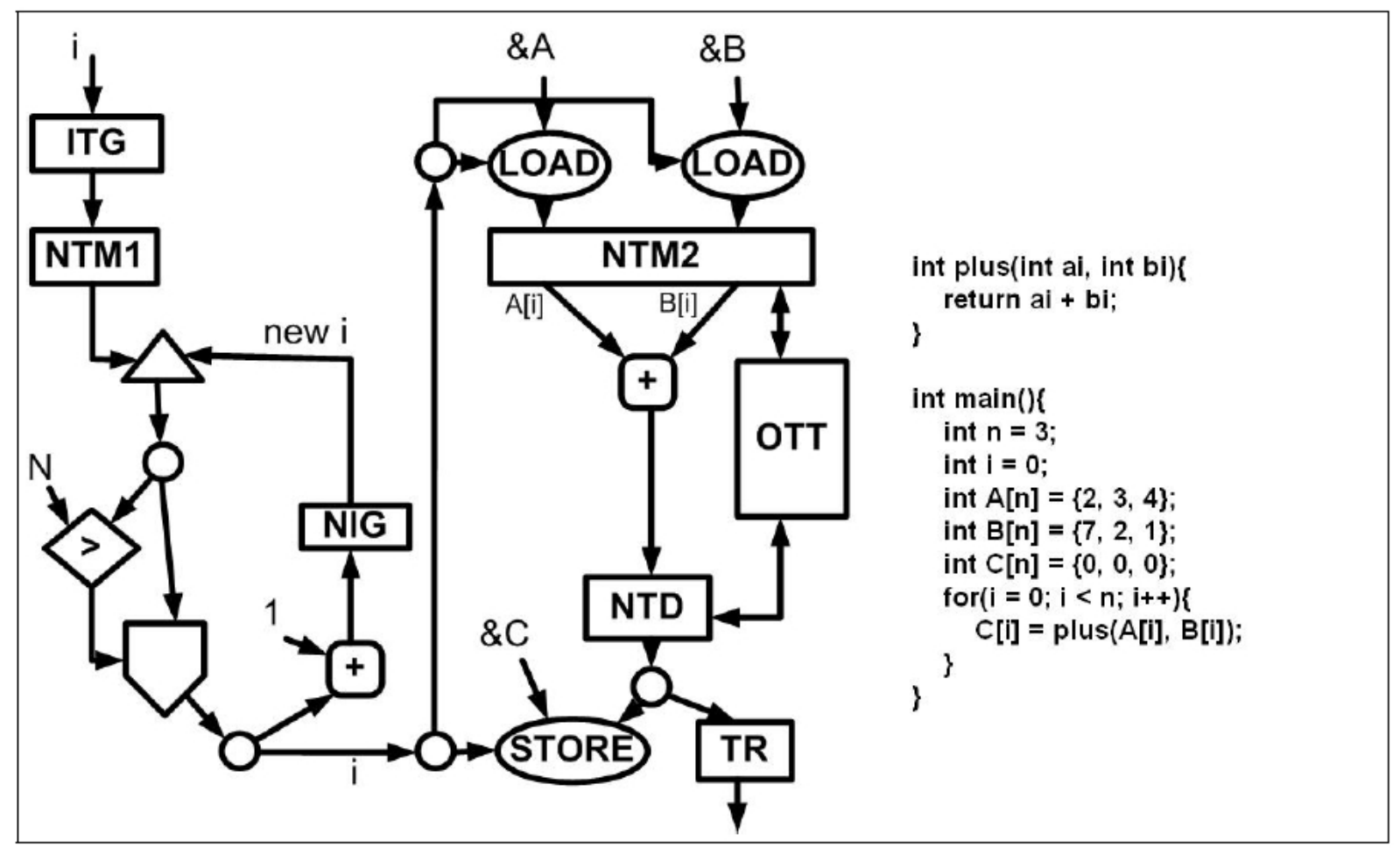

Figura 7.17: Soma de vetores, elemento por elemento, que utiliza todos os operadores de gerenciamento de tags propostos para a arquitetura ChipCflow (Silva (2011b))

O código $C$ relacionado ao $D F G$ possui uma função chamada plus que recebe dois parâmetros e retorna a soma entre eles. A função principal do programa possui um loop que chama a função plus para cada elemento dos vetores A e B e armazena os resultados no vetor C. No início da execução do grafo, as constantes (endereço dos vetores A, B e C; os valores das variáveis i e n) são carregados da memória ou alocados em registradores pelo compilador. Todas as constantes estão esperando por seus dados parceiros enquanto $i$ entra no ITG e recebe sua tag inicial e se torna $(\langle 0.0 .0 ; 0\rangle)$. Guando a variável i entra no NTM1, sua ativação de sub-grafo recebe o valor da ativação do NTM1, 
que é zero. O NTM1 é referente ao início do loop do código. Se a comparação lógica retorna VERDADEIRO, o operador de soma incrementa o valor de $i$, o NIG incrementa a parte da tag referente a iteração atual e o token se torna $(<0.0 .1 ; 1>)$. Paralelamente ao incremento de $i$, a sua cópia chega nos operadores load e store do grafo. O operador store não executa ainda, pois falta o dado parceiro de i. Após a execução das instruções de load, A [0] e B [0] são enviados ao NTM2, que é referente ao início da função plus. Depois que o NTM2 recebe A [0] e B [0], os valores dos tokens são $(<0.0 .0 ; 2>)$ para $A[0]$ e $(<0.0 .0 ; 7>)$ para $B[0]$. Suas tags antigas são associadas às novas e são armazenadas no OTT. Quando o resultado da soma entre A [0] e B [0] chega ao NTD, a tag antiga é recuperada, a instrução store recebe o parceiro que faltava e armazena o dado em $\mathrm{C}[0]$. Ao mesmo tempo, uma cópia do resultado é enviado para o operador $T R$ que remove a tag e envia o dado para algum dispositivo de entrada/saída. O ciclo de execução continua até que a comparação lógica entre i e n retorne FALSO (Silva (2011b)). 


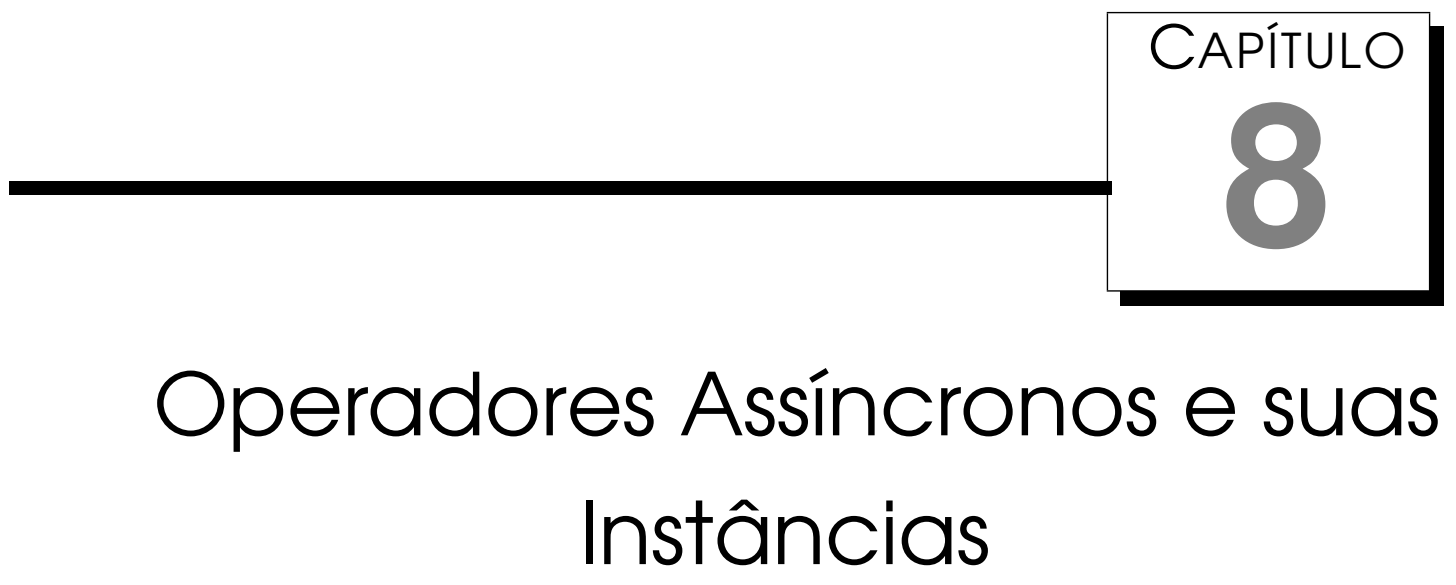

Como já mencionado nos capítulos anteriores, o objetivo geral desta tese foi utilizar o modelo de implementação assíncrono do operador e suas instâncias para que um grafo utilizando esses operadores fosse caracterizado como uma máquina a fluxo de dados dinâmica, explorando o máximo das vantagens do modelo assíncrono, do modelo de arquiteturas a fluxo de dados dinâmica e computação reconfigurável, no desenvolvimento de aplicação em hardware que demandam baixo consumo e alto desempenho.

Os objetivos específicos dessa tese foram: utilizar o modelo assíncrono na implementação dos operadores; nas estruturas do operador assíncrono, definir todos os requisitos necessários para que o conjunto de operadores caracterizassem o modelo de arquiteturas a fluxo de dados dinâmicas; definir todos os requisitos necessários para que instâncias dos operadores trabalhassem também na forma assíncrona, mas sincronizado com seu operador de base; implementar os operadores na plataforma de desenvolvimento Virtex-II Pro da Xilinx; implementar as instâncias também na plataforma de desenvolvimento Virtex-II Pro da Xilinx; validar a execução dos operadores e suas instâncias, considerando diferentes quantidades de instâncias e finalmente, gerar dados de consumo, ocupação e desempenho para diversos testes realizados.

Neste capítulo, portanto são apresentados os operadores e suas instâncias, implementados a partir dos objetivos específicos, descritos acima, bem como os resultados de desempenho, ocupação e consumo obtidos nas implementações realizadas.

Como visto nos capítulos anteriores, tagged-tokens estão associados ao mo- 
delo a fluxo de dados dinâmico onde diferentes dados podem estar presentes em um arco. A maioria das máquinas a fluxo de dados, vistas nos capítulos anteriores possuem EPs complexos e unidades de matching com grande capacidade para armazenar tokens parceiros. O modelo a fluxo de dados escolhido para o ChipCflow (SILVA et al. (2009a)), ao contrário das outras arquiteturas a fluxo de dados, permite que novas instâncias dos operadores sejam alocadas para cada dado que chegue em um arco em um determinado operador, assim os dados que possuem o mesmo tagged-token serão parte da mesma instâncias de um operador.

\subsection{O modelo de instâncias}

Um exemplo de aplicação que caracteriza o uso de tagged-token e a criação de novas instâncias é mostrado no Algoritmo 2.

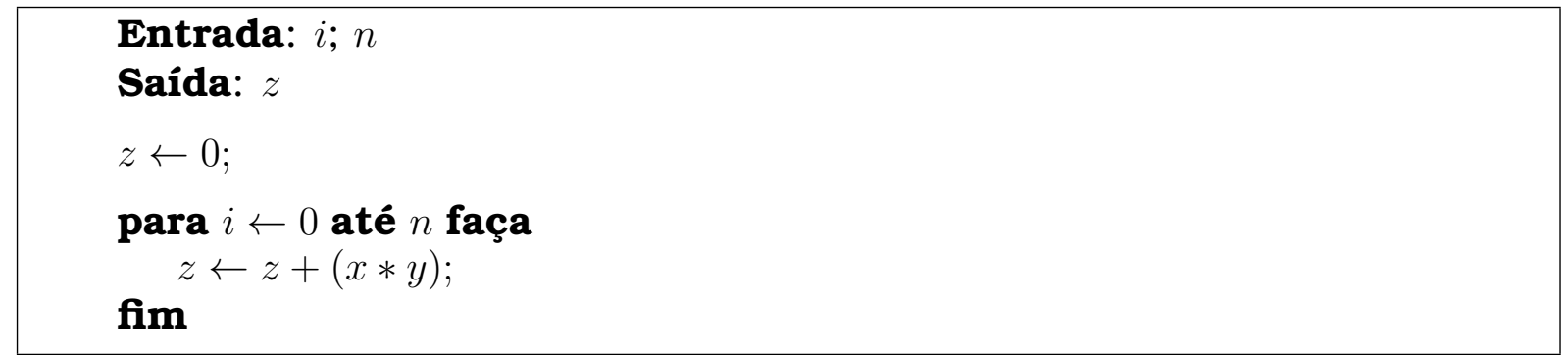

Algoritmo 2: Um exemplo de um algoritmo que caracteriza o uso do "tagged-token" através da instrução para

Na Figura 8.1 é mostrado a máquina a fluxo de dados associado ao Algoritmo 2, onde várias instâncias do operador "*" foram geradas.

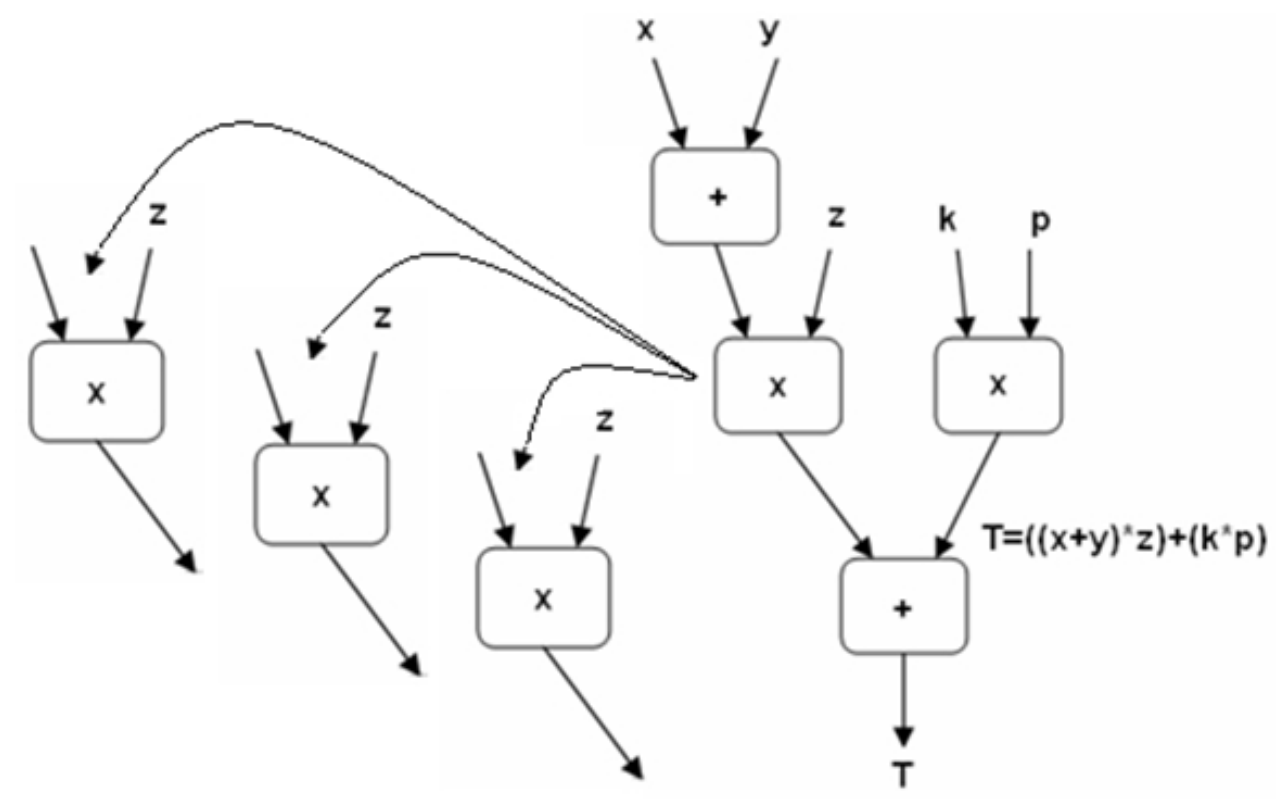

Figura 8.1: Instâncias diferentes para o operador " * " (SILVA et al. (2009a)) 
A geração das várias instâncias descritas na Figura 8.1 deve-se ao fato que em geral, operações de multiplicação são mais lentas que operações de soma e no caso da Figura 8.1, o operador soma associado às entradas "x" e "y" irá gerar resultados mais rapidamente do que o operador de multiplicação consegue consumir, portanto, para cada dado vindo do operador soma que não é consumido no operador de multiplicação, o dado é alocado em uma nova instância do operador de multiplicação.

No caso da Figura 8.1, todas as instâncias geradas do operador de multiplicação já possuem seus dados e, portanto, todas estão executando em paralelo e a medida que os resultados vão sendo gerados em cada instância, esse dado será enviado de volta ao operador de multiplicação, para que este o encaminhe para o próximo operador ligado a ele.

Uma outra situação que pode ocorrer, diferente do descrito acima, é a chegada de vários dados em um dos arcos de entrada de um operador, mas que deverão esperar pelos seus dados parceiros vindos de outros arcos de entrada naquele mesmo operador.

Da mesma forma, todo o dado que chega e não pode ser tratado pelo operador, neste caso por falta de dados parceiros, o dado é alocado em uma das instâncias daquele operador e ficará aguardando seus dados parceiros. À medida que os dados vão chegando nos outros arcos de entrada naquele operador, é preciso identificar nas instâncias ou no próprio operador, se existem dados parceiros àquele que acabou de chegar.

Essa identificação também foi realizada por processo de Matching das tags, processo esse comum em praticamente todas as máquinas descritas nos capítulos anteriores, entretanto, no projeto ChipCflow o Matching das tags é realizado simultaneamente entre todas as instâncias e até mesmo no operador. Por isso foi preciso acrescentar em cada instância e no operador uma unidade de Matching de forma que, quando chegar um dado em algum arco de entrada naquele operador, ele é disponibilizado em um barramento comum em cada unidade de Matching, identificando se há parceiros, se alojando nas instâncias ou no operador quando existir o parceiro ou então forçando a criação de uma nova instância para aquele operador quando não houver parceiros.

No projeto ChipCflow as instâncias são pré-configuradas e vão sendo utilizadas conforme a necessidade. Pensou-se em reconfiguração parcial dinâmica para a criação ou destruição das instâncias (Junior (2011)), entretanto o overhead da reconfiguração inviabilizou num primeiro momento o uso desse processo, mas, dependendo dos avanços nessa área, esse método pode ser retomado.

A seguir são detalhados a implementação dos operadores e suas instâncias. 


\subsection{Implementação dos operadores e suas instâncias}

Os operadores Deterministic Merge, Branch, Operator e Decisor são implementados utilizando o modelo de instâncias, como descrito na Figura 8.1. Os operadores Non-Deterministic Merge e Copy não possuem instâncias.

\subsection{Operador Deterministic Merge}

O operador Deterministic Merge (DM) e suas instâncias é descrito na Figura 8.2. Como pode ser visto na Figura 8.2, o operador $D M$ possui três entradas de tokens, nomeadas pelas letras A, B com 28 bits e C com 13 bits e uma saída de tokens, nomeada pela letra S com 28 bits.

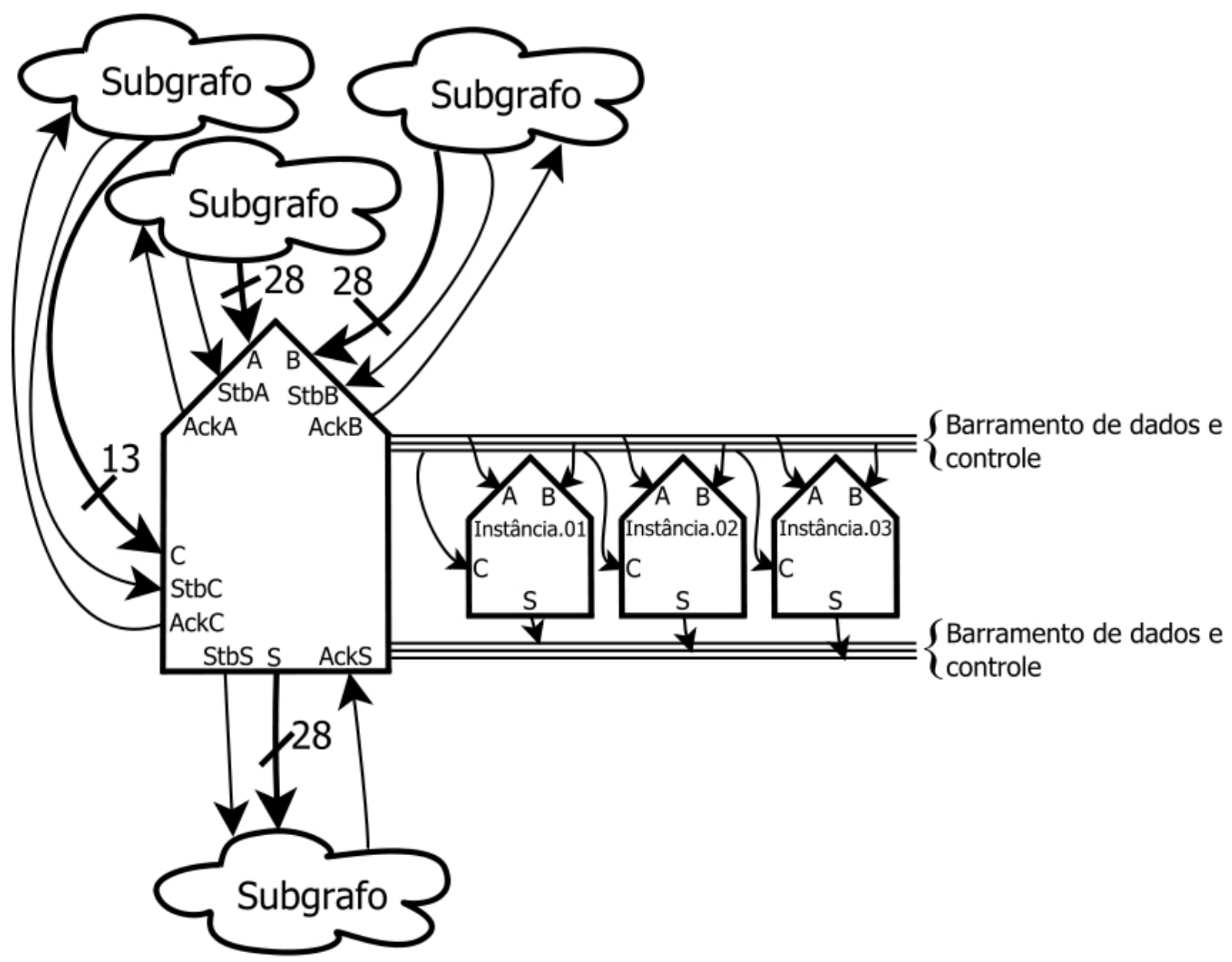

Figura 8.2: Transporte de tokens entre operadores na máquina a fluxo de dados

Os sinais de entrada/saída A, B, C e S do operador são ligados a barramentos, os quais transportam os tokens entre os operadores na máquina a fluxo de dados.

Os operadores recebem ou enviam tokens de forma sincronizada, por meio do protocolo handshake descrito nos capítulos anteriores. 


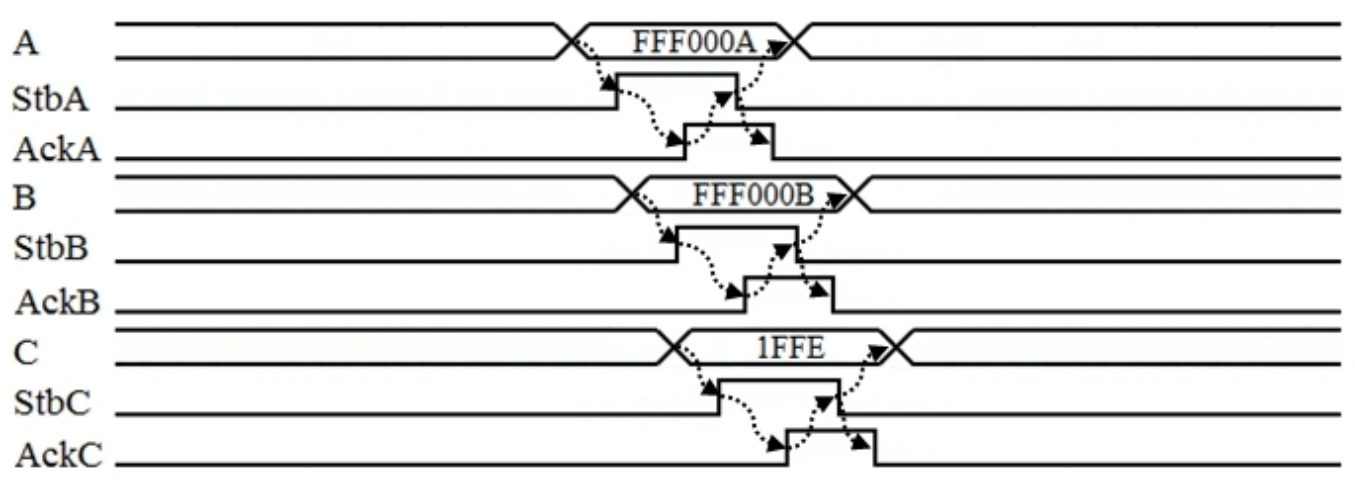

Figura 8.3: Fluxo de sinais para entradas de dados no operador DM

Na Figura 8.3 é descrito o fluxo de sinais básicos para as entradas de dados no operador DM. Como pode ser visto na Figura 8.3, o protocolo handshake é utilizado para cada entrada de dados nos arcos de entrada do operador DM.

Da mesma forma, na Figura 8.4 é descrito o fluxo de sinais para as saídas de dados no operador DM.

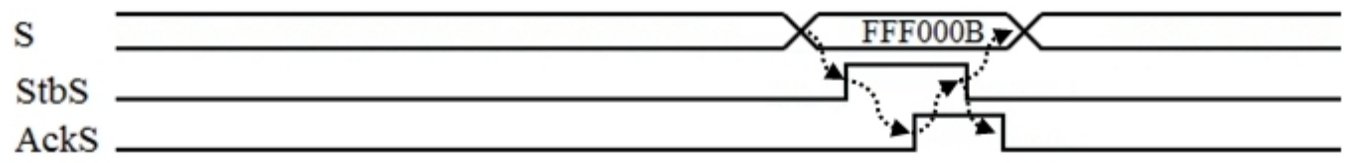

Figura 8.4: Fluxo de sinais para saídas de dados no operador $D M$

Ainda na Figura 8.2, várias instâncias estão conectadas ao operador DM e são descritas a seguir.

Na Figura 8.5 é mostrado, de forma detalhada, uma instância do operador $D M$. Assim como o operador $D M$, sua instância possui três entradas de tokens, nomeadas pelas letras A, B com 28 bits e C com 13 bits e uma saída de tokens, nomeada pela letra S com 28 bits. Os sinais de entrada/saída A, B, C e S da instância são ligados a barramentos, os quais transportam os tokens entre a instância e o operador $D M$. Da mesma forma que no operador $D M$, sua instância recebe ou envia tokens de forma sincronizada, por meio do protocolo handshake, entretanto, por se tratar de uma instância, alguns sinais foram inseridos para controle.

Na Figura 8.6 é descrito o fluxo de sinais para acesso a uma instância do operador DM. Conforme descrido na Figura 8.6, o protocolo handshake é utilizado para todos os dados trocados entre o operador e a instância. Para todo o dado que encontra um parceiro na instância, o sinal ack_ informa que o dado foi aceito (nível lógico alto), caso contrário, o sinal Nao_é que vem informando a não existência de dado parceiro (nível lógico alto) naquela instância (exemplo: sinal $N a o B$ na Figura 8.6). O sinal ArmIn é utilizado para informar ao operador $D M$ se a instância está vazia (nível lógico baixo) ou ocupada (nível lógico alto). 


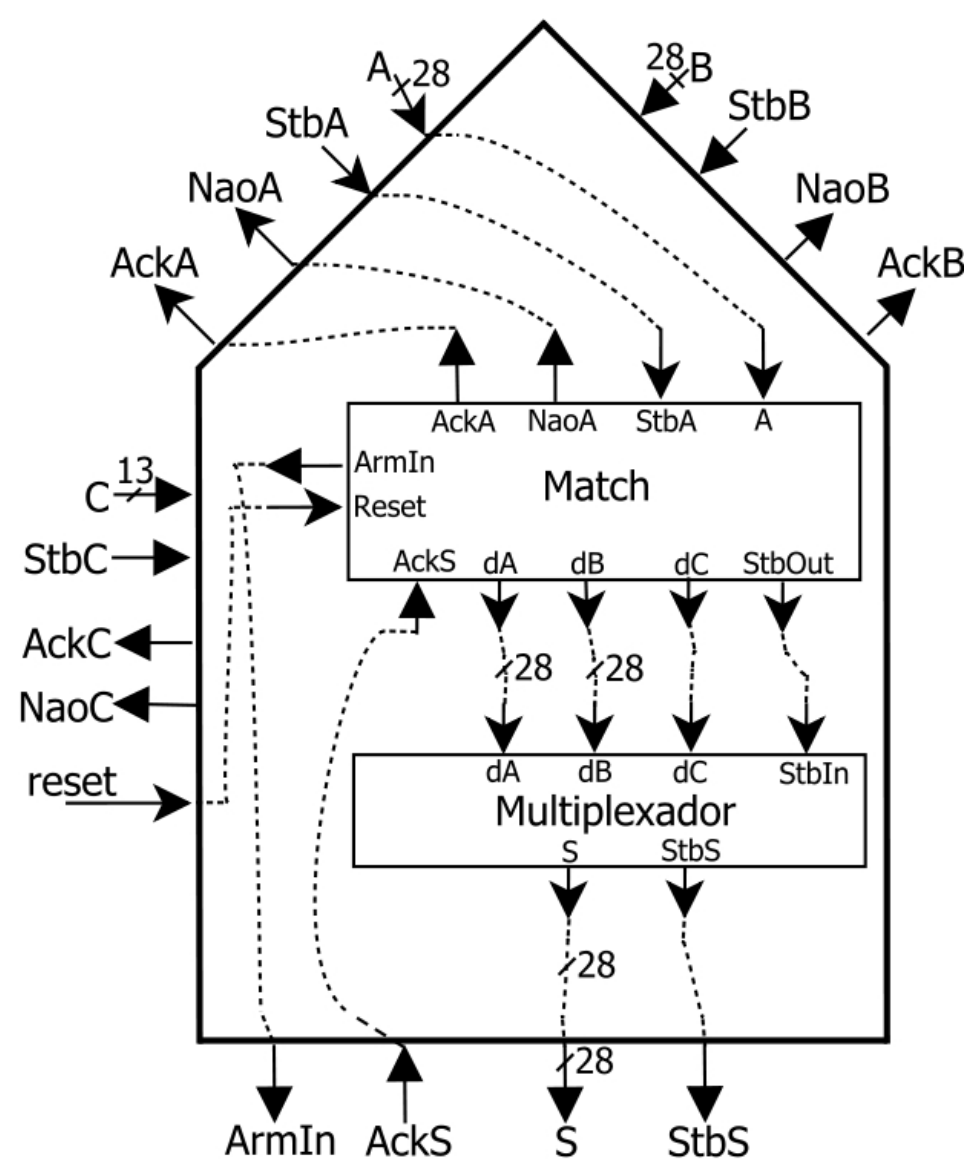

Figura 8.5: Instância do operador $D M$

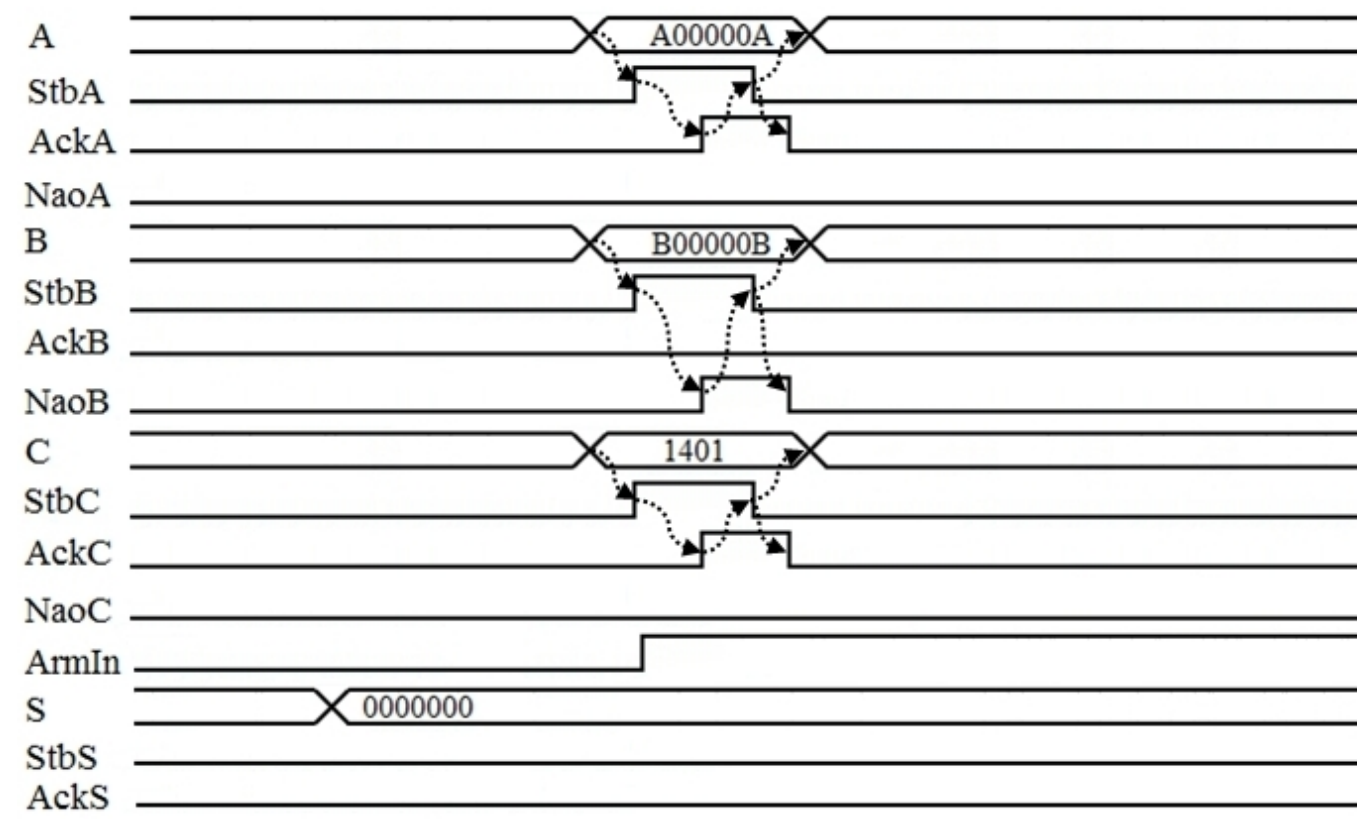

Figura 8.6: Fluxo de sinais para acesso à uma instância do operador $D M$ 
Ainda na Figura 8.5, a instância do operador DM, possui os módulos: Match e Multiplexador. A função do módulo Match é sincronizar os dados de entrada e fazer a correspondência entre os tokens parceiros que chegam na instância. $\mathrm{O}$ módulo Multiplexador possui a função de selecionar uma das entradas A ou B à saída $\mathrm{S}$, dependendo do dado carregado pelo token na entrada $\mathrm{C}$, executando assim a função da instância $D M$.

O operador DM envia tokens para as instâncias por meio dos sinais A_out, B_Out com 28 bits, C_Out com 13 bits e recebem tokens das instâncias, por meio dos sinais S_0 até S_n com 28 bits cada, ligados a barramentos de comunicação entre o operador e as instâncias. Para cada sinal de entrada/saída na comunicação de tokens entre o operador e as instâncias é executado o protocolo handshake.

Na Figura 8.7 é descrito a estrutura do operador DM para funcionar com suas instâncias. Além dos sinais básicos para entradas e saídas de dados no operador $D M$, descrito anteriormente, vários sinais foram inseridos para permitir a completa atuação do operador $D M$ e suas instâncias.

Na Figura 8.8 é descrito o fluxo de sinais para gerenciamento do operador $D M$ e suas instâncias. Como descrito na Figura 8.8, os sinais A_Out, StbAO, Ack_Acf e Nao_Acf, estão conectados aos sinais A, StbA, AckA e NaoA, respectivamente, em cada instância conectada ao operador DM. O mesmo para o dado $B$ e $C$. Entretanto, como cada instância pode enviar um dado de saída para o operador $D M$, vários sinais foram pré-definidos para essa função, cumprindo também o protocolo handshake para cada dado vindo de uma instância para o operador DM. É o caso dos sinais Stb_SO, S_O e Ack_SO até Stb_Sn, S_n e Ack_Sn.

Ainda na Figura 8.7, o operador DM é constituído de onze módulos internos: Confirma; Match; Aloca; Multiplexador; Disparo; Mult_A; Mult_B; Mult_C; $D M \_A ; D M \_B$ e $D M \_C$, que são utilizados para gerenciar o operador $D M$ com suas funções básicas e todo o relacionamento entre as instâncias. Os módulos são detalhados a seguir.

\section{Módulo Confirma}

O módulo Confirma é responsável por verificar a existência de tokens parceiros, armazenados nas instâncias do operador. Na Figura 8.9 é mostrado as conexões entre o módulo Confirma e uma instância do operador.

O módulo Confirma possui três entradas de tokens, vindas do operador, nomeadas pelas letras A, B com 28 bits e C com 13 bits, uma entrada de reset e um sinal de entrada chamado StatusIn, $\operatorname{com} n$ bits indicando o status ocupado/desocupado de cada instância. O módulo possui três saídas de tokens, nomeadas pelas letras A, B com 28 bits e C com 13 bits, as quais enviam to- 


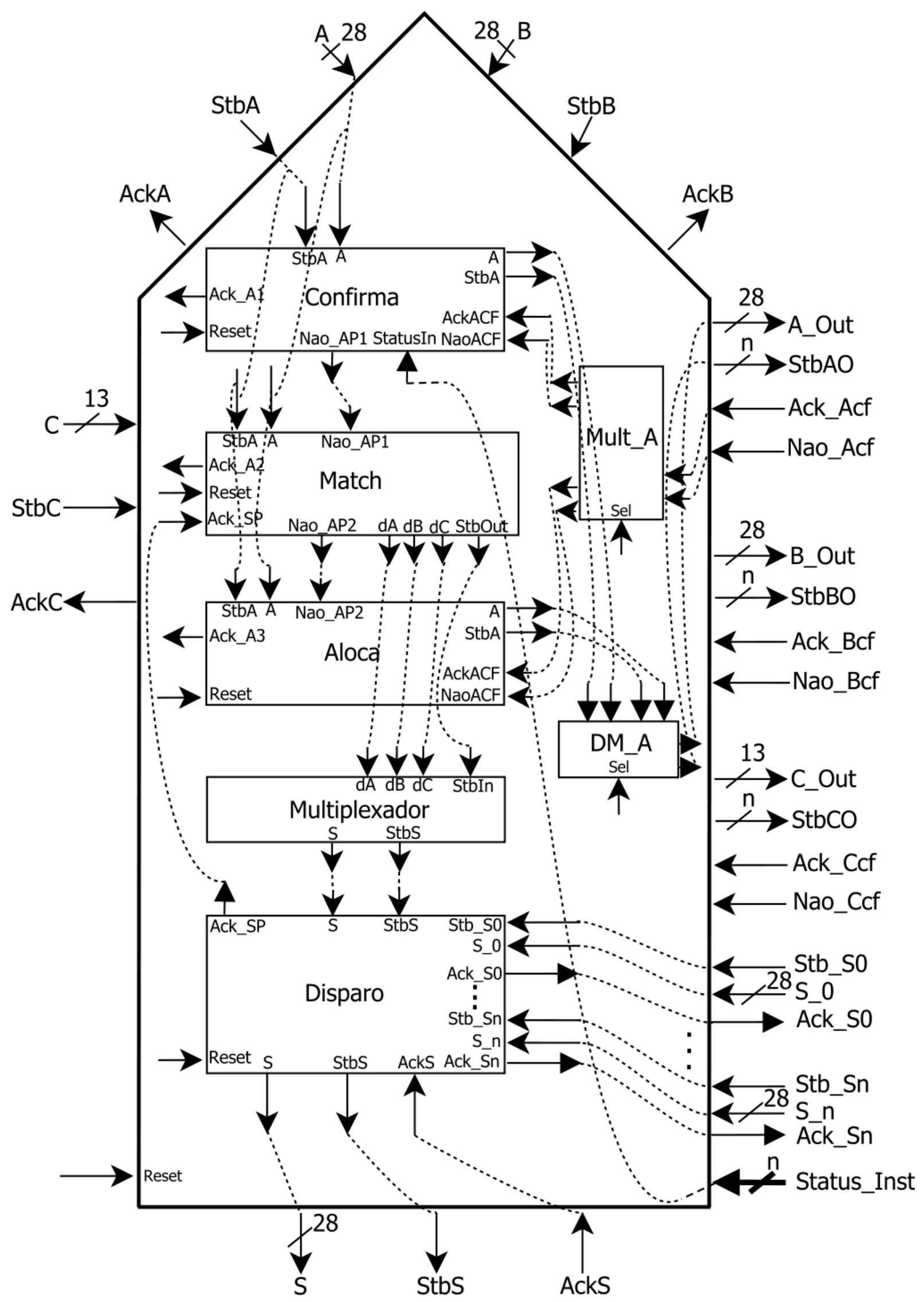

Figura 8.7: Operador DM implementado para funcionar utilizando-se o modelo de instâncias 


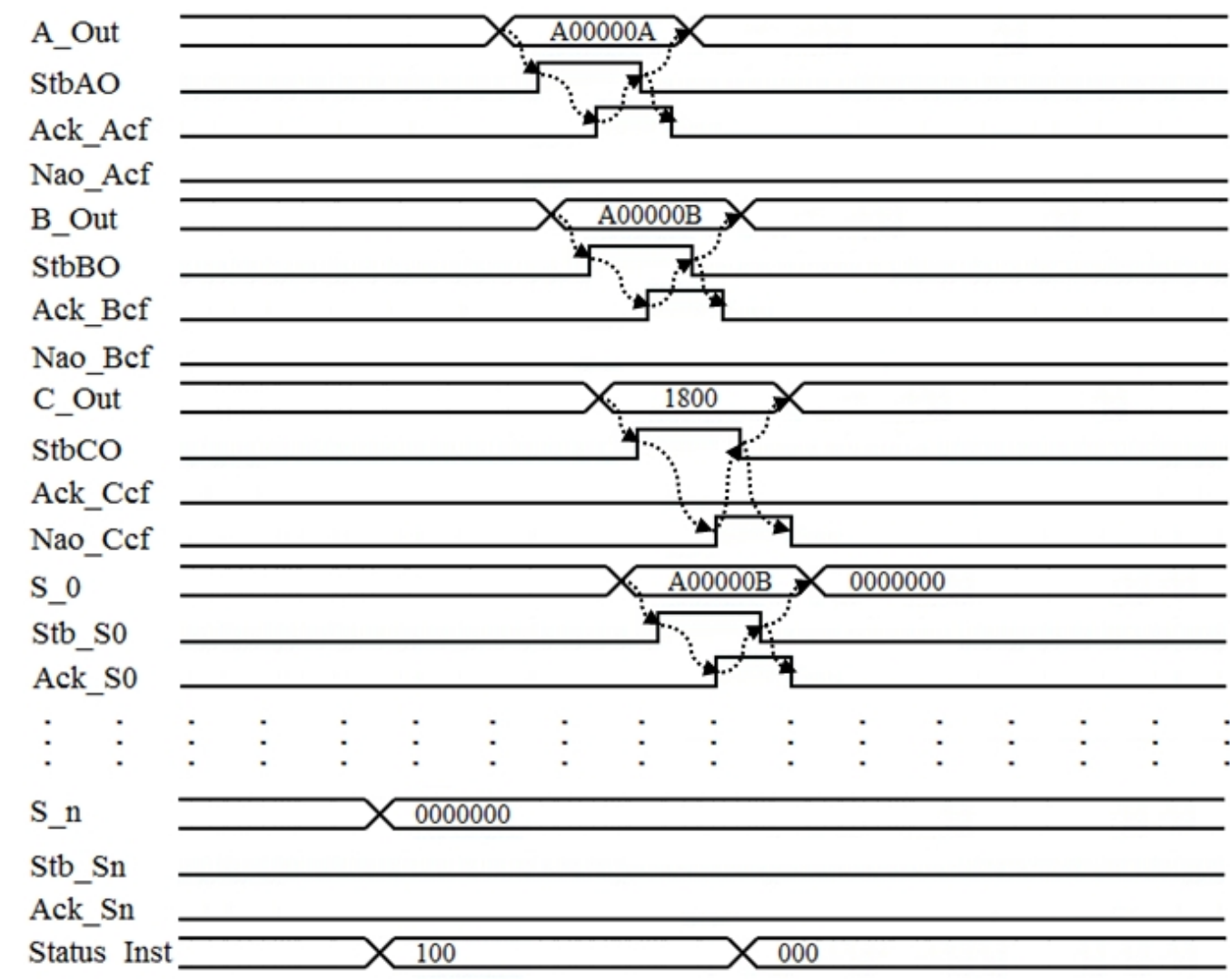

Figura 8.8: Fluxo de sinais para gerenciamento do operador $D M$ e suas instâncias

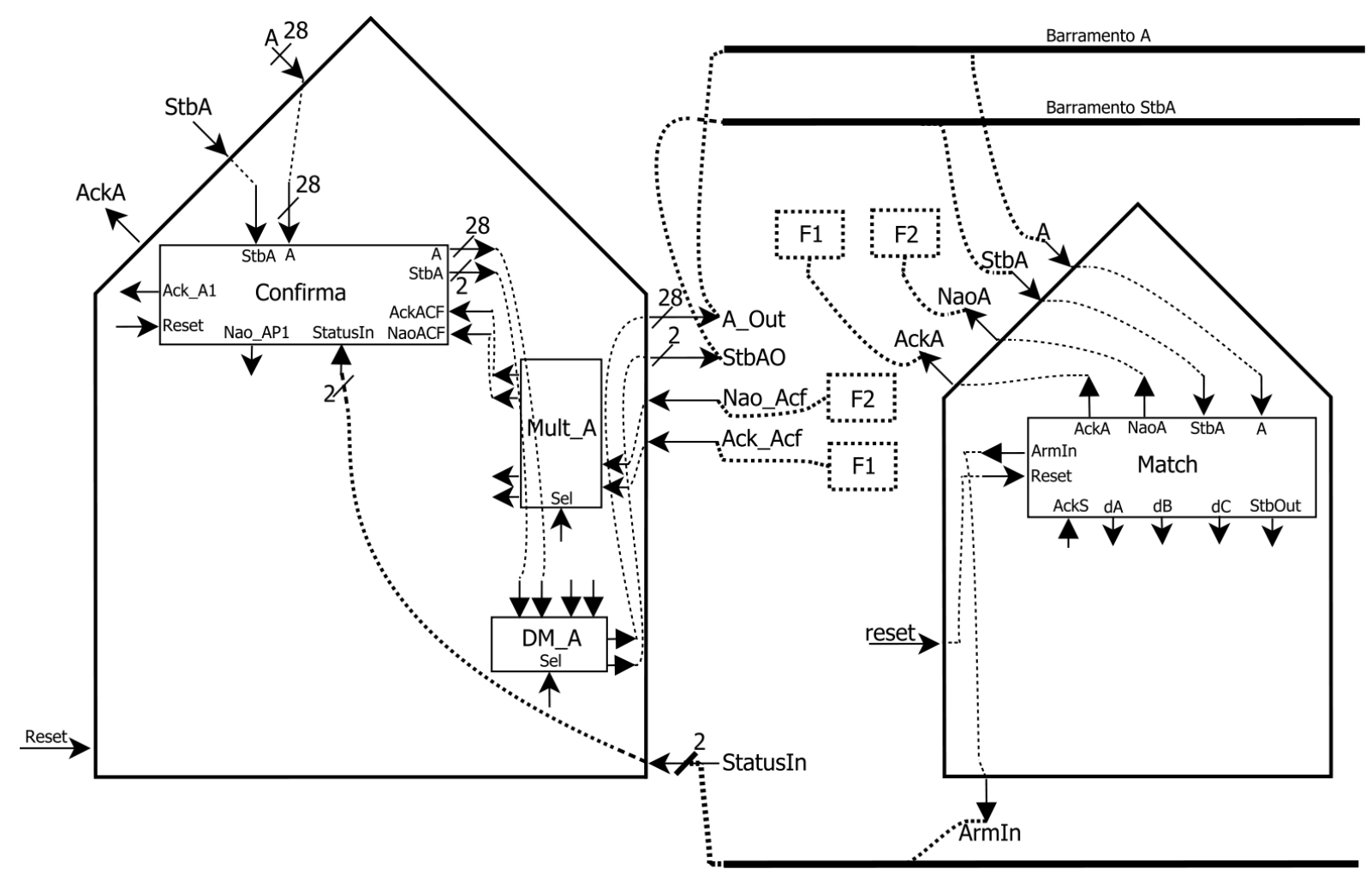

Figura 8.9: Módulo Confirma do operador DM 
kens às instâncias. Esse módulo só envia tokens às instâncias, ou seja, não recebe tokens delas.

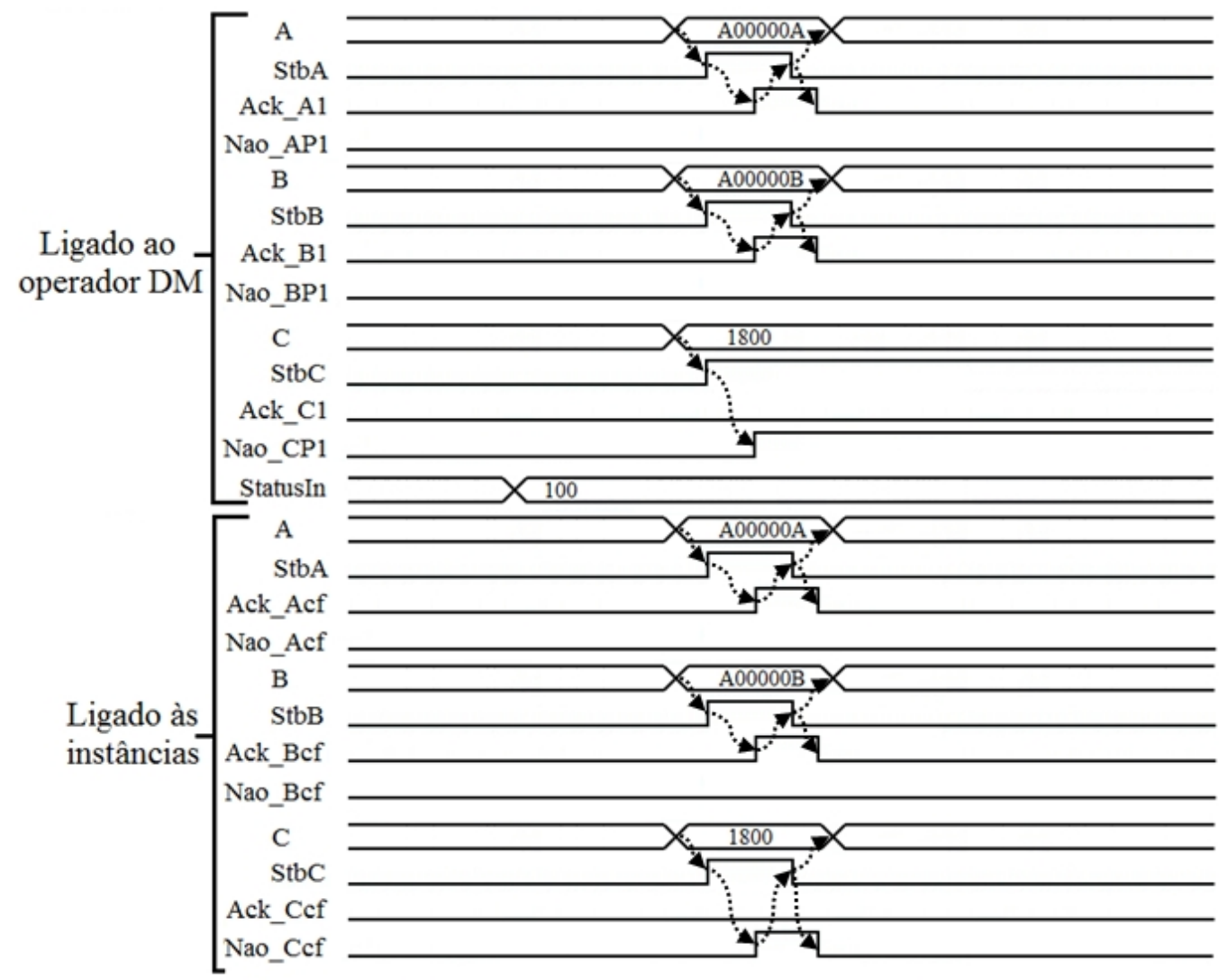

Figura 8.10: Fluxo de sinais do módulo Confirma no operador DM

Na Figura 8.10 pode ser visto o fluxo de sinais do módulo Confirma no operador DM. Como pode ser visto na Figura 8.10, os dados A, StbA e Ack_A1 estão conectados diretamente aos sinais $A$, StbA e AckA no operador $D M$ que executam o protocolo de entradas para o dado $A$. O mesmo acontece com o dado $B$ e $C$.

O sinal StatusIn, com $n$ bits indica o estado ocupado/desoculado em cada instância, em um total de $m$ instâncias.

Os sinais $A$, StbA, AckAcf e NaoAcf estão ligados às instâncias por meio dos módulos Mult_A e $D M \_A$, e realizam o protocolo de entrada para o dado $A$ nas instâncias. O mesmo para o dado $B$ e $C$.

Os sinais Nao_AP1, Nao_BP1 e Nao_CP1 estão ligados ao módulo Match e tem como funções: informar ao módulo Match do operador DM que não houve correspondência entre os tokens enviados pelo módulo Confirma às instâncias e conseqüentemente ativar o módulo Match do operador $D M$ para verificar a correspondência no próprio DM. No caso da Figura 8.10, o sinal Nao_CP1 em nível lógico alto, indica que não houve correspondência entre as instâncias para o dado $C$ que chegou do operador $D M$.

Os módulos Mult_A e DM_A são utilizados pelo módulo Confirma para a 
troca de informações entre ele e as instâncias, neste caso por informações relacionadas ao dado $A$. Os módulos Mult_B, DM_B e Mult_C e DM_C são utilizados para as entradas $B$ e $C$, respectivamente.

Em termos de funcionamento global, o módulo Confirma pode encontrar diferentes situações no relacionamento operador $D M$ e instâncias.

Supondo-se um operador DM com três instâncias conectadas a ele, de imediato, duas situações podem ser destacadas.

A primeira é quando chega dado no operador e não há tokens armazenados nas instâncias. Na Figura 8.11 é descrito o fluxo de sinais para essa situação.

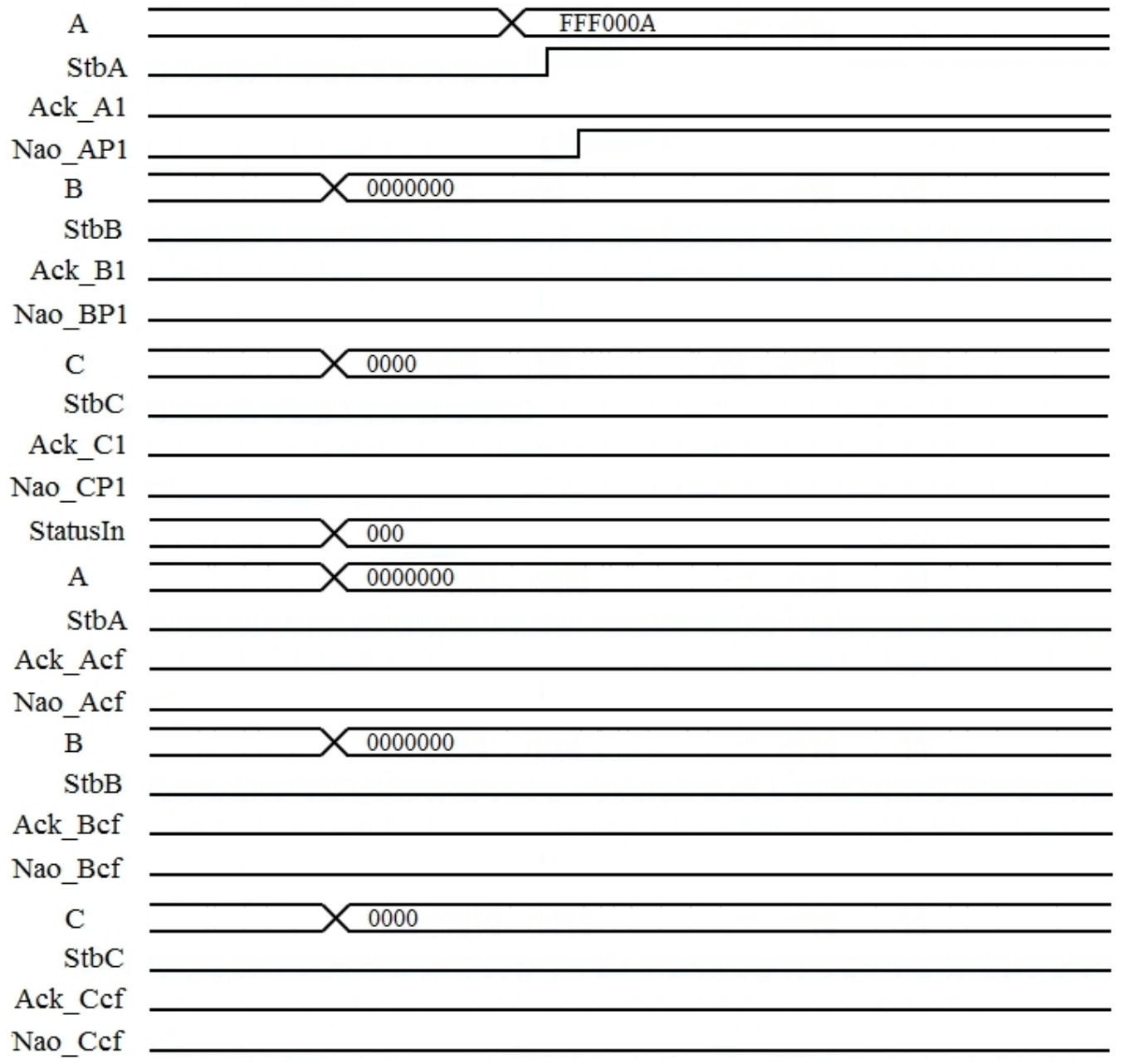

Figura 8.11: Diagrama de Sinais do módulo Confirma - com instâncias desocupadas

Conforme descrito na Figura 8.11, as instâncias estão desocupadas, como mostrado pelo sinal StatusIn="OOO"(Hex). Na entrada $A$ do operador DM chega um token $\mathrm{A}=$ "FFF000A" (Hex) e seu respectivo sinal de strobe. Por não haver tokens nas instâncias, o sinal Nao_A1 é setado para nível lógico alto. Essa ação aciona o módulo Match do operador para receber o token relativo a entrada $A$.

A segunda situação de destaque do módulo Confirma, é quando há tokens armazenados nas instâncias, em particular assumiu-se o armazenamento 
presente nas instâncias "um" e "três". Como há tokens armazenados nas instâncias, o módulo Confirma trata essas informações em duas etapas. Na primeira etapa, o módulo Confirma envia o token presente na entrada $A$ do operador $D M$, às instâncias ocupadas. Na Figura 8.12 é descrito o fluxo de sinais desta etapa.

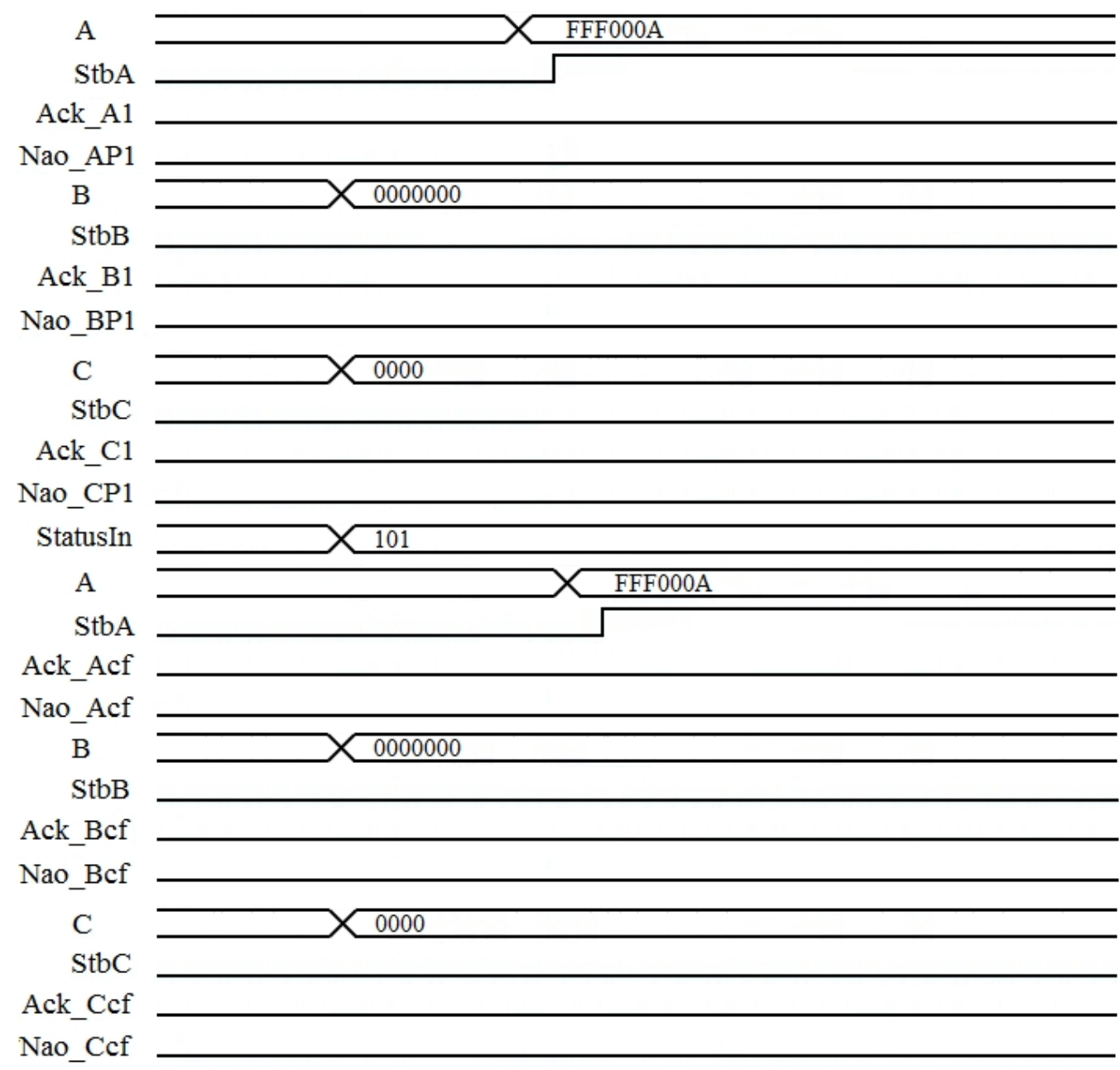

Figura 8.12: Diagrama de Sinais do módulo Confirma - com envio de token para instâncias ocupadas

Conforme descrito na Figura 8.12, o sinal StatusIn indica quais instâncias estão ocupadas e nesse caso, o token será enviado a todas as instâncias ocupadas pois somente elas receberão o sinal de strobe em nível lógico alto.

Na segunda etapa, o módulo Confirma aguarda o sinal de reconhecimento vindo das instâncias ocupadas. Nas Figuras 8.13 e 8.14 são mostrados o fluxo de sinais para essas etapas, quando há reconhecimento e quando não há reconhecimento, respectivamente.

Conforme pode ser visto na Figura 8.13, houve correspondência entre o token enviado às instâncias pelo operador e o token armazenado em uma das instâncias, sinal $A c k \_A 1$ com nível lógico alto. O recebimento do sinal de reconhecimento pelo módulo Confirma vindo das instâncias, Ack_A1, é 


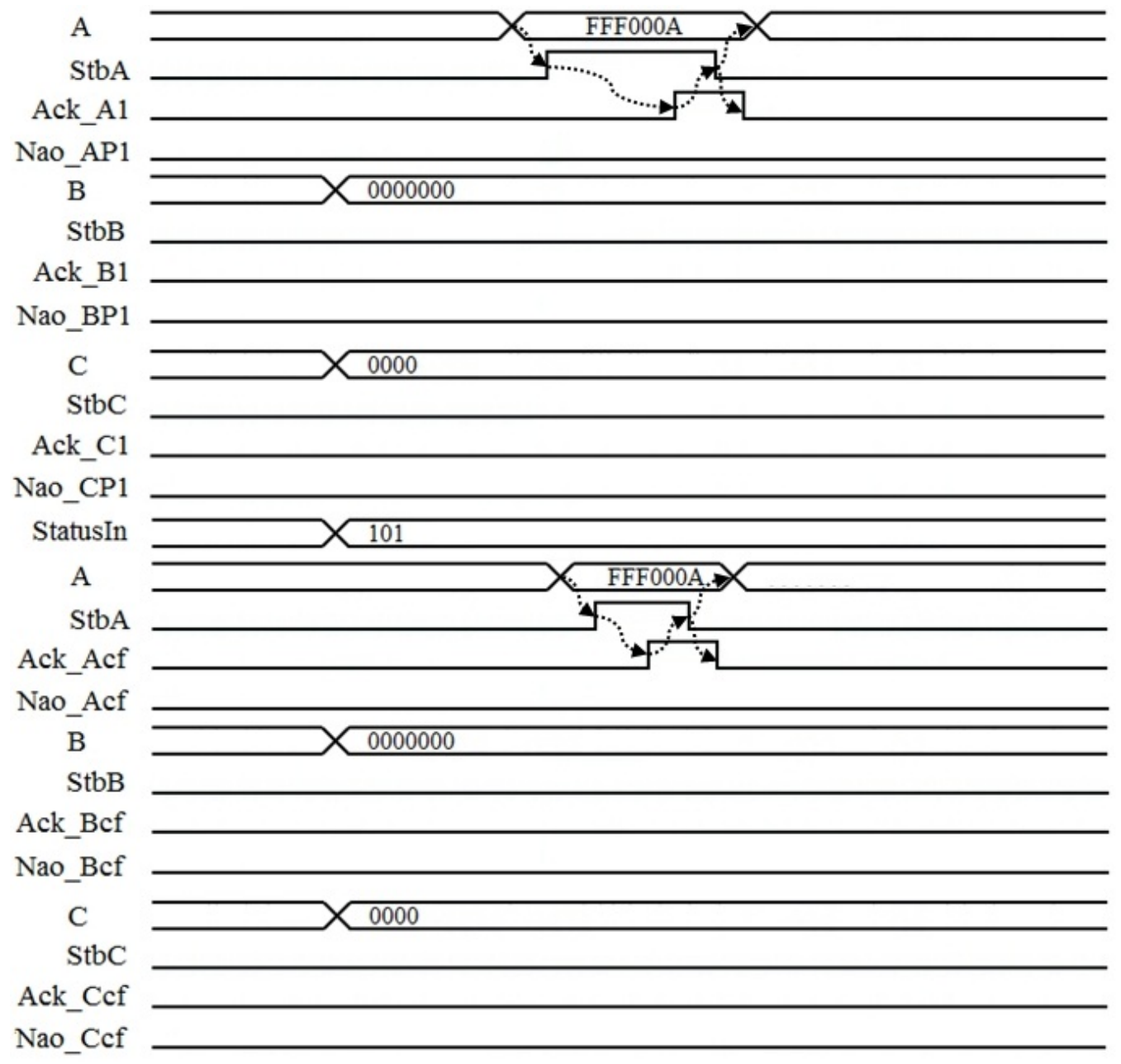

Figura 8.13: Diagrama de Sinais do módulo Confirma - com recebimento de reconhecimento pelas instâncias 
repassado para o sinal de reconhecimento no operador, AckA, completando o ciclo de recebimento de dado pela entrada $A$ do operador $D M$.

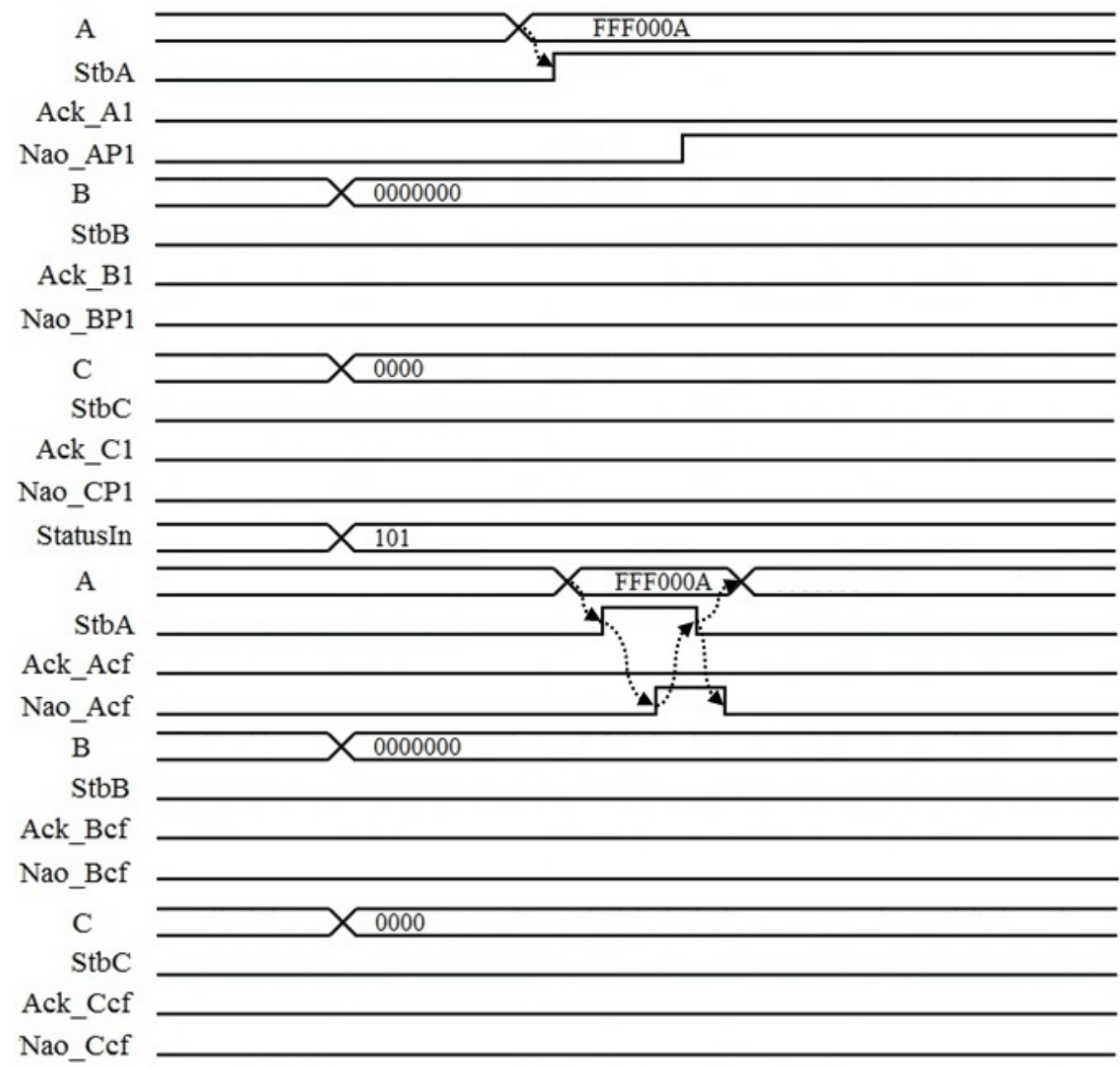

Figura 8.14: Diagrama de Sinais do módulo Confirma - com recebimento de não reconhecimento pelas instâncias

No caso da Figura 8.14, não houve correspondência entre o token enviado às instâncias pelo operador e o token armazenado em uma das instâncias, nesse caso, o sinal NaoACf com nível lógico alto, que força o sinal Nao_A1 no módulo Confirma para nível lógico alto, acionando assim o módulo Match do operador DM para verificar se existe correspondência com os tokens armazenados nele.

Na Figura 8.15 é descrito a simulação do operador DM módulo Confirma, acoplado a três instâncias simuladas no ambiente ISE da Xilinx. Como característica inicial descrito na Figura 8.15 pode-se destacar a ausência do sinal de clock, implicando que toda a transição de sinal é decorrente de outros sinais que o provocam.

Na Figura 8.15 o sinal StatusIn descrito anteriormente é caracterizado por três sinais: tsinsto, tsinst1 e tsinst2, respectivamente, sinais que indicam se uma instância está ocupada ou não. O sinal inst_ocp em nível lógico alto, 

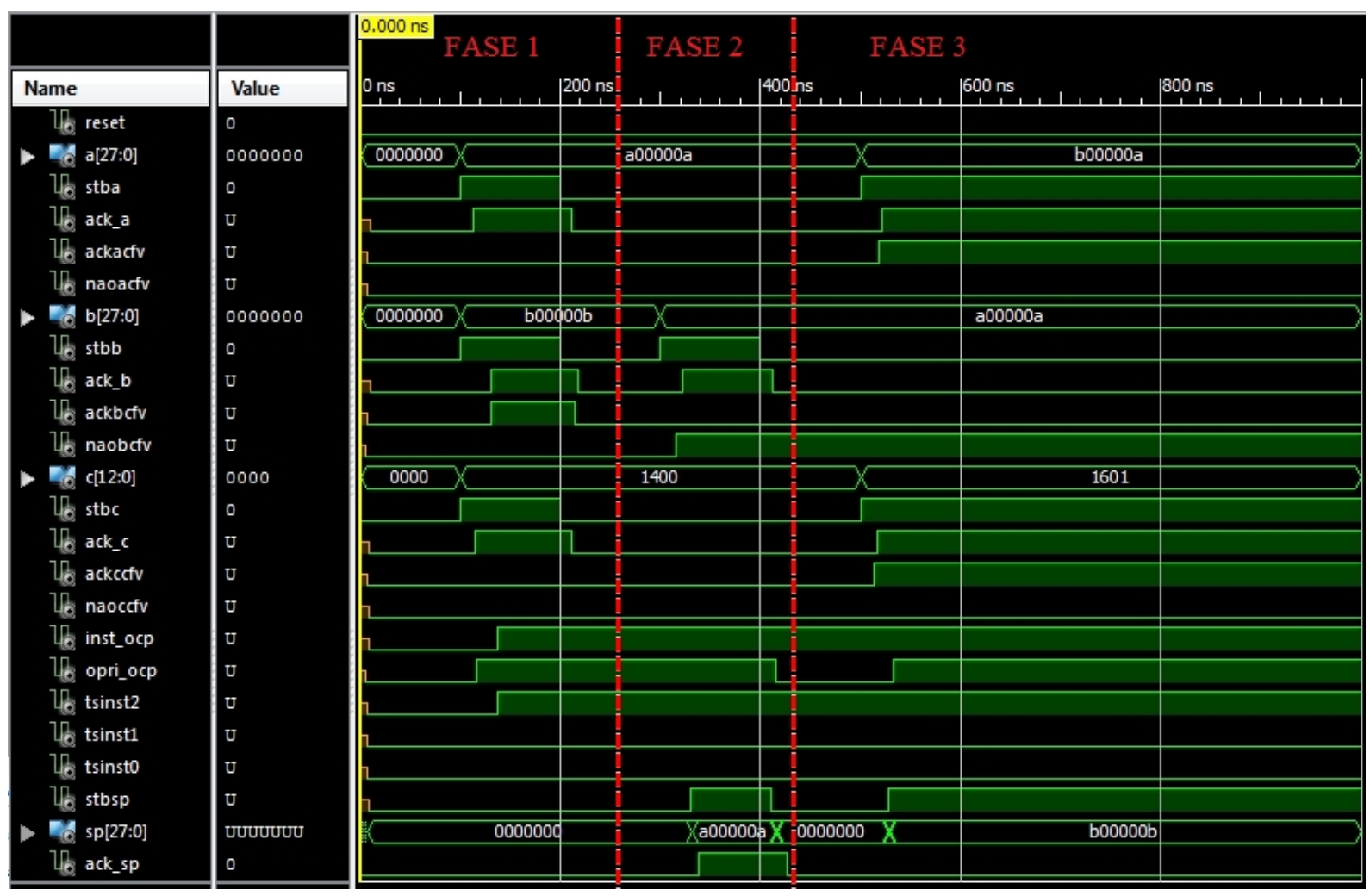

Figura 8.15: Simulação do operador $D M$, exemplo do funcionamento do módulo Confirma

indica que há pelo menos uma instância ocupada e o sinal opri_ocp em nível lógico alto indica que o módulo Match do operador possui pelo menos um token armazenado.

Ainda na Figura 8.15 pode-se observar três diferentes momentos de simulação: (Fase1, Fase2 e Fase3, utilizados na simulação do módulo Confirma do operador DM.

Na Fase1, o operador e as instâncias estão desocupados, comprovados pelos sinais tsinst0, tsinst1, tsinst2, inst_ocp e opri_ocp, todos em nivel lógico baixo; quando chegam simultaneamente tokens nas entradas $A=$ " $A 00000 A^{\prime \prime}$ (Hex), $B=" B 00000 B{ }_{(H e x)}$ e $C=" 1400{ }_{(H e x)}$ do operador, com seus respectivos sinais de strobe. Por não haver tokens armazenados nas instâncias, Nao_A1, Nao_B1 e Nao_C1 vão para nível lógico alto, que aciona o módulo Match do operador para receber os tokens. Cabe ressaltar que esses sinais não estão presentes na Figura 8.15 pois são sinais do módulo Match.

Ainda na Fase1, e conforme discutido acima, os tokens presentes em $A$ e $C$ possuem a mesma tag e o token presente em $B$ possui tag diferente. Isso faz com que o armazenamento dos tokens $A$ e $C$ ocorram no módulo Match do operador, indicado pelo sinal opri_ocp que vai para nível lógico alto e o armazenamento do token $B$ ocorra na primeira instância do operador, indicado pelo sinal tsinst2 que vai para nível lógico alto. Uma vez armazenados os tokens $A, B$ e $C$, os sinais $A c k \_A 1, A c k \_B 1$ e $A c k \_C 1$ vão para nível lógico alto, 
que por sua vez, faz com que os sinais $A c k A, A c k B$ e $A c k C$ no operador também vão para nível lógico alto.

Na Fase2 a primeira instância está ocupada, o módulo Match do operador também está ocupado, quando chega o token B="A00000A" (Hex) na entrada do operador com seu respectivo sinal de strobe. Como há instância ocupada, o módulo Confirma envia o token $B=$ " $A 00000$ " $_{(H e x)}$ à instância ocupada, recebendo um $A c k B c f$ (AckBcfv na Figura 8.15) em nível lógico baixo, uma vez que as tags não coincidem (Primeira instância com valor "B00000B (Hex)) e um NaoBcf (NaoBcfv na Figura 8.15) com nível lógico alto significando que não houve correspondência entre as tags nas instâncias e portanto finalizando o protocolo de comunicação entre o módulo Confirma do operador e a instância ocupada.

O sinal NaoBcf em nível lógico alto faz o sinal Nao_B1 ir para nível lógico alto, que como descrito anteriormente, aciona o módulo Match do operador a receber o token e verificar se há correspondência entre os tokens armazenados nele.

Como a tag do sinal $B$ é igual aos dos sinais $A$ e $C$, já armazenados no módulo Match do operador, há o disparo no operador, indicado pelo strobe do sinal SP ( $S t b s p)$, que possui o dado de saída resultante da execução do operador DM, protocolo completado pelos sinais SP, StbSP e Ack_sp, descrito na Figura 8.15, Fase2. Cabe ressaltar que o recebimento do sinal de reconhecimento Ack_SP em nível lógico alto foi forçado, uma vez que não havia no contexto dessa simulação, nenhum operador para receber o dado vindo do operador DM.

Na Fase3, a primeira continua ocupada, o módulo Match do operador foi desocupado, descrito pelo sinal opri_ocp em nível lógico baixo, quando chegam os tokens $A=$ "B00000A" (Hex) e $C={ }^{1601}$ " (Hex) nas entradas do operador com seus respectivos sinais de strobe. Novamente, como há instância ocupada, o módulo Confirma envia os tokens $A=$ "B00000A (Hex) e $C=" 1600 "$ (Hex) à instância ocupada, que neste caso reconhece os tokens recebendo o sinal AckAcf (AckAcfv na Figura 8.15) em nivel lógico alto e AckCcf (AckCcfv na Figura 8.15) também com nível lógico alto, tornando também o sinal Ack_A1 e $A c k \_C 1$ para nível lógico alto e conseqüentemente AckA e AckC no operador para nível lógico alto. Como todos os parceiros estão disponíveis na instância, há o disparo como observado pelos sinais Stbsp, Sp na Figura 8.15, fase 3.

Para efeito de simulação, na Fase 3, descrito na Figura 8.15, não foi forçado um reconhecimento, ou seja, sinal (Ack_Sp em nível lógico alto), assim, embora tenha havido o disparo, não houve desocupação da instância. 
O módulo Match do operador DM possue três registradores: dois registradores de 28 bits, relativos às entradas A e B e um registrador de 13 bits, relativo à entrada $\mathrm{C}$. Os registradores armazenam os tokens, enquanto eles aguardam seus parceiros. Um bit extra em cada registrador, indica se o mesmo encontrase desocupado ou com token armazenado. As entradas A, B e C acompanham um par de sinais para o protocolo de sincronismo, como já mencionado.

O módulo Match, tem como função a sincronização dos dados de entrada e correspondência entre os tokens parceiros. Na Figura 8.16 é descrito o módulo Match do operador DM.

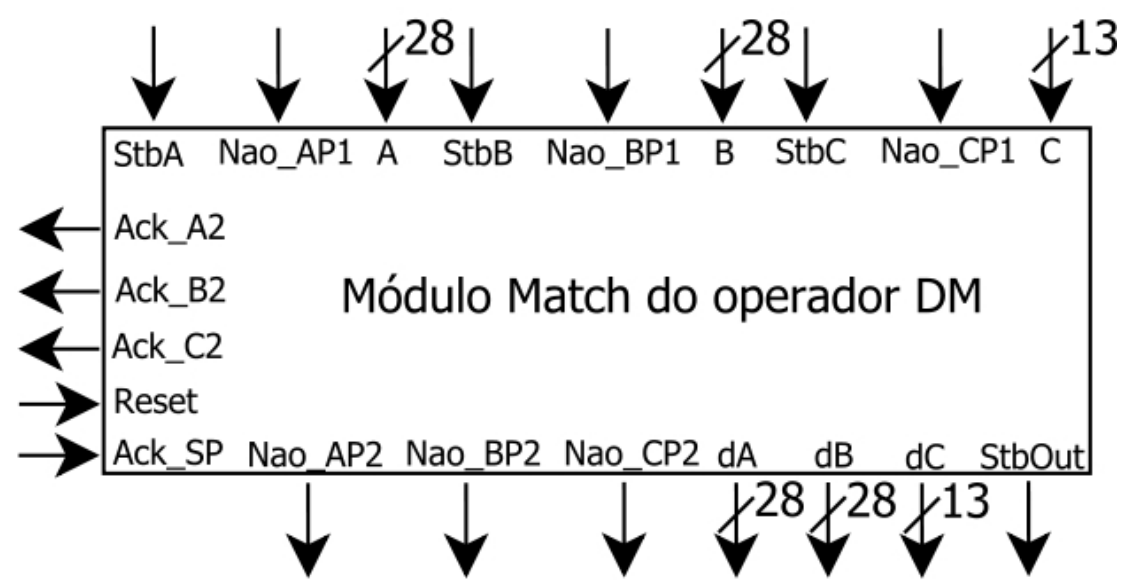

Figura 8.16: Módulo Match do operador DM

Na Figura 8.17 é descrito a simulação do operador DM módulo Match acoplado a três instâncias, simulado no ambiente ISE da Xilinx. Também como característica inicial descrito na Figura 8.17 pode-se destacar a ausência do sinal de clock, implicanco que todas as transições de sinal é decorrente de outros sinais que o provocam.

Na Figura 8.17 os sinais $N a o A P 1$, NaoBP1 e NaoCP1 são gerados a partir do módulo Confirma e ativam o módulo Match para que esse receba os tokens presentes nos sinais de entrada $A, B$ e $C$, respectivamente.

Ainda na Figura 8.17, os sinais Ack_A2, Ack_B2 e Ack_C2 indicam se houve correspondência entre os tokens recebidos nos sinais de entrada $A, B$ e $C$ e os tokens armazenados no Match. Esses sinais são utilizados para enviar os sinais AckA, AckB e AckC do operador.

Os sinais Nao_AP2, Nao_BP2 e Nao_CP2, também presentes na Figura 8.17 possuem a mesma função que os sinais $N a O A, N a O B$ e $N a O C$ presentes nas instâncias e indicam que não houve correspondência entre os tokens recebidos nos sinais de entrada $A, B$ e $C$ e os armazenados no módulo Match.

O sinal Ack_SP é utilizado para receber o sinal de reconhecimento do dado que foi enviado para o operador. 

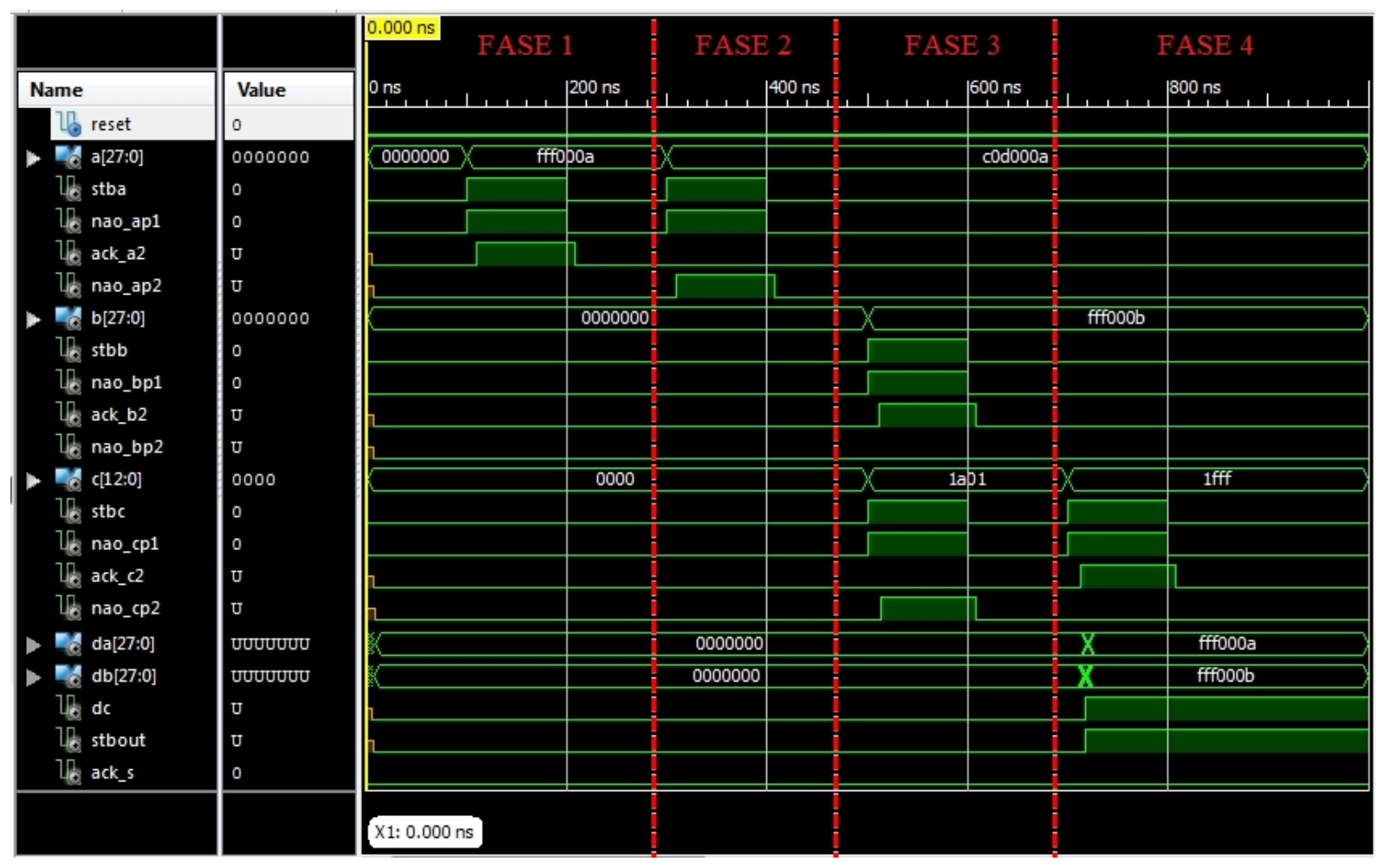

Figura 8.17: Simulação do módulo Match do operador DM

Os sinais de saída $d A, d B$ e $d C$ são os dados de saída correspondentes aos tokens armazenados nos registradores do módulo Match.

Finalmente o sinal StbOut indica que houve um disparo com os tokens armazenados no módulo. Esse sinal associado ao Ack_SP completa o protocolo para dados de saída do módulo Match.

Também na Figura 8.17, pode-se observar quatro diferentes momentos da simulação: Fase1, Fase2, Fase3 e Fase4 utilizados na simulação do módulo Match do operador DM.

Na Fase 1, inicialmente, não há tokens armazenados no módulo Match até chegar um token A="FFFOOOA" (Hex) presente no sinal de entrada $A$ do operador e seu respectivo sinal de strobe em nível lógico alto e o sinal Nao_AP1 em nível lógico alto, implicando que esse dado é para ser recebido no módulo Match e ser armazenado no registrador referente à entrada $A$ do módulo e imediatamente tornar o sinal Ack_A2 em nível lógico alto devendo com isso acionar o sinal AckA do operador $D M$, completando o protocolo para a recepção do dado $A$.

Se mais que um token chegar simultaneamente no módulo e o módulo não tiver tokens armazenados, a prioridade de armazenamento é dado a entrada $A$, seguido de $B$ e finalmente $C$.

Na Fase2, há token armazenado no registrador interno no módulo Match, referente à entrada $A$ e chega um novo token na própria entrada $A=$ "CODOOOA" (Hex), e seus respectivos sinais de strobe e Nao_AP1. Neste caso, o token não é 
armazenado no registrador referente à entrada $A$, pois o mesmo já se encontra ocupado, assim, o sinal Nao_AP2 é colocado para nível lógico alto, infomando que não houve correspondência entre os tokens no módulo.

Na Fase3, chegam simultaneamente os tokens B=" FFFOOOB" ${ }_{(\mathrm{Hex})}$ e $C=$ " $1 A 01$ " (Hex) e seus respectivos sinais de strobe, Nao_BP1 e Nao_CP1 em nível lógico alto. O token $B=$ "FFFOOOB" é correspondente ao token armazenado no registrador vindo da entrada $A$ no módulo Match e portanto é armazenado no registrador vinculado à entrada $B$ e imediatamente torna o sinal $A c k \_B 2$ para nível lógico alto, acionando assim o sinal $A c k B$ do operador $D M$, completando o protocolo para a recepção do dado $B$. O token $C=$ " $1 A O 1$ " não é armazenado e o sinal Nao_CP2 é tornado em nível lógico alto, informando que não houve correspondência.

Finalmente na Fase4, há tokens armazenados nos registradores internos do módulo Match, referente às entradas $A$ e $B$ e chega o token $C=$ " $1 F F F$ " (Hex) e seus respectivos sinais strobe e Nao_CP1. O token $C=$ " $1 F F F$ " possui correspondência aos tokens armazenados nos registradores referentes as entradas $A$ e $B$ e portanto, é armazenado no registrador vinculado à entrada $C$ e imediatamente torna o sinal Ack_CP2 para nível lógico alto, acionando assim o sinal AckC do operador DM completando o protocolo para a recepção do dado $C$.

Como os três tokens parceiros estão disponíveis no módulo Match, ocorrerá o disparo. Os sinais de saída $d A$ e $d B$ transportam os tokens dos registradores internos, referentes às entradas $A$ e $B$, respectivamente. $O$ sinal de saída $d C$ transporta apenas 1 bit, referente ao dado armazenado no registrador referente à entrada $C$, que representa um valor booleano "verdadeiro" ou "falso".

Com o disparo do módulo Match, o sinal StbOut é alterado para nível lógico alto, indicando que há token válido no barramento correspondente.

Também nesse caso, o sinal Ack_S não foi alterado para nível lógico alto, significando que o protocolo não foi completado e portanto nenhum dos valores armazenados serão alterados, caso contrário o módulo Match seria esvaziado e estaria apto a armazenar novos tokens.

\section{Módulo Aloca}

O módulo Aloca, do operador DM é responsável por procurar instâncias desocupadas e enviar os tokens presentes nas entradas do módulo à primeira instância vazia. Na Figura 8.18 é mostrado as conexões entre o módulo Aloca e uma instância do operador.

O módulo Aloca possui três entradas de tokens, vindas do operador, nomeadas pelas letras A, B com 28 bits e C com 13 bits, uma entrada de reset e um sinal de entrada chamado StatusIn vindo das instâncias, com $n$ bits indicando o status ocupado/desocupado de cada instância. O módulo possui três saídas 


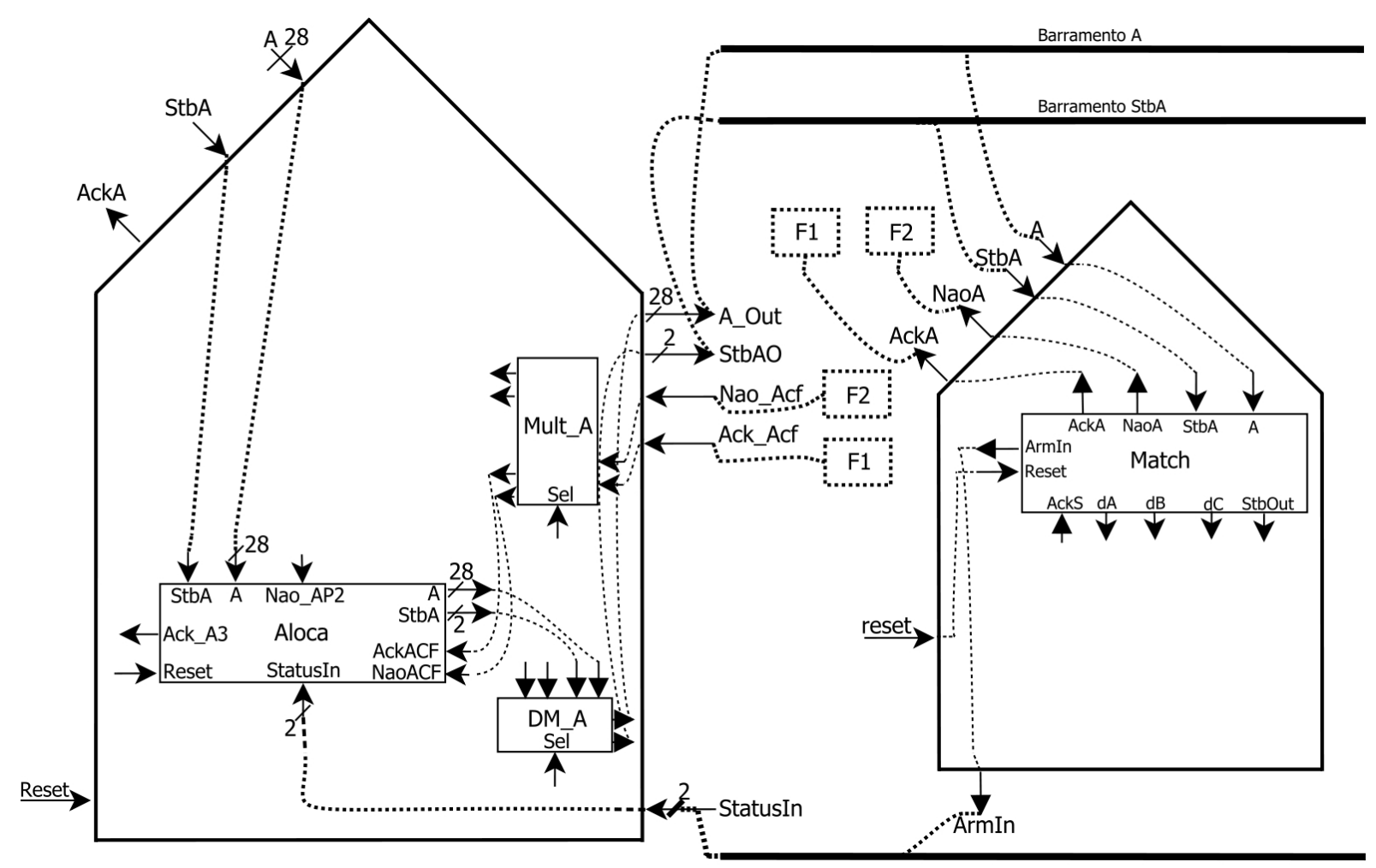

Figura 8.18: Módulo Aloca do operador DM

de tokens, nomeadas pelas letras A, B com 28 bits e C com 13 bits, as quais enviam tokens às instâncias. Esse módulo só envia tokens às instâncias, ou seja, não recebe tokens delas.

Vários sinais de entradas e saídas de dados e sinais de controle fazem parte do módulo Acloca. Na Figura 8.19 é descrito o fluxo de sinais gerados pelo módulo Aloca.

Como pode ser visto na Figura 8.19, os dados A, StbA, AckAcf e NaoAcf informam se o token recebido na entrada $A$ possui parceiro nas instâncias (sinal AckAcf em nível lógico alto) ou não (sinal NaoAcf em nível lógico alto). O mesmo corresponde aos sinais $B$ e $C$ vindos do operador.

Ainda na Figura 8.19, os sinais Ack_A3 e Nao_AP2 são utilizados para repasse do sinal de reconhecimento em Ack_A3 para o sinal AckA diretamente ligado ao operador. Já o sinal Nao_AP2, quando em nível lógico alto, indica que o token recebido na entrada $A$ deve ser alocado na entrada $A$ da primeira instância livre do operador, pelo módulo Aloca, o mesmo valendo para as entradas $B$ e $C$.

Os módulos Mult_A e DM_A também são utilizados pelo módulo Aloca, para a troca de informações entre ele e as instâncias, referente ao dado $A$. Mult_B, $D M \_B, M u l t C$ e $D M \_C$ referem-se aos dados $B$ e $C$, respectivamente.

Em termos de funcionamento geral, o módulo Aloca pode encontrar diferentes situações no relacionamento operador $D M$ e instâncias.

Supondo-se novamente um operador $D M$ com três instâncias conectadas a 


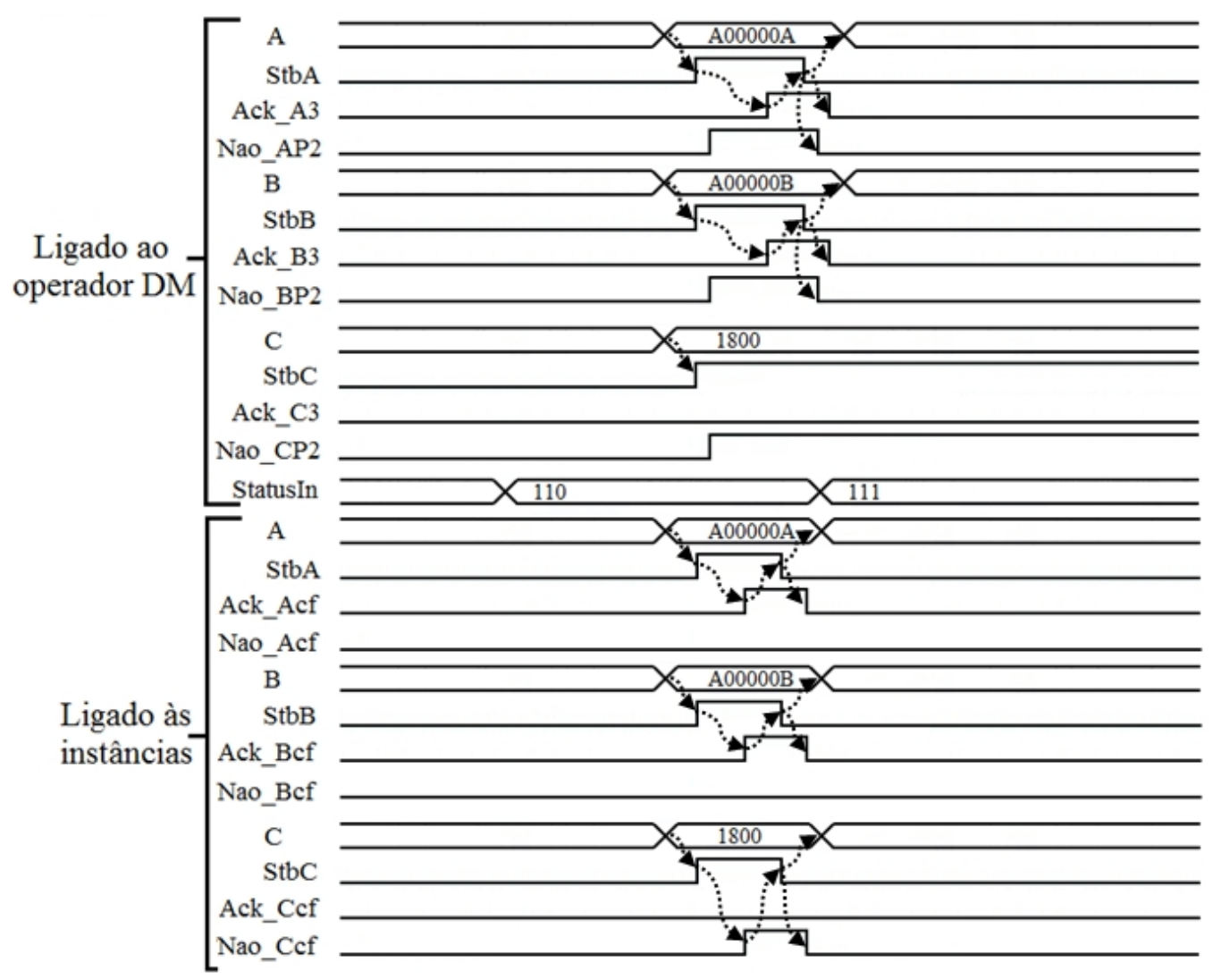

Figura 8.19: Fluxo de sinais do módulo Aloca no operador DM

ele, de imediato três situações podem ser destacadas.

A primeira situação, entre as três a se destacar para o módulo Aloca, é quando chega apenas um token na entrada $A, B$ ou $C$ no módulo Aloca.

Na Figura 8.20 é discutido essa situação.

Conforme descrito na Figura 8.20, as instâncias estão desocupadas, como mostrado pelo sinal StatusIn="OOO" (Hex). Na entrada $A$ chega o token $A=$ "FFFO $O O A{ }^{\prime}$ (Hex) e seu respectivo sinal de strobe. Por não haver tokens nas instâncias, o sinal Nao_AP2 é setado para nível lógico alto, gerado pelo sinal Nao_AP2 vindo do módulo Match, significando que esse token não teve correspondência com o token armazenado no módulo Match e assim, esse dado precisa ser alocado na entrada $A$ da primeira instância desocupada. Isso ocorre em duas etapas:

Na primeira etapa, o módulo Aloca procura nas instâncias do operador, qual a primeira instância desocupada e envia o token a ela.

Na Figura 8.21 é descrito o fluxo de sinais para a busca da primeira instância desocupada.

Como pode ser visto na Figura 8.21, o sinal StatusIn indica ao módulo Aloca, quais instâncias estão desocupadas, então, o token será enviado, a partir do sinal de saída A do módulo Aloca, a todas as instâncias, entretanto, apenas a primeira instância desocupada o receberá, pois somente ela receberá o sinal de saída StbA em nível lógico alto para essa função. 


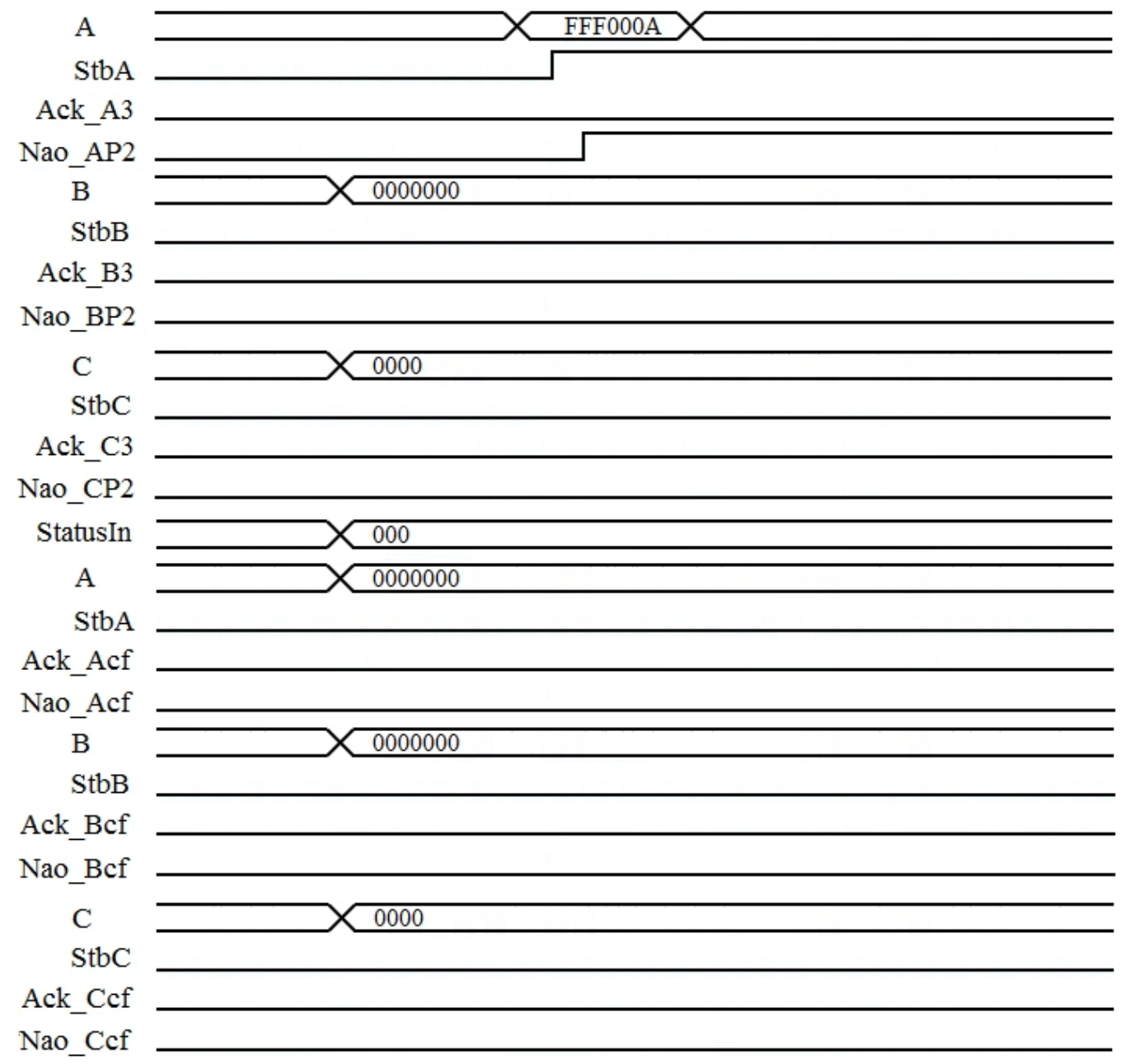

Figura 8.20: Diagrama de sinais do módulo Aloca - com apenas um token de entrada 


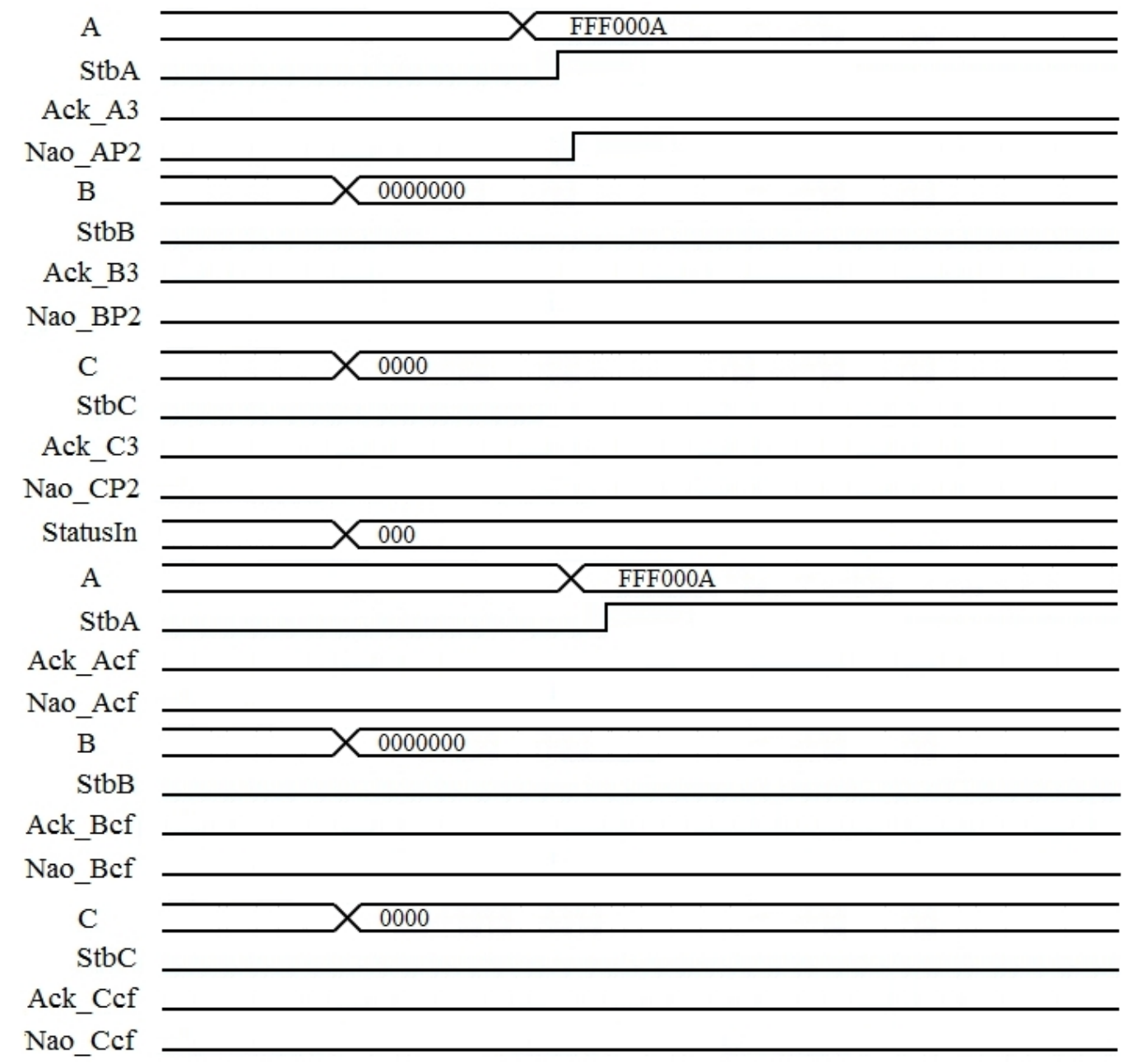

Figura 8.21: Diagrama de sinais do módulo Aloca - com envio de token às instâncias 
Na segunda etapa, o módulo Aloca aguarda o sinal de reconhecimento, neste caso, AckAcf em nível lógico alto ou não reconhecimento (NaoAcf em nível lógico alto), vindo da instância ocupada na etapa anterior. As Figuras 8.22 e 8.23 mostram o diagrama de sinais para essa etapa.

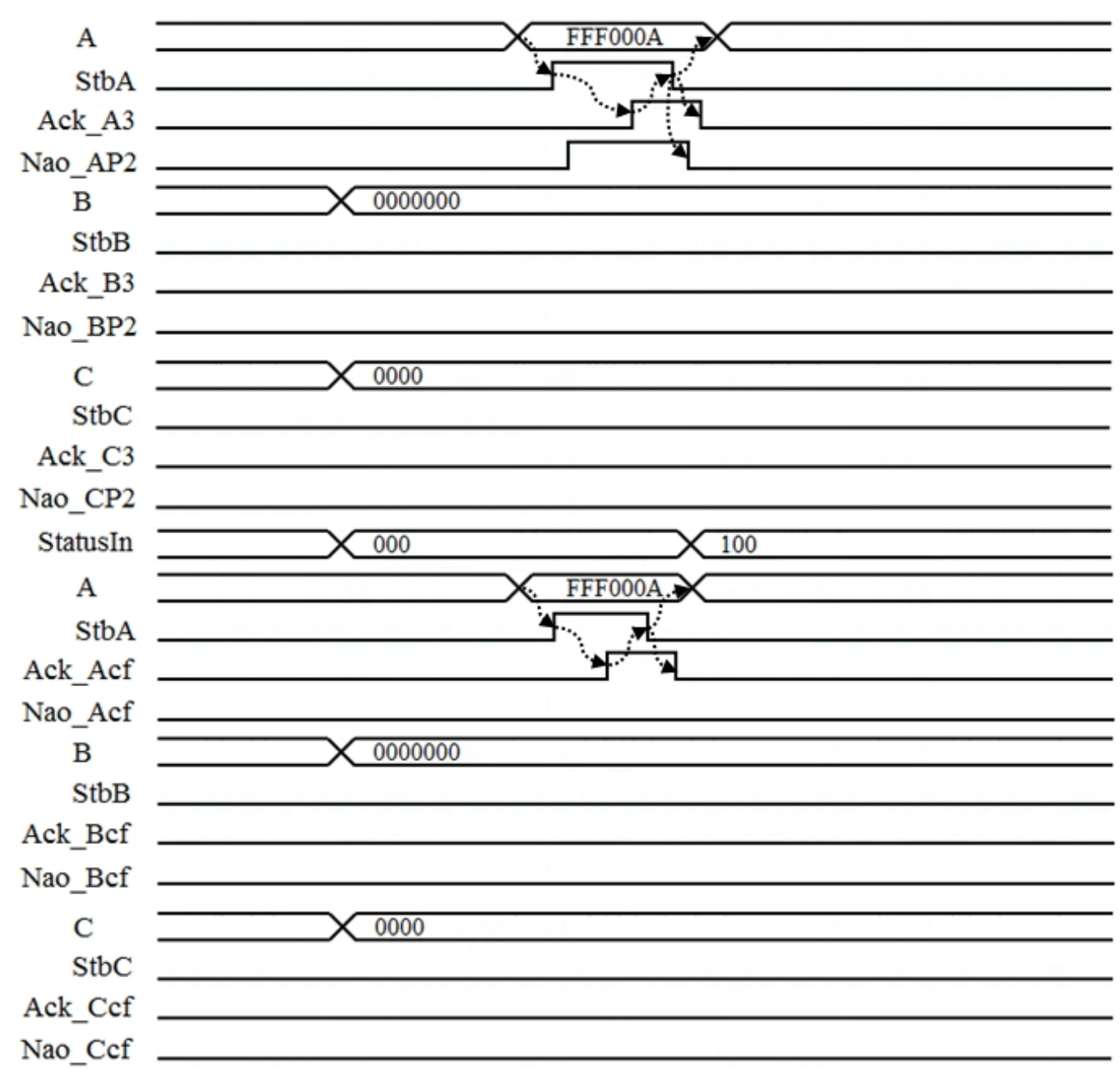

Figura 8.22: Diagrama de sinais do módulo Aloca - com recebimento de reconhecimento pelas instâncias

Como descrito na Figura 8.22, o recebimento do sinal de reconhecimento em nível lógico alto, ou seja, nesse caso houve ocupação da primeira instância desocupada. O recebimento do sinal de reconhecimento pelo módulo Aloca indica que o ciclo do protocolo na comunicação entre o módulo e a primeira instância ocupada está completo. Assim, o sinal Ack_A3 é setado em nível lógico alto e é enviado ao operador emissor pelo sinal AckA do operador receptor, ocasionando o fim do ciclo do protocolo na comunicação entre os operadores envolvidos no envio e recebimento de tokens.

Na Figura 8.23 é descrito o recebimento do sinal NaoAcf em nível lógico alto, indicando o não reconhecimento, isso significa que não houve ocupação da primeira instância desocupada, por algum motivo. O recebimento do sinal NaoAcf pelo módulo Aloca encerra o ciclo do protocolo na comunicação entre o módulo e a primeira instância desocupada, porém, o sinal NaoAcf em nível 


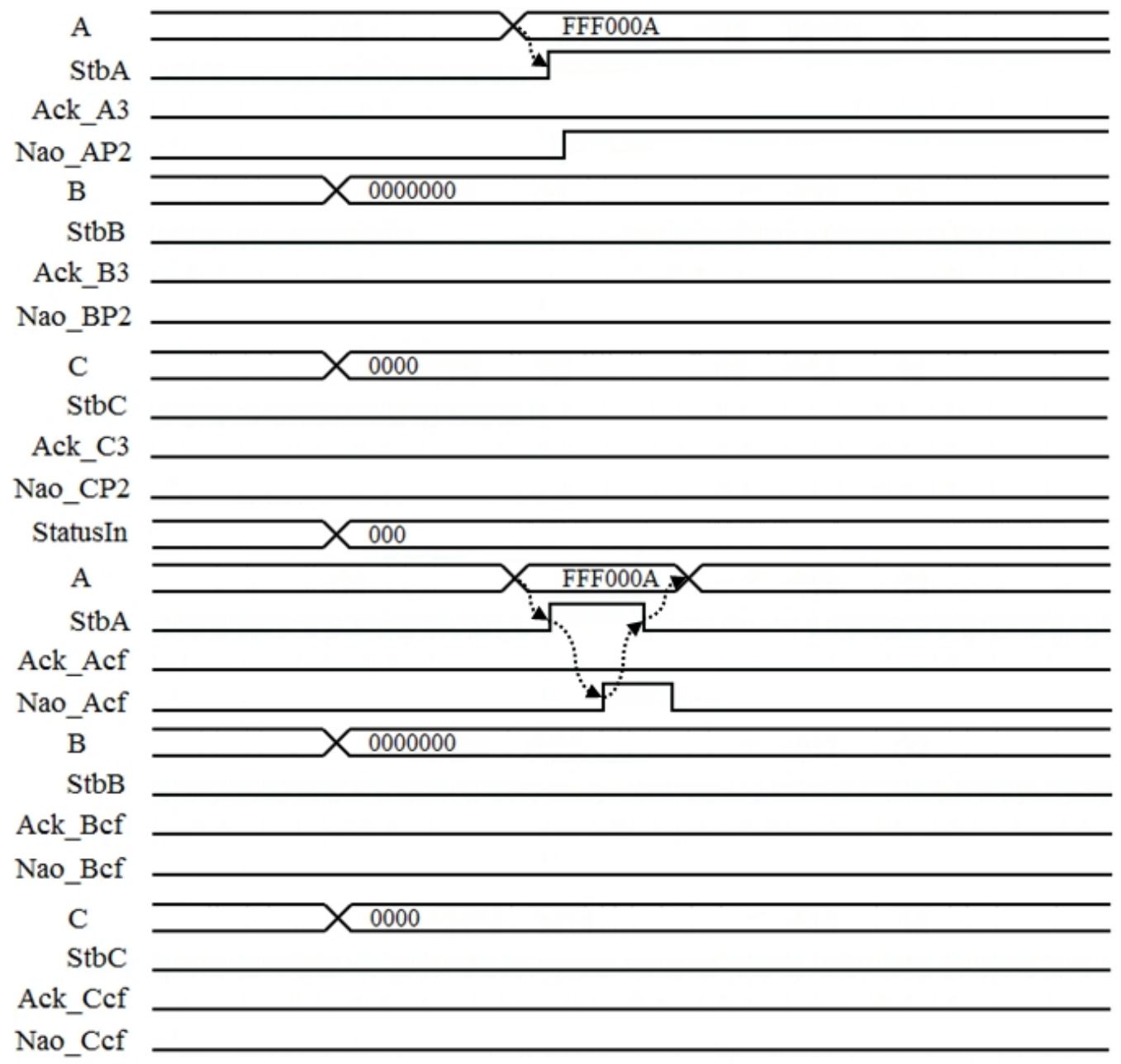

Figura 8.23: Diagrama de sinais do módulo Aloca - com recebimento de não reconhecimento pelas instâncias 
lógico alto faz o sinal Ack_A3 do módulo Aloca ser setado em nível lógico baixo e o sinal AckA do operador também ser setado em nível lógico baixo. Nesse caso ocorre um erro de exceção, pois a falta do sinal de reconhecimento (Ack) ocasionará a falta do sinal de reconhecimento de forma recursiva em todos os operadores de nível superior, ligados a esse operador que ocasionou o erro, paralisando o grafo ou o sub-grafo onde encontra-se esse operador. Tratamento de exceção não foram previstos, ainda, no projeto ChipCflow.

O mesmo procedimento será adotado, para os tokens nas entradas de letras B ou C.

A segunda situação a se destacar para o módulo Aloca, é quando chegam dois tokens simultâneos, um em cada entrada de tokens do módulo Aloca. Na Figura 8.24 é descrito o diagrama de sinais para essa situação.

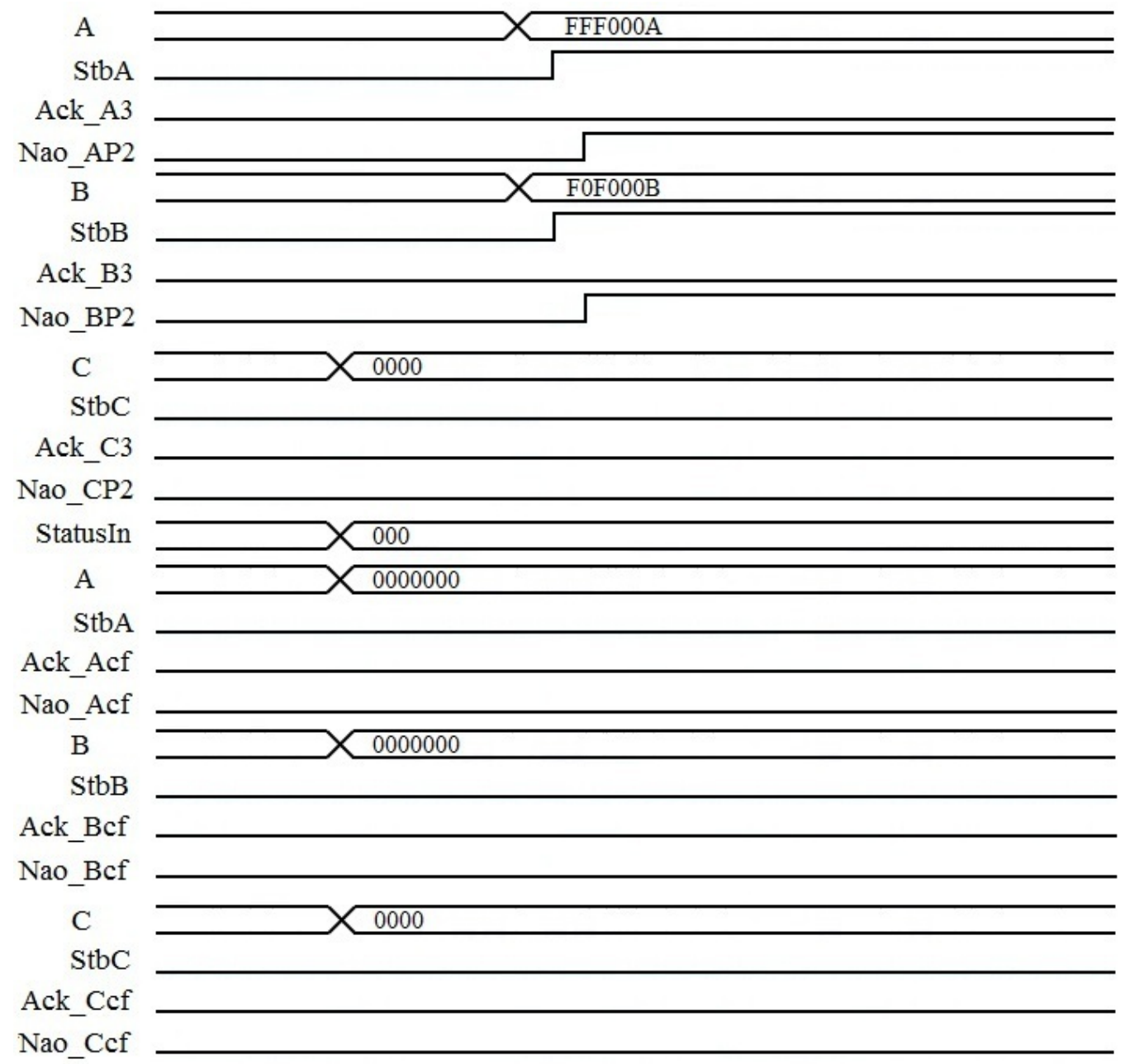

Figura 8.24: Diagrama de sinais do módulo Aloca - com envio simultâneo de dois tokens às instâncias

Conforme descrito na Figura 8.24, as instâncias estão desocupadas desocupadas, mostrado pelo sinal Status $I n=000 "{ }_{(\mathrm{Hex})}$ e chegam simultaneamente os tokens $\mathrm{A}=" \mathrm{FFF} 000 \mathrm{~A}^{\prime}{ }_{(\mathrm{Hex})}$ e $\mathrm{B}=" \mathrm{FOFO0OB}{ }_{(\mathrm{Hex})}$ e seus respectivos sinais de strobe e os sinais Nao_AP2 e Nao_BP2 em nível lógico alto. Como mais 
do que uma entrada de tokens do módulo Aloca recebeu tokens simultaneamente, o módulo Aloca verificará se os tags dos dois tokens são iguais ou diferentes. Se forem iguais, ambos os tokens deverão ser enviados a primeira instância desocupada, caso contrário, o token presente na entrada A do módulo Aloca deverá ser enviado à primeira instância desocupada e o token presente na entrada B do módulo Aloca deverá ser enviado à segunda instância desocupada e isso também ocorrerá em duas etapas.

Na primeira etapa, o módulo Aloca procura nas instâncias do operador, qual a primeira e a segunda instância desocupada para enviar os tokens para elas. Na Figura 8.25 é descrito o diagrama de sinais para a busca das instâncias desocupadas.

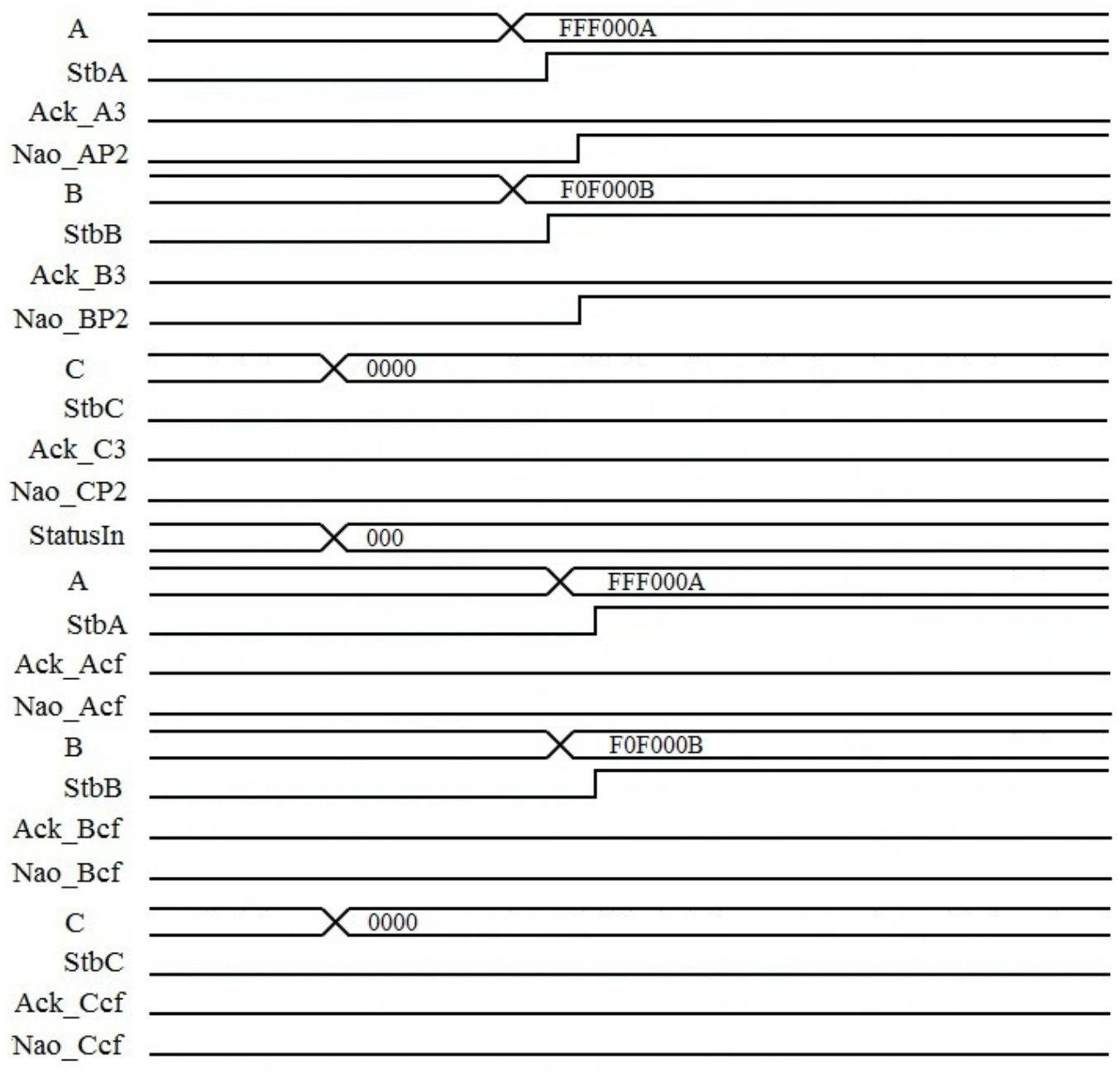

Figura 8.25: Diagrama de sinais do módulo Aloca - com alocação de dois tokens simultâneos nas instâncias

Como pode ser visto na Figura 8.25, nas entradas A e B do módulo Aloca, chegam os tokens $\mathrm{A}=" \mathrm{FFF} 000 \mathrm{~A}$ " e $\mathrm{B}=" \mathrm{FOFOOOB",} \mathrm{respectivamente.} \mathrm{Esses} \mathrm{to-}$ kens serão enviados a todas as instâncias do operador, mas apenas a primeira instância desocupada receberá o token $\mathrm{A}=" \mathrm{FFF} 000 \mathrm{~A}$, pois apenas ela receberá o sinal de StbA em nível lógico alto. O mesmo ocorre com o token 
$\mathrm{B}=$ "FOFOOOB" e a segunda instância desocupada o receberá, pois apenas ela receberá o sinal de $\mathrm{StbB}$ em nível lógico alto.

Na segunda etapa, o módulo Aloca aguarda o sinal de reconhecimento, no caso AckAcf e AckBcf ou o não reconhecimento, NaoAcf e NaoBcf ambos em nível lógico alto, vindo das instâncias na etapa anterior. Na Figura 8.26 é descrito o diagrama de sinais para essa etapa.

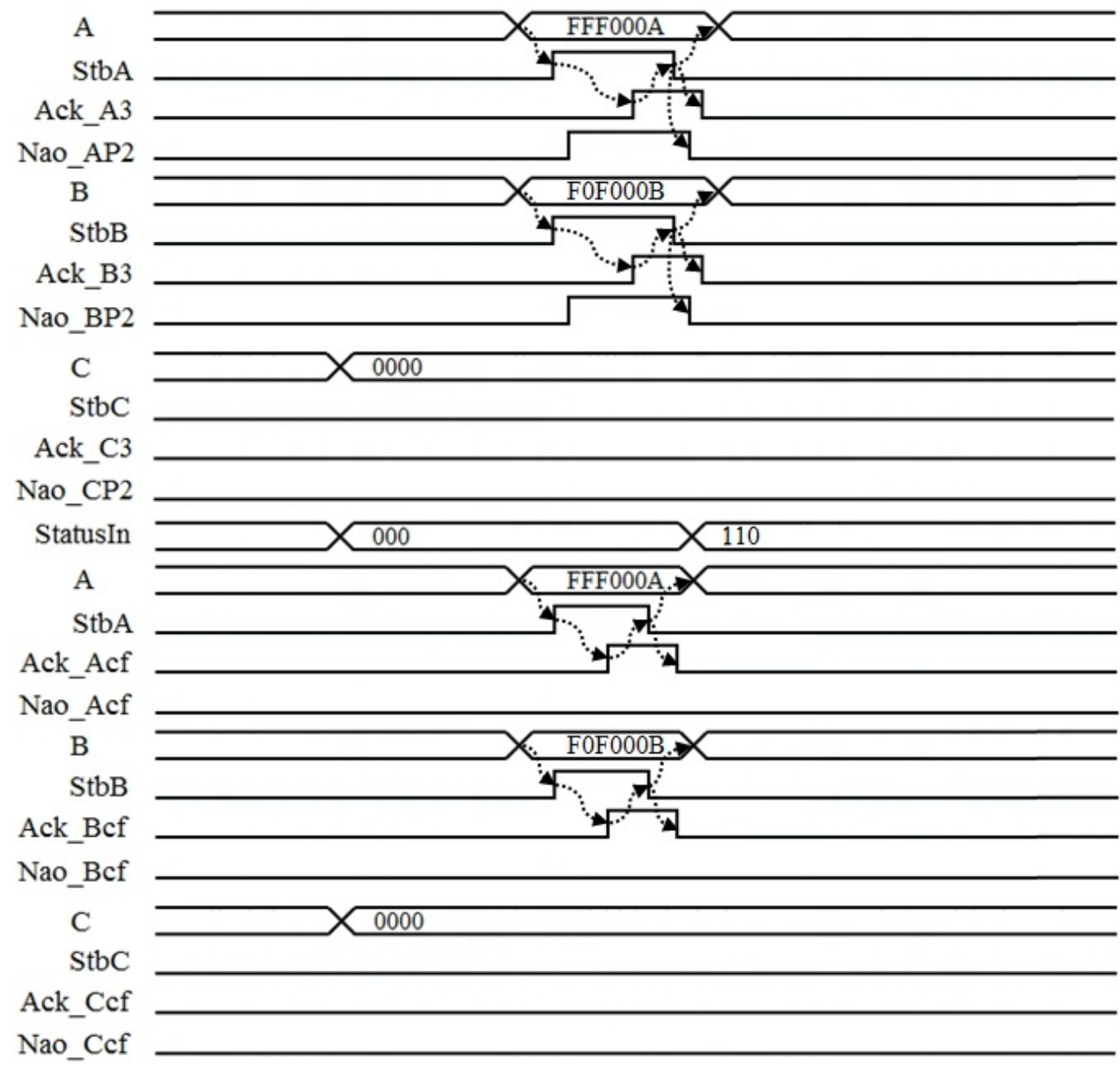

Figura 8.26: Diagrama de sinais do módulo Aloca - com recebimento de reconhecimento de dois tokens simultâneos pelas instâncias

Como descrito na Figura 8.26, o recebimento dos sinais de reconhecimento pelo módulo Aloca indicam que o ciclo do protocolo na comunicação entre o módulo e as instâncias 'um' e 'dois' ocupadas está completo. Assim, os sinais Ack_A3 e Ack_B3 são setados em nível lógico alto e são enviados aos operadores emissores pelos sinais AckA e AckB do operador receptor, ocasionando o fim do ciclo do protocolo na comunicação entre os operadores envolvidos no envio e recebimento de tokens.

O procedimento mostrado acima vale para qualquer par de tokens que entram simultaneamente no operador.

A terceira e última situação a se destacar para o módulo Aloca é quando chegam três tokens simultâneos, um em cada entrada de tokens do módulo. 
Nessa situação, assim como mostrado na segunda situação, mais do que uma entrada de tokens do módulo Aloca recebeu tokens simultaneamente. O módulo Aloca portanto deve verificar se os tags dos três tokens são iguais ou diferentes.

Na Tabela 8.1 são descritos diferentes situações para a chegada simultânea de tokens nas entradas A, B e C, com seus respectivos sinais de strobe. Tag('X') é utilizada para simplificar a representação da tag do token na entrada ' $\mathrm{X}^{\prime}$.

Tabela 8.1: Diferentes situações, nas quais podem chegar tokens simultaneamente nas entradas A, B e C do operador

\begin{tabular}{|c|c|}
\hline$(1)\left(\operatorname{tag}\left({ }^{\prime} \mathrm{A}^{\prime}\right)=\operatorname{tag}\left({ }^{\prime} \mathrm{B}\right)\right)=\operatorname{tag}\left({ }^{\prime} \mathrm{C}^{\prime}\right)$ & $\begin{array}{l}\text { Tokens } A, B \text { e } C \text { vão para a primeira instância } \\
\text { livre }\end{array}$ \\
\hline$(2)\left(\operatorname{tag}\left({ }^{\prime} \mathrm{A}^{\prime}\right)=\operatorname{tag}\left({ }^{\prime} \mathrm{B}^{\prime}\right)\right) \neq \operatorname{tag}\left({ }^{\prime} \mathrm{C}^{\prime}\right)$ & $\begin{array}{l}\text { Tokens } A \text { e } B \text { vão para a primeira instância } \\
\text { livre e token } C \text { vai para a segunda }\end{array}$ \\
\hline$(3)\left(\operatorname{tag}\left({ }^{\prime} \mathrm{A}^{\prime}\right)=\operatorname{tag}\left({ }^{\prime} \mathrm{C}^{\prime}\right)\right) \neq \operatorname{tag}\left({ }^{\prime} \mathrm{B}\right)$ & $\begin{array}{l}\text { Tokens } A \text { e } C \text { vão para a primeira instância } \\
\text { livre e token } B \text { vai para a segunda }\end{array}$ \\
\hline$\left.(4) \operatorname{tag}\left({ }^{\prime} \mathrm{A}^{\prime}\right) \neq\left(\operatorname{tag}\left({ }^{\prime} \mathrm{B}\right)\right)=\operatorname{tag}\left({ }^{\prime} \mathrm{C}^{\prime}\right)\right)$ & $\begin{array}{l}\text { Token } A \text { vai para a primeira instância } \\
\text { livre e os tokens } B \text { e } C \text { vão para a segunda }\end{array}$ \\
\hline $\begin{array}{l}\text { ( } 5) \operatorname{tag}\left(' A^{\prime}\right) \neq \operatorname{tag}(' B ') \neq \operatorname{tag}\left({ }^{\prime} C^{\prime}\right) \\
\text { e } \operatorname{tag}(' A ') \neq \operatorname{tag}(' C)^{\prime}\end{array}$ & $\begin{array}{l}\text { Token } A \text { vai para a primeira instância, } \\
\text { livre, token } B \text { vai para a segunda e token } C \\
\text { vai para a terceira }\end{array}$ \\
\hline
\end{tabular}

Independente das tags dos tokens, o módulo Aloca processará conforme as diferentes situações e etapas descritas acima. Portanto, quando chegam tokens simultâneos, a entrada A tem prioridade sobre as entradas B e C e a entrada $B$ tem prioridade sobre a entrada $C$.

Ainda no módulo Aloca foi implementado uma função responsável por localizar instâncias desocupadas, utilizando-se dos sinais L1s, L2s e L3s. Conforme as instâncias disparam e há o ciclo completo no protocolo de comunicação, elas serão desocupadas e podem receber novos tokens. Assim, pode haver instâncias desocupadas entre instâncias ocupadas. Na Figura 8.27 é descrito a simulação da função de localização de instâncias desocupadas.

Como pode ser visto, na Figura 8.27, foi simulado um operador com cinco instâncias, representas pelo sinal StatusIn. Nesse exemplo, as instâncias 'um' e 'três' estão ocupadas e as instâncias 'dois', 'quatro' e 'cinco' estão desocupadas, o sinal Status $I n=" 10100 "$. Os valores gerados para L1s, L2s e L3s, nesse exemplo, são: L1s="01000", L2s="00010" e L3s="00001". A função de localização de instâncias desocupadas funciona em tempo real, pois tão logo uma instância é ocupada ou desocupada, os módulos responsáveis por enviar tokens às instâncias tem que ser informados imediatamente pelo sinal StatusIn.

Na Figura 8.28 é descrito a simulação do operador DM (módulo Aloca), aco- 

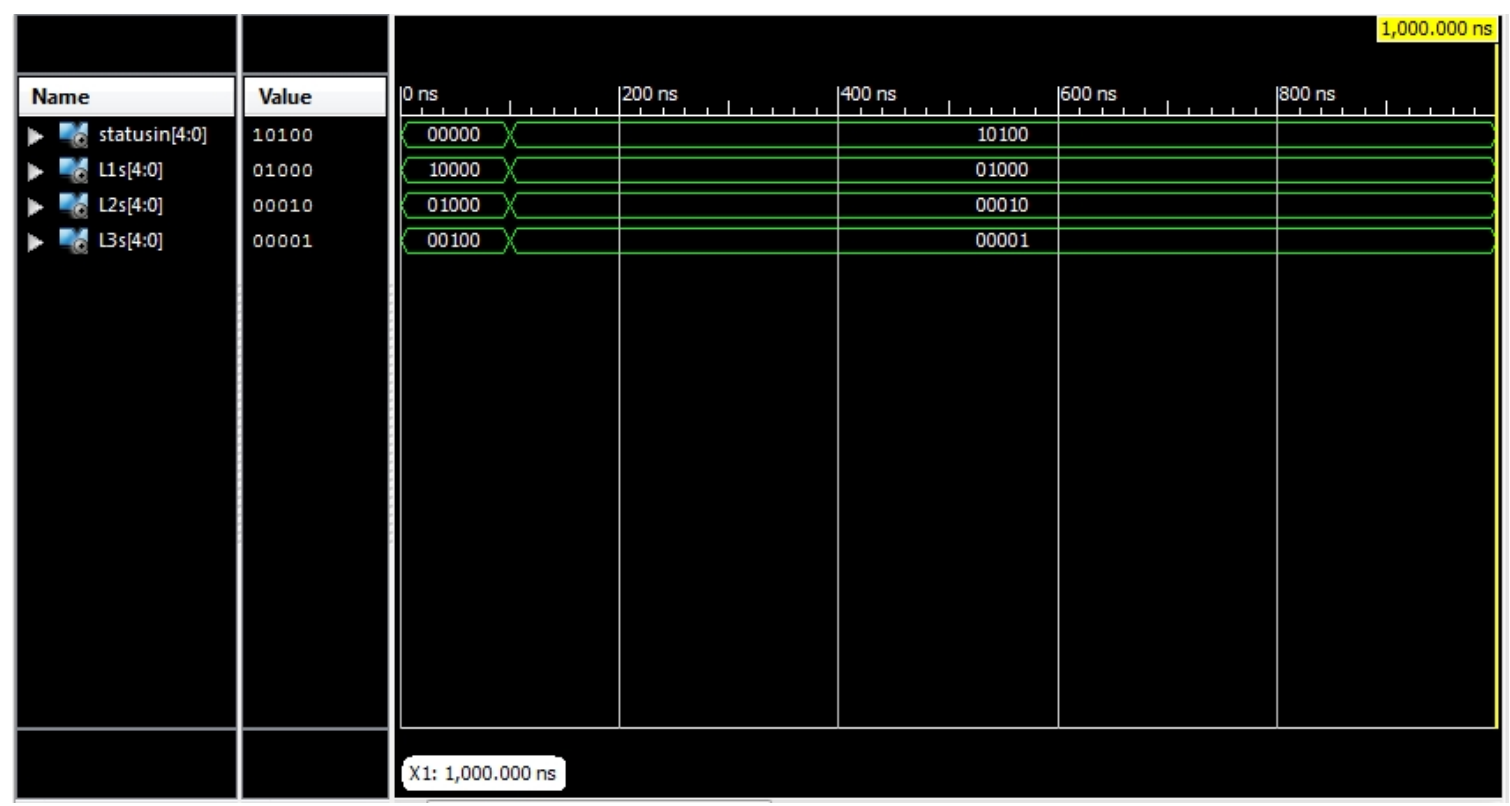

Figura 8.27: Simulação da função de localização de instâncias desocupadas

plado a três instâncias simuladas no ambiente ISE da Xilinx. Também como característica inicial, descrita na Figura 8.28, pode-se destacar a ausência do sinal de clock.

Na Figura 8.28, os sinais tsinst2, tsinst1 e tsinsto indicam se há ou não tokens armazenados nas instâncias. O mesmo para o sinal opri_ocp para tokens armazenados no operador. O restante dos sinais são os mesmos apresentados em outras simulações em seções anteriores.

Da mesma forma, na Figura 8.28, pode-se destacar dois diferentes momentos da simulação: Fase1 e Fase2, utilizado na simulação do módulo Aloca do operador $D M$.

Na Fase1, inicialmente não há tokens nas instâncias, comprovado pelos valores de tsinst2, tsinst 1 e tsinsto, todos em nível lógico baixo, nem no operador, comprovado pelo valor de opri_ocp em nível lógico baixo.

Ainda na Fase 1, chegam simultaneamente pelas entradas $A, B$ e $C$ os to-

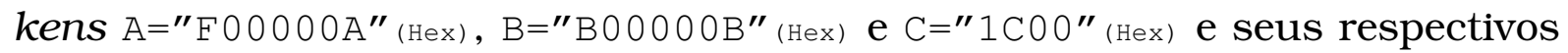
sinais de strobe, vindo das entradas do operador $D M$.

Por não haver tokens armazenados nas instâncias, o módulo Confirma aciona o módulo Match para receber os tokens presentes nas entradas $A, B$ e $C$ do operador.

Como $A$ possui tag diferente de $B$ e $C$, isso faz com que o módulo Match do operador armazene o token recebido na entrada $A$ do operador, acionando assim todo o procedimento para o protocolo de recepção do dado vindo da entrada A do operador, comprovado pelo sinal AckA, descrito na Figura 8.28. Ao mesmo tempo, o módulo Match aciona o módulo Aloca para que esse receba os dados $B$ e $C$, vindo das entradas $B$ e $C$ do operador para serem alocados 

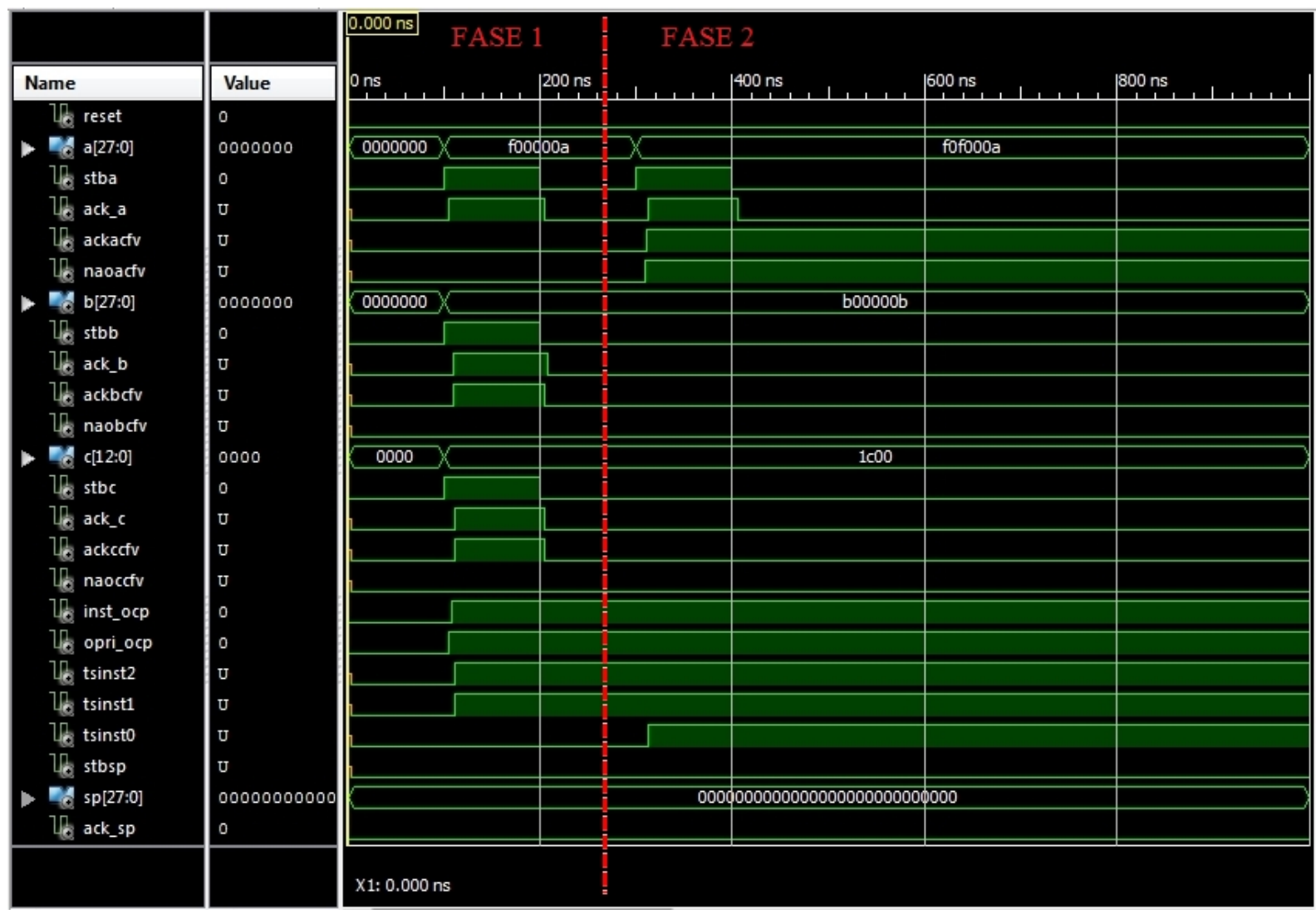

Figura 8.28: Simulação do módulo Aloca do operador DM

nas instâncias.

Uma vez de posse dos dados, o módulo Aloca verificará se $B$ e $C$ possuem a mesma tag nos respectivos tokens. Como as tags são diferentes, o token na entrada $B$ é enviado à primeira instância desocupada e o token presente na entrada $C$ é enviado à segunda instância desocupada. Os sinais $A c k B c f v$ e tsinst2, ambos em nível lógico alto, descrito na Figura 8.28, comprovam a alocação do token $B$ na primeira instância e os sinais AckCcfv e tsinst1, ambos em nível lógico alto, comprovam a alocação do token $C$ na segunda instância.

Cabe ressaltar que a comprovação de que o token $B$ de fato foi alocado na primeira instância e o token $C$ na segunda instância, foi realizado nos exemplos simulados para o funcionamento do módulo Aloca do operador DM, descrito nas Figuras 8.24, 8.25 e 8.26.

Finalmente na Fase 1 é possível comprovar portanto, pelos sinais opri_ocp e inst_ocp ambos com nível lógico alto, que existem tokens armazenados no operador $D M$ e em suas instâncias.

Na Fase 2 chega o token na entrada $A=" F 0 F 000 A^{\prime \prime}$ (Hex) e seu respectivo strobe. Por haver tokens armazenados tanto no operador como nas instâncias, o módulo Confirma primeiro faz a verificação se existe instâncias com o mesmo token, caso contrário, o módulo Match do operador é acionado para ver se o token coincide com os tokens armazenados no operador. 
Em ambos os casos, o token recebido em $A$ não coincide com nenhum dos tokens armazenados, nem no operador, nem nas instâncias, nesse caso, esse novo token deve ser alocado em uma instância desocupada, executado pelo módulo Aloca, que pode ser visto por meio dos sinais AckA em nível lógico alto significando que o protocolo de recepção do dado $A$ pela entrada $A$ do operador $D M$ foi concluído; pelo sinal AckAcf em nível lógico alto, significando que uma instância foi alocada para o token; pelo sinal NaoAcf em nível lógico alto confirmando que não houve coincidência nas instâncias, para os tokens enviados pelo módulo Confirma; finalmente tsinsto em nível lógico alto, comprovando que o token foi alocado na última instância disponível.

\section{Módulo Multiplexador}

O módulo Multiplexador do operador DM tem como função selecionar uma das entradas A ou B e direcioná-la à saída $S$, dependendo do dado carregado pelo token na entrada C. Na Figura 8.29 é descrito as conexões entre os módulos Multiplexador, o módulo Match e módulo Disparo do operador.

O módulo Multiplexador é composto pelos sinais de entrada: dA, dB de 28 bits, $\mathrm{dC}$ de 1 bit e StbIn de 1 bit, ligados às saídas $\mathrm{dA}, \mathrm{dB}$ de 28 bits, $\mathrm{dC}$ de 1 bit e Stbout de 1 bit do módulo Match. Os sinais dA e dB transportam os tokens parceiros, do módulo Match para o módulo Multiplexador. O sinal dC transporta apenas um bit indicando se a saída $S$ do módulo Multiplexador receberá a entrada $\mathrm{dA}$ ou $\mathrm{dB}$. O sinal StbIn é usado quando o módulo Match dispara e, assim, ativa o módulo Multiplexador para receber os tokens nas entradas do operador. A tag do sinal dC é descartado, pois foi utilizado apenas no módulo Match. Os sinais de saída S e StbS são ligados ao módulo Disparo. Esse mesmo processo vale para todas as instâncias do operador DM.

\section{Módulo Disparo}

O módulo Disparo, do operador DM é responsável por gerenciar o token recebido do módulo Multiplexador e pelos tokens vindos das instâncias. Na Figura 8.29 além das conexões entre os módulos Disparo, Multiplexador e Match do operador, são descritas as conexões entre o operador e as suas instâncias.

O módulo Disparo possui o sinal reset de entrada, $n+1$ entradas de tokens, onde uma entrada de token, nomeada pela letra $\mathrm{S}$ de 28 bits vem do módulo Multiplexador do operador e as outras entradas de tokens, nomeadas pelas letras S_0 até S_n de 28 bits vem da saída de tokens de cada uma das instâncias. Há uma saída de tokens, nomeada pela letra $S$ de 28 bits que liga o módulo Disparo e a saída de tokens do operador. Diferente dos módulos Confirma e Aloca do operador, o módulo Disparo só recebe tokens vindos do módulo Multiplexador do operador e das instâncias. 


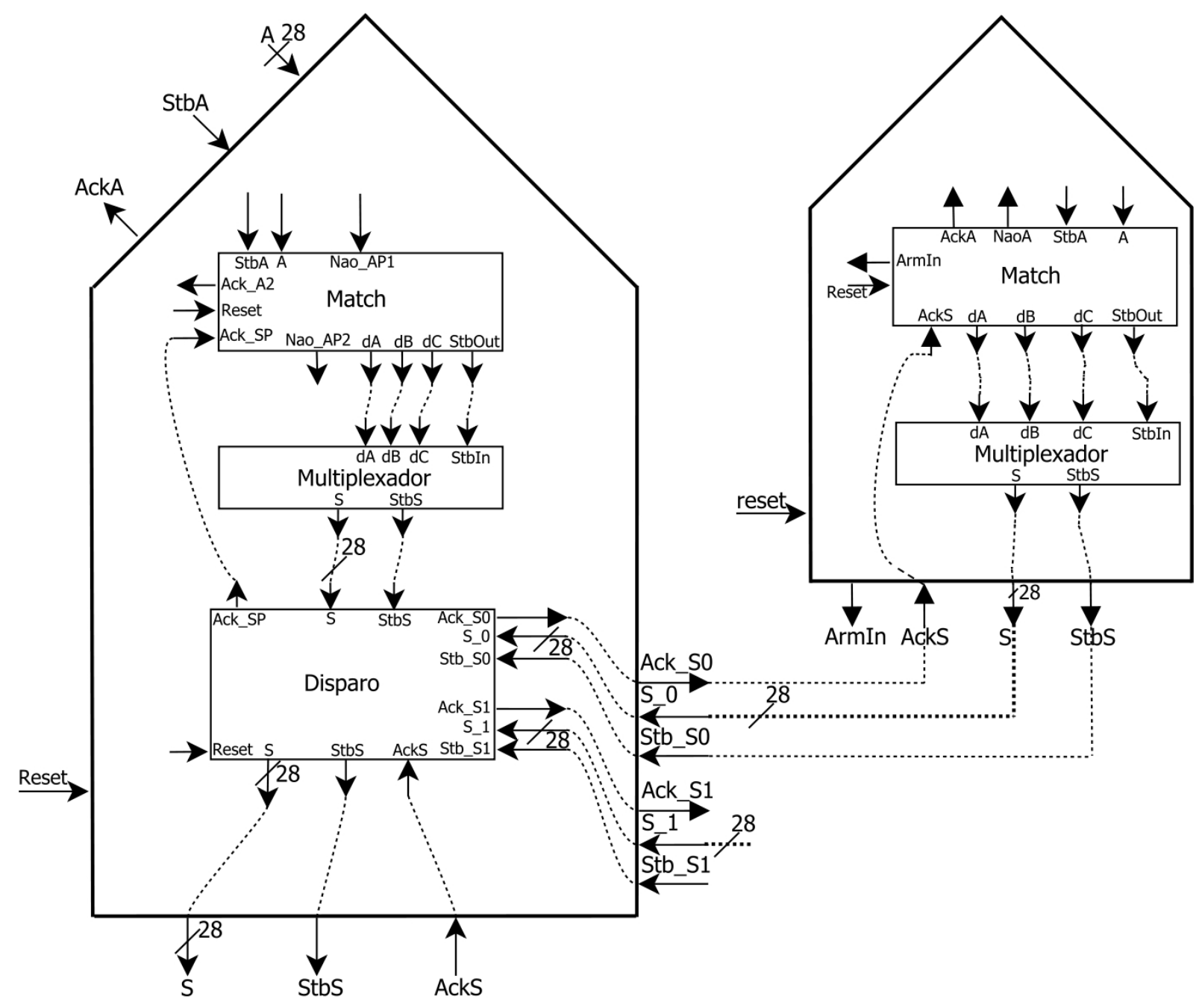

Figura 8.29: Módulo Disparo do operador DM 
Além dos sinais de dado de entradas e saídas dos tokens no módulo Disparo, vários sinais de controle fazem parte deste módulo.

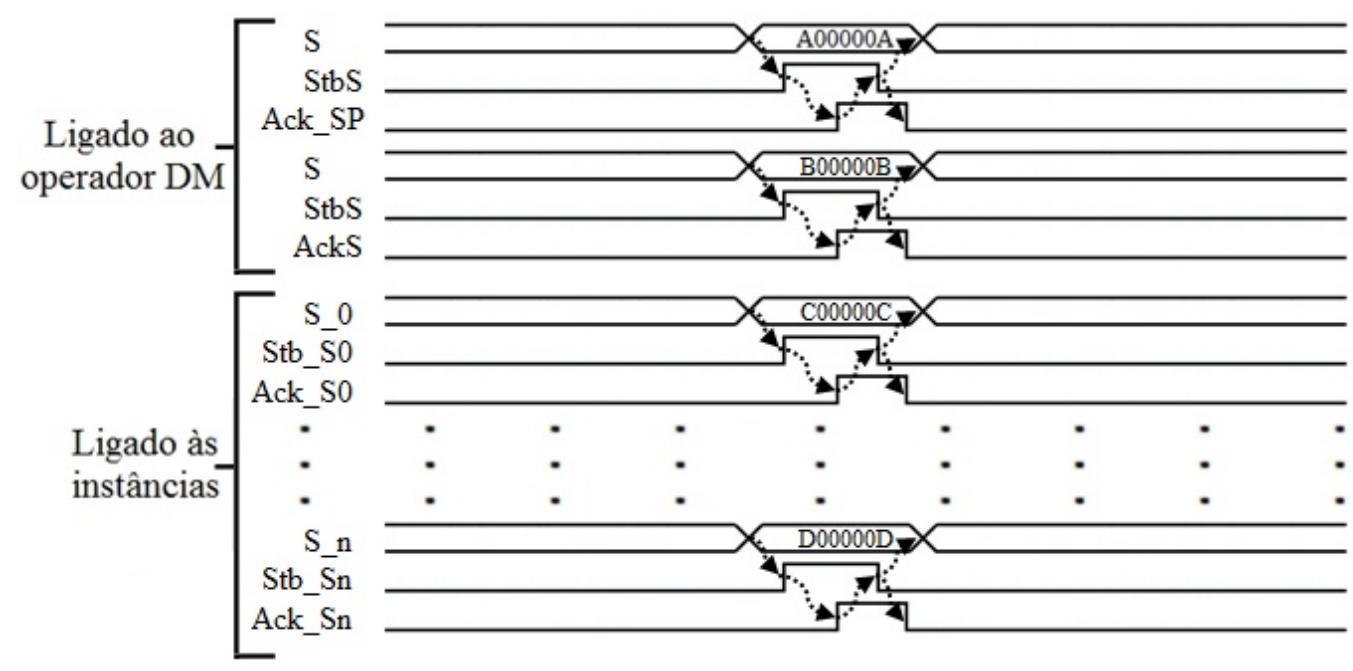

Figura 8.30: Fluxo de sinais do módulo Disparo no operador DM

Na Figura 8.30 é descrito o fluxo de sinais gerenciado pelo módulo Disparo. Como discutido na Figura 8.30, os sinais $S$ e StbS estão diretamente ligados ao módulo Multiplexador e são utilizados para enviar os tokens ao módulo Disparo; o sinal Ack_SP está diretamente ligado ao módulo Match do operador $D M$, servindo para enviar o sinal de reconhecimento que junto com os sinais $S$ e $S t b S$ ligados ao módulo Multiplexador cumprem o protocolo de comunicação entre os módulos. O mesmo acontece com os sinais S_O, Stb_SO e Ack_SO para receber os tokens vindos da primeira instância acoplada ao operador $D M$ e servem para cumprir o protocolo de comunicação entre o módulo e a primeira instância. O mesmo acontece para o restante das instâncias, sinais S_1, Stb_S1 e Ack_S1 até $S \_n, S t b \_S n$ e Ack_Sn.

Toda vez que há um ou vários disparos simultâneos, vindos do operador ou das instâncias, o módulo Disparo coloca os tokens recebidos, um por vez, na saída $\mathrm{S}$ do módulo, através de uma fila de disparo, e seta o sinal Stb.S em nível lógico alto. Esses sinais, como já citados anteriormente, são ligados as saídas S e Stbs do operador e são enviados ao operador receptor ligado diretamente a esses sinais na máquina a fluxo de dados. Ao receber o sinal AckS em nível lógico alto do operador receptor, o módulo Disparo o encaminha ao módulo Match do operador ou a uma das instâncias, responsável pelo disparo do token, desocupando-o. Assim, o próximo token na fila de disparo é colocado na saída $\mathrm{S}$ do módulo e o processo é repetido enquanto houver dados para serem enviados.

Na Figura 8.31 é mostrado um exemplo no qual podem acontecer três disparos simultâneos, supondo-se a existência deste operador $D M$ e três instâncias acopladas a ele. 


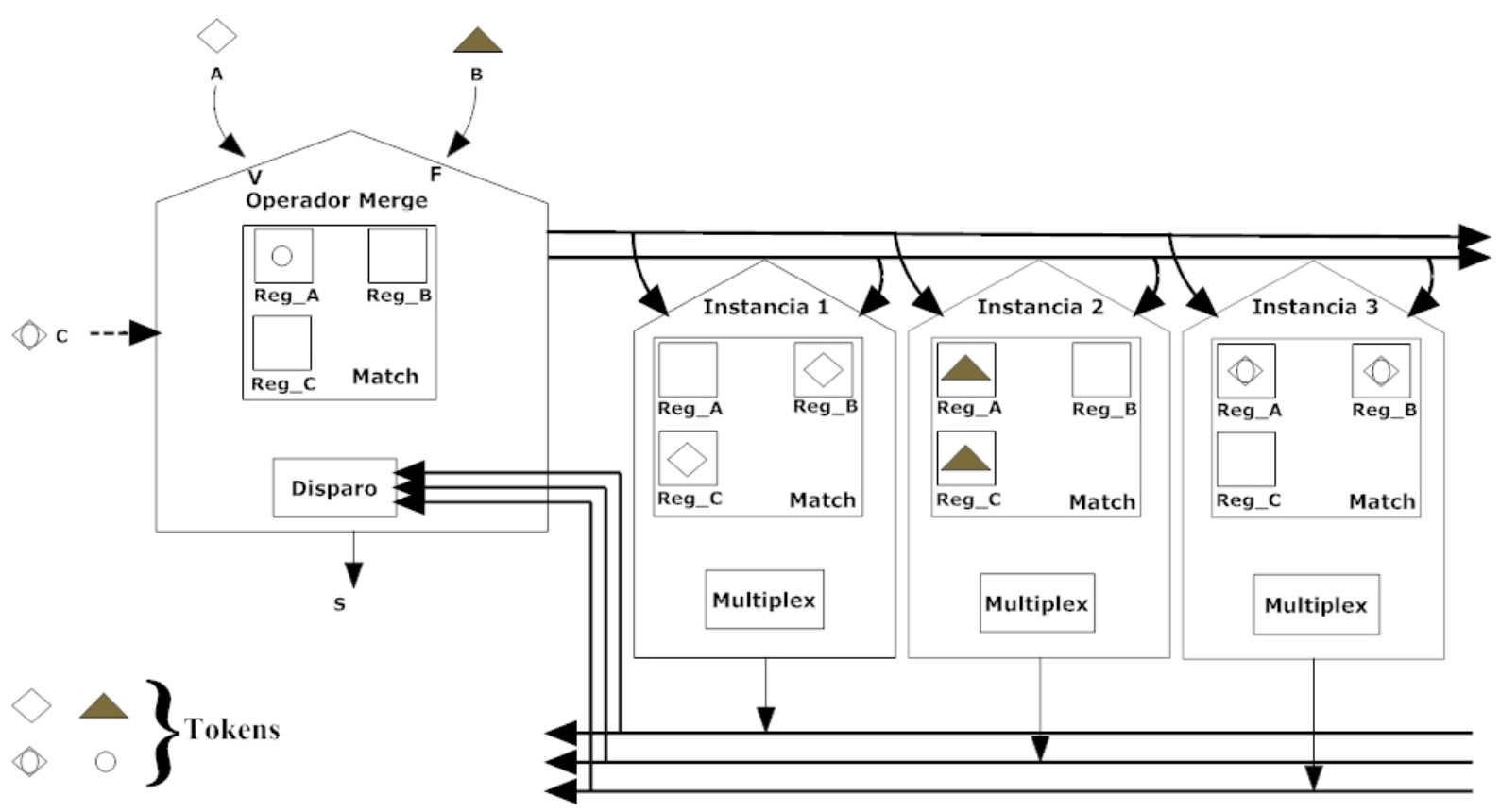

Figura 8.31: Situação em que o módulo Disparo do operador DM recebe três tokens disparados simultaneamente

Como discutido na Figura 8.31, o módulo Match do operador possui o registrador A ocupado. A instância 'um' possui os registradores B e C do módulo Match ocupados. A instância 'dois' possui os registradores A e C do módulo Match ocupados. Finalmente a instância 'três' possui os registradores A e B do módulo Match ocupados.

Considerando então estas condições, supor a chegada de três tokens simultaneamente nas entradas A, B e C do operador DM. Como há instâncias ocupadas, o módulo Confirma do operador DM os enviará as instâncias ocupadas. Os tokens nas entradas A, B e C do operador DM são tokens parceiros que faltavam nas instâncias 'um', 'dois' e 'três', respectivamente. Essa situação causa o disparo de tokens das três instâncias ao mesmo tempo.

Sempre que há dois ou mais disparos simultâneos no módulo Disparo, é dado uma prioridade na ordem de disparo dos tokens. O módulo Multiplexador do operador $D M$ tem prioridade sob as instâncias. Nas instâncias, a instância 'um' tem prioridade sob as instâncias 'dois' e 'três'; a instância 'dois' tem prioridade de disparo sob a instância 'três' e assim sucessivamente.

Apesar da ordem de prioridade para o disparo dos tokens, há duas situações diferentes a serem tratadas pelo módulo Disparo.

Na primeira situação, chega um token por vez, vindo da módulo Match ou de uma das instâncias e não houve disparos anteriores ou do operador ou das instâncias.

Essa primeira situação é descrito na Figura 8.32

Conforme pode ser visto na Figura 8.32, chega um token $S_{-} O=$ "FFFOOOA" 


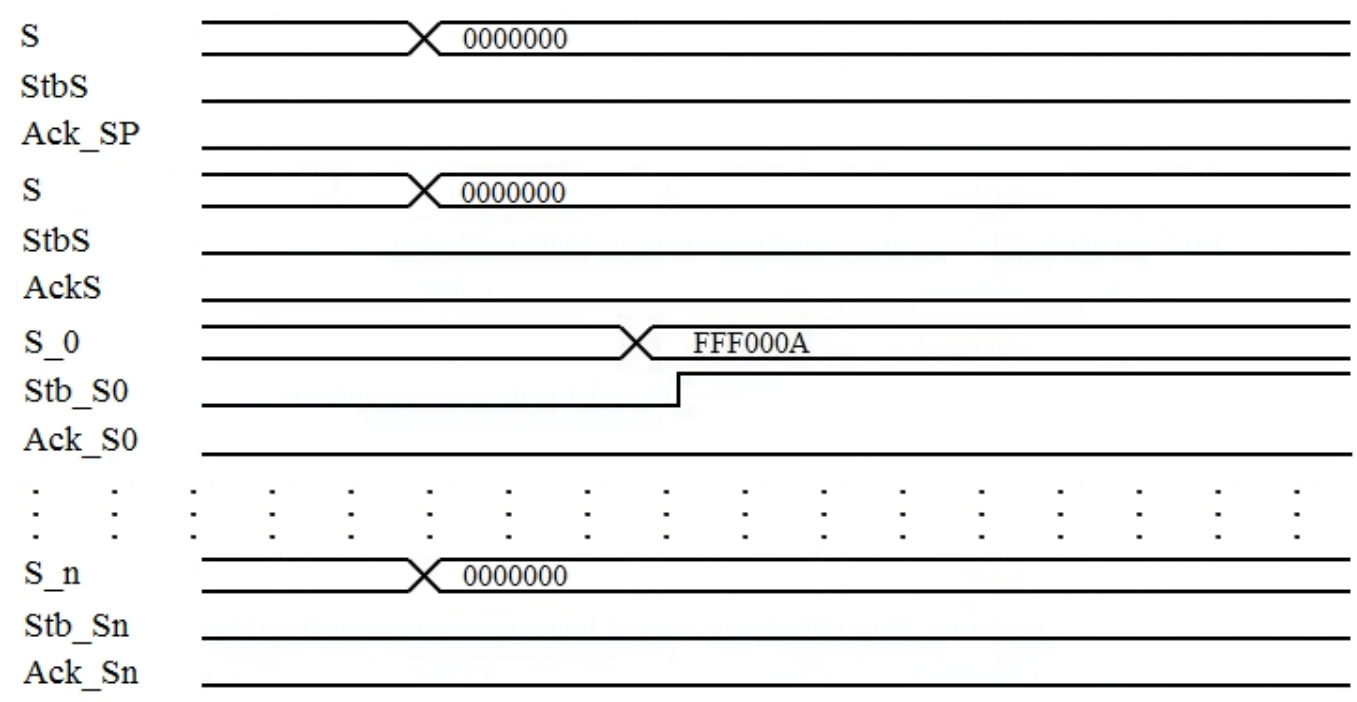

Figura 8.32: Diagrama de sinais do módulo Disparo - quando não ocorre disparo anterior

(Hex) e seu sinal de strobe (Stb_SO, disparado pela instância "um".

O módulo Disparo irá processar essa situação em duas etapas.

Na primeira etapa, o token presente no sinal de entrada $S \_O$ é colocado no sinal de saída $S$ e tornando o sinal $S t b S$ para nível lógico alto, conforme descrito na Figura 8.33.

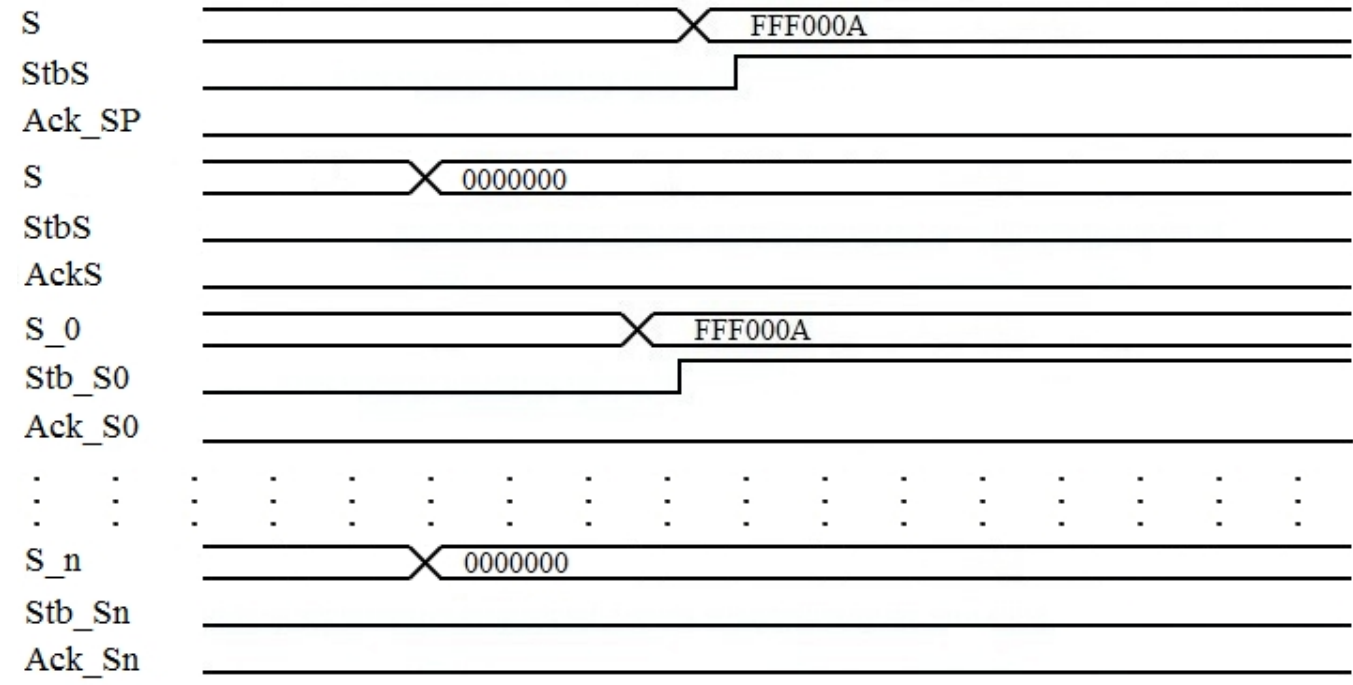

Figura 8.33: Diagrama de sinais do módulo Disparo - com um primeiro disparo

Na segunda etapa, o módulo Disparo aguarda o sinal de reconhecimento vindo do operador receptor ligado à saída do operador $D M$, conforme descrito na Figura 8.34.

Tão logo o sinal de reconhecimento é recebido pelo módulo Disparo, ele é transmitido para a instância "um" para que seja desocupada (sinal Ack_SO em nível lógico alto). Essa ação finaliza o ciclo no protocolo de comunicação de tokens, então, o módulo Disparo do operador DM e a instância "um", zerando 


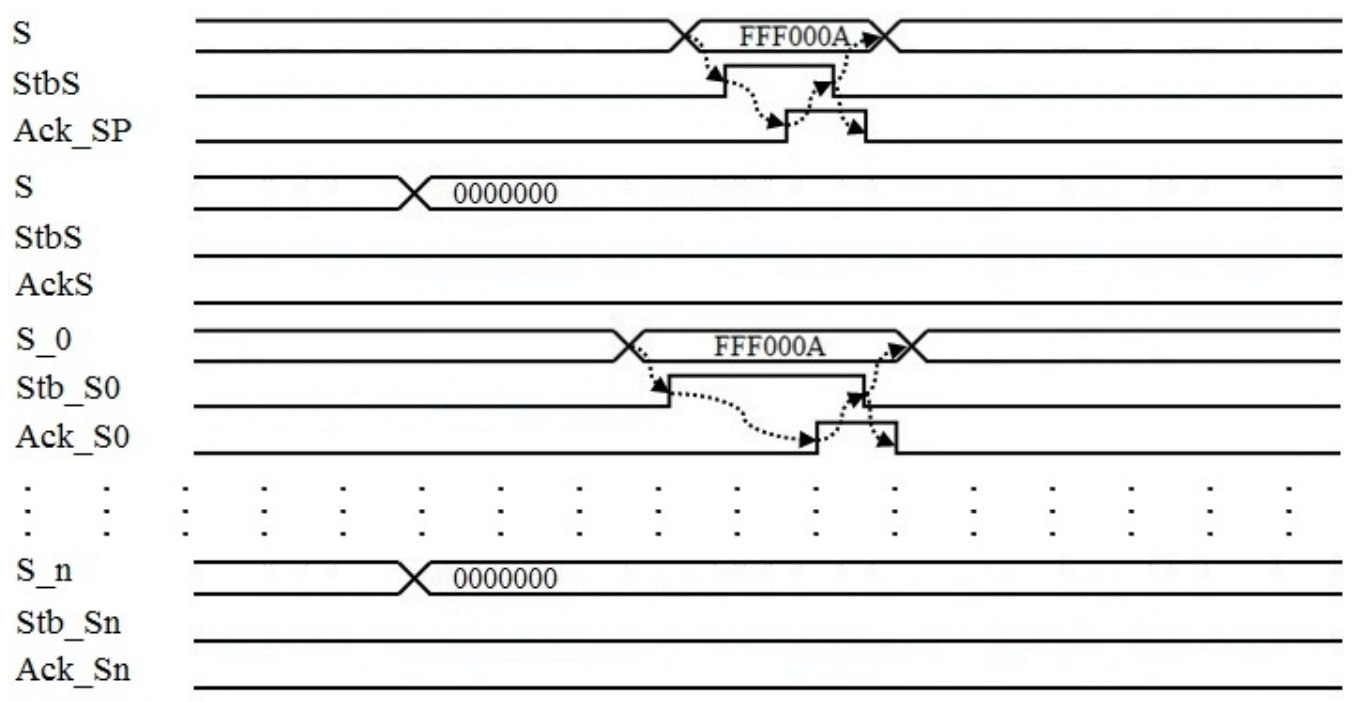

Figura 8.34: Diagrama de sinais do módulo Disparo - com recebimento de reconhecimento para um disparo

S_O e tornando Stb_SO também para nível lógico baixo, conforme descrito na Figura 8.34.

Na segunda situação, chegam dois tokens simultaneamente, um vindo do módulo Multiplexador no operador $D M$ e um de alguma das instâncias. Supondo também que não houve disparos anteriores.

Essa segunda situação é descrito na Figura 8.35.

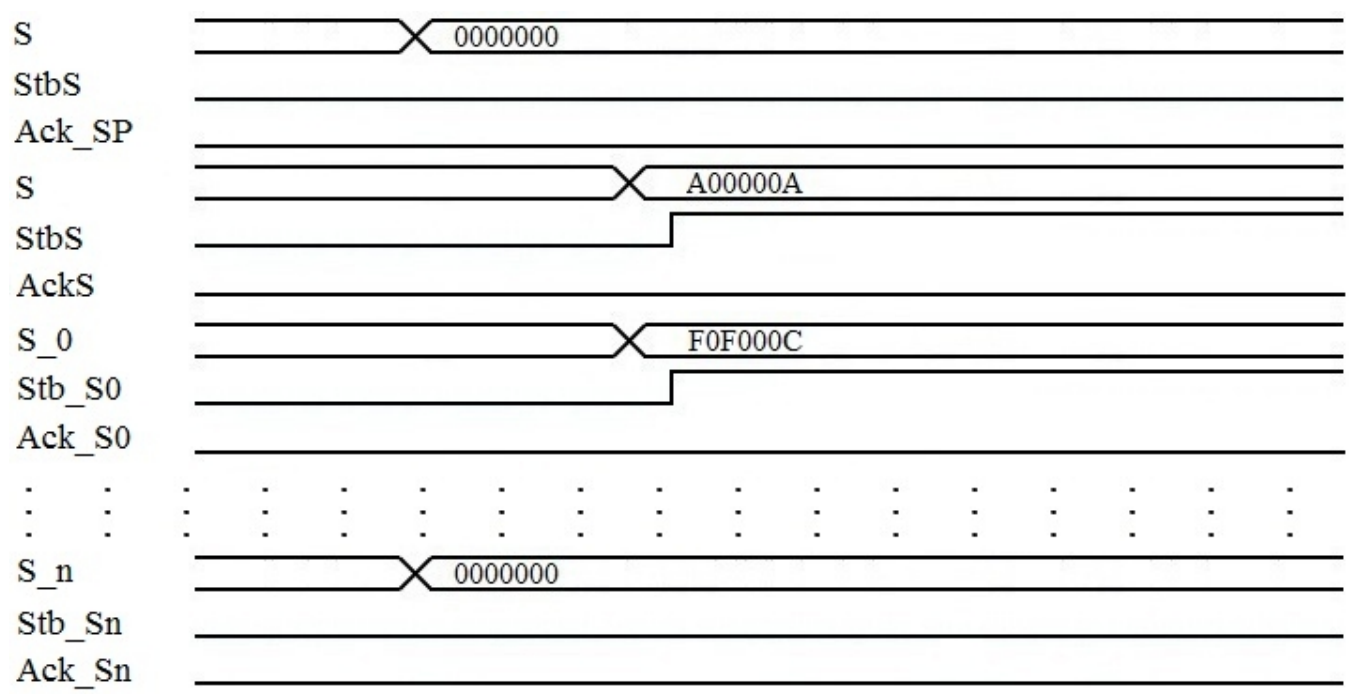

Figura 8.35: Diagrama de sinais do módulo Disparo - com dois disparos simultâneos

Conforme pode ser visto na Figura 8.35, chegam simultaneamente os tokens $S=$ "AOOOOOA” (Hex) e $S \_O=$ "FOFOOOC” (Hex) nas entradas S e S_O, respectivamente e seus respectivos sinais de strobe, StbS e Stb_SO.

O token $\mathrm{S}=" \mathrm{~A} 00000 \mathrm{~A}$ " é disparado pelo módulo Multiplexador do operador $D M$ e o token S_O="FOFOOOC" é disparado pela instância "um", conforme é 
descrito no diagrama de sinais na Figura 8.35. O módulo Disparo irá processar essa situação em duas etapas.

Na primeira etapa, o token vindo do módulo Multiplexador do operador DM, presente no sinal de entrada $S$ do módulo Disparo é colocado no sinal de saída $\mathrm{S}$ do módulo, o sinal Stbs é colocado em nível lógico alto e o token vindo da instância "um" é colocado na fila de disparos do módulo Disparo. A Figura 8.36 mostra o diagrama de sinais para essa etapa.

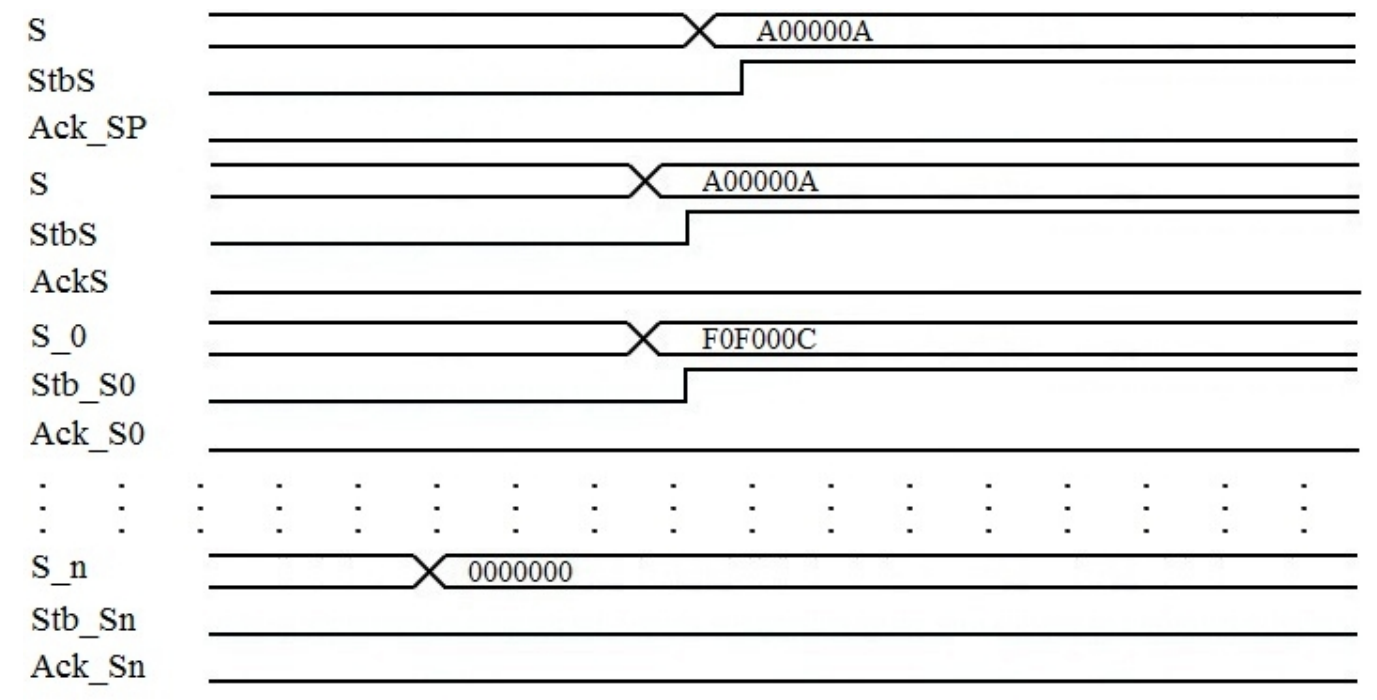

Figura 8.36: Diagrama de sinais do módulo Disparo - com envio de dado do operador DM e armazenamento de dado da instância "um"

Na segunda etapa, o módulo Disparo aguarda o recebimento do sinal de reconhecimento, vindo do operador receptor ligado a saída do operador $D M$ emissor. Na Figura 8.37 é descrito o diagrama de sinais para essa etapa.

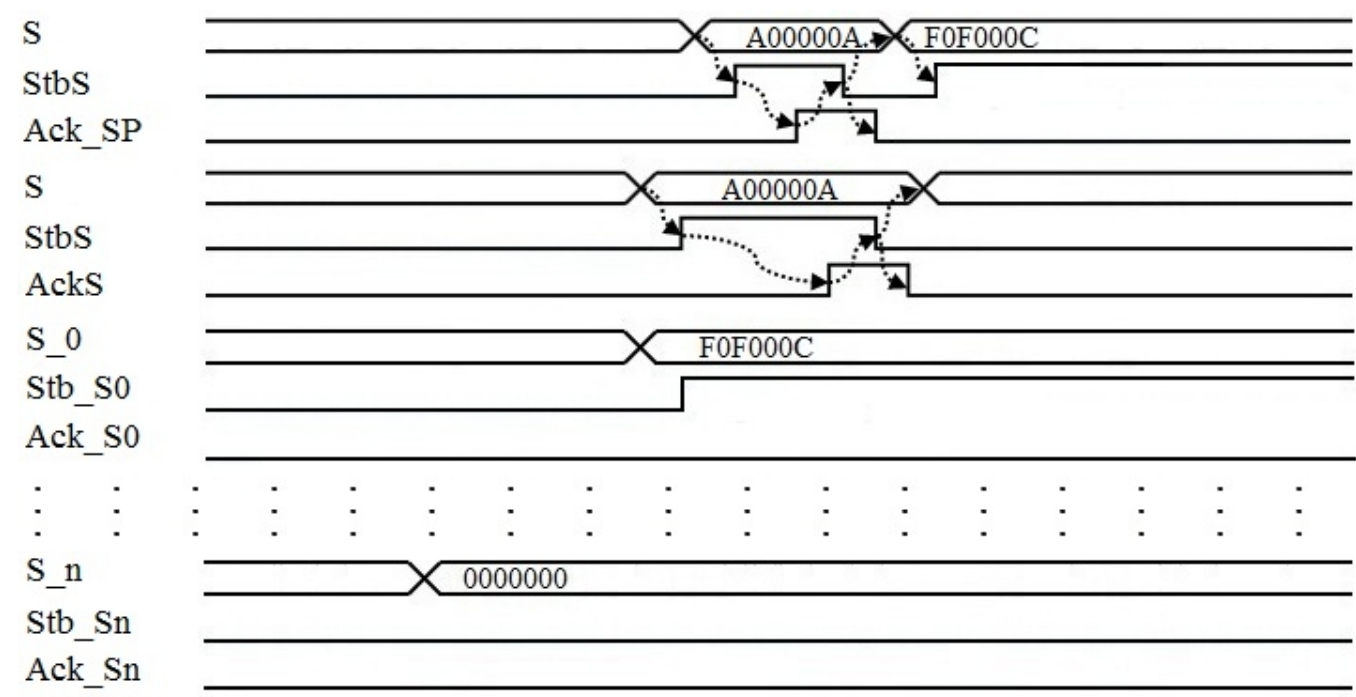

Figura 8.37: Diagrama de sinais do módulo Disparo - com recebimento de reconhecimento para dois disparos simultâneos

Como descrito na Figura 8.37, o sinal de reconhecimento Acks em nível 
lógico alto, vindo do operador receptor ligado a saída do operador $D M$ é transmitido ao módulo Match do operador DM, causando a sua desocupação. Essa ação finaliza o ciclo no protocolo de comunicação de tokens entre o módulo Disparo do operador DM e os módulos Match e Multiplexador do operador DM, zerando os sinais $S$ e $S t b S$. Ao mesmo tempo, finaliza o ciclo no protocolo de comunicação de tokens entre o operador emissor e o operador receptor, zerando os sinais $S$ e $S t b S$ do operador emissor.

Após o encerramento do ciclo no protocolo de comunicação de tokens entre o módulo Disparo do operador DM e os módulos Match e Multiplexador do operador DM, o token presente no sinal de entrada S_0 do módulo Disparo, vindo da instância "um", presente na fila de disparos do módulo é colocado no sinal de saída S e o sinal de strobe StbS é setado em nível lógico alto e todo o processo é repetido até a completa transmissão do token de saída vindo da instância "um".

Na Figura 8.38 é descrito a simulação do operador DM, módulo Disparo, acoplado a três instâncias, também simulado no ambiente ISE da Xilinx. Da mesma forma como nas outras simulações, a característica inicial descrito na Figura 8.38 é a ausência do sinal de clock.
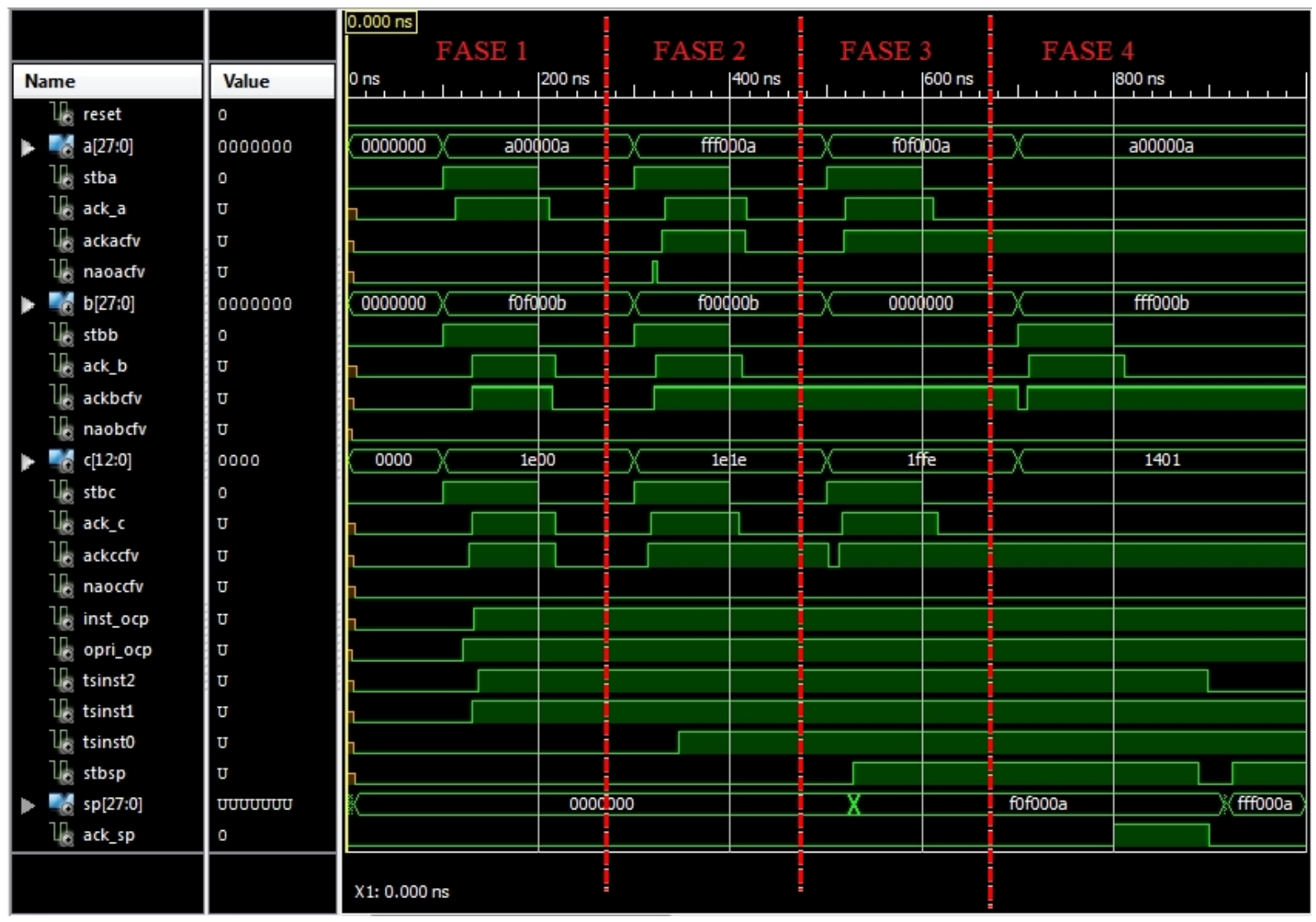

Figura 8.38: Simulação do módulo Disparo do operador DM

Na Figura 8.38, os sinais são os mesmos apresentados em outras simulações, em seções anteriores. Também na Figura 8.38, pode-se destacar quatro 
momentos diferentes para a simulação do módulo Disparo: Fase1, Fase2, Fase3 e Fase4.

Na Fase1, inicialmente não há tokens nas instâncias, comprovado pelos valores de tsinst2, tsinst 1 e tsinsto, todos em nivel lógico baixo, nem no operador, comprovado pelo valor de opri_ocp em nível lógico baixo.

Ainda na Fase1, chegam simultaneamente pelas entradas $A, B$ e $C$, os

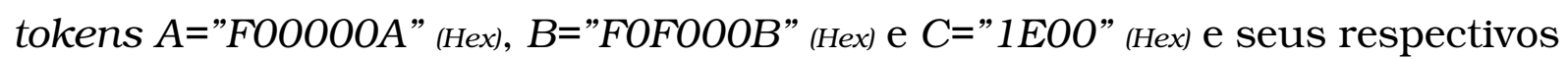
sinais de strobe vindo das entradas do operador $D M$.

Por não haver tokens armazenados nas instâncias, o módulo Confirma aciona o módulo Match para receber os tokens presentes nas entradas $A, B$ e $C$ do operador.

Como $A$ possui tag diferente de $B$ e $C$, isso faz com que o módulo Match do operador armazene o token recebido na entrada $A$ do operador, e ao mesmo tempo o módulo Match aciona o módulo Aloca para que esse receba os dados $B$ e $C$, vindos das entradas $B$ e $C$ do operador, para serem alocados nas instâncias.

Uma vez de posse dos dados, o módulo Aloca verifica se $B$ e $C$ possuem a mesma tag nos respectivos tokens. Como as tags são diferentes, o token presente na entrada $B$ é enviado à primeira instância desocupada e o token presente na entrada $C$ é enviado à segunda instância desocupada. Os sinais $A c k B c f$ e tsinst2, ambos em nível lógico alto, descrito na Figura 8.38, comprovam a alocação do token $B$ na primeira instância e os sinais AckCcf e tsinst1, ambos em nível lógico alto, comprovam a alocação do token $C$ na segunda instância.

Na Fase2 chegam simultaneamente novos tokens pelas entradas $A, B$ e $C$

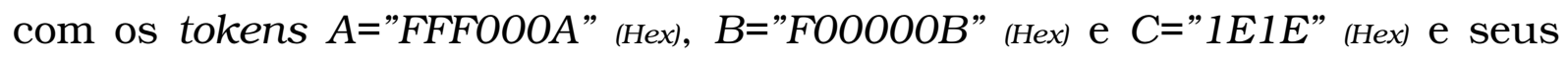
respectivos sinais de strobe vindo das entradas do operador DM. Por haver instâncias ocupadas, o módulo Confirma enviará esses três novos tokens a elas para verificar se há tokens correspondentes. No caso os tokens $B=$ BOOOOOB" e $C=" 1 E 1 E$ " são correspondentes aos tokens armazenados nas instâncias "dois" e "um", respectivamente, e portanto, são armazenados, comprovado pelos sinais AckBcf e AckCcf ambos em nível lógico alto. Entretanto o token $A=$ "FFFOOOA" não possui correspondência aos tokens armazenados nas instâncias, comprovado pelo sinal NaoAcf em nível lógico alto. Isso força o módulo Confirma a acionar o módulo Match para verificar se existe correspondência do token recebido na entrada $A$ do operador com os tokens armazenados no operador que constata tags diferentes, acionando então o módulo Aloca do operador para receber o token. O token é então enviado para a instância "três", como comprovado pelo sinal tsinsto em nível lógico alto.

Na Fase3, novos tokens chegam simultaneamente na entrada A="FOFOOOA" 
(Hex) e $C=" 1 F F E "$ (Hex) e seus respectivos sinais de strobe, vindo das entradas do operador DM. As três instâncias e o operador estão ocupados, comprovado pelos sinais tsinst2, tsinst1 e tsinsto e opri_ocp em nível lógico alto.

Da mesma forma que na Fase2, por haver instâncias ocupadas, o módulo Confirma enviará esses dois tokens a elas. Os tokens $A=$ "FOFOOOA" e $C=$ " $1 F F E "$ são correspondentes aos tokens nas instâncias "um" e "três" comprovado pelos sinais AckAcf e AckCcf em nível lógico alto, que conseqüentemente são armazenados nas respectivas instâncias. Havendo o disparo, pelo módulo Disparo, da instância "um", comprovado pelo sinal StbSP em nível lógico alto e no sinal $S P=" F O F O O O A "$.

O módulo Disparo ficará aguardando o sinal de reconhecimento do operador receptor, mas que não chega durante a Fase3 da simulação.

Por fim na Fase4, um token chega na entrada $B$ do operador DM, B="FFFOO $O B{ }^{\prime}$ (Hex) com seus respectivo sinal de strobe.

Como na instância "um" ainda não houve reconhecimento do sinal enviado, as três instâncias continuam ocupadas e o operador também, comprovado pelos sinais tsinst2, tsinst1, tsinstO e opri_ocp todos em nível lógico alto.

Por haver instâncias ocupadas, o módulo Confirma envia esse token a elas. O token B="FFFOOOB" é correspondente aos tokens armazenados na instância "três", comprovado pelo sinal AckBcf em nível lógico alto; havendo o disparo, pelo módulo Disparo, da instância "três".

Como discutido anteriormente, o módulo Disparo gerencia todos os resultados vindo das instâncias e do operador, entretanto como não houve o reconhecimento do resultado enviado na Fase3, comprovado pelo sinal SP="FOFOOOA" na Figura 8.38, o resultado gerado pela instância "três" é colocado na fila de disparos no módulo Disparo e aguardará a sua vez para ser enviado.

Tão logo chegue o reconhecimento, comprovado pelo sinal Ack_SP em nível lógico alto, na Fase4 da simulação, esse sinal é transmitido a instância "um", causando a sua desocupação, comprovado pelo sinal tsinst 2 em nível lógico baixo.

A partir desse ponto, o módulo Disparo retira o token que está na fila de disparo e o transmite, seguindo todos os passos descritos acima.

\section{Módulos Mult_A, Mult_B e Mult_C do Operador Principal}

O módulo Mult_A é um circuito demultiplexador um para dois, para os sinais de entrada Ack_Acf e Nao_Acf. Há dois sinais de saídas Ack_Acf e dois sinais de saídas Nao_Acf nesse módulo. O sinal de entrada Ack_Acf é demultiplexado para um dos dois sinais de saída Ack_Acf e o sinal de entrada Nao_Acf é demultiplexado para um dos dois sinais de saída Nao_Acf. Os sinais de saída são ligados aos módulos Confirma e Aloca. O sinal sel no mó- 
dulo demultiplexador é um sinal de entrada de 2 bits, cuja função é selecionar o sinal de entrada Ack_Acf para um dos dois sinais de saída Ack_Acf e o sinal de entrada Nao_Acf para um dos sinais de saída Nao_Acf.

Assim, se o sinal sel="10", os dados nos sinais de entrada Ack_Acf e Nao_Acf serão selecionados para as saídas Ack_Acf e Nao_Acf ligadas ao módulo Confirma; caso contrário, se o sinal sel="01", os dados nos sinais de entrada Ack_Acf e Nao_Acf serão selecionados para as saídas Ack_Acf e Nao_Acf ligadas ao módulo Aloca.

O sinal sel é simultaneamente controlado pelos módulos Confirma e Aloca.

Além do módulo Mult_A, há no módulo principal os módulos Mult_B e Mult_C, cujas funções são iguais a do módulo Mult_A, porém para as entradas e saídas B e $C$.

\section{Módulos DM_A, DM_B e DM_C do Operador Principal}

O módulo $D M \_A$ é um circuito multiplexador dois para um, para os sinais de entrada A e StbA. Há dois sinais de entrada A e dois sinais de entrada StbA nesse módulo e um sinal de saída A e um sinal de saída StbA. Os sinais de entrada são multiplexados para os sinais de saída. Os sinais de entrada são ligados às saídas A e StbA dos módulos Confirma e Aloca. O sinal sel no módulo multiplexador é um sinal de 2 bits, cuja função é selecionar uma das duas entradas $A$ e uma das duas entradas $S t b A$, ligadas aos módulos Confirma e Aloca, respectivamente, às saídas $A$ e $S t b A$, ligadas aos sinais de saída do operador DM, A_Out e StbAO, respectivamente.

Assim, se o sinal sel="10", os dados nos sinais de entrada A e StbA, ligadas ao módulo Confirma serão enviados aos sinais de saída $A$ e $S t b A$, ligadas aos sinais de saída A_Out e StbAO, respectivamente, do operador DM; caso contrário, se o sinal sel="01", os dados nos sinais de entrada A e StbA, ligadas ao módulo Aloca serão enviados aos sinais de saída $A$ e $S t b A$, ligadas aos sinais de saída $A \_O u t$ e $S t b A O$, respectivamente, do operador $D M$.

O sinal sel é simultaneamente controlado pelos módulos Confirma e Aloca.

Além do módulo $D M \_A$, há no módulo principal os módulos $D M \_B$ e $D M \_C$, cujas funções são iguais a do módulo $D M \_A$, porém para as entradas e saídas B e C.

\section{Expressão $F 1$ e F2}

Como mostrado na Figura 8.9, todas as instâncias possuem o sinal de saída AckA e NaoA. Todos os sinais de saída AckA das instâncias, mostrado na Figura 8.9 foram ligados a uma caixa tracejada com a palavra $F 1$ que por sua vez foi ligada a entrada do sinal Ack_Acf no operador principal. Para um operador com ' $n$ ' instâncias há ' $n$ ' sinais de saída AckA. Esses 'n' sinais 
AckA são ligados em um sinal de entrada Ack_Acf que possui apenas 1 bit. $O$ sinal Ack_Acf é necessário aos módulos Confirma e Aloca, como já discutido anteriormente. A palavra $F 1$ representa a seguinte expressão:

$\mathrm{F} 1<=\mathrm{AckA}^{\prime} 2^{\prime}$ ou $\mathrm{AckA}^{\prime} 1^{\prime} \ldots$ ou ... ou AckA' $\mathrm{n}^{\prime}$

Se houver correspondência em algum token na entrada A das instâncias, F1 retornará nível lógico alto; caso contrário, retornará nível lógico baixo.

Todos os sinais de saída NaoA das instâncias, mostrado na Figura 8.9 foram ligados a uma caixa tracejada com a palavra F2 que por sua vez foi ligada a entrada do sinal Nao_Acf no operador principal. Para um operador com 'n' instâncias há ' $n$ ' sinais de saída NaoA. Esses ' $n$ ' sinais NaoA são ligados em um sinal de entrada Nao_Acf que possui apenas 1 bit. O sinal Nao_Acf é necessário aos módulos Confirma e Aloca, como já discutido anteriormente. A palavra $\mathrm{F} 2$ representa a seguinte expressão:

$\mathrm{F} 2<=\left(\left(\left(\mathrm{NaOA}^{\prime} 2^{\prime}\right.\right.\right.$ xnor $\left.\mathrm{StbA} A^{\prime} 2^{\prime}\right) \mathbf{e}\left(\mathrm{NaOA}^{\prime} 1^{\prime}\right.$ xnor $\left.\mathrm{StbA}{ }^{\prime} 1^{\prime}\right) \ldots \quad$ e $\quad \ldots$ e $\left(N a O A^{\prime} n^{\prime}\right.$ xnor $\left.\left.S t b A^{\prime} n^{\prime}\right)\right)$ e $\left(S t b A^{\prime} 2^{\prime}\right.$ ou $S t b A^{\prime} 1^{\prime} \ldots$ ou ... ou $\left.S t b A^{\prime} n^{\prime}\right)$ );

A Tabela 8.2 mostra as diferentes situações para a expressão $F 2$ acima. Nesse exemplo, afim de simplificar a Tabela 8.2, o operador principal possui apenas duas instâncias.

Tabela 8.2: diferentes situações para a expressão $F 2$

\begin{tabular}{llllll}
\hline Linha & StbA_1 & NaoA_1 & StbA_2 & NaoA_2 & F2 \\
\hline 01 & 0 & 0 & 0 & 0 & 0 \\
\hline 02 & 0 & 0 & 0 & 1 & 0 \\
\hline 03 & 0 & 0 & 1 & 0 & 0 \\
\hline 04 & 0 & 0 & 1 & 1 & 1 \\
\hline 05 & 0 & 1 & 0 & 0 & 0 \\
\hline 06 & 0 & 1 & 0 & 1 & 0 \\
\hline 07 & 0 & 1 & 1 & 0 & 0 \\
\hline 08 & 0 & 1 & 1 & 1 & 0 \\
\hline 09 & 1 & 0 & 0 & 0 & 0 \\
\hline 10 & 1 & 0 & 0 & 1 & 0 \\
\hline 11 & 1 & 0 & 1 & 0 & 0 \\
\hline 12 & 1 & 0 & 1 & 1 & 0 \\
\hline 13 & 1 & 1 & 0 & 0 & 1 \\
\hline 14 & 1 & 1 & 0 & 1 & 0 \\
\hline 15 & 1 & 1 & 1 & 0 & 0 \\
\hline 16 & 1 & 1 & 1 & 1 & 1
\end{tabular}

Na Tabela 8.2, o sinal StbA_' $\mathrm{n}^{\prime}={ }^{\prime} \mathrm{O}^{\prime}$ significa não envio de tokens e sinais de strobe à instância 'n', pelos módulos Confirma ou Aloca do operador principal. O sinal $\mathrm{NaOA}_{-} \mathrm{n}^{\prime}={ }^{\prime} \mathrm{O}^{\prime}$ pode significar duas situações: O não envio de token à instância 'n', conseqüentemente nível lógico baixo no sinal NaoA_' $\mathrm{n}$ ' ou o envio de token à instância 'n', sendo a resposta da instância 'n' igual a 
AckA_' $n^{\prime}=^{\prime} 1^{\prime}$, conseqüentemente nível lógico baixo no sinal NaoA_' $n^{\prime}$.

Conforme mostra a Tabela 8.2, a expressão F2 retornará nível lógico alto, somente se houver pelo menos uma instância ocupada no operador principal e se todas as instâncias ocupadas retornarem o sinal $\mathrm{NaOA}_{-} \mathrm{n}^{\prime}=^{\prime} 1^{\prime}$, caso contrário, a expressão $F 2$ terá nível lógico baixo. A expressão $F 2$ permite haver instâncias desocupadas entre as instâncias ocupadas do operador principal, como pode ser visto nas linhas 04 e 13 da Tabela 8.2. A linha 16 mostra que todas as instâncias do operador estão ocupadas e todas retornaram o sinal NaoA_' $n^{\prime}={ }^{\prime} 1^{\prime}$, conseqüentemente, a expressão $F 2$, nesse caso, terá nível lógico alto. Os casos mostrados nas linhas 02, 05, 06, 07, 08, 10 e 14, não pode ocorrer, pois não é possível que uma instância ' $n$ ' retorne o sinal NaoA_' $n^{\prime}={ }^{\prime} 1^{\prime}$, sem que tenha recebido um token. As linhas 03, 09, 11, 12 e 15 mostram pelo menos uma situação em que uma das instâncias recebeu sinal de strobe, mas retornou $N a \circ A_{-} n^{\prime}={ }^{\prime} 0^{\prime}$, ou seja, AckA ${ }^{\prime} n^{\prime}=^{\prime} 1^{\prime}$. Na linha 01 é mostrado que não foi enviado sinal de strobe a nenhuma instância, ou seja, todas as instâncias estão desocupadas e todas retornaram o sinal $\mathrm{NaOA}_{-} \mathrm{n}^{\prime}={ }^{\prime} \mathrm{O}^{\prime}$, conseqüentemente, a expressão F2, nesse caso, terá nível lógico baixo.

Na Figura 8.9, é mostrado apenas as expressões $F 1$ e $F 2$, correspondente aos sinais de entrada do operador principal Ack_Acf e Nao_Acf, respectivamente. As expressões $F 1$ e $F 2$ também são aplicadas aos sinais de entrada Ack_BCf, Nao_BCf, Ack_Ccf e Nao_Ccf, trocando-se as letras A por B e C.

\section{Sinal $A c k A, A c k B$ e AckC}

Os sinais AckA, AckB e AckC mostrados no operador deterministc merge, Figura 8.9 é formado pela combinação dos sinais Ack_A1, Ack_A2, Ack_A3, Ack_B1, Ack_B2, Ack_B3, Ack_C1, Ack_C2, Ack_C3, respectivamente, dos módulos Confirma, Match e Aloca, no operador principal. As expressões abaixo resumem o funcionamento dos sinais $A c k A, A c k B$ e AckC.

$A c k A<=A c k \_A 1$ or $A c k \_A 2$ or $A c k \_A 3 ; A c k B<=A c k \_B 1$ or $A c k \_B 2$ or Ack_B3; $A C k C<=A C k \_C 1$ or $A C k \_C 2$ or ACk_C 3 ;

\subsubsection{Operador Branch}

O operador Branch é descrito na Figura 8.39. Como pode ser visto na Figura 8.39, o operador Branch possui duas entradas de tokens, nomeadas pelas letras A com 28 bits e B com 13 bits e duas saída de tokens, nomeadas pelas letras Y e $\mathrm{Z}$ com 28 bits.

Os sinais de entrada/saída A, B, Y e Z são ligados a barramentos, nos quais são transportados os tokens entre os operadores principais na máquina a fluxo de dados. Os operadores recebem ou enviam tokens de forma sincronizada, 
por meio do protocolo handshake, simbolizados pelos sinais StbA, StbB, AckA, AckB, StbY, AckY, StbZ e AckZ, disparo strobe e reconhecimento ack.

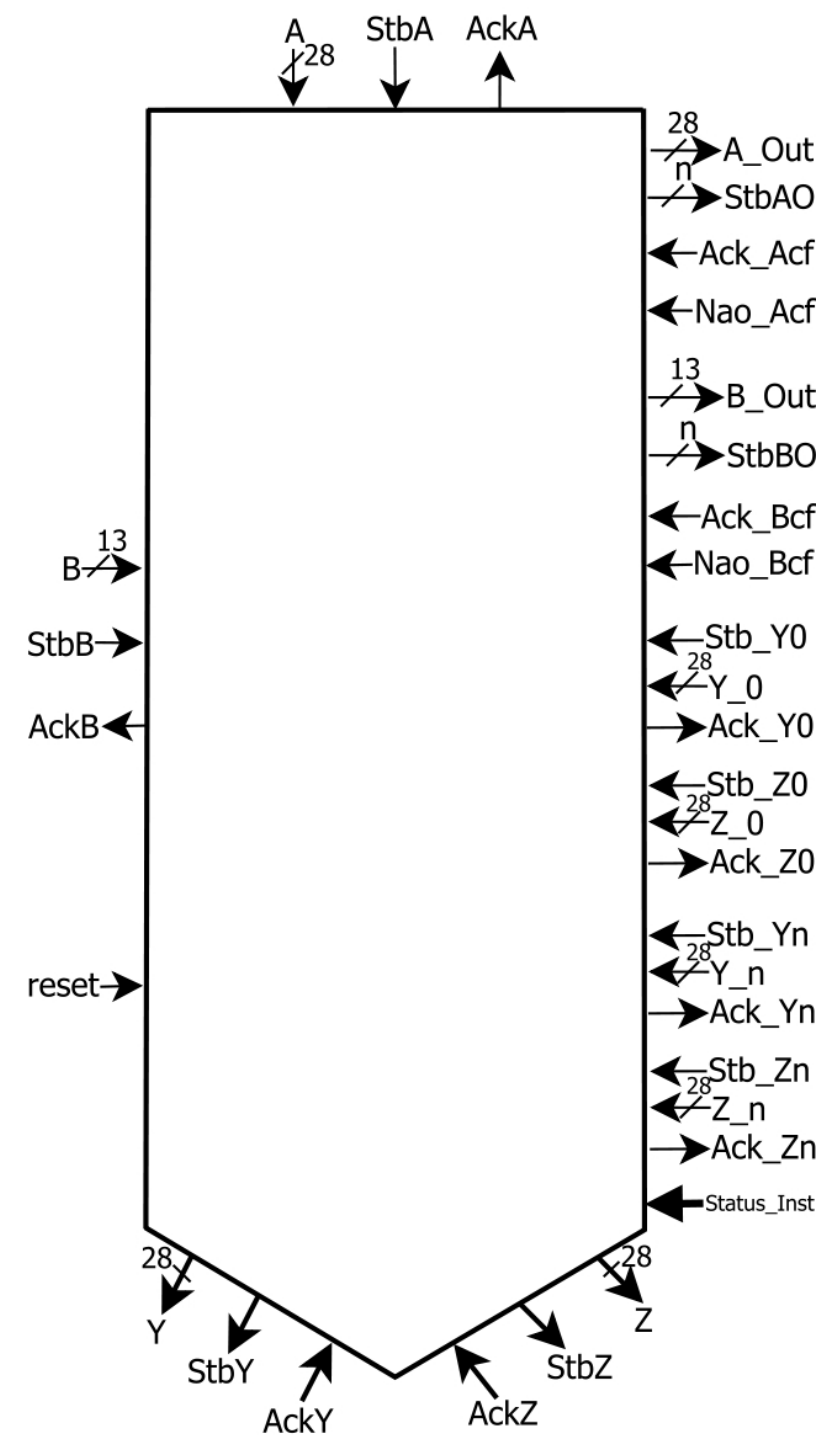

Figura 8.39: Operador branch projetado para funcionar utilizando-se o modelo de instâncias

Os sinais de entrada/saída A_Out, StbAO, Ack_Acf, Nao_Acf, B_Out, StbBO, Ack_BCf, Nao_Bcf são responsáveis por transportar os tokens entre o operador principal e as instâncias e possuem as mesmas funções que os sinais com o mesmo nome mostrado na implementação do operador DM. Os sinais Y_0, Stb_Y0, Ack_Y0, Z_0, Stb_Z0, Ack_Z0 até Y_n, Stb_Yn, Ack_Yn, Z_n, Stb_Zn e Ack_Zn são responsáveis por transportar os tokens resultados entre as instâncias e o operador principal.

As diferenças entre a estrutura do operador branch e a estrutura do operador DM, são relacionadas aos módulos Confirma, Match, Aloca, Disparo e aos módulos Mult_A, Mult_B, DM_A e $D M \_B$ e são descritas a seguir.

No que se refere a quantidade de bits de entrada/saída, no operador $D M$, as entradas/saídas são relacionadas as letras A, B e C, no operador branch há 
apenas as entradas/saídas relacionadas as letras A e B.

No operador $D M$ há os módulos Mult_A, Mult_B, Mult_C, DM_A, DM_B e $D M_{-} C$. No operador branch há apenas os módulos Mult_A, Mult_B, DM_A e $D M \_B$.

No operador $D M$ há o módulo multiplexador, cuja função é selecionar as informações em uma das entradas $\mathrm{A}$ ou $\mathrm{B}$, a partir de um bit de controle na entrada C, para a saída S. No operador branch há o módulo demultiplexador, cuja função é selecionar a informação na entrada $A$, a partir de um bit de controle na entrada B, para uma das duas saídas Y ou Z.

No operador $D M$ o módulo match possui três registradores, sendo um registrador para cada entrada do operador ou instância, cuja função é armazenar tokens até a chegada de seus parceiros. Assim há o disparo sempre que os três tokens parceiros estão presentes no módulo. No operador branch há apenas dois registradores no módulo match. Assim há o disparo sempre que os dois tokens parceiros estão presentes no módulo.

No operador $D M$ há o módulo Disparo, cuja função é gerenciar o disparo recebido pelas instâncias e pelo operador principal. No operador DM há uma entrada de token disparado pelo módulo multiplexador, no operador principal e uma entrada de token disparado para cada instância, com seus respectivos sinais de sincronismo. No operador branch, o módulo Disparo possui duas entradas de token disparados pelo módulo demultiplexador, no operador principal e duas entrada de token disparados para cada instância, com seus respectivos sinais de sincronismo. Das duas entradas de disparo de tokens, presentes no operador principal e nas instâncias, apenas uma vai ter o token disparado, a outra entrada não terá dados.

Como mostrado na Figura 8.39, as instâncias do operador branch e o operador principal possuem dois sinais de reconhecimento como entrada, ou seja, AckY e AckZ. Como há duas saídas de tokens, mas apenas uma delas é ativada em determinado tempo, tanto o sinal de reconhecimento AckY quanto AckZ apagarão os registradores no módulo Match, das instâncias ou do operador principal.

No módulo Disparo do operador DM, há uma fila para três disparos de tokens simultâneos, na saída de tokens do operador principal. No módulo Disparo do operador branch, porém, há duas filas para dois disparos de tokens simultâneos, um para cada saída de tokens do operador principal.

\subsubsection{Operador Operator}

Na Figura 8.40 é mostrado um operador Operator projetado para funcionar utilizando-se o modelo de instâncias. Esse operador possui duas entradas de tokens, nomeadas pelas letras A e B com 28 bits e uma saída de tokens, 
nomeada pela letra S com 28 bits.

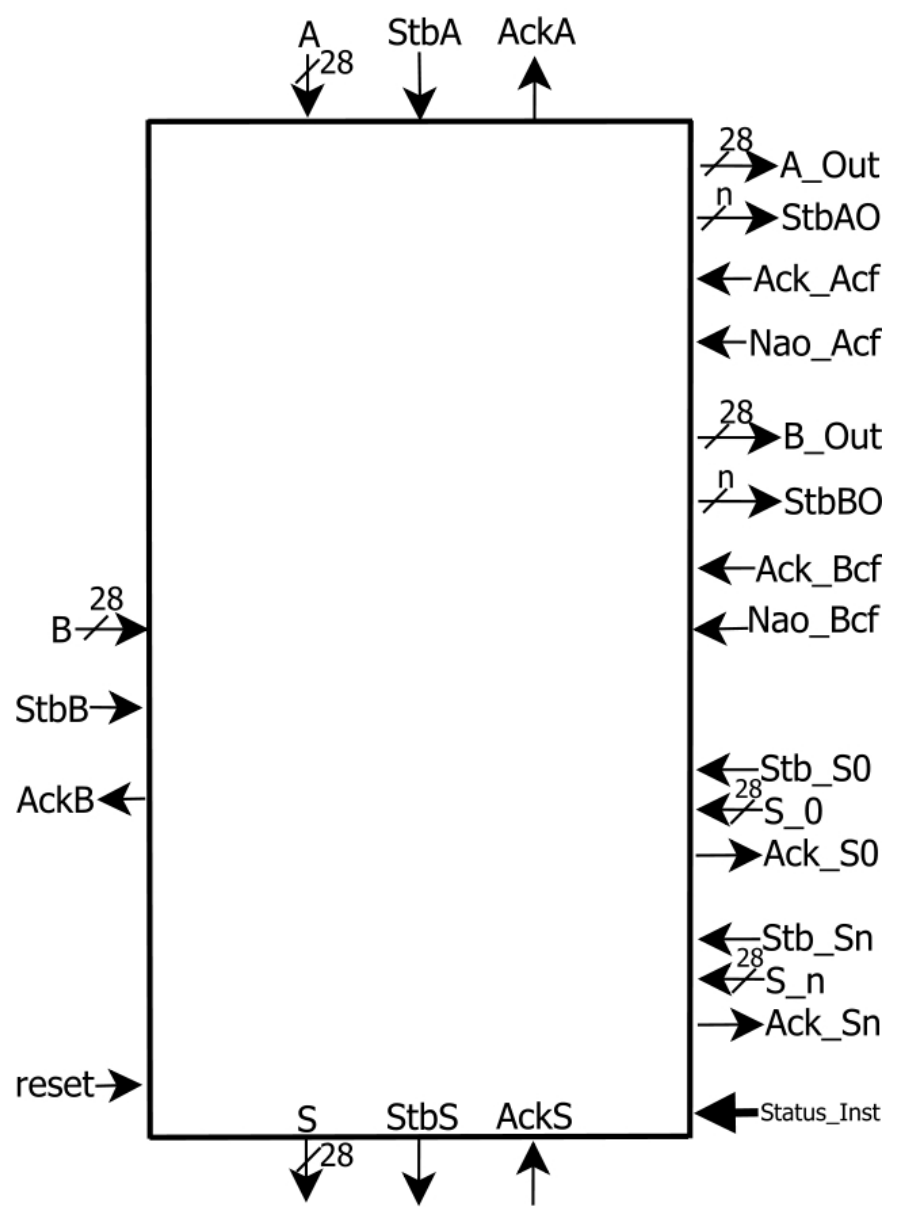

Figura 8.40: Operador Operator projetado para funcionar utilizando-se o modelo de instâncias

Os sinais de entrada/saída A, B e S são ligados a barramentos, nos quais são transportados os tokens entre os operadores principais na máquina a fluxo de dados. Os operadores recebem ou enviam tokens de forma sincronizada, por meio do protocolo handshake, simbolizados pelos sinais StbA, StbB, AckA, AckB, StbS, AckS, disparo ("strobe") e reconhecimento ("ack"). Os sinais de entrada/saída A_Out, StbAO, Ack_Acf, Nao_Acf, B_Out, StbBO, Ack_Bcf, Nao_Bcf são responsáveis por transportar os tokens entre o operador principal e as instâncias e possuem as mesmas funções que os sinais com o mesmo nome mostrado na implementação do operador DM. Os sinais S_0, Stb_S0, Ack_S0 até S_n, Stb_Sn, Ack_Sn, onde 'n' é o número de instâncias do operador principal, são responsáveis por transportar os tokens entre as instâncias e o operador principal. O sinal Status_Inst indica ao operador principal quais instâncias possuem e quais não possuem tokens armazenados e possui a mesma função que o sinal status_Inst implementado no operador DM.

As diferenças entre a estrutura do operador operator e a estrutura do operador $D M$, são relacionadas aos módulos Confirma, Match, Aloca, Disparo e aos módulos Mult_A, Mult_B, DM_A e DM_B são descritas a seguir. 
No que se refere a quantidade de bits de entrada/saída. No operador DM, as entradas/saídas são relacionadas as letras A, B e C. No operador operator há apenas as entradas/saídas relacionadas as letras A e B.

No operador $D M$ há os módulos Mult_A, Mult_B, Mult_C, DM_A, DM_B e $D M \_C$. No operador operator há apenas os módulos Mult_A, Mult_B, DM_A e DM_B.

No operador $D M$ há o módulo multiplexador, cuja função é selecionar as informações em uma das entradas $A$ ou $B$, a partir de um bit de controle na entrada $\mathrm{C}$, para a saída S. No operador operator há o módulo $f$, cuja função é processar alguma operação lógica ou aritmética sob os tokens nas entradas A e B do operador ou instâncias e produzir o resultado na saída S. O operador principal e as instâncias de um dado operador opetator processarão a mesma operação $f$. Em um grafo ChipCflow haverá diferentes operadores operator implementados, cada um especializado em processar uma dada operação lógica ou aritmética.

No operador $D M$ o módulo match possui três registradores, sendo um registrador para cada entrada do operador ou instância, cuja função é armazenar tokens até a chegada de seus parceiros. Assim há o disparo sempre que os três tokens parceiros estão presentes no módulo. No operador operator há apenas dois registradores no módulo match. Assim há o disparo sempre que os dois tokens parceiros estão presentes no módulo.

O funcionamento dos módulos Disparo do operador DM e do operador operator são idênticas. No módulo Disparo do operador $D M$, há uma fila para disparos de tokens simultâneos, na saída de tokens do operador principal. No módulo Disparo do operador operator, também há uma fila para disparos de tokens simultâneos.

\subsubsection{Operador Decisor}

A Figura 8.41 é mostrado um operador Operator projetado para funcionar utilizando-se o modelo de instâncias. Esse operador possui duas entradas de tokens, nomeadas pelas letras A e B com 28 bits e uma saída de tokens, nomeada pela letra $S$ com 13 bits.

Os sinais de entrada/saída A, B e S são ligados a barramentos, nos quais são transportados os tokens entre os operadores principais na máquina a fluxo de dados. Os operadores recebem ou enviam tokens de forma sincronizada, por meio do protocolo handshake, simbolizados pelos sinais StbA, StbB, AckA, AckB, StbS, AckS, disparo ("strobe") e reconhecimento ("ack"). Os sinais de entrada/saída A_Out, StbAO, Ack_Acf, Nao_Acf, B_Out, StbBO, Ack_Bcf, Nao_Bcf são responsáveis por transportar os tokens entre o operador principal e as instâncias e possuem as mesmas funções que os sinais 


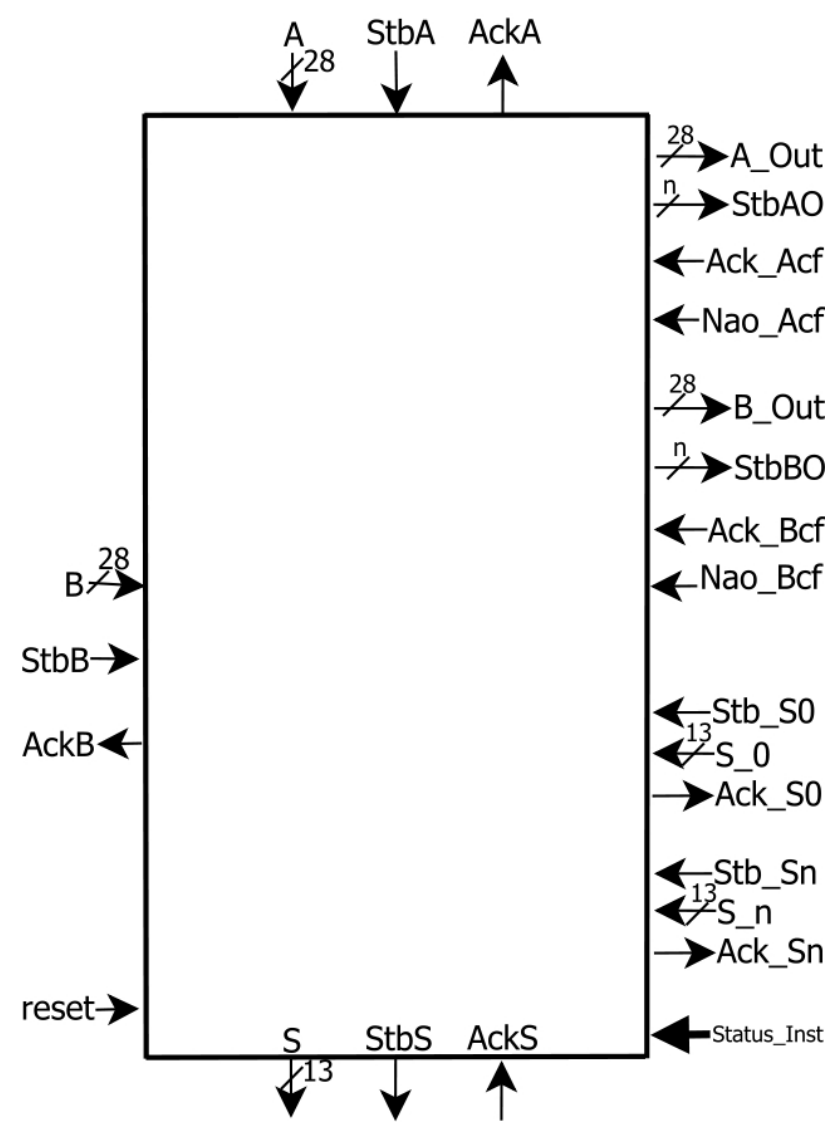

Figura 8.41: Operador decisor projetado para funcionar utilizando-se o modelo de instâncias

com o mesmo nome mostrado na implementação do operador. Os sinais S_0, Stb_S0, Ack_S0 até S_n, Stb_Sn, Ack_Sn, onde 'n' é o número de instâncias do operador principal, são responsáveis por transportar os tokens entre as instâncias e o operador principal. O sinal Status_Inst indica ao operador principal quais instâncias possuem e quais não possuem tokens armazenados e possui a mesma função que o sinal status_Inst implementado no operador $D M$.

As diferenças entre a estrutura do operador decisor e a estrutura do operador operator, são relacionadas aos módulos Match e $f$.

No operador operator há o módulo $f$, cuja função é processar alguma operação lógica ou aritmética sob os tokens nas entradas $A$ e $B$ do operador e produzir o resultado na saída $\mathrm{S}$. No operador decisor há o módulo $t$, cuja função é relacional entre os tokens nas entradas A e B do operador ou instâncias e produzir um resultado booleano na saída $\mathrm{S}$.

\subsubsection{Operador Non-Deterministic Merge}

Na Figura 8.42 é mostrado um operador NDM. Diferente dos operadores do ChipCflow já mostrados acima, o operador NDM não possui instâncias. Esse operador possui duas entradas de tokens, nomeadas pelas letras A e B com 28 
bits e uma saída de tokens, nomeada pela letra S com 28 bits.

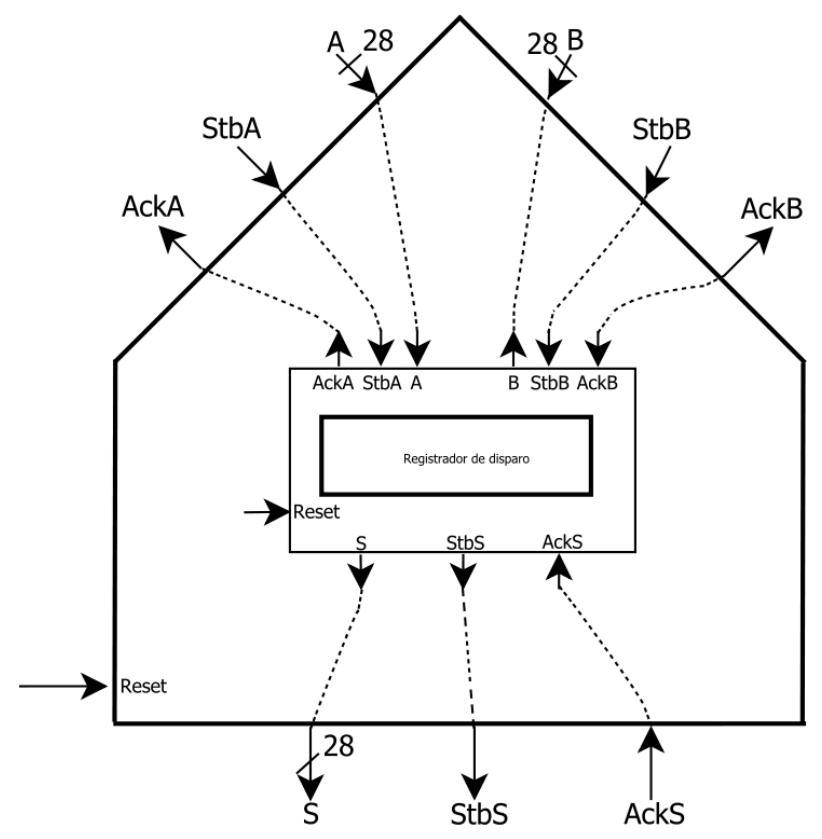

Figura 8.42: Operador NDM

Os sinais de entrada/saída A, B e S são ligados a barramentos, nos quais são transportados os tokens entre os operadores principais na máquina a fluxo de dados. Os operadores recebem ou enviam tokens de forma sincronizada, por meio do protocolo handshake, simbolizados pelos sinais StbA, StbB, AckA, AckB, StbS, AckS, disparo ("strobe") e reconhecimento ("ack").

Por não existir módulos para inserção e remoção de tokens em instâncias, a estrutura do operador NDM é mais simples do que a estrutura dos operadores DM, Branch, Operator e Decisor, já mostrados.

No operador NDM não há uma regra de habilitação estrita. O operador dispara tokens em sua saída, tão logo uma de suas portas de entrada contenha um token. Quando ele dispara, uma cópia de seu token de entrada é enviada para a saída.

Na estrutura interna do operador NDM há um módulo chamado Registrador de disparo. Sua função é colocar na saída S do operador, o primeiro token que chegar, pela entrada A ou B e travar o disparo de novos tokens até que o operador receba um sinal de reconhecimento AckS.

No exemplo abaixo, é mostrado quatro situações diferentes para o operador NDM.

Na primeira situação, o Registrador de disparo está vazio e chega o token $\mathrm{A}=$ "FFF000A" ${ }_{\text {(Hex) }}$ com seu respectivo sinal de strobe. O Registrador de disparo irá travar o recebimento de novos tokens no operador, ou seja, se chegar um token na entrada A ou B do operador, ele não será recebido. Ao mesmo tempo que o Registrador de disparo trava o recebimento de novos tokens, ele coloca o token recebido na saída $\mathrm{S}$ do operador, com seu respectivo sinal de strobe. Ao 
receber um sinal de reconhecimento na entrada AckS do operador, o módulo Registrador de disparo irá enviar esse sinal à saída AckA e liberar a entrada de novos tokens no operador.

Na segunda situação, o Registrador de disparo está vazio e chega o token $\mathrm{B}=" \mathrm{~F} 0 \mathrm{FOOOB}$ " (Hex) com seu respectivo sinal de strobe. O Registrador de disparo irá travar o recebimento de novos tokens no operador, ou seja, se chegar um token na entrada A ou B do operador, ele não será recebido. Ao mesmo tempo que o Registrador de disparo trava o recebimento de novos tokens, ele coloca o token recebido na saída $\mathrm{S}$ do operador, com seu respectivo sinal de strobe. Ao receber um sinal de reconhecimento na entrada AckS do operador, o módulo Registrador de disparo irá enviar esse sinal à saída AckB e liberar a entrada de novos tokens no operador.

Na terceira situação, o Registrador de disparo está vazio e chega o token $\mathrm{A}=$ "FFFO0OA" (Hex) com seu respectivo sinal de strobe. O Registrador de disparo irá travar o recebimento de novos tokens no operador. O Registrador de disparo trava o recebimento de novos tokens e coloca o token recebido na saída $S$ do operador, com seu respectivo sinal de strobe. Porém, nesse momento, chega o token $\mathrm{B}=" \mathrm{~F} 00000 \mathrm{~B}^{\prime \prime}{ }_{\text {(Hex) }}$ com seu respectivo sinal de strobe. Como o registrador não recebeu o sinal de reconhecimento, o token na entrada B não será recebido pelo operador, e, novos tokens não poderão mais chegar na entrada $B$ do operador, até que um sinal de reconhecimento AckB seja enviado ao operador que disparou o token em B.

Ao receber um sinal de reconhecimento na entrada Acks do operador, o módulo Registrador de disparo irá enviar esse sinal à saída AckA e liberar a entrada de novos tokens no operador, ou seja, o operador vai permitir a entrada do token que estava aguardando na entrada B do operador e, em seguida, travar o recebimento de novos tokens até receber um sinal de reconhecimento na entrada Acks do operador.

Finalmente naquela situação, o Registrador de disparo está vazio e chega

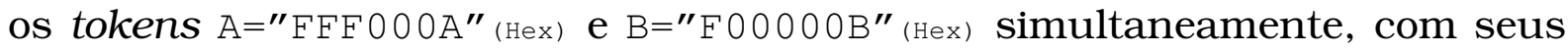
respectivos sinais de strobe. A entrada $A$ do operador tem prioridade sob a entrada B. O operador colocará o token recebido na saída $\mathrm{S}$ do operador, com seu respectivo sinal de strobe e ao mesmo tempo irá travar o recebimento de novos tokens. Porém, nesse momento, chega o token $A=" F 0 F 000 A^{\prime \prime}$ (Hex) com seu respectivo sinal de strobe.

Ao receber um sinal de reconhecimento na entrada AckS do operador, o módulo Registrador de disparo irá enviar esse sinal à saída AckA e liberar a entrada de novos tokens no operador, ou seja, o operador vai permitir a entrada do token que estava aguardando na entrada B do operador e, em seguida, travar o recebimento de novos tokens até receber um sinal de reconhecimento 
na entrada AckS do operador.

Embora após o travamento do operador estejam esperando tokens nas entradas A e B do operador, o operador deixará entrar o token que estava aguardando na entrada $\mathrm{B}$ do operador, pois esse token chegou antes do token que estava aguardando na entrada A. Assim, a entrada A do operador só terá prioridade sob a entrada $B$ no primeiro disparo do operador ou se chegarem simultaneamente tokens na entrada A e B e o Registrador de disparo do operador estiver vazio

\subsubsection{Operador Copy}

Na Figura 8.43 é mostrado um operador Copy. Da mesma forma que o operador NDM, o operador Copy não possui instâncias. Esse operador possui uma entrada de tokens, nomeadas pelas letras A com 28 bits e duas saídas de tokens, nomeadas pelas letras Y e Z com 28 bits.

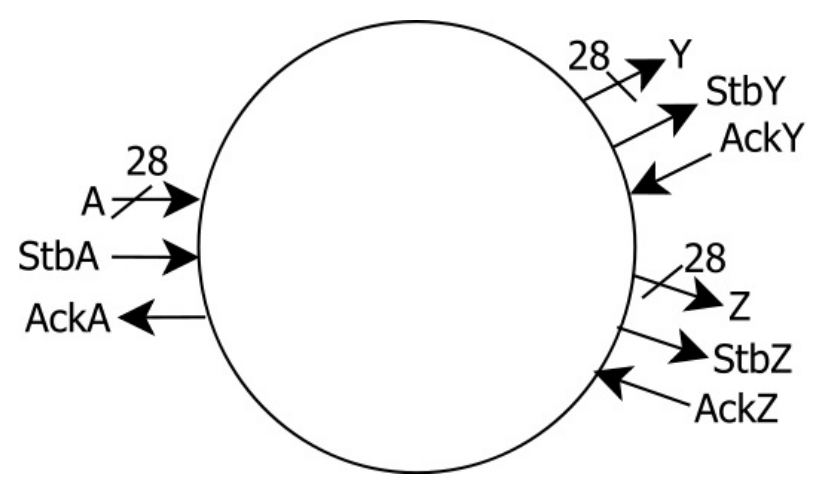

Figura 8.43: Operador Copy

Os sinais de entrada/saída A, Y e Z são ligados a barramentos, nos quais são transportados os tokens entre os operadores principais na máquina a fluxo de dados. Os operadores recebem ou enviam tokens de forma sincronizada, por meio do protocolo handshake, simbolizados pelos sinais StbA, StbY, StbZ, AckA, AckY, AckZ, disparo ("strobe") e reconhecimento ("ack").

Como o operador Copy possui apenas uma entrada, não há restrição a entrada de tokens, como ocorre com o operador Non Determinist Merge. Assim, a estrutura do operador Copy é mais simples do que a estrutura do operador Non Determinist Merge.

No operador Copy não há uma regra de habilitação estrita. O operador dispara cópias de tokens em suas saídas, tão logo receba um token em sua entrada.

A estrutura interna do operador Copy é simples, havendo apenas a implementação do sincronismo, por meio do protocolo handshake. O operador Copy não pode receber novos tokens a menos que haja recebido os sinais de reconhecimento nas entradas AckY e AckZ. 
O operador Copy pode ter em sua entrada A tokens com 28 bits quanto tokens de controle, gerados pelo operador Decisor, de 13 bits. Como as saídas Y e $\mathrm{z}$ do operador Copy possuem 28 bits, os bits menos significativos das saídas são preenchidos com zero.

\subsection{Resultados de sintese nos FPGAs da empresa Xilinx}

Nesta seção, são apresentados os resultados de síntese na implementação do operador DM, gerados pela ferramenta ISE 10.1 da empresa Xilinx. Para a síntese foi utilizado o FPGA Virtex-II Pro XC2VP30-FF896-7, existentes nas placas de prototipação $X U P V 2 P$, no laboratório $L C R$. Por fim, serão mostrados resultados de ocupação e freqüência máxima com a variação no número de instâncias para diferentes dispositivos, o Virtex-II Pro XC2VP30-FF896-7 e o Virtex-7 xc7v2000t-2-ffg1925. O Virtex-7 xc7v2000t-2-ffg1925 foi escolhido por ser esse o FPGA mais moderno da empresa Xilinx e possuir maior quantidade de recursos lógicos.

\subsubsection{Sintese dos operadores}

Inicialmente, antes da descrição dos resultados de síntese do operador, é preciso destacar a importância da implementação do módulo Match para cada operador, pois é o módulo que mais consome recurso no FPGA em função de sua replicação. A seguir portanto, é descrito os resultados de síntese do módulo Match para cada operador e os resultados de síntese completo do operador $D M$ é mostrado em seguida.

Na Figura 8.44 é mostrado um gráfico com o resultado de síntese para o módulo Match dos operadores DM, Decider, Operator e Branch, implementado somente no Virtex-II Pro.

O operador Branch possui duas entradas, sendo uma entrada de 28 bits de dados e uma entrada de 13 bits de controle, além disso, possui duas saídas de 28 bits de dados. O módulo Match do operador Branch, assim como o operador Branch, possui duas entradas, sendo uma entrada de 28 bits de dados e uma entrada de 13 bits de controle, diretamente ligadas as entradas do operador e duas saídas, as quais uma possui 28 bits de dados e a outra possui 13 bits de controle, diretamente ligadas as entradas módulo demultiplexador.

O operador Operator possui duas entradas de 28 bits de dados e uma saída de 28 bits de dados. O módulo Match do operador Operator, assim como o operador Operator, possui duas entradas de 28 bits de dados, diretamente ligadas as entradas do operador e duas saídas de 28 bits de dados, diretamente ligadas as entradas módulo $f$. 


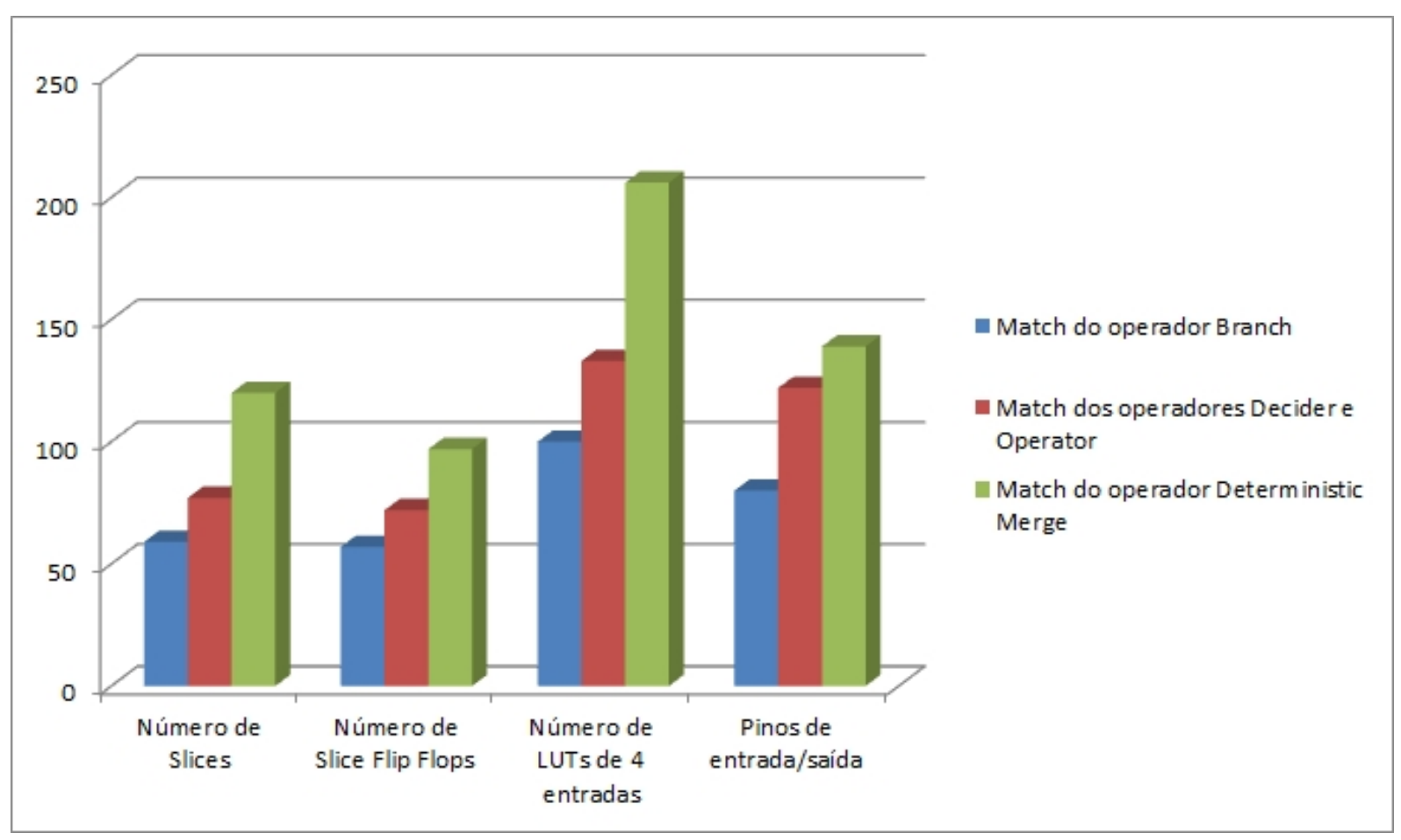

Figura 8.44: Gráfico com o resultado de síntese dos módulos Match dos operadores DM, Decider, Operator e Branch

O operador Decisor possui duas entradas de 28 bits de dados e uma saída de 13 bits de controle. O módulo Match do operador Decisor, assim como seu operador, possui duas entradas de 28 bits de dados, diretamente ligadas as entradas do operador e duas saídas de 28 bits de dados, diretamente ligadas as entradas módulo $t$.

Como já mostrado anteriormente, o operador $D M$ possui três entradas, sendo duas entradas de 28 bits de dados e uma entrada de 13 bits de controle. O módulo Match do operador DM, assim como seu operador, possui duas entradas de 28 bits de dados e uma entrada de 13 bits de controle, diretamente ligadas as entradas do operador e três saídas, as quais, duas possuem 28 bits de dados e uma possui 13 bits de controle, diretamente ligadas as entradas do módulo Multiplexador.

Conforme mostra o gráfico na Figura 8.44, o módulo Match do operador Branch ocupa menos recursos lógicos que os módulos Match dos outros operadores. Os módulos Match dos operadores Decider e Operator possuem uma ocupação intermediária de recursos lógicos, comparando-se com os resultados dos módulos Match dos operadores Branch e DM. Por fim, o módulo Match do operador DM possui a maior ocupação de recursos lógicos entre os módulos Match dos outros operadores.

A Tabela 8.3 complementa as informações mostradas na Tabela 3.2 e mostra a quantidade de recursos lógicos disponíveis no FPGA Virtex-II Pro XC2VP3O.

Os dados mostrados no gráfico da Figura 8.44 e na Tabela 8.3 demonstram 
Tabela 8.3: Quantidade de recursos lógicos disponíveis no FPGA Virtex-II Pro XC2VP30 (Xilinx (2008)), (Lopes (2007)))

\begin{tabular}{ll} 
Tipo de recurso & Disponível no FPGA \\
\hline Número de Slices & 13969 \\
Número de Slice Flip Flops & 27392 \\
Número de Luts de 4 entradas & 27392 \\
Número de pinos de entrada/saída & 556
\end{tabular}

que o módulo com o maior gasto de recursos lógicos na FPGA, ou seja, o módulo Match do operador DM teve um gasto de 0,94\% em número de Slices, 0,75\% de gastos em número de LUTs de 4 entradas e 0,35\% de gastos em número de Slice Flip Flops e 25\% em número de pinos de entrada/saída. Todos os três módulos Match mostrados nessa seção tiveram um período mínimo de $2.074 \mathrm{~ns}$ e freqüência máxima de $482.182 \mathrm{MHz}$.

\subsubsection{Variação no número de instâncias no operador Determinis- tic Merge}

A Figura 8.45 mostra um gráfico com diferentes resultados nos gastos dos Slices do FPGA Virtex-II Pro para diferentes implementações do operador DM, cada qual com um número diferente de instâncias.

Na implementação do operador $D M$ com $O$ instâncias, o operador principal não possui implementados os módulos para inserção e remoção de tokens nas instâncias, ou seja, o operador principal não possui implementados os módulos Confirma e Aloca. Conseqüentemente, as implementação do módulo Disparo é simplificada, uma vez que esse módulo deve gerenciar apenas os disparos do operador principal. Já a implementação do operador DM com 1 ou mais instâncias, há a implementação dos módulos para inserção e remoção tokens nas instâncias. Conseqüentemente, as implementações dos módulos Confirma, Aloca e Disparo são mais complexas a medida em que aumentam o número de instâncias implementadas no operador principal. Assim, conforme o gráfico da Figura 8.45, houve um aumento de 469,45\% no número de Slices gastos no FPGA entre as implementações do operador DM com $O$ instâncias e a implementação do mesmo operador com 1 instância.

A comparação dos dados da Figura 8.45 e da Tabela 8.3 mostram que a implementação do operador $D M$ com 10 instâncias, teve um gasto de $12 \%$ no número total de Slices disponíveis no FPGA.

Na Figura 8.46 é descrito um gráfico com diferentes resultados nos gastos dos Slice Flip Flops do FPGA Virtex-II Pro para diferentes implementações do operador $D M$, cada qual com um número diferente de instâncias.

Como mostrado no gráfico da Figura 8.46, houve um aumento de $684 \%$ 


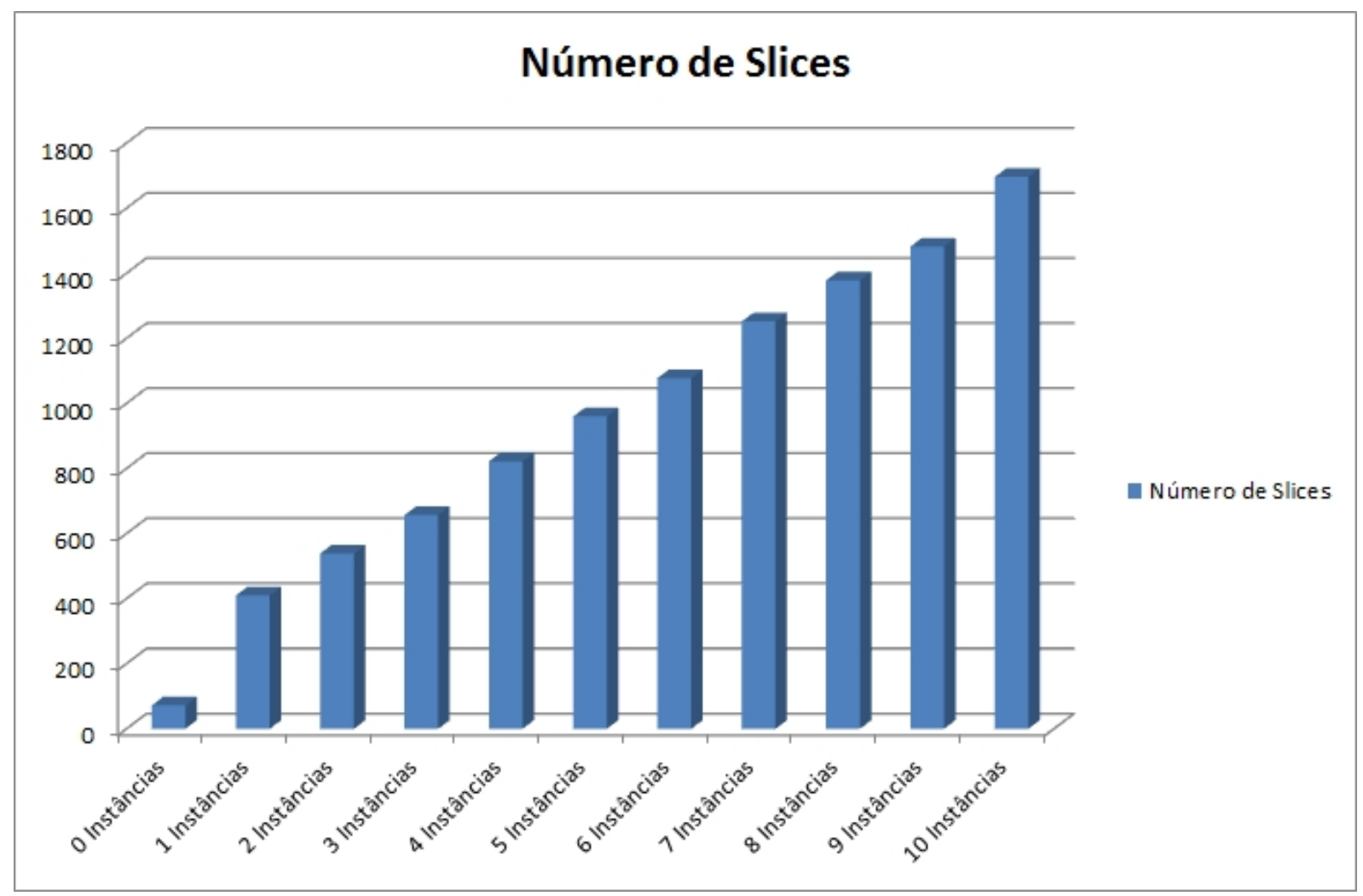

Figura 8.45: Gráfico com diferentes resultados no número de Slices gastos no FPGA para a implementação do operador DM com diferentes números de instâncias

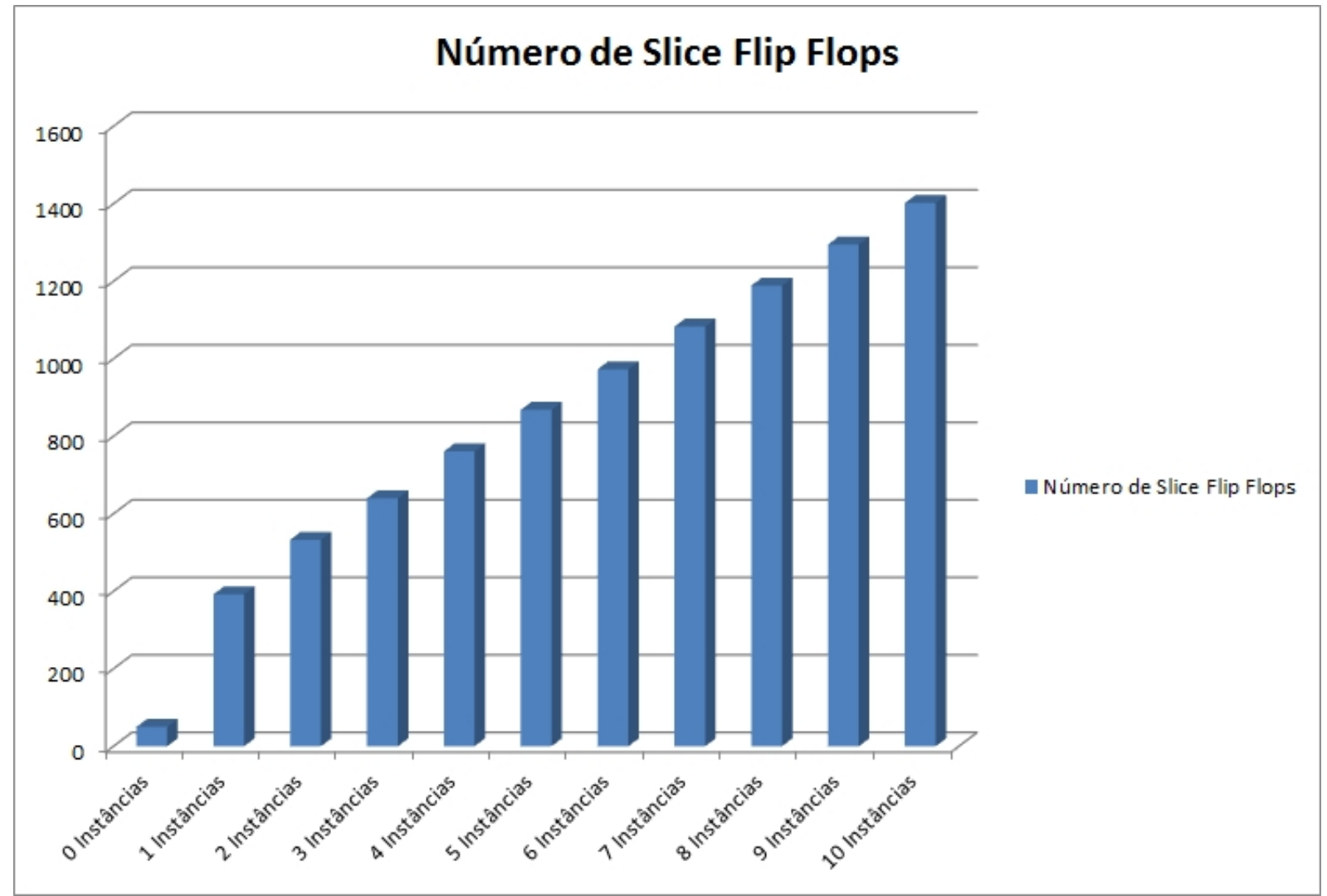

Figura 8.46: Gráfico com diferentes resultados no número de Slice Flip Flops gastos no FPGA para a implementação do operador DM com diferentes números de instâncias 
no número de Slice Flip Flops gastos no FPGA entre as implementações do operador $D M$ com $O$ instâncias e a implementação do mesmo operador com 1 instância. A comparação dos dados mostrados na Figura 8.46 e na Tabela 8.3 mostram que a implementação do operador $D M$ com 10 instâncias, obteve um gasto total de 5\% no número de Slice Flip Flops disponiveis no FPGA.

A Figura 8.47 mostra um gráfico com diferentes resultados nos gastos de LUTs de 4 entradas do FPGA Virtex-II Pro para diferentes implementações do operador $D M$, cada qual com um número diferente de instâncias.

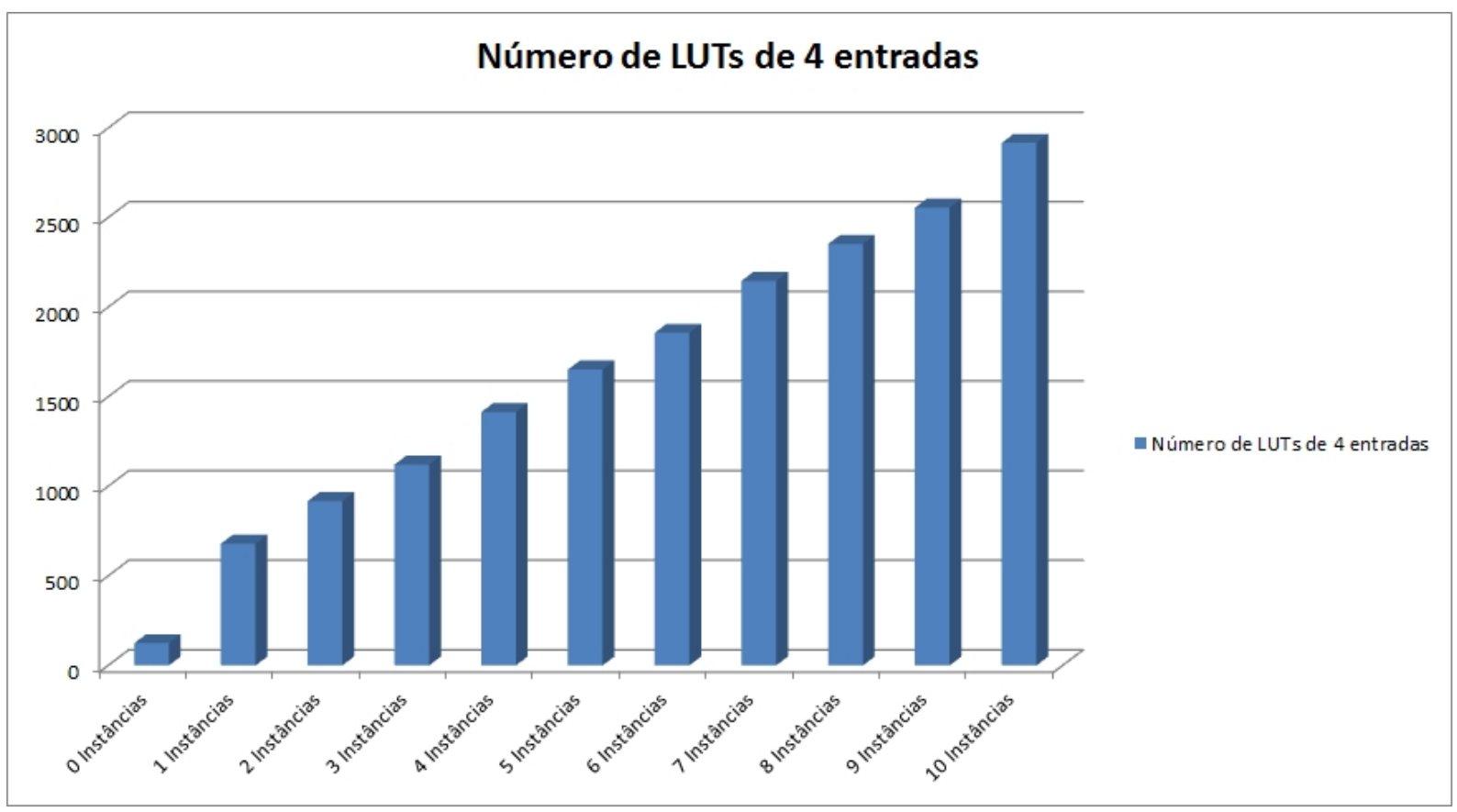

Figura 8.47: Gráfico com diferentes resultados no número de LUTs de 4 entradas gastos no FPGA para a implementação do operador DM com diferentes números de instâncias

Conforme o gráfico da Figura 8.47, houve um aumento de 448,39\% no número de LUTs de 4 entradas gastos no FPGA entre as implementações do operador $D M$ com $O$ instâncias e a implementação do mesmo operador com 1 instância. Os dados mostrados na Figura 8.47 e na Tabela 8.3 demonstram que a implementação do operador $D M$ com 10 instâncias, houve um gasto de 10\% no número total de LUTs de 4 entradas disponiveis no FPGA.

A Figura 8.48 mostra um gráfico com diferentes resultados de Freqüência Máxima nos FPGA Virtex-II Pro e Virtex-7 xc7v2000t-2-ffg1925, para diferentes implementações do operador $D M$, cada qual com um número diferente de instâncias.

Os diferentes resultados, mostrados na Figura 8.48, no número da Freqüência Máxima de operação no FPGA Virtex-II Pro, foram obtidos na operação de síntese gerada pela ferramenta ISE 10.1 da empresa Xilinx e os diferentes resultados no número da Freqüência Máxima de operação no FPGA Virtex-7 


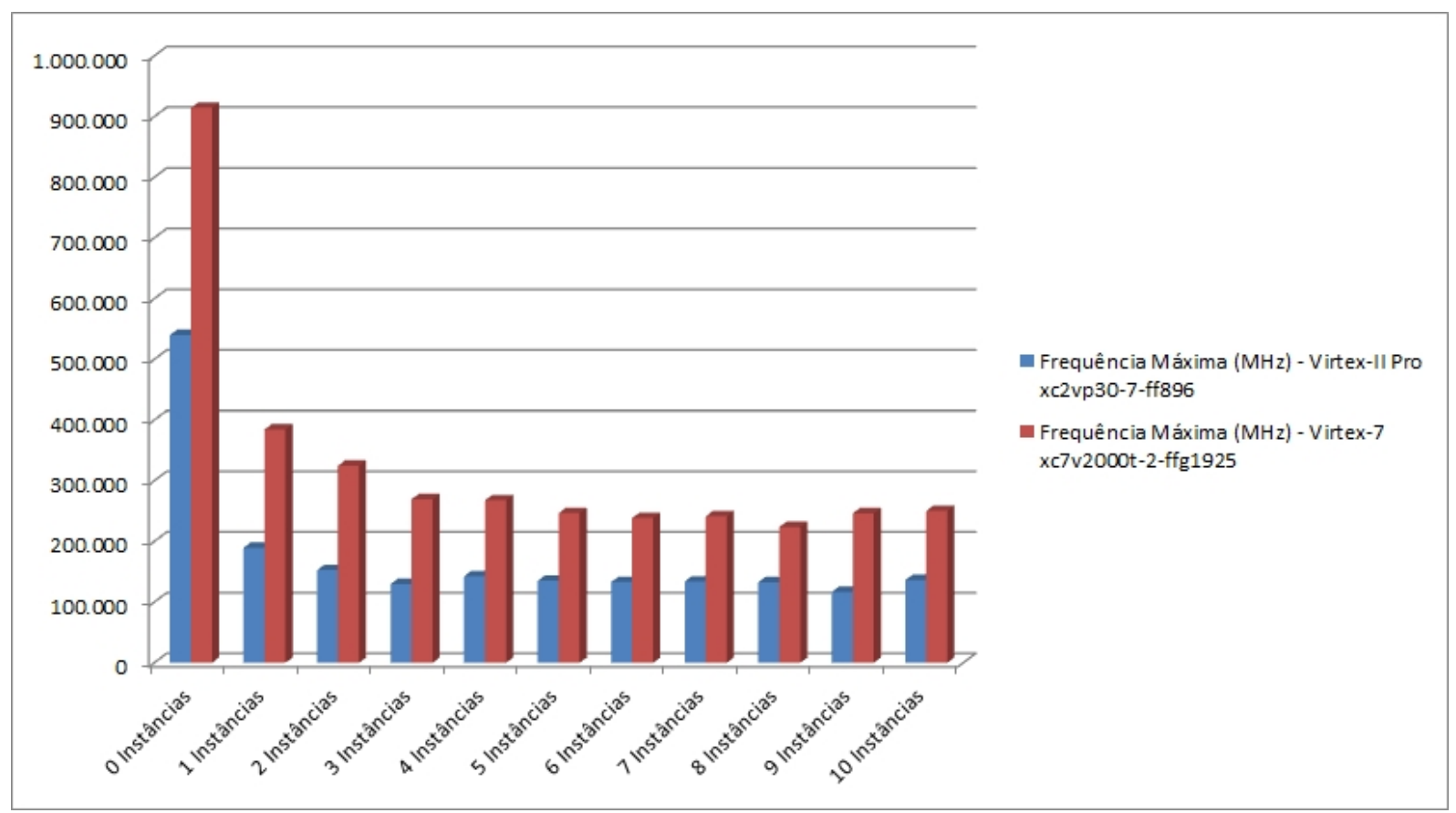

Figura 8.48: Gráfico com diferentes resultados no número da Freqüência Máxima de operação nos FPGAs FPGA Virtex-II Pro e Virtex-7 xc7v2000t-2-ffg1925, para a implementação do operador $D M$ com diferentes números de instâncias

xc7v2000t-2-ffg1925, foram obtidos na operação de síntese gerada pela ferramenta ISE 13.1 da empresa Xilinx. Isso porque nem a ferramenta ISE 10.1 suporta o Virtex-7 nem a ferramenta ISE 13.1 suporta o Virtex-II.

As diferenças nas freqüências máximas de operação, mostrados na Figura 8.48 devem-se a complexidade dos módulos implementados do operador $D M$, as otimizações feitas pela ferramenta ISE da Xilinx e as tecnologias disponíveis nos dois FPGAs-alvo escolhidos. Pode-se observar na Figura 8.48 que a síntese da implementação do operador $D M$ com $O$ instâncias gerou uma freqüência de operação superior, tanto no FPGA Virtex-II quanto no Virtex-7.

Nos gráficos nas Figuras 8.45, 8.46, 8.47 e 8.48 foi mostrado os resultados de síntese gerados na implementação do operador $D M$ em relação ao número de instâncias implementadas. Nos quatro gráficos, pode-se observar que conforme aumenta o número de instâncias no operador, aumenta também o gasto de área no FPGA e há a diminuição na freqüência máxima de operação do operador. Esse aumento é natural, pois com o aumento no número das instâncias, aumenta a complexidade no gerenciamento dos tokens das instâncias, pois o aumento dos bits de dados para um número maior de instâncias ocasionam aumento no barramento para transportar esses dados, além de aumento na complexidade das arquiteturas das unidades que compõem o operador. O maior salto em número, tanto no gasto de área quanto na diminuição do número da freqüência máxima da-se entre a implementação do operador $D M$ com $O$ instância e a implementação do operador $D M$ com 
1 instância. A partir da implementação com uma instância, observa-se um menor aumento, relativamente constante, nos gastos de área do operador e na diminuição da freqüência máxima de operação. Assim, conclui-se que o gargalo no gasto de área e na diminuição do número máximo de freqüência de operação é causado pela complexa implementação dos módulos Confirma e Aloca. Embora houve esse aumento de recursos gastos nos FPGA e a diminuição no número da freqüência máxima de operação do operador, com relação a complexidade dos módulos de gerenciamento de tokens nas instâncias, a maior contribuição das instâncias ao operador é o aumento proporcional do paralelismo oferecido por elas.

Se três instâncias do operador Operator possuírem seus tokens parceiros, por exemplo, e a função aritmética implementada no operador for uma multiplicação, haverá, nesse caso, três multiplicações feitas em paralelo, ou seja, haverá maior ganho de desempenho comparado ao operador sem instâncias implementadas. 


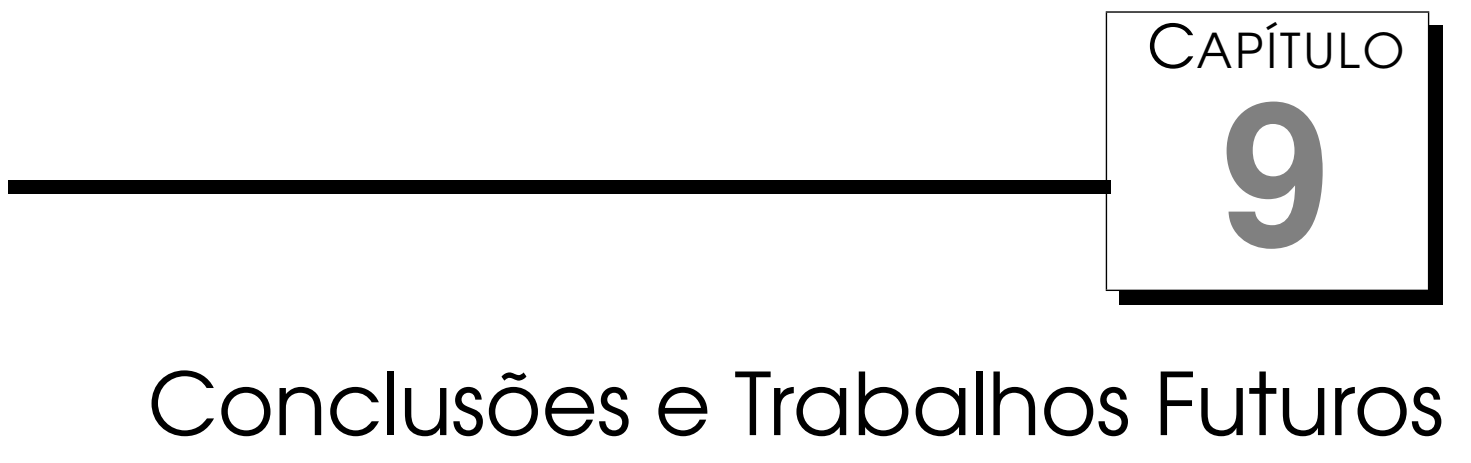

Nesta tese foi apresentado inicialmente dados sobre avanço da micro eletrônica, que gerou o dispositivo Field Programmable Gate Array (FPGA) posicionado em termos de aplicação, consumo, desempenho e flexibilidade, entre os dispositivos Application Specific Integrated Circuit (ASIC) e o General Purpose Processor (GPP), seguido do detalhamento desse dispositivo, sua estrutura interna, ferramentas de desenvolvimento e plataformas de trabalho, ressaltando uma das características do FPGA que é o paralelismo interno, em termo de blocos lógicos e a flexibilidade na configuração e reconfiguração desses elementos.

Em seguida foi apresentado um conjunto de ferramentas que convertem programas escritos na linguagem $C$ para plataformas FPGA motivada pelo aumento na complexidade nas aplicações e a demanda por hardware cada vez mais complexos, com exigências especificas totalmente dependente de programação e linguagens voltadas exclusivamente para hardware.

O projeto ChipCflow, descrito nesta tese, tem essencialmente esse objetivo, ser uma ferramenta que converte programas em linguagem $C$ para plataformas FPGA, entretanto, diferente das outras ferramentas, o projeto propõe que o hardware gerado seja implementado em uma arquitetura a fluxo de dados dinâmica com o objetivo de aproveitar o máximo o paralelismo natural neste modelo de arquiteturas, associado ao paralelismo presente nos dispositivos FPGA.

Em função da proposta do projeto ChipCflow, foram apresentados todos os conceitos sobre máquinas a fluxo de dados estática e dinâmicas e o conjunto de máquinas existentes, tradicionais e contemporâneas.

Passou-se então ao detalhamento de características do projeto ChipCflow 
dentre elas o proprio diagrama de fluxo de projeto sobre como e quais partes são necessárias para que um programa escrito em linguagem $C$ seja convertido em uma máquina a fluxo de dados dinâmica, gerado em linguagem de descrição de hardware (VHDL) pronta para ser sintetizado, implementado e executado.

Ainda sobre o projeto ChipCflow foram descritos todos os módulos necessários para a completa geração da ferramenta, quais já foram implementados e quais estão em desenvolvimento. Em particular destaca-se a implementação de operadores básicos; a implementação de grafos simples a partir de comandos do $C$ como if, while, for e repeat e a implementação de um précompilador que converte linguagem $C$ para uma representação básica na linguagem VHDL; todos voltados para a máquina a fluxo de dados estáticos.

Duas tentativas foram realizadas na implementação da máquina a fluxo de dados dinâmicas, por meio de reconfiguração parcial dinâmica, que momentaneamente se mostraram ineficientes pelo overhead da reconfiguração parcial dinâmica que ainda é muito lenta.

Iniciou-se então o projeto da máquina a fluxo de dados dinâmica, que no projeto ChipCflow utiliza tagged-token na identificação de dados parceiros.

Como primeira atividade na implementação do modelo a fluxo de dados dinâmica está a descrita nesta tese, que é a implementação dos operadores, para que uma máquina a fluxo de dados, utilizando esses operadores, gerado pela ferramenta ChipCflow, se caracterizasse como uma máquina a fluxo de dados dinâmico.

Em paralelo à esta implementação um módulo fundamental foi a criação de operadores iterativos para o gerenciamento de loops, responsável pela criação, manipulação e destruição de tag para cada dado que circula na máquina a fluxo de dados dinâmico.

Na transição da implementação de máquinas a fluxo de dados estática para a máquina a fluxo de dados dinâmica, resolveu-se um dos grandes problemas presentes nas máquinas a fluxo de dados que faz uso do tagged-token, que é a identificação dos tokens circulando em uma máquina a fluxo de dados a partir de seu tag, cuja solução passou por implementações como memória associativa, memória hashing.

A solução empregada no projeto ChipCflow foi a criação de instâncias de um operador para cada dado que chega à espera de seus dados parceiros. A instância de um operador é praticamente a duplicação em hardware do operador para cada dado novo que chega ao operador e está a espera de seu parceiro. Como dito acima, pensava-se na geração de instâncias utilizando a reconfiguração parcial dinâmica, inviabilizada pelo overhead da reconfiguração. Optamos portanto pela pré-definição de $n$ instâncias disponiveis para 
cada operador, onde $n$ deverá ser definido futuramente por análises vindas do compilador.

Em cada instância existe um circuito Match que identifica dados parceiros. Toda vez que um dado chega a um operador, esse dado é disponibilizado por barramentos internos, a todas as instâncias vinculadas aquele operador e portanto a analise de correspondência dos tags é feita instanteneamente em todas as instâncias. Havendo coincidências o dado é alocado e o operador informado, caso contrário, uma nova instância será ocupada por aquele dado, tudo gerenciado pelo operador.

No desenvolvimento do operador para o modelo a fluxo de dados dinâmico, o tema desta tese, era necessário que o mesmo executasse sua função de origem, conforme operadores descrito para o projeto ChipCflow, mas também administrasse todo o relacionamento com as instâncias.

Ainda, durante o desenvolvimento do operador, questionou-se as limitações das implementações realizadas até aquele momento, para uma arquitetura a fluxo de dados, que utilizava o modelo síncrono em todos os módulos do projeto ChipCflow diretamente relacionado ao hardware da máquina.

Optou-se portanto pela implementação dos operadores no modelo assíncrono para a máquina a fluxo de dados, que como já abordado, aproveita o máximo paralelismo natural neste modelo de arquitetura, associado ao paralelismo presente nos dispositivos FPGA, acrescido agora da característica do assincronismo, ressaltando a não existência do clock, que teoricamente terá ainda mais velocidade ao hardware, característica essa sendo considerada como uma das vantagens entre a escolha por circuitos síncronos e assíncronos, mas com vantagens adicionais que são o menor consumo e menor aquecimento do hardware assíncrono, justamente por não ter o sinal de clock distribuído por todo o hardware, uma vez que os sinais assíncronos circulam livremente pelo hardware e só aparecem quando necessários.

Conforme objetivo específico descrito para o desenvolvimento desta tese, o operador assíncrono foi especificado, implementado e suas funções validadas em ferramentas ISE da Xilinx na plataforma Virtex-II Pro também da Xilinx; as instâncias foram especificadas, implementadas e suas funções validadas também na ferramenta ISE da Xilinx na plataforma Virtex-II Pro; o relacionamento entre operadores e instâncias foi validado também na ferramenta ISE da Xilinx na plataforma Virtex-II Pro também da Xilinx; finalmente foram gerados dados de ocupação e desempenho para operadores sem instâncias e com diferentes quantidades de instâncias, neste caso foi utilizado as ferramentas ISE da Xilinx em duas plataformas diferentes a Virtex-II Pro e a Virtex-7 ambos da Xilinx motivado pelas diferenças entre as duas plataformas, uma vez que a Virtex-7 é uma das FPGAs mais recentes da Xilinx e com isso poder testar freqüências 
máximas e ocupação entre as duas plataformas para análise apenas especulativas não descritas na tese, do que será a implementação completa de uma máquina a fluxo de dados com várias instâncias para cada operador.

De forma mais detalhada, como visto nos capítulos anteriores, existem dois modelos de arquiteturas a fluxo de dados: estático e dinâmico. Como essa tese foi possível dominar as técnicas de desenvolvimento do modelo dinâmico da arquitetura da máquina a fluxo de dados, o qual permite mais que um dado estar presente no arco. Foram apresentas as características de algumas arquiteturas de máquinas a fluxo de dados dinâmicas. As arquiteturas foram escolhidas tendo como base a demonstração dos principais conceitos básicos da área, demonstradas nos trabalhos iniciais mais influentes e as arquiteturas a fluxo de dados mais divulgadas. As máquinas a fluxo de dado, no ChipCflow, diferente das outras arquiteturas a fluxo de dados mostradas nessa tese, são traduzidos em operadores implementados em hardware e são executados diretamente no FPGA. Portanto, a estrutura da arquitetura do ChipCflow é composto, basicamente pelo número de operadores existentes na máquina a fluxo de dados construído pelo compilador do ChipCflow, em andamento. Os operadores, assim como na máquina a fluxo de dados, são interligados por um barramento local. Isso permite uma diminuição no overhead ocasionado pelas redes de comunicação mostrados em outras arquiteturas.

A Figura 9.1 mostra o exemplo de uma visão abstrata de uma máquina a fluxo de dados implementado no projeto ChipCflow.

Cada operador, na figura, possui duas instâncias. Foi assumido que não há dependência entre as variáveis no programa e, então, foi colocado oito bancos de memória interna ao FPGA. Cada banco de memória guarda instâncias de uma variável do programa, por exemplo, um vetor com 'n' posições. Há oito operadores ITG, ligados a um operador NTM. As instâncias do operador, foram desenhadas na Figura 9.1 de modo a deixar claro a visão abstrata do paralelismo alcançado nos operadores do ChipCflow. Conforme observado, cada operador possui duas instâncias, assim, empiricamente, o paralelismo é triplicado pela execução de três grafos ao mesmo tempo. A ferramenta ChipCflow surge com o intuito de propor soluções para o paralelismo em hardware reconfigurável utilizando o modelo a fluxo de dados dinâmico, cujo paralelismo é considerado intrínseco ao modelo e como alternativa para as arquiteturas tradicionais multicore.

Diferente da maioria das arquiteturas a fluxo de dados mostradas nessa tese, as máquinas a fluxo de dados do ChipCflow são montados, em linguagem de descrição de hardware, de acordo com o programa escrito em linguagem de alto nível, tal como $C$, submetido ao compilador. O hardware final gerado é flexivel, ou seja, ele pode aumentar ou diminuir de acordo com as neces- 


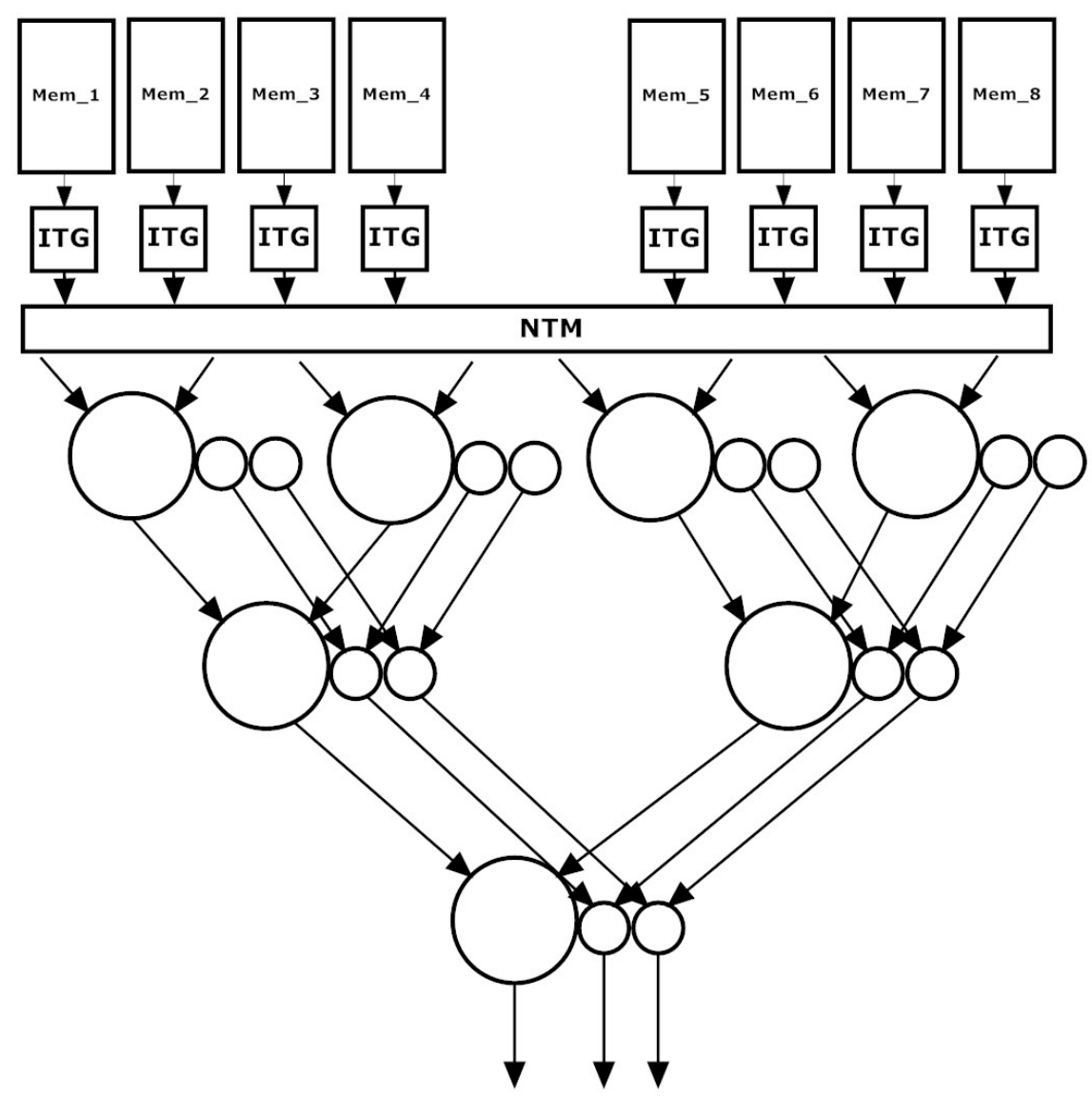

Figura 9.1: Abstração das instâncias no projeto ChipCflow

sidades do programa submetido ao compilador. A maioria das arquiteturas mostradas, porém, o hardware é fixo, e pode haver desperdício de recursos, se a máquina a fluxo de dados submetido ao hardware for pequeno ou pode haver overflow ${ }^{1}$, caso o grafo submetido ao hardware seja maior do que ele pode suportar.

As arquiteturas a fluxo de dados mostradas ou possui grandes unidades centralizadas e especializadas com barramentos complexos para transporte dos tokens ou são arquiteturas híbridas von-Neumann/fluxo de dados. A maioria das arquiteturas a fluxo de dados os tokens são encapsulados em pacotes de dados por unidades centralizadas e especializadas. No ChipCflow, os dados armazenados na memória são encapsulados em tokens por unidades pequenas e descentralizadas, como mostrado no exemplo da Figura 9.1. Isso aumenta o paralelismo, pois possibilita que vários operadores recebam os tokens ao mesmo tempo, o que causa imediato processamento, além de diminuir o overhead, já que não há um único barramento para transporte dos tokens entre unidades centralizadas.

As unidades de Match no ChipCflow possuem duas ou três entradas de tokens e são distribuídas entre os operadores e suas instâncias. Assim, o ChipC-

\footnotetext{
${ }^{1} \mathrm{O}$ overflow pode ocorrer em vários níveis diferentes do hardware, por exemplo, na memória onde é armazenado o grafo no interior do hardware.
} 
flow não precisa ter uma grande capacidade de armazenamento de memória para armazenar os tokens parceiros de todo o sistema, conseqüentemente, não há a necessidade de um hardware complexo para fazer o emparelhamento de todos os tokens que nela chegam. Cada unidade de Match no ChipCflow deve armazenar apenas os tokens parceiros relativos ao operador ou a instância na qual a unidade está implementada. A quantidade de memória total, no ChipCflow, para o armazenamento dos tokens em uma máquina a fluxo de dados implementado em hardware é exatamente a quantidade de operadores e instâncias necessários para a execução de um determinado grafo. Vários autores destacam uma importância grande a unidade de Match, por ser um dos problemas mais complicados em máquinas de fluxo de dados dinâmicas. Como o projeto ChipCflow ainda está incompleto, uma análise detalhada a respeito da quantidade de recursos gastos e o impacto sob o tempo necessário para o processamento de um dado problema com o aumento ou diminuição de instâncias e por consequência unidade de Match ainda não foi possível. Uma análise empírica sob a arquitetura de cada operador com suas respectivas instâncias aponta que, diferentemente das outras arquiteturas a fluxo de dados dinâmicas, a unidade de Match não é um dos problemas mais complicados na arquitetura do ChipCflow.

Quando o projeto ChipCflow estiver completo, o compilador analizará um programa escrito em linguagem de alto nível, como $C$ e determinará a máquina a fluxo de dados necessário para implementar o programa em hardware. Além de desenhar a máquina a fluxo de dados, o compilador determinará a quantidade de bancos de memória necessários para armazenar as variáveis do programa, afim de diminuir as dependências de dados entre as variáveis e determinará a quantidade de instâncias necessárias a cada operador na máquina a fluxo de dados para executar o programa com o mínimo de recursos necessários no FPGA.

Os operadores load e store do ChipCflow permitem o tratamento a estrutura de dados. No ChipCflow, diferentemente das outras arquiteturas a fluxo de dados mostradas, não requer que todos os elementos que compõe a estrutura sejam transformados em dados escalares nem necessita de tipos especiais de armazenamento para grandes estruturas de dados. Os operadores load e store permitem que cada elemento da estrutura de dados possa ser lido ou escrito mais do que uma vez. Assim a estrutura toda não precisa ser passada para cada operação referenciada, não causando assim uma grande sobrecarga na transmissão dos valores pelos operadores e conseqüentemente, alto custo. Na Figura 7.15 foi mostrado os operadores load e store. Como os operadores recebem o endereço base da variável e o deslocamento do elemento no banco de memória, definidos pelo compilador do ChipCflow em tempo de 
compilação, a manipulação de elementos numa estrutura de dados torna-se natural ao grafo implementado em hardware. Portanto, os operadores load e store atuam como ponteiros de dados na memória, sem quebrar a elegância formal do paradigma das máquinas a fluxo de dados.

Como visto nos capítulos anteriores, os operadores DM, Branch, Decisor e Operator possuem instâncias e os operadores NDM e Copy não. Os módulos responsáveis pela criação e destruição das instâncias em tempo de execução, mostrados em detalhe na descrição da implementação do operador DM, Figura 8.7 são Confirma e Aloca e o módulo responsável pela destruição das instâncias é o módulo Disparo. Conforme há o aumento na quantidade de instâncias no operador, aumenta-se também a quantidade de bits no barramento responsável por transportar os tokens entre o operador principal e as instâncias, assim, aumenta a complexidade das arquiteturas das unidades que compõem o operador principal. O operador DM com uma ou mais instâncias é o operador com a arquitetura mais complexa entre todos. Isso deve-se a quantidade de entradas nesse operador: duas entradas de 28 bits e uma entrada de 13 bits. Portanto, há três barramentos para o envio de tokens para as instâncias: um para cada entrada e um barramento para o recebimento de tokens das instâncias, um para cada instância. O número de barramentos necessários para o gerenciamento das instâncias no operador $D M$ e a quantidade de bits em sua entrada tornam os módulos de gerenciamento de instâncias mais complexos, por conseguinte, haverá um maior gasto nos recursos do FPGA.

A quantidade de recursos gastos pelos módulos Match implementado para os operadores DM, Branch, Decisor e Operator no FPGA Virtex-II Pro XC2VP3OFF896-7 foi relativamente baixa e o módulo Match do operador DM, mostrado no gráfico da Figura 8.44 foi o que obteve maior gasto nos recursos do FPGA.

A quantidade de recursos gastos pelo operador $D M$ com instâncias foi maior do que o mesmo operador sem instâncias. Isso conclui que o gasto maior foi nas unidades de gerenciamento de tokens nas instâncias. A diferença de recursos gastos no FPGA Virtex-II Pro XC2VP30-FF896-7 para o operador DM com uma e dez instâncias foi de: $313,65 \%$ superior em gastos em Número de Slices; 257, 65\% superior em gastos em Número de Slice Flip Flops e 328, 97\% superior em gastos em Número de LUTs de 4 entradas. A freqüência máxima de operação caiu 28, $04 \%$ no FPGA Virtex-II Pro XC2VP30-FF896-7 e 34, 89\% no FPGA Virtex-7 xc7v2000t-2-ffg1925. Esses resultados mostram que o paralelismo do operador $D M$ cresceu 11 vezes, o custo nos gastos de área apenas 3 vezes e o número máximo na freqüência de operação caiu apenas $30 \%$.

Como trabalho futuro, já está em andamento a implementação dos operadores de forma síncrona para arquiteturas a fluxo de dados dinâmicas, a fim de comparar as reais diferenças entre o modelo síncrono e o assíncrono; 
também em andamento o projeto de um conversor de programas escritos em $C$ para VHDL tendo como base um front-end open source, focando portanto na implementação do back-end gerando máquinas a fluxo de dados dinâmicos com as características básicas e de otimização citadas nessa tese; ainda em desenvolvimento, um sistema de memória que forneça dados à máquina a fluxo de dados na velocidade exigida pelo grafo.

Finalmente ainda, como projeto a ser desenvolvido, pode-se destacar, na própria ferramenta ChipCflow, um ambiente codesign que divide o hardware/ software do programa de aplicação escrito originalmente em $C$ e toda a interface entre o hardware e o software, um sistema (profile comum na maioria das ferramentas) para levantamento de dados do desempenho das aplicações escritas na ferramenta ChipCflow e poder comprová-la a outras ferramentas semelhantes. 


\section{Referências Bibliográficas}

Ahmed, S. Z., Sassatelli, G., Torres, L., and Rouge, L. (2010). Survey of new trends in industry for programmable hardware: Fpgas, mppas, mpsocs, structured asics, efpgas and new wave of innovation in fpgas. International Conference on Field Programmable Logic and Applications, 0:291-297. 24

Amarasinghe, S. P., Anderson, J. M., Lam, M. S., and wen Tseng, C. (1993). An overview of the suif compiler for scalable parallel machines. In In Proceedings of the Seventh SIAM Conference on Parallel Processing for Scientific Computing, pages 662-667. 94

Aragão, A. C. d. O. S. (1998). Uma arquitetura sistólica para solução de sistemas lineares implementada com circuitos fpgas. Master's thesis, Ciências de Computação e Matemática Computacional - ICMC - USP - São Carlos. 6, $23,24,26,31$

Arvind (2005). Dataflow: Passing the token. ISCA Keynote, 0. 15, 16, 84

Arvind and Culler, D. E. (1986). Dataflow architectures. pages 225-253. 70, $71,72,73,74,77,84,86$

Arvind, A. and Gostelow, K. (1982). The u-interpreter. Computer, 15(2):42-49. 70

Arvind, K. and Nikhil, R. S. (1990). Executing a program on the mit taggedtoken dataflow architecture. IEEE Trans. Comput., 39:300-318. 15, 84, 85, 86

Astolfi, V. F. (2009). Chipcflow - em hardware dinamicamente reconfigurável. Dissertação de mestrado, Ciências de Computação e Matemática Computacional - ICMC - USP - São Carlos. 20, 108

Astolfi, V. F. and Silva, J. L. (2007). Execution of algorithms using a dynamic dataflow model for reconfigurable hardware commands in dataflow graph. 
The 3th IEEE - Southern Conference on Programmable Logic - SPL, pages 225 - 230. 20, 108

Bobda, C. (2003). Synthesis of dataflow graphs for reconfigurable systems using temporal partitioning and temporal placement. Master's thesis, Faculty of Computer Science, Electrical Engineering and Mathematics of the University of Paderborn. 34, 37, 38, 40

Bobda, C. (2007). Introduction to Reconfigurable Computing: Architectures, Algorithms, and Applications. Springer Publishing Company, Incorporated, 1st edition. $3,5,6,10,11,26,27,28,29,30,31,32,34,35,36,37,38,39$, $40,41,42,43$

Bolsens, I. (2006). Programming Modern FPGAs. Technical Talks and Presentations - MPSOC'06. Disponivel em http://www.mpsocforum.org/2006/slides/Bolsens.pdf (Acessado em Agosto de 2011). 7, 8, 23,24

Bonato, V. (2004). Projeto de um módulo de aquisição e pré-processamento de imagem colorida baseado em computação reconfigurável e aplicado a robôs móveis. Master's thesis, Ciências de Computação e Matemática Computacional - ICMC - USP - São Carlos. 43

Broy, M., editor (1987). Control Flow and Data Flow: concepts of distributed programming. Springer-Verlag New York, Inc., New York, NY, USA. 71

Buck, J. T. (1993). SCHEDULING DYNAMIC DATAFLOW GRAPHS WITH BOUNDED MEMORY USING THE TOKEN FLOW MODEL. PhD thesis, EngineeringElectrical Engineering and Computer Sciences of the UNIVERSITY of CALIFORNIA at BERKELEY. 84, 85

Budiu, M. (2003). Spatial Computation. PhD thesis, School of Computer Science - Carnegie Mellon University. 93, 95

Budiu, M., Artigas, P., and Goldstein, S. (2005). Dataflow: A complement to superscalar. In Performance Analysis of Systems and Software, 2005. ISPASS 2005. IEEE International Symposium on, pages 177 -186. 94, 95, 97

Budiu, M. and Goldstein, S. C. (2002). Compiling application-specific hardware. In Proceedings of the Reconfigurable Computing Is Going Mainstream, 12th International Conference on Field-Programmable Logic and Applications, FPL '02, pages 853-863, London, UK, UK. Springer-Verlag. 93, 94, 95, 96

Budiu, M., Venkataramani, G., Chelcea, T., and Goldstein, S. C. (2004). Spatial computation. SIGPLAN Not., 39:14-26. 95, 97 
Burger, D., Keckler, S. W., McKinley, K. S., Dahlin, M., John, L. K., Lin, C., Moore, C. R., Burrill, J., McDonald, R. G., Yoder, W., and Team, t. T. (2004). Scaling to the end of silicon with edge architectures. Computer, 37:44-55. 70,98

Buyukkurt, B., Cortes, J., Villarreal, J., and Najjar, W. A. (2010). Impact of high-level transformations within the roccc framework. ACM Trans. Archit. Code Optim., 7:17:1-17:36. 55

Cappelatti, E. A. (2011). Implementação do padrão de barramento pci para interação hardware/software em dispositivos reconfiguráveis. Master's thesis, PONTIFÍCIA UNIVERSIDADE CATÓLICA DO RIO GRANDE DO SUL. 27

Cappelli, A., Lodi, A., Mucci, C., Toma, M., and Campi, F. (2004). A dataflow control unit for c-to-configurable pipelines compilation flow. In FCCM '04: Proceedings of the 12th Annual IEEE Symposium on Field-Programmable Custom Computing Machines, pages 332-333, Washington, DC, USA. IEEE Computer Society. 15, 18

Cardoso, J. M. P. (2000). COMPILAÇÃO DE ALGORITMOS EM JAVA PARA SISTEMAS COMPUTACIONAIS RECONFIGURÁVEIS COM EXPLORAÇÃO DO PARALELISMO AO NÍVEL DAS OPERAÇÕES. PhD thesis, UNIVERSIDADE TÉCNICA DE LISBOA. 3, 19, 32, 33, 53, 54, 57, 58, 59, 61

Cardoso, J. M. P. and Neto, H. C. (2003). Compilation for fpga-based reconfigurable hardware. IEEE Des. Test, 20:65-75. 4, 19, 53, 57, 58

Cavenaghi, M. A. (1992). Implementação de um simulador para arquitetura fluxo de dados wolf. Master's thesis, Departamento de física e ciência dos materiais, Instituto de Física e Química, Universidade de São Paulo, São Carlos. 79

Cavenaghi, M. A. (1997). IMPLEMENTAÇÃO E ESTUDO DA ARQUITETURA A FLUXO DE DADOS WOLF. PhD thesis, DEPARTAMENTO DE FISICA E INFORMATICA, lnstituto de Física, Universidade de São Paulo, São Carlos. 79, $82,84,86,88$

Celoxica (2004). The application of retiming to the synthesis of $C$ based languages using the Celoxica DK Design Suit. Inc., Celoxica, 1.0 edition. Disponivel em http://www.celoxica.com/techlib/default.asp?Action=1 $\&$ CatID=23\&CatType $=1 \&$ OrderBy $=1$ (Acessado em Novembro 2006) .61

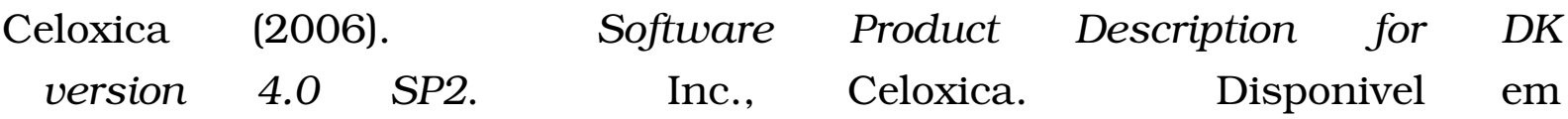


http://www.celoxica.com/support/view_article.asp?ArticleID=52 1 (Acessado em Novembro 2006). 61, 62

Compton, K. and Hauck, S. (2000). An introduction to reconfigurable computing. IEEE Computer. 32, 33

Compton, K. and Hauck, S. (2002). Reconfigurable computing: a survey of systems and software. ACM Comput. Surv., 34:171-210. 3, 6, 32

Correia, V. M. (2009). Chipcflow - uma ferramenta para execução de algoritmos utilizando o modelo a fluxo de dados dinâmico em hardware reconfigurável - operadores em grafos a fluxo de dados. Master's thesis, Ciências de Computação e Matemática Computacional - ICMC - USP - São Carlos. 20, 108, 113

Craven, S. D. (2008). Structured approach to dynamic computing application development. Master's thesis, Bradley Department of Electrical and Computer Engineering Blacksburg, Virginia. 37

Culler, D. E., Sah, A., Schauser, K. E., von Eicken, T., and Wawrzynek, J. (1991). Fine-grain parallelism with minimal hardware support: a compilercontrolled threaded abstract machine. In Proceedings of the fourth international conference on Architectural support for programming languages and operating systems, ASPLOS-IV, pages 164-175, New York, NY, USA. ACM. 69

da Costa, K. A. P. (2009). Chipcflow - uma ferramenta para execução de algoritmos utilizando o modelo a fluxo de dados dinâmico em hardware reconfigurável: Módulo de conversão c em grafo a fluxo de dados. Tese doutorado, Escola de Engenharia de São Carlos - EESC - USP - São Carlos. 20, 108

Davis, A. L. (1978). The architecture and system method of ddm1: A recursively structured data driven machine. In Proceedings of the 5th annual symposium on Computer architecture, ISCA '78, pages 210-215, New York, NY, USA. ACM. 69

Delavallee, T., Manet, P., Vandierendonck, H., and Legat, J. (2011). Embedding functional simulators in compilers for debugging and profiling. In Faible Tension Faible Consommation (FTFC), 2011, pages 55-58. 100

Dennis, J. (1974). First version of a data flow procedure language. In Robinet, B., editor, Programming Symposium, volume 19 of Lecture Notes in Computer Science, pages 362-376. Springer Berlin / Heidelberg. http://dx.doi.org/10.1007/3-540-06859-7_145. 69, 70, 71 
Dennis, J. B. (1998). Retrospective: a preliminary architecture for a basic data flow processor. In ISCA '98: 25 years of the international symposia on Computer architecture (selected papers), pages 2-4, New York, NY, USA. ACM. 70

Dennis, J. B., Boughton, G. A., and Leung, C. K. (1980). Building blocks for data flow prototypes. In ISCA '80: Proceedings of the 7th annual symposium on Computer Architecture, pages 1-8, New York, NY, USA. ACM. 69

Dennis, J. B., Gao, G. R., and Todd, K. W. (1984). Modeling the weather with a data flow supercomputer. IEEE Trans. Computers, 33(7):592-603. 70

Dennis, J. B. and Misunas, D. P. (1975). A preliminary architecture for a basic data-flow processor. In Proceedings of the 2nd annual symposium on Computer architecture, ISCA '75, pages 126-132, New York, NY, USA. ACM. $15,69,70$

Duarte, F. L. (2006). Phoenix - um framework para trabalhos em síntese de alto nível de circuitos digitais. Master's thesis, Faculdade de Computação Universidade Federal de Uberlândia. 58, 60

Edwards, S. A. (2006). The challenges of synthesizing hardware from c-like languages. IEEE Des. Test, 23:375-386. 54, 55

Eto, E. (2007). Difference-Based Partial Reconfiguration. Inc., Xilinx. Disponivel em http://www.xilinx.com/support/documentation/application_notes/ xapp290.pdf (acessado em Junho 2008). 39

FERLIN, E. P. (2008). ARQUITETURA PARALELA RECONFIGURÁVEL BASEADA EM FLUXO DE DADOS IMPLEMENTADA EM FPGA. PhD thesis, UNIVERSIDADE TECNOLÓGICA FEDERAL DO PARANÁ. 2, 12, 17, 18, 100

Flynn, M. J. (1972). Some computer organizations and their effectiveness. Computers, IEEE Transactions on, C-21(9):948 -960. 2, 17

Giering, III, E. W. and Baker, T. P. (1992). Using posix threads to implement ada tasking: description of work in progress. In Proceedings of the conference on TRI-Ada '92, TRI-Ada '92, pages 518-529, New York, NY, USA. ACM. 101

Gokhale, M. (2006). Streams-C: Stream-Oriented C Programming for FPGAs. Los Alamos National Laboratory, 1.4 edition. Disponivel em http://www.streams-c.lanl.gov/ (Acessado em Fevereiro 2007). 64

Grafe, V. G., Davidson, G. S., Hoch, J. E., and Holmes, V. P. (1989). The epsilon dataflow processor. SIGARCH Comput. Archit. News, 17:36-45. 69 
Gupta, S., Gupta, R., Dutt, N., and Nicolau, A. (2004). Spark - A Parallelizing Approach to the High-Level Synthesis of Digital Circuits. Kluwer Academic Publishers. 58, 60, 61, 95

Hall, M. W., Anderson, J. M., Amarasinghe, S. P., Murphy, B. R., Liao, S.-W., Bugnion, E., and Lam, M. S. (1996). Maximizing multiprocessor performance with the suif compiler. Computer, 29:84-89. 64

Hauck, S. (1998). The roles of fpgas in reprogrammable systems. Proceedings of the IEEE, 86(4):615-638. 3

Hauck, S. and DeHon, A. (2008). RECONFIGURABLE COMPUTING: THETHEORY AND PRACTICE OF FPGA-BASED COMPUTATION. Penrose, Denise E. M. 32, 33, 34, 36, 38, 39, 41

Hicks, J., Chiou, D., Ang, Boon, S., and Arvind (1993). Performance studies of id on the monsoon dataflow system. J. Parallel Distrib. Comput., 18:273-300. 84,86

Hiraki, K., Shimada, T., and Nishida, K. (1986). A hardware design of the SIGMA-1, a data flow computer for scientific computations, pages 61-68. IEEE Computer Society Press, Los Alamitos, CA, USA. 86

Hoare, C. A. R. (1978). Communicating sequential processes. Commun. ACM, $21: 666-677.63$

Hoare, C. A. R. (1985). Communicating Sequential Processes. Prentice-Hall, Inc., Upper Saddle River, NJ, USA. 63

Iannucci, R. A. (1988). Toward a dataflow/von neumann hybrid architecture. SIGARCH Comput. Archit. News, 16:131-140. 87

Júnior, J. M. d. A. (2010). State of the art in FPGA technology. LCR - ICMC - USP. Disponivel em http://www.merlintec.com/download/jecel_osso.pdf (Acessado em 08/2011). 34

Johnston, W. M., Hanna, J. R. P., and Millar, R. J. (2004). Advances in dataflow programming languages. ACM Comput. Surv., 36:1-34. 70, 71

J.R. and Gurd (1985). The manchester dataflow machine. Computer Physics Communications, 37(1-3):49 - 62. 69, 79, 80, 82, 83, 84

Junior, F. d. S. (2011). Chipcflow - validação e implementação do modelo de partição e protocolo de comunicação no grafo a fluxo de dados dinâmico. Master's thesis, Ciências de Computação e Matemática Computacional ICMC - USP - São Carlos. 20, 108, 127 
Junior, F. S., Sanches, L. B., Astolfi, V. F., and Silva, J. L. (2010a). Reserach and partial analysis of overhead of a partition model for a partially reconfigurable hardware in a data-driven machine - chipcflow. The 6th IEEE Southern Conference on Programmable Logic - SPL, pages 191-194. 20, 108

Junior, F. S., Silva, J. L., Sanches, L. B., and Astolfi, V. F. (2010b). Research and partial analysis of overhead of a partition model for a partially reconfigurable hardware in a data-driven machine - chicflow. In Programmable Logic Conference (SPL), 2010 VI Southern, pages 191 -194. 108

Kamienski, C. A. (1994). Armazenamento de Resultados em uma Arquitetura de Fluxo de Dados. PhD thesis, Instituto de Matemátíca, Estatística e Ciéncia da Computação, UNlCAMP. 71, 73, 79, 80, 81, 82, 83, 84

Kirner, C. (1989). Design of a recursively structured parallel computer. In Proceedings of the 17th conference on ACM Annual Computer Science Conference, CSC '89, pages 416-416, New York, NY, USA. ACM. 89

Kishi, M., Yasuhara, H., and Kawamura, Y. (1983). Dddp-a distributed data driven processor. In Proceedings of the 10th annual international symposium on Computer architecture, ISCA '83, pages 236-242, New York, NY, USA. ACM. 69

Koch, D. and Torresen, J. (2010). Advances and Trends in Dynamic Partial Run-time Reconfiguration. In Dagstuhl-Seminar 10281: Dynamically Reconfigurable Architectures, page 6, Schloss Dagstuhl, Germany. Internationales Begegnungs- und Forschungszentrum für Informatik (IBFI), Schloss Dagstuhl, Germany. 3, 4, 34

Kodama, Y., Sakai, S., and Yamaguchi, Y. (1991). Load balancing by function distribution on the em-4 prototype. In Proceedings of the $1991 \mathrm{ACM} / \mathrm{IEEE}$ conference on Supercomputing, Supercomputing '91, pages 522-531, New York, NY, USA. ACM. 87

Kodama, Y., Sakai, S., and Yamaguchi, Y. (1992). A prototype of a highly parallel dataflow machine em-4 and its preliminary evaluation. Future Generation Computer Systems, 7(2-3):199 - 209. 87, 88

Kodama, Y. and Yuba, T. (1990). Design of the dataflow single-chip processor emc-r. J. Inf. Process., 13:165-173. 87, 88

Lee, B. and Hurson, A. (1994). Dataflow architectures and multithreading. Computer, 27(8):27-39. 71, 79 
Lopes, J. J. (2007). Estudos e avaliações de compiladores para arquiteturas reconfiguráveis. Master's thesis, Ciências de Computação e Matemática Computacional - ICMC - USP - São Carlos. 54, 60, 179

Lorenzo, P. A. R. (1985). AnÁlise das causas da perda de desempenho da mfdm e possivel solução: Impacto do escalonamento de instruÇÕes. Master's thesis, Instituto de Matemática, Estatística e Ciência da Computação, UNICAMP. 79, 80, 81, 82, 83, 84

Mahram, A., Najibi, M., and Pedram, H. (2007). An asynchronous fpga logic cell implementation. In Proceedings of the 17th ACM Great Lakes symposium on VLSI, GLSVLSI '07, pages 176-179, New York, NY, USA. ACM. 13

MARKOFF, J. (2004). Intel's big shift after hitting technical wall. New York Times. Disponivel em http://www.nytimes.com/2004/05/17/business/17intel.html?ex= $1400212800 \&$ en $=482 \mathrm{e} 58801$ aa02ede $\&$ ei=5007 $\&$ partner=USERLAND (acessado em junho 2011). 2

MARQUES, E. (1993). PROJETO DE UM ELEMENTO DE PROCESSAMENTO DE UM COMPUTADOR MACIÇAMENTE PARALELO PARA EXECUÇÃO DIRIGIDA A FLUXO DE DADOS. Tese, Universidade de São Paulo. 2, 15, 17, 69, 72, $73,74,79,81,82,83,84,85,86,88,89,90,91,92$

Marzulo, L. A. J. (2011). EXPLORANDO LINHAS DE EXECUÇÃO PARALELAS COM PROGRAMAÇÃO ORIENTADA POR FLUXO DE DADOS. PhD thesis, Engenharia de Sistemas e Computação, COPPE, Universidade Federal do Rio de Janeiro. 104, 105

MÔCHO, R. U. R. (2006). Circuitos assíncronos na plataforma fpga. Master's thesis, FACULDADE DE INFORMÁTICA - PUCRS - Porto Alegre. 13, 14

Menotti, R. (2010). LALP: uma linguagem para exploração do paralelismo de loops em computação reconfigurável. PhD thesis, Ciências de Computação e Matemática Computacional - ICMC - USP - São Carlos. 29, 55

Mentor Graphics, I. (2009). Mentor graphics extends high level synthesis leadership with acquisition of agility design solutions inc. c synthesis suite. Technical report, Mentor Graphics. Disponivel em http://www.mentor.com/esl/news/agility-design-solutions (Acessado em Agosto 2010). 60

Mentor Graphics, I. (2010). DK DESIGN SUITE: RAPID IMPLEMENTATION FROM C TO FPGA. Mentor Graphics Corporation. Disponivel em 
http://www.mentor.com/products/fpga/handel-c/dk-design-suite/ (Acessado em Junho 2011). 61

Mercaldi, M. (2005). Development of a wavescalar performance model. Master's thesis, University of Washington. 100, 101

Mercaldi, M., Swanson, S., Petersen, A., Putnam, A., Schwerin, A., Oskin, M., and Eggers, S. J. (2006). Instruction scheduling for a tiled dataflow architecture. In Proceedings of the 12th international conference on Architectural support for programming languages and operating systems, ASPLOS-XII, pages 141-150, New York, NY, USA. ACM. 18

Mesquita, D. G. (2002). Contribuições para reconfiguração parcial, remota e dinâmica de fpgas. Master's thesis, Faculdade de Informática, Pontifícia Universidade Católica do Rio Grande do Sul. 47

Montminy, D., Baldwin, R., Williams, P., and Mullins, B. (2007). Using relocatable bitstreams for fault tolerance. In Adaptive Hardware and Systems, 2007. AHS 2007. Second NASA/ESA Conference on, pages 701 -708. 39

Nachiket, K. and André, D. (2009). Performance comparison of singleprecision spice model-evaluation on fpga, gpu, cell, and multi-core processors. International Conference on Field Programmable Logic and Applications (FPL), pages $65-72.9,10$

Nagarajan, R., Sankaralingam, K., Burger, D., and Keckler, S. W. (2001). A design space evaluation of grid processor architectures. In MICRO 34: Proceedings of the 34th annual ACM/IEEE international symposium on Microarchitecture, pages 40-51, Washington, DC, USA. IEEE Computer Society. 18

Najjar, W. and Villarreal, J. (2009). Reconfigurable computing in the new age of parallelism. In Proceedings of the 9th International Workshop on Embedded Computer Systems: Architectures, Modeling, and Simulation, SAMOS '09, pages 255-262, Berlin, Heidelberg. Springer-Verlag. 1, 2, 3, 4, 5

Nezami, K., Stephens, P., and Walker, S. (2008). Handel-c implementation of early-access partial-reconfiguration for software defined radio. In Wireless Communications and Networking Conference, 2008. WCNC 2008. IEEE, pages 1103 -1108. 40, 41, 42

Nikhil, R. S. (1989). Can dataflow subsume von neumann computing? SIGARCH Comput. Archit. News, 17:262-272. 87 
Okamoto, K., Kodama, Y., Sakai, S., and Yamaguchi, Y. (1992a). Methodologies in development and testing of the dataflow machine em-4. Parallel Computing, 18(8):901 - 912. 86, 88

Okamoto, K., Kodama, Y., Sakai, S., and Yamaguchi, Y. (1992b). Methodologies in development and testing of the dataflow machine em-4. Parallel Comput., 18:901-912. 86, 88

Ordonez, E. D. M., Pereira, F. D., Penteado, C. G., and Pericini, R. A. (2003). Projeto, desempenho e aplicações de sistemas digitais em circuitos programáveis (FPGAs). Bless Gráfica e Editora Ltda. 11

Palma, José Carlos; Melo, A. V. d. C. N. M. M. F. G. (2002). Interface de comunicaÇÃo de cores em fpgas. VIII Workshop Iberchip. 47

Papadopoulos, G. M. (1988). Implementation of a general purpose dataflow multiprocessor. PhD thesis, Department of Electrical Engineering and Computer Science, MIT (Massachusetts Institute of Technology). 86

Papadopoulos, G. M. and Culler, D. E. (1998). Monsoon: an explicit tokenstore architecture. In 25 years of the international symposia on Computer architecture (selected papers), ISCA '98, pages 398-407, New York, NY, USA. ACM. 69

Papadopoulos, G. M. and Traub, K. R. (1991). Multithreading: a revisionist view of dataflow architectures. In Proceedings of the 18th annual international symposium on Computer architecture, ISCA '91, pages 342-351, New York, NY, USA. ACM. 86

Pedrino, E. C. (2008). Arquitetura pipeline reconfigurável através de instruções geradas por programação genética para processamento morfológico de imagens digitais utilizando FPGAs. Tese, Escola de Engenharia de São Carlos EESC - USP - São Carlos. 24, 25, 26, 31

Pellerin, D. and Thibault, S. (2005). Practical FPGA Programming in C. Prentice Hall PTR. 3, 5, 32, 54, 55, 63, 64, 65, 66, 67, 68

Pham-Quoc, C. and Dinh-Duc, A.-V. (2010). Hazard-free muller gates for implementing asynchronous circuits on xilinx fpga. Electronic Design, Test and Applications, IEEE International Workshop on, 0:289-292. 13, 14

Piacentino, M. R., Vanderwal, G. S., and Hansen, M. W. (1999). Reconfigurable elements for a video pipeline processor. In Proceedings of the Seventh Annual IEEE Symposium on Field-Programmable Custom Computing Machines, FCCM '99, pages 82-, Washington, DC, USA. IEEE Computer Society. 3 
Pontes, J. J. H. (2008). Projeto e prototipaÇÃo de interfaces e redes intrachip nÃo-sÍncronas em fpgas. Master's thesis, FACULDADE DE INFORMÁTICA PUCRS - Porto Alegre. 13

Quadri, I.-r., Meftali, S., and Dekeyser, J.-1. (2007). An mde approach for implementing partial dynamic reconfiguration in fpgas. In in 16th International Workshop on IP Based System-on-chip, IPO7. 41

Radunovic', B. and Milutinovic', V. (1998). A survey of reconfigurable computing architectures. In Hartenstein, R. and Keevallik, A., editors, FieldProgrammable Logic and Applications From FPGAs to Computing Paradigm, volume 1482 of Lecture Notes in Computer Science, pages 376-385. Springer Berlin / Heidelberg. 10.1007/BFb0055265. 4, 53

Redaelli, F., Santambrogio, M. D., and Sciuto, D. (2008). Task scheduling with configuration prefetching and anti-fragmentation techniques on dynamically reconfigurable systems. In Proceedings of the conference on Design, automation and test in Europe, DATE '08, pages 519-522, New York, NY, USA. ACM. 5

Reiner, W. H., Juergen, B., Michael, H., and Ulrich, N. (1996). Codesign and high-performance computing: scenes and crisis. High-Speed Computing, Digital Signal Processing, and Filtering Using Reconfigurable Logic, Proc. SPIE 2914, 271. 3

Ribeiro, A. A. d. L. (2002). Reconfigurabilidade dinâmica e remota de fpgas. Master's thesis, Ciências de Computação e Matemática Computacional ICMC - USP - São Carlos. 6, 10, 23, 24, 26, 27, 28, 30, 31, 32, 33, 43

Rutzig, M., Beck, A., and Carro, L. (2007). Transparent dataflow execution for embedded applications. In VLSI, 2007. ISVLSI 'O7. IEEE Computer Society Annual Symposium on, pages 47 -54. 99

Sakai, Kodama, and Yamaguchi (1991a). Prototype implementation of a highly parallel dataflow machine em-4. Parallel Processing Symposium, International, 0:278-286. 86, 87, 88

Sakai, S., Kodama, Y., Sato, M., Shaw, A., Matsuoka, H., Hirono, H., Okamoto, K., and Yokota, T. (1995). Reduced interprocessor-communication architecture and its implementation on em-4. Parallel Computing, 21(5):753 $-769.87$

Sakai, S., Kodama, Y., and Yamaguchi, Y. (1991b). Architectural design of a parallel supercomputer em-5. In JOINT SIMPOSIUM ON PARALLEL PROCES- 
SING, pages 149-156. , publisher $=$, note $=$, abstract $=$, keywords $=, .86$, 88

Sakai, S., Kodama, Y., and Yamaguchi, Y. (1993). Design and implementation of a circular omega network in the em-4. Parallel Computing, 19(2):125 142. 87,88

Sakai, S., Yamaguchi, y., Hiraki, K., Kodama, Y., and Yuba, T. (1989). An architecture of a dataflow single chip processor. In Proceedings of the 16th annual international symposium on Computer architecture, ISCA '89, pages 46-53, New York, NY, USA. ACM. 69, 87

Sanches, L. B. (2010). Chipcflow - partição e protocolo de comunicação no grafo a fluxo de dados dinâmico. Master's thesis, Ciências de Computação e Matemática Computacional - ICMC - USP - São Carlos. 20, 108

Sang, K. K., Lawrence, C. M., Peter, L. M., and Kunle, O. (2009). A highly scalable restricted boltzmann machine fpga implementation. Field Programmable Logic and Applications, 2009. FPL 2009, pages 367 - 372. 8

Sankaralingam, K., Nagarajan, R., Liu, H., Kim, C., Huh, J., Burger, D., Keckler, S. W., and Moore, C. R. (2003). Exploiting ilp, tlp, and dlp with the polymorphous trips architecture. SIGARCH Comput. Archit. News, 31(2):422433. 18,69

Santos, R. R. d. (2007). 2D-VLIW: Uma Arquitetura de Processador Baseada na Geometria da Computação. $\mathrm{PhD}$ thesis, Instituto de Computação - Universidade Estadual de Campinas. 1, 98, 100, 101

SARTORI, G. H. (2005). Estudo e implementação de somador com detecção de fim de cálculo para circuitos assíncronos. Master's thesis, FACULDADE DE INFORMÁTICA - PUCRS - Porto Alegre. 13, 14, 15

Sato, M., Kodama, Y., Sakai, S., Yamaguchi, Y., and Koumura, Y. (1992). Thread-based programming for the em-4 hybrid dataflow machine. SIGARCH Comput. Archit. News, 20:146-155. 87

Schneider Beck Fl., A. C. and Carro, L. (2010). Dynamic Reconfigurable Architectures and Transparent Optimization Techniques: Automatic Acceleration of Software Execution. Springer Publishing Company, Incorporated, 1st edition. 12, 98, 99, 101

Scott, H., Katherine, C., Ken, E., Mark, H., Shawn, P., and Akshay, S. (2006). Totem: Domain-specific reconfigurable logic. IEEE Transactions on VLSI Systems. 3, 4, 6 
Shimada, T., Hiraki, K., Nishida, K., and Sekiguchi, S. (1986). Evaluation of a prototype data flow processor of the sigma- 1 for scientific computations. In Proceedings of the 13th annual international symposium on Computer architecture, ISCA '86, pages 226-234, Los Alamitos, CA, USA. IEEE Computer Society Press. 69, 86

Silva, A. C. F. d. (2011a). ChipCFlow: ferramenta para conversão de código C em uma arquitetura a fluxo de dados dinâmica em hardware reconfigurável. Qualificação de doutorado, Ciências de Computação e Matemática Computacional - ICMC - USP - São Carlos. 109

Silva, B. d. A. (2011b). Gerenciamento de tags na arquitetura chipcflow: uma máquina a fluxo de dados dinâmica. Master's thesis, Ciências de Computação e Matemática Computacional - ICMC - USP - São Carlos. 15, 16, 20, 73, 74, 79, 84, 95, 108, 112, 113, 114, 115, 116, 117, 118, 119, 120, 121, 122,123

Silva, J. L. (1992). Processamento a Fluxo de Dados Tolerante a Falhas em um Computador Paralelo. Tese, Universidade Estadual de Campinas. 2, 12, 15, 20, 69, 70, 71, 72, 74, 75, 79, 89, 91, 92, 93, 107, 109

Silva, J. L. (2006). Execution of algorithms using a dynamic dataflow model for reconfigurable hardware - a purpose for matching data. In System-on-Chip for Real-Time Applications, The 6th International Workshop on, pages 115 119. 107,108

Silva, J. L. and Correia, V. M. (2009). C commands implemented direct into the hardware using the chipcflow machine. In The Reconfigurable Computing and Applications Conference - JCRA, pages 1-9, Alcalá. 108

Silva, J. L., da Costa, K. A. P., and Roda, V. O. (2009). The c compiler generating a source file in vhdl for a dynamic dataflow machine being executed direct into a hardware. W. Trans. on Comp., 8:1908-1916. 18, 108

Silva, J. L. and Lopes, J. J. (2010). A dynamic dataflow architecture using partial reconfigurable hardware as an option for multiple cores. W. Trans. on Comp., 9:429-444. 12, 18, 20, 107, 110, 111, 112, 113, 114

SILVA, J. L., LOPES, J. J., PONTARA, K. A., and RODA, V. O. (2009a). Chipcflow- a dynamic dataflow machine using dynamic reconfigurable hardware. 5th. IEEE - Southern Programmable Logic Conference - SPL, pages 1-4. 20, 107, 108, 126 
Silva, J. L. and Marques, E. (2006). Executing algorithms for dynamic dataflow reconfigurable hardware -the operators protocol. In Reconfigurable Computing and FPGA's, 2006. ReConFig 2006. IEEE International Conference on, pages $1-7.107,108,111$

SILVA, J. L., PONTARA, K. A., RODA, V. O., and LOPES, J. J. (2009b). The compiler to convert $\mathrm{c}$ into a dataflow graph to be executed into the chipcflow, a dynamic dataflow machine. The IFIP International Conference on research and Practical Issues of Enterprise Information Systems an International Forum for Exploring the Research Frontier in EIS, pages 1-10. 20, 108

Silva, S. R. P. d. (1991). Modelagem e análise de desentpenho de uma arquitetura de fluxo de dados. Master's thesis, Departamento de Ciência da Computação IMECC - UNICAMP. 74, 79, 81, 82, 83

Spars, J. and Furber, S. (2010). Principles of Asynchronous Circuit Design: A Systems Perspective. Springer Publishing Company, Incorporated, 1st edition. 13, 14

Steven Swanson, Ken Michelson, A. S. and Oskin, M. (2003). Dataflow: The road less complex. In the Workshop on Complexity-effective Design (WCED) held in conjunction with the 30th Annual International Symposium on Computer Architecture (ISCA). 18

Swanson, S., Michelson, K., Schwerin, A., and Oskin, M. (2003). Wavescalar. In Proceedings of the 36th annual IEEE/ACM International Symposium on Microarchitecture, MICRO 36, pages 291-, Washington, DC, USA. IEEE Computer Society. 15, 18, 69, 98

Swanson, S., Putnam, A., Mercaldi, M., Michelson, K., Petersen, A., Schwerin, A., Oskin, M., and Eggers, S. J. (2006). Area-performance trade-offs in tiled dataflow architectures. SIGARCH Comput. Archit. News, 34(2):314-326. 18, 70, 104

Swanson, S., Schwerin, A., Mercaldi, M., Petersen, A., Putnam, A., Michelson, K., Oskin, M., and Eggers, S. J. (2007). The wavescalar architecture. ACM Trans. Comput. Syst., 25:4:1-4:54. 18, 69, 100, 101, 102, 103, 104

Synfora (2007a). Synfora PICO Technology: Elevate, Innovate, Accelerate - PICO Technology White Paper. Inc., Synfora, v.10 edition. Disponivel em Disponivel em http://www.synfora.com/products/picoexpress.html (acessado em Março 2007. 55, 56, 57

Synfora (2007b). Synfora Revolutionizing Complex SoC Design - Pico Express. Inc., Synfora. Disponivel em 
http://www.synfora.com/products/picoexpress.html (acessado em Março 2007. 55, 56

Synfora (2007c). Synphony C Compiler: Optimized Hardware from High-Level $\mathrm{C} / \mathrm{C}++$. Inc., Synfora, v.10 edition. Disponivel em http://www.synfora.com/about/files/PICO_technology_whitepaper_v1.0.pdf. (acessado em Março 2007. 56

Szewinski, J. (2005). Software for development and communication with fpga based hardware. Proceedings of SPIE, pages 59480H-59480H-8. 46

Tadigotla, V., Sliger, L., and Commuri, S. (2006). Fpga implementation of dynamic run-time behavior reconfiguration in robots. In Computer Aided Control System Design, 2006 IEEE International Conference on Control Applications, 2006 IEEE International Symposium on Intelligent Control, 2006 IEEE, pages 1220 -1225. 34, 38, 40, 41

Tanenbaum, A. S. (2005). Structured Computer Organization (5th Edition). Prentice-Hall, Inc., Upper Saddle River, NJ, USA. 10

Teifel, J. and Manohar, R. (2004a). An asynchronous dataflow fpga architecture. Computers, IEEE Transactions on, 53(11):1376-1392. 18

Teifel, J. and Manohar, R. (2004b). Highly pipelined asynchronous fpgas. In Proceedings of the 2004 ACM/SIGDA 12th international symposium on Field programmable gate arrays, FPGA '04, pages 133-142, New York, NY, USA. ACM. 13

Teifel, J. and Manohar, R. (2004c). Static tokens: Using dataflow to automate concurrent pipeline synthesis. In In Proceedings of International Symposium on Asynchronous Circuits and Systems, pages 17-27. 18

Upegui, A. and Sanchez, E. (2005). Evolving hardware by dynamically reconfiguring xilinx fpgas. In ICES'05, pages 56-65. 39

Veen, A. H. (1986). Dataflow machine architecture. ACM Comput. Surv., 18(4):365-396. 15, 71, 72, 74, 75, 76

Venkataramani, G., Budiu, M., Chelcea, T., and Goldstein, S. C. (2004). C to asynchronous dataflow circuits: An end-to-end toolflow. In IEEE 13th International Workshop on Logic Synthesis (IWLS), Temecula, CA. 95, 97

Villasenor, J. and Smith, W. H. M. (1997). Configurable computing. Scientific American. 3 
Wang, J., Ping, L., Wang, J., and Sun, K. (2006). A new computing model for c-like hardware description languages. In Proceedings of the First International Multi-Symposiums on Computer and Computational Sciences - Volume 2 (IMSCCS'O6) - Volume 02, IMSCCS '06, pages 249-256, Washington, DC, USA. IEEE Computer Society. 54, 55

Whiting, P. and Pascoe, R. (1994). A history of data-flow languages. Annals of the History of Computing, IEEE, 16(4):38-59. 71

Wilson, R. P., French, R. S., Wilson, C. S., Amarasinghe, S. P., Anderson, J. M., Tjiang, S. W. K., Liao, S.-W., Tseng, C.-W., Hall, M. W., Lam, M. S., and Hennessy, J. L. (1994). Suif: an infrastructure for research on parallelizing and optimizing compilers. SIGPLAN Not., 29:31-37. 94

Xilinx (2004). Two Flows for Partial Reconfiguration: Module Based or Difference Based. Inc., Xilinx, 1.2 edition. Disponivel em http://china.xilinx.com/support/documentation/application_notes/ xapp290.pdf (acessado em Maio 2008). 34, 38

Xilinx (2005). PowerPC 405 Processor Block Reference Guide. Inc., Xilinx. Disponivel em http://www.xilinx.com/products/silicon_solutions/fpgas/virtex/ virtex_II_pro_fpgas/capabilities/powerpc.htm (acessado em agosto 2008). 45, 46

Xilinx (2006). Early Access Partial Reconfiguration User Guide. Inc., Xilinx, 1.1 edition. Disponivel em http://www12.informatik.unierlangen.de/esmwiki/images/f/f3/Pr_flow.pdf (acessado em Março 2008). $34,41,42$

Xilinx (2007a). The Embedded Development Kit (EDK) is an all encompassing solution for designing embedded programmable systems. Inc., Xilinx. Disponivel em http://www.xilinx.com/ise/embedded_design_prod/platform_studio.htm (acessado em Maio 2007). 50, 52

Xilinx (2007b). ISE - The design suite voted \#1 by FPGA Engineers for a third consecutive year. Inc., Xilinx. Disponivel em http://www.xilinx.com/ise/logic_design_prod/index.htm (acessado em Maio 2007). 49

Xilinx (2007c). Xilinx: The Programmable Logic Company. Inc., Xilinx. Disponivel em http://www.xilinx.com (acessado em Janeiro 2007). 43, 49 
Xilinx (2007d). Xilinx XUP Virtex II Pro Development System. Inc., Xilinx. Disponivel em http://www.xilinx.com/univ/xupv2p.html (acessado em Julho 2007). 47

Xilinx (2008). XUP Virtex-II Pro Development System. Inc., Xilinx, 1.1 edition. Disponivel em http://www.xilinx.com/univ/XUPV2P/Documentation/ug069.pdf (acessado em Maio 2008). 43, 44, 47, 49, 179

Xilinx (2011a). $\quad 7$ Series FPGAs Overview: Advance Product Specification. Inc., Xilinx. Disponivel em http://www.xilinx.com/support/documentation/data_sheets/ ds180_7Series_Overview.pdf (acessado em Setembro 2011. 7, 34

Xilinx (2011b). Virtex-7 FPGAs Data Sheet: DC and Switching Characteristics - Advance Product Specification. Inc., Xilinx, 1.1 edition. Disponivel em http://www.xilinx.com/support/documentation/data_sheets/ ds183_Virtex_7_Data_Sheet.pdf (acessado em Outubro 2011). 34

Xilinx (2012). Virtex-7 FPGA Family. Xilinx Inc. Disponivel em http://www.xilinx.com/products/silicon-devices/fpga/virtex-7/index.htm (Acessado em Abril de 2012). 24

Yuba, T., Shimada, T., Hiraki, K., and Kashiwagi, H. (1985). Sigma-1: A dataflow computer for scientific computations. Computer Physics Communications, 37(1-3): $141-148.86$

Zheng, W. H., Marzwell, N., and Chau, S. (2005). In-system partial run-time reconfiguration for fault recovery applications on spacecrafts. In Systems, Man and Cybernetics, 2005 IEEE International Conference on, volume 4, pages 3952 - 3957 Vol. 4.38 